\title{
TENDENCIAS DE LA ALFABETIZACIÓN INFORMATIVA EN IBEROAMÉRICA
}

COORDINADORA

Patricia Hernández Salazar

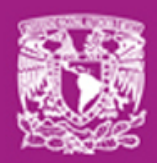


La presente obra está bajo una licencia de:

http://creativecommons.org/licenses/by-ncsa/3.0/deed.es MX

\section{(c) cointive}

Eres libre de:

(15)

copiar, distribuir y comunicar públicamente la obra

(D) hacer obras derivadas

Bajo las condiciones siguientes:

Atribución - Debes reconocer la autoría de la obra en los términos

especificados por el propio autor o licenciante.

No comercial - No puedes utilizar esta obra para fines comerciales.

Licenciamiento Reciproco - Si alteras, transformas o creas una obra a

partir de esta obra, solo podrás distribuir la obra resultante bajo una licencia igual a ésta.

Esto es un resumen fácilmente legible del: texto legal (de la licencia completa)

\section{En los casos que sea usada la presente obra, deben respetarse los términos especificados en esta licencia.}
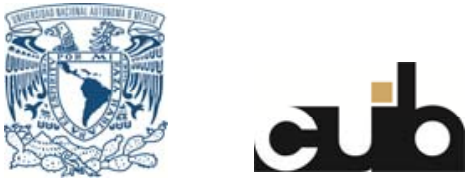
Tendencias de la Alfabetización Informativa en Iberoamérica 
COLECCIÓN

Seminarios de Investigación 19

Centro Universitario de Investigaciones Bibliotecológicas 


\title{
Tendencias de la Alfabetización Informativa en Iberoamérica
}

\author{
Coordinadora
}

Patricia Hernández Salazar

Universidad Nacional Autónoma de México 2012 
ZA3075

T45A54 Tendencias de la Alfabetización Informativa en Iberoamérica / coordinadora, Patricia Hernández Salazar. - México : UNAM, Centro Universitario de Investigaciones Bibliotecológicas, 2012.

ix, 496 p. - (Seminarios de Investigación ; 19) ISBN: 978-607-02-0767-9

1. Alfabetización Informativa - Tendencias - América Latina

2. Desarrollo de Habilidades Informativas - América Latina

3. Alfabetización Informativa - Tendencias Puerto Rico

4. Formación de Usuarios - Tendencias - América Latina

I. Hernández Salazar, Patricia, coordinadora II. ser.

Diseño de portada: Mario Ocampo Chávez

Primera Edición, 2012

DR (C) UNIVERSidAd NACIONAL AUTÓNOMA DE MÉXICO

Ciudad Universitaria, 04510, México, D.F.

Impreso y hecho en México

ISBN: 978-607-02-0767-9 


\section{Contenido}

Introducción ..................... . . .

\section{LA ALFABETIZACIÓN INFORMATIVA COMO UN PROYECTO NACIONAL}

Contexto teórico de la Alfabetización

INFORMATIVA ................ 3

Patricia Hernández Salazar

Las Políticas de Información en el Marco

DE LOS ESTUDIOS SOBRE LA ALFABETIZACIÓN

INFORMATIVA ..................... 47

Egbert J. Sánchez Vanderkast

A AlfabetizaÇão Informativa e a inclusção

NA SOCIEDADE DA INFORMAÇÃO . . . . . . . . 73

Emir José Suaiden

ESTADO DEL ARTE DE LA AlfabeTización

INFORMACIONAL EN COLOMBIA . . . . . . . 89

Alejandro Uribe Tirado

La Alfabetización en InformaCión:

UNA NECESIDAD DESDE LA

EDUCACIÓN PRIMARIA . . . . . . . . . . . . . . 135

Ana María Reusch Hevia

ALFIN PARA ALUMNOS DE EDUCACIÓN PRIMARIA:

PROPUESTA DE MODELO Y PERSPECTIVAS

DE APLICACIÓN . . . . . . . . . . . . . . . . 159

Guadalupe Vega Díaz y Sylvia Rojas-Drummond 


\title{
EXPERIENCIAS DE FORMACIÓN DE USUARIOS \\ Y DE HABILIDADES INFORMATIVAS EN \\ EDUCACIÓN SUPERIOR
}

\begin{abstract}
LA FORMACIÓN de USUARIOS EN EL CENTRO de ENSEÑANZA DE LENGUAS EXTRANJERAS DE LA UNAM: UNA EXPERIENCIA DE TRABAJO DE MÁS DE DIEZ AÑoS . . . . . . . . . . . . . . 209 Jesús Valdez Ramos

EL DESARROLLO DE COMPETENCIAS INFORMATIVAS EN ESTUDIANTES UNIVERSITARIOS. UNA VISIÓN SOBRE AVANCES Y PERSPECTIVAS DESDE LA UNIVERSIDAD AUTÓNOMA DE CiUdad JuÁrez . . . . . . . . . . . . . . . . 233 Jesús Cortés
\end{abstract}

Programa de Desarrollo de Habilidades INFORMATIVAS DE LA DIRECCIÓN GENERAL de Bibliotecas de la UNAM . . . . . . . . . . . . 263 María de Lourdes Rovalo Sandoval

Comunidad de Práctica de Destrezas de INFORMACIÓN DE LA UNIVERSIDAD DE PUERTO Rico (UPR): COLABORAR Y Compartir Conocimiento Hacia UNA Misma MeTA . . . . . . . . . . . . . . . . . . . 287 Noraida Domínguez, Yesenia Hernández y Magda Pérez

EXPERIENCIAS EN FORMACIÓN PARA LA INFORMACIÓN en el Instituto Politécnico Nacional . . . . . . . 309 Noel Angulo Marcial

DESARROLLO DE LA FORMACIÓN DE USUARIOS EN el Sistema de Bibliotecas de la UASLP, ¿HACIA LA ALFABETIZACIÓN INFORMATIVA? . . . . . . . 327 Celia Mireles Cárdenas y Laura Figueroa Barragán 
ESTUDIANTES UNIVERSITARIOS ¿NATIVOS DIGITALES?

UNA REFLEXIÓN SOBRE SUS COMPETENCIAS

TECNOLÓGICAS Y SU FORMACIÓN EN

COMPETENCIAS ................. 361

Enedina Ortega Gutiérrez

\section{LA ALFABETIZACIÓN INFORMATIVA Y}

EL SECTOR CULTURAL

\section{Alfabetización INFORMATIVA, ASIGNATURA PENDIENTE}

en la Red Nacional de Bibliotecas Públicas . . . . 385

Daniel Bañuelos Beaujean

INFORMACIÓN Y EDUCACIÓN NO FORMAL EN EL

InStituto NaCional de ANTROpología E

historia a través de su Programa

de Trabajo . . . . . . . . . . . . . . . . 413

Miguel Nájera Pérez

Formación profesional para alfabetizar

Informativamente

ENTRE NOVELES Y HACEDORES . . . . . . . . . . . . 439

Judith Licea de Arenas y José Antonio Gómez-Hernández

INNOVACIÓN Y MENTORIZACIÓN PARA LA FORMACIÓN

EN ALFIN: NUEVOS RETOS PARA LAS BIBLIOTECAS

UNIVERSITARIAS ..................447

María Pinto 


\section{Introducción}

A partir de la última década del siglo XX se han henuevo tipo de aprendizaje que incluye procesos de pensamiento, habilidades y competencias que les permitan a los seres humanos vivir una vida bien informada, $y$ que esta información le posibilite plantearse objetivos dignos; vivir juiciosamente y en armonía con los demás; y tener prosperidad.

Entre los ejemplos más sobresalientes está la quinta reunión de la Unesco/CONFINTEA (Conferencia Internacional sobre Educación de Adultos) realizada en Hamburgo en 1997, en la que se establece que las bibliotecas, los museos y las instituciones culturales se deberían fortalecer para convertirse en lugares que promuevan el aprendizaje para toda la vida, acordes con una ciudadanía moderna (CONFINTEA: Adult Education: The Hamburg Declaration: The agenda for the future, 1997).

Ya en este siglo la OCDE genera el documento 21st Century Skills and Competences for New Millennium Learners in OECD Countries, en el cual se determina que el nuevo entorno tecnológico digital requiere conceptualizar y analizar sus efectos en el desarrollo cognitivo de 
la gente joven, sus valores, estilos de vida y expectativas educativas, y examinar las respuestas emergentes que las políticas de educación le están dando a este nuevo fenómeno. (Ananiadou, K. and M. Claro 2009, 21st Century Skills and Competences for New Millennium Learners in OECDCountries, OECD Education Working Papers, No. 41, OECD Publishing, p. 5 Disponible en: http:// dx.doi.org/10.1787/218525261154 [consulta: 24 de febrero del 2011).

En el ámbito en el que se han profundizado más estas posturas es en el educativo, desde 1998 a la fecha se han realizado Conferencias Mundiales sobre Educación Superior, cuyos propósitos han sido que la educación tienda a:

- Transformar más que a transmitir.

- Facilitar el aprendizaje progresivo, reflexivo y crítico.

- Seguir paradigmas responsables para vivir, ser y para llegar a ser, tanto individual como colectivamente.

El fin último de estos propósitos es generar un bien público que conceda valor a la sociedad, educación a las personas para que sean ciudadanos productivos, y el arribo o la consolidación de las Sociedades de la Información o del Conocimiento. (Conferencia Mundial sobre la Educación Superior: La educación superior en el siglo XXI: Visión y acción, 1998, disponible en: http:// www.unesco.org/education/educprog/wche/declaration_spa.htm, [consulta: 10 de enero del 2011). 
Se pretende lograr que los sujetos profundicen sobre el concepto de conocimiento como la base para construir una sociedad ética, equitativa, con acceso a todos los recursos que existan y con calidad de vida. Se busca también que perciban a la información como el inicio y el producto de ese conocimiento: quien tiene acceso a la información podrá generar conocimiento. El acceso a la información requiere un conjunto de habilidades y procesos de pensamiento tal que les permite resolver problemas de cualquier índole.

Una de las propuestas para que las personas adquieran dichas habilidades está representada por la Alfabetización Informativa (en lo sucesivo AI), a este respecto instancias nacionales e internacionales han lanzado proclamas (Unesco, 2000; IFLA, 2002; The Prague Declaration, 2003; The Alexandria Proclamation, 2005; Declaración de Toledo, 2006), en las que determinan que la AI debe verse como un tema nacional, ya sea como parte de los sistemas educativos formales o los informales, lo importante es que llegue a todos los sectores de una población.

Para que esto se logre las comunidades de profesionales de la bibliotecología y la información debemos trabajar en forma conjunta, para que la AT sea incluida en las agendas nacionales de las instancias de todos los sectores: educativos, empresariales, de producción, industriales, políticos, culturales y sociales, y trabajar con las instituciones que pueden beneficiarse. Esto se logrará cuando tengamos claro que los resultados de la AI deben ser concretos y visibles a corto, mediano y largo plazos. 
No deberá ser éste un esfuerzo aislado que esté definido por un tipo de instrucción o un tipo de bibliotecario o de usuario, deberá ser un proyecto incluyente que congregue además de los bibliotecarios a profesores, empresarios, agencias gubernamentales, agencias sociales, y a todos los ciudadanos de un país. Esto nos permitirá generar, utilizar y compartir un lenguaje común; explorar aplicaciones similares en diferentes escenarios; y enfrentar una mirada más amplia e inclusiva de la Alfabetización Informativa, (AI).

En México y en algunos países de Iberoamérica la AI se sigue considerando como un proyecto concentrado en las instituciones de educación y más concretamente las de educación superior. Se han dejado de lado los niveles de educación básica, y media superior, y las comunidades de sujetos que no están insertas en programas educativos formales, como pueden ser las amas de casa y los adultos mayores, entre otros.

El presente libro tiene por objetivo presentar las experiencias que existen sobre el uso adecuado de la información, cabe resaltar que la utilización del término experiencias se hace en su sentido más amplio, puesto que se incluyen programas de instrucción; habilidades informativas; formación y educación; y cualquier proceso que tenga que ver con la enseñanza de la explotación adecuada de recursos, herramientas y servicios de información, no necesariamente circunscritos al espacio biblioteca o unidad de información. Algunas de ellas podrán ser consideradas como Alfabetización Informativa y otras no. 
El libro está organizado en cuatro partes que abordan el fenómeno en forma holística, desde su delimitación conceptual y descripción de experiencias puntuales en diversas instituciones, hasta los retos que los profesionales de la bibliotecología y la información deben enfrentar para proveer la AI y cómo podría hacerlo.

La primera parte La Alfabetización Informativa como un proyecto nacional incluye seis artículos que tocan los siguientes temas: el establecimiento de un concepto de trabajo; la necesidad de políticas nacionales sobre la AI; el estado del arte en Colombia; y tres propuestas de corte nacional para diferentes comunidades.

La siguiente sección Experiencias de formación de usuarios y de habilidades informativas en Educación Superior, incorpora siete capítulos que explican programas específicos circunscritos básicamente a instituciones de educación superior y que no pueden considerarse como propuestas de AI, pero que valdría la pena tomar como modelos para generar alguna estrategia para este sector educativo.

Como su nombre lo indica la fracción La Alfabetización Informativa y el sector cultural expresa el panorama de este proceso en las instituciones culturales de México, representadas por las bibliotecas públicas y las dependencias del Instituto Nacional de Antropología e Historia, se adelanta que en este sector no existen programas que promuevan la generación de habilidades, procesos mentales y actitudes que le permitan al ciudadano en general la explotación adecuada de los recursos de información disponibles en esas instituciones. 
Tendencias de la Alfabetización Informativa en Iberoamérica

La cuarta y última parte Formación profesional para alfabetizar informativamente, ubica la AI como uno de los aspectos que los especialistas de la bibliotecología e información debemos considerar con mayor énfasis y una alternativa que puede apoyarla.

Se espera que este libro aporte al esclarecimiento del sentido de la Alfabetización Informativa y las experiencias descritas den luz a los profesionales interesados en generar estrategias y propuestas sobre el tema. 
La Alfabetización Informativa como un proyecto nacional 


\title{
Contexto teórico de la Alfabetización Informativa
}

\author{
PATRICIA HERNÁNDEZ SALAZAR
}

Universidad Nacional Autónoma de México

\section{INTRODUCCIÓN}

C

on la llegada de las microcomputadoras y la innovación de las telecomunicaciones por medio de redes en la década de los setenta del siglo XX, el acceso a gran cantidad de recursos de información se incrementó exponencialmente. Situación que pareciera ventajosa para los sujetos que requieren resolver algún problema; sin embargo, también los puso ante grandes disyuntivas de selección, al aumentar la cantidad de decisiones que deberían tomar sobre qué herramienta o recurso era el más indicado de acuerdo con una necesidad específica.

Ante este panorama los profesionales de la información han incrementado el esfuerzo que durante décadas han venido haciendo de formar a sus usuarios, $y$ han requerido ampliar su campo de acción y abarcar un rango 
mayor de individuos: además de los usuarios que asisten a la unidad de información, piensan en los que no lo hacen pero que eventualmente necesitarán algún recurso.

El contexto social actual, permeado por la presencia constante de las tecnologías de información y comunicación (TIC), requiere que las personas desarrollen diversas habilidades, procesos de pensamiento y actitudes. Para lograr que cualquier sujeto que precise información sea capaz de manejarla eficientemente, en las últimas cuatro décadas se ha hablado de la Alfabetización Informativa (AI). Existe una gran controversia acerca del sentido que esta frase encierra: si debemos entenderla como un proceso mayor que incluye las acciones ya mencionadas, relacionadas con conceder aprendizajes sobre el uso efectivo de la información, como son la formación y educación de usuarios, la instrucción bibliográfica y/o bibliotecaria; o si se trata de un nuevo término para nombrarlas; o si hablamos de una nueva opción que tiene características, estrategias y procedimientos propios.

Para tratar de resolver esta controversia, este capítulo analiza los conceptos y/o definiciones que se han generado sobre la AI, y derivado de este análisis genera un concepto de trabajo. El estudio abarca desde la aparición de la frase en 1974 hasta la primera década de este siglo, y se hace tomando como base la identificación y explicación de los elementos que componen un concepto: esencia, características y objetivo, de tal manera que se examinaron solamente aquéllos que contuvieran al menos dos de estos elementos. 
Se rastrea el origen de la frase, se examinan los diversos conceptos, se genera un concepto y se identifican las aportaciones y las proclamas que a nivel internacional han aparecido. A manera de preámbulo vale adelantar que la AI se percibe como un fenómeno que tiene una delimitación propia, que no es mayor o menor que cualquiera de las antes mencionadas, sino que es diferente, y que debe ser esencial para cualquier ciudadano de un país que requiera resolver un problema, ya sea de índole personal o profesional, dentro de un entorno social dinámico, equitativo e inclusivo.

\section{ORIGEN DEL USO DE LA FRASE}

La Alfabetización Informativa (AI) es un fenómeno que desde la década de los setenta del siglo pasado ha recibido una gran atención por parte de las comunidades bibliotecológicas de diversos países, originalmente sólo pareció interesarle a los Estados Unidos, el Reino Unido y Australia, en la actualidad forma parte de la agenda de países tales como Colombia, Chile y España.

Este fenómeno ha pasado por diversos estadios que van desde considerarla como una estrategia para apoyar el desarrollo de la industria de la información, hasta percibirla como uno de los elementos clave en el proceso de aprendizaje para toda la vida.

Algunos autores consideran que la Alfabetización Informativa es una evolución de procesos realizados en las bibliotecas con anterioridad, tales como: orientación, instrucción bibliográfica y bibliotecaria, educación de usuarios, y habilidades de instrucción para el uso de bibliotecas (Grassian y Kaplowitz, 2001) y que 
éstos dependen jerárquicamente o están incluidos en la AI y sólo les añaden pequeños matices a los significados.

Otros establecen que es un nuevo término para lo que siempre han hecho los profesionales de la información. Este es el caso de Grassian y Kaplowitz, (2001), quienes marcan como fecha de inicio de la AI el año de 1876, año en el que Melvil Dewey declaró a la biblioteca como escuela y al bibliotecario como maestro. Idea que no se comparte, pero que sin embargo, presenta un panorama somero de las experiencias que desde ese año hasta la fecha se han desarrollado con la intención de proveer aprendizajes sobre la recuperación y el uso de recursos de información en forma eficiente.

Básicamente estos aprendizajes se han dirigido a comunidades de instituciones educativas de todos los niveles, desde preescolar hasta posgrado.

Las estrategias han tenido diversas formas:

- Cursos con valor curricular: investigación bibliotecaria; uso de la biblioteca; aumento de la calidad de las investigaciones.

- Cursos sin valor curricular, con carácter obligatorio.

- Conferencias: uso de la biblioteca; naturaleza y uso de los recursos de información.

- Asesorías o tutorías individuales de corte informal.

- Materiales didácticos: videos; discos compactos; dvd's; audios (visitas autoguiadas); programas de instrucción asistida por computadora; libros de trabajo autoaplicados.

Y también modalidades:

- Presencial.

- A distancia: sincrónica; asincrónica. 
La Alfabetización Informativa como un proyecto nacional

- Mezclada (blended-learning).

Los bibliotecarios y especialistas de la información que han incursionado en el diseño y desarrollo de estas experiencias se han enfrentado a los siguientes problemas:

- No tienen estatus de docentes.

- El contacto entre bibliotecarios, docentes y tomadores de decisiones es mínimo.

- Los profesionales de la información no intervienen en el desarrollo curricular.

- Las experiencias de formación no llegan a comunidades no escolarizadas.

Una posible solución a esta problemática aparece con la idea de alfabetización informativa que Zurkowski lanza en 1974, cuando era presidente de la Asociación de la Información para la Industria (Information Industry Association) y formaba parte de la Comisión Nacional sobre Bibliotecas y Ciencia de la Información (National Commission on Libraries and Information Science) de Estados Unidos. Como parte de sus actividades generó el documento The information service environment, relationships and priorities, en el que propuso la creación de un programa nacional para alcanzar la alfabetización informativa universal en 1984, y estableció una primera caracterización de la persona alfabetizada como:

Personas entrenadas o capacitadas en la aplicación de los recursos de información a su trabajo [...] que han aprendido técnicas y habilidades para utilizar la amplia variedad de herramientas de información y también los recursos primarios para encontrarle solu- 
ción a sus problemas con la información, (Zurkowski, 1974, h. 6).

A partir de esta definición y propuesta para universalizar la AI, una parte considerable de investigadores del tema creen en la AI como un nuevo concepto que representa una manera novedosa de pensar acerca de nuestras metas y responsabilidades profesionales, postura con la que en general se está totalmente de acuerdo, por lo que el origen de la frase se ubica en 1974, con Paul Zurkowski.

A continuación se describen las acciones que sobre AI se han realizado en países de América, Europa y Oceanía.

\section{Estados Unidos}

Éste es uno de los países que más ha trabajado sobre el tema, reconocen a la AI como un proyecto colectivo de interés nacional a nivel de gobierno. De hecho, como se pudo notar en párrafos anteriores, con la existencia de la Comisión Nacional sobre Bibliotecas y Ciencia de la Información, desde los años setenta las bibliotecas y la información son tópicos de interés gubernamental.

En EUA la $\mathrm{AI}$ ha estado vinculada directamente con la educación. En 1981 se creó la Comisión Nacional sobre Excelencia en Educación, con el fin de examinar la calidad de la educación y generar recomendaciones que la reformaran. Se hizo una investigación de 18 meses, cuyos resultados se vertieron en el documento $A$ Nation at Risk (1983), el informe incluía los riesgos a los que se enfrentaba la nación, que estaban relacionados con la educación y las recomendaciones que se deberían seguir 
para pasar por encima ese riesgo. El documento destaca que el conocimiento, el aprendizaje, la información y la inteligencia habilitadas son el nuevo conjunto de materiales del comercio internacional. (A Nation at Risk. Disponible en: http://www2.ed.gov/pubs/NatAtRisk /index.html, [consulta: 8 de mayo del 2010]).

La intención era lograr que Estados Unidos se convirtiera en una Sociedad del Aprendizaje, mediante la estrategia de aprendizaje para toda la vida, elemento relacionado directamente con la AI. Como respuesta a este documento en 1984 miembros de la Comisión Nacional sobre Bibliotecas y Ciencia de la Información antes mencionada, establecieron que para apoyar el desarrollo de la educación el objetivo básico debería ser que cada estudiante aprendiera cómo identificar la información que le es necesaria; localizarla, organizarla y presentarla de manera clara y persuasiva, idea que deriva de la propuesta de Zurkowski y que refuerza la necesidad de que los sujetos exploten adecuadamente la información y, lo más importante, que los recursos fueran seleccionados de tal manera que les resolviera una necesidad específica.

A partir de la década de los ochenta, las tecnologías de información y comunicación (TIC) empiezan a permear todas las actividades de los ciudadanos norteamericanos: escolares; profesionales; laborales; y trámites cotidianos culturales y sociales en general, lo que provocó que el nivel de alfabetización educativa se incrementara y se incluyera como aprendizaje básico el uso de dichas tecnologías. 
Cabe decir que en ese país las asociaciones profesionales han tenido una gran influencia en el desarrollo de la AI, de tal manera que las definiciones, estrategias y normas utilizadas han surgido de éstas; a continuación se presenta el Cuadro 1 que muestra las aportaciones de cada asociación:

\begin{tabular}{|c|c|c|}
\hline \multicolumn{3}{|c|}{$\begin{array}{l}\text { Cuadro } 1 \\
\text { Aportaciones de las asociaciones }\end{array}$} \\
\hline Asociación & Aportación & Año \\
\hline Información para la Industria & $\begin{array}{l}\text { Definición de persona alfabetizada } \\
\text { / } \\
\text { Zurkowski }\end{array}$ & 1974 \\
\hline $\begin{array}{l}\text { Americana de Bibliotecas (American Li- } \\
\text { brary Association - ALA) }\end{array}$ & $\begin{array}{l}\text { Definición de persona alfabeti- } \\
\text { zada. } \\
\text { - Recomendaciones para crear } \\
\text { programas }\end{array}$ & 1989 \\
\hline $\begin{array}{l}\text { Americana de Bibliotecas Escolares } \\
\text { (American Association of School Libra- } \\
\text { ries - AASL) - sección de la ALA }\end{array}$ & - Normas K-12* & 1998 \\
\hline $\begin{array}{l}\text { Academia Nacional de las Ciencias (US } \\
\text { National Academy of the Sciences) }\end{array}$ & - Definición de fluidez informativa & 1999 \\
\hline $\begin{array}{l}\text { Bibliotecas de Colegios e Investigación } \\
\text { (Association of College and Research Li- } \\
\text { braries - ACRL) - sección de la ALA }\end{array}$ & - Normas & 2000 \\
\hline \multicolumn{3}{|c|}{$\begin{array}{l}\text { * Término usado en EUA, Canada y Australia para designar la educación básica, los niveles de primara y se- } \\
\text { cundaria. }\end{array}$} \\
\hline
\end{tabular}


Estas aportaciones han originado la creación de diversas instancias que se dedican a generar propuestas y programas de AI, como son el Foro Nacional sobre Alfabetización Informativa (http://infolit.org/) y el Instituto para la Alfabetización Informativa, (http:// www.ala.org/ala/mgrps/divs/acrl/issues/infolit/professactivity/iil/welcome.cfm ). El primero, es un grupo formado por más de 93 organizaciones nacionales e internacionales que busca generar el empoderamiento individual dentro de la sociedad de la información; por su parte, el segundo tiene como objetivo preparar y apoyar a bibliotecarios y otros educadores de educación superior de EUA a desarrollar y enseñar programas de AI.

Existen también esfuerzos por dotar de habilidades informativas a otros sectores de la población, tal es el caso de la AOL Time Warner Foundation's 21st Century Literacy Initiative, cuyo objetivo es ayudar a la gente joven a adquirir las habilidades de Alfabetización del Siglo XXI que necesitan para tener éxito en la escuela, el trabajo y en sus comunidades, (Eisenberg; Lowe y Spitzer, 2004).

Algunas agencias nacionales como la American Association of Higher Education \& Accreditation (AAHE http://www.aahea.org/); la National Education Association (NEA http://www.nea.org/); la National Council for the Social Studies (NCSS http://www.socialstudies.org); la Western Association of Schools and Colleges (WASC www.wascweb. org/); y la Commission on Higher Education (CHE http://202.57.63.198/ chedwww/index.php ) han influido para aumentar la 
importancia de la AI, y han generado normas y propuestas sobre el tema.

Este panorama nos muestra que diversas instancias de ese país están trabajando a nivel nacional estrechamente con docentes y profesionales de otras disciplinas, pero siempre dirigidas por profesionales de la información.

Algunos otros países han hecho aportaciones interesantes al tema, a continuación se presenta un breve panorama. Cabe mencionar que se consideraron sólo aquéllos en los que la AI es considerada como un proyecto nacional.

\section{Reino Unido}

Los bibliotecarios de instituciones de educación básica y superior han desarrollado teorías y programas relacionados con las habilidades informativas y la Alfabetización Informativa, AI. En este país el esfuerzo también ha sido colegiado, por parte de los bibliotecarios y profesionales de la información, pues la Sociedad de las Bibliotecas Universitarias Nacionales y de los Colegios Universitarios (Colleges) (Society of College, National and University Libraries-SCONUL) ha trabajado el tema desde 1997, a través de su Advisory Committee on Information Literacy (ACIL), básicamente para la educación superior. En 1998 esta Asociación realizó una investigación sobre las habilidades de información en estudiantes de nivel superior, cuyo objetivo fue estimular el debate sobre el lugar que tenían estas habilidades en el contexto de ese momento. Como resultado de esa investigación publicó en 1999 el documento Briefing paper: 
information skills in higher education, documento que incluye una definición de habilidades informativas y un modelo de AI, representado por 7 habilidades básicas (Seven Pillars Model of Information Literacy) que llevan al sujeto desde ser un aprendiz a ser un experto. Asimismo la SCONUL ha diseñado cursos para educación de adultos y aprendizaje abierto.

Posteriormente un organismo nacional el Comité Conjunto de Sistemas de Información (Joint Information Systems Committee-JISC), retoma la propuesta de SCONUL y genera sus normas y recomendaciones contenidas en The big blue information skills for students (2002). Sus recomendaciones son de carácter nacional y van dirigidas a personas mayores de 16 años (post-16), que han concluido la educación obligatoria básica (primaria y secundaria), y que buscan opciones educativas diferentes a las ofrecidas en universidades: colegios (collages); instituciones de aprendizaje comunitarias o para adultos; y aprendizaje basado en el trabajo. A este tipo de educación se le denomina educación continua (Further Education-FE). Si bien la comunidad meta es la mencionada anteriormente, las normas también aplican para las instituciones de educación superior.

En 2002, en Escocia, la Universidad de Glasgow organizó una conferencia sobre Información Tecnológica y Alfabetización Informativa, en la que se plantearon diversas estrategias de enseñanza, (disponible en www. iteu.gla.ac.uk/elit/itilit2002, consulta: 15 de diciembre del 2010).

La propia SCONUL publica en 2004 el documento Learning Outcomes and Information Literacy, el cual des- 
cribe seis casos de universidades en los que se ha logrado relacionar la alfabetización informativa, la filosofía educativa del aprendizaje y las estrategias de enseñanza.

\section{Australia y Nueva Zelanda}

Motivados por el gran desarrollo de la AI en Estados Unidos, la Universidad del Sur de Australia y el Consejo de Bibliotecarios Universitarios de Australia (Council of Australian University Librarians-CAUL) realizaron un taller nacional para revisar las Normas de Alfabetización Informativa para la Educación Superior (Information Literacy standards for higher education) publicadas por la ACRL en 2000 y generar las propias.

En 2001 publican sus Normas de Alfabetización Informativa (Information Literacy Standards), dirigidas a estudiantes de educación superior. Posteriormente la CAUL trabaja conjuntamente con especialistas de Nueva Zelanda y crean el Instituto de Australia y Nueva Zelanda para la Alfabetización Informativa (Australian and New Zealand Institute for Information LiteracyANZIIL http://www.anziil.org/)

Este Instituto organizó en 2003 un taller para repasar las normas del 2001, actualizarlas e integrar nuevas aproximaciones relacionadas con el aprendizaje independiente y el aprendizaje para toda la vida. El producto de este ejercicio, fue el texto titulado Australian and New Zealand Information Literacy Framework: principles, standards and practice, en el que amplían su alcance al dirigirlas a todos los sectores educativos y a sectores no escolarizados, con el fin de ayudar a resolver problemas personales, relacionados con el trabajo o aspectos 
sociales amplios. En total han realizado cuatro conferencias nacionales cuyo tema es la AI.

El escenario de estos países nos lleva a declarar que los programas de AI deben ser incluyentes, dirigidos a diversas comunidades, y de corte nacional o regional. Asimismo, se aprecia que existe una clara participación de asociaciones de profesionales de la información y la convergencia de diversas instancias y sectores.

El análisis del origen y desarrollo de la AI en los países mencionados nos muestra que sólo en Estados Unidos ha estado vigente la AI desde hace cuatro décadas, en el resto puede ubicarse en los últimos años del siglo pasado. Esto nos lleva a pensar que su evolución ha sido lenta y que este problema no es privativo de los países en desarrollo, como México, Colombia y Brasil.

Cabe destacar que se ha trabajado básicamente en generar normas, sin profundizar en el entramado conceptual tan necesario para el establecimiento de estrategias, políticas y/o acciones concretas.

\section{CONCEPTO DE ALFABETIZACIÓN INFORMATIVA}

No es un ejercicio ocioso delimitar el significado de la AI en tanto la mayoría de estudiosos del tema coincide en señalar que es básico establecerlo, pues esto determinará la tarea que los bibliotecarios y especialistas de la información tienen como instructores. Sin el entendimiento cabal de esta frase no sabremos cómo lograr que otros aprendan y cómo evaluar lo aprendido; y la generación de acciones, estrategias, políticas, y/o programas 
deberá derivar de un sustento conceptual. Existe una gran variedad de aproximaciones que no pretenden ser definitorias sino meras caracterizaciones.

Para tener un significado más o menos unívoco de lo que es la AI, se analizaron varias conceptos ${ }^{1}$ o definiciones, ${ }^{2}$ siguiendo la premisa de que incluyeran al menos dos de los tres elementos básicos que se establecen en la generación de definiciones, (Hempel, 1988) a saber:

1) Esencia - ¿qué es?

2) Características o propiedades - ¿cómo es?

3) Objetivo o función - ¿para qué es?

Uno de los primeros hallazgos fue que se identificaron dos fenómenos, la AI y al sujeto producto de esa alfabetización, la persona alfabetizada informativamente hablando. Si nos atenemos a los principios epistemológicos de creación de marcos conceptuales, ambas frases no representan la misma idea, de tal manera que no deberían ser consideradas como sinónimos. Dado que la mayoría de autores las usa indistintamente, el análisis considera ambas posturas.

1 Se conciben como delimitación intelectual y lingüística de una entidad. El significado de un término que designa una entidad, es decir, su explicación.

2 Se hace una diferenciación entre uno y otros. Los conceptos se entienden como las representaciones mentales de una entidad, un universal que determina su naturaleza, tanto la esencia (lo que es), como substancia (cómo es). 
En el Cuadro 2 se muestra en orden cronológico las definiciones encontradas, desglosadas en los elementos antes enunciados (esencia, características y/o función).

Cabe aclarar que algunos de los autores más citados, como es el caso de Eisenberg y Brown (1992), no hablan específicamente de AI, en realidad ellos desarrollaron un modelo denominado Big6TM Skills, basado en la idea de Habilidades de Instrucción en Biblioteca e Información, que ha sido ampliamente utilizado para diseñar experiencias de AI.

Por su parte, Behrens (1994) desarrolla un interesante panorama histórico sobre el concepto de AI, organizado por décadas, desde 1970 hasta principios de los noventa del siglo pasado. Aunque este panorama rescata las características más importantes de cada división temporal, no presenta un concepto propio, por lo que esta autora no fue considerada en el presente análisis.

Vayamos pues a detallar lo que se percibe en el Cuadro 2. Los 16 conceptos abarcan un periodo de tres décadas, lo que demuestra que no se ha logrado la univocidad tan necesaria en la generación de marcos teóricos. Como era de esperarse existe preeminencia de autores provenientes de Estados Unidos. A partir de los primeros años de la década de los noventa, el Reino Unido ha trabajado en forma continua, incluso el último estudio fue creado por Hannelore Rader, autora británica. 


\begin{tabular}{|c|c|c|c|c|}
\hline : & 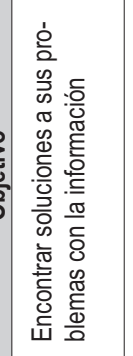 & 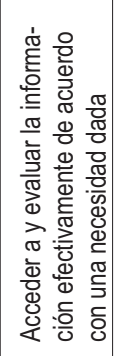 & 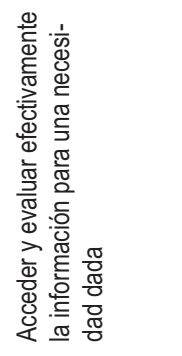 & 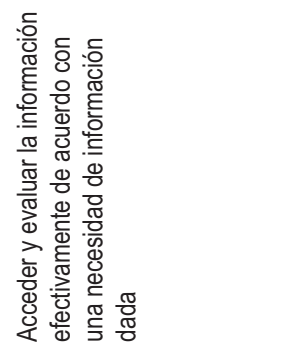 \\
\hline 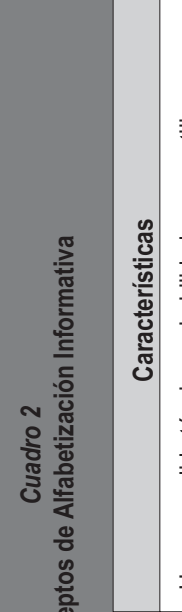 & 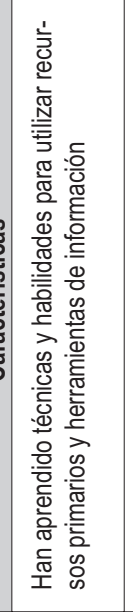 & & 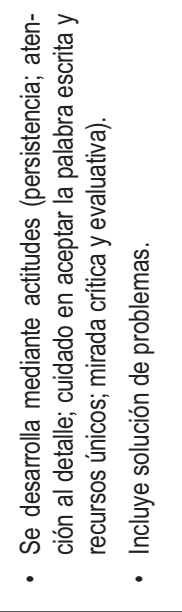 & 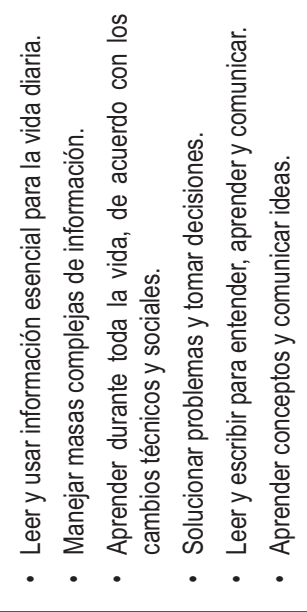 \\
\hline : & 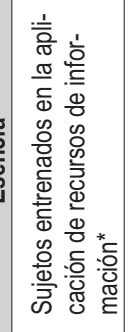 & 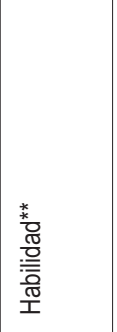 & 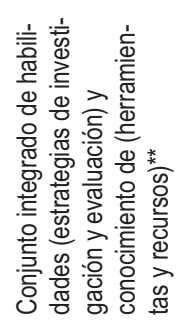 & 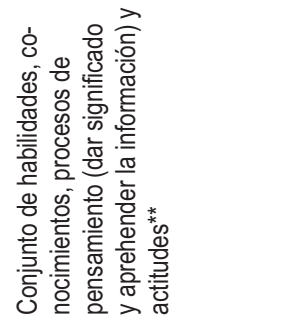 \\
\hline & 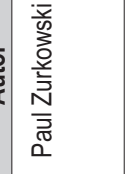 & 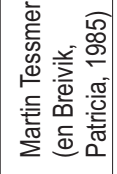 & 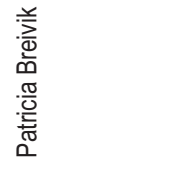 & 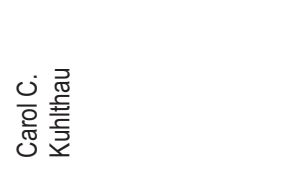 \\
\hline & 喜 & 言 & 㽞 & 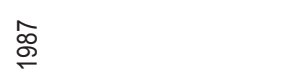 \\
\hline
\end{tabular}




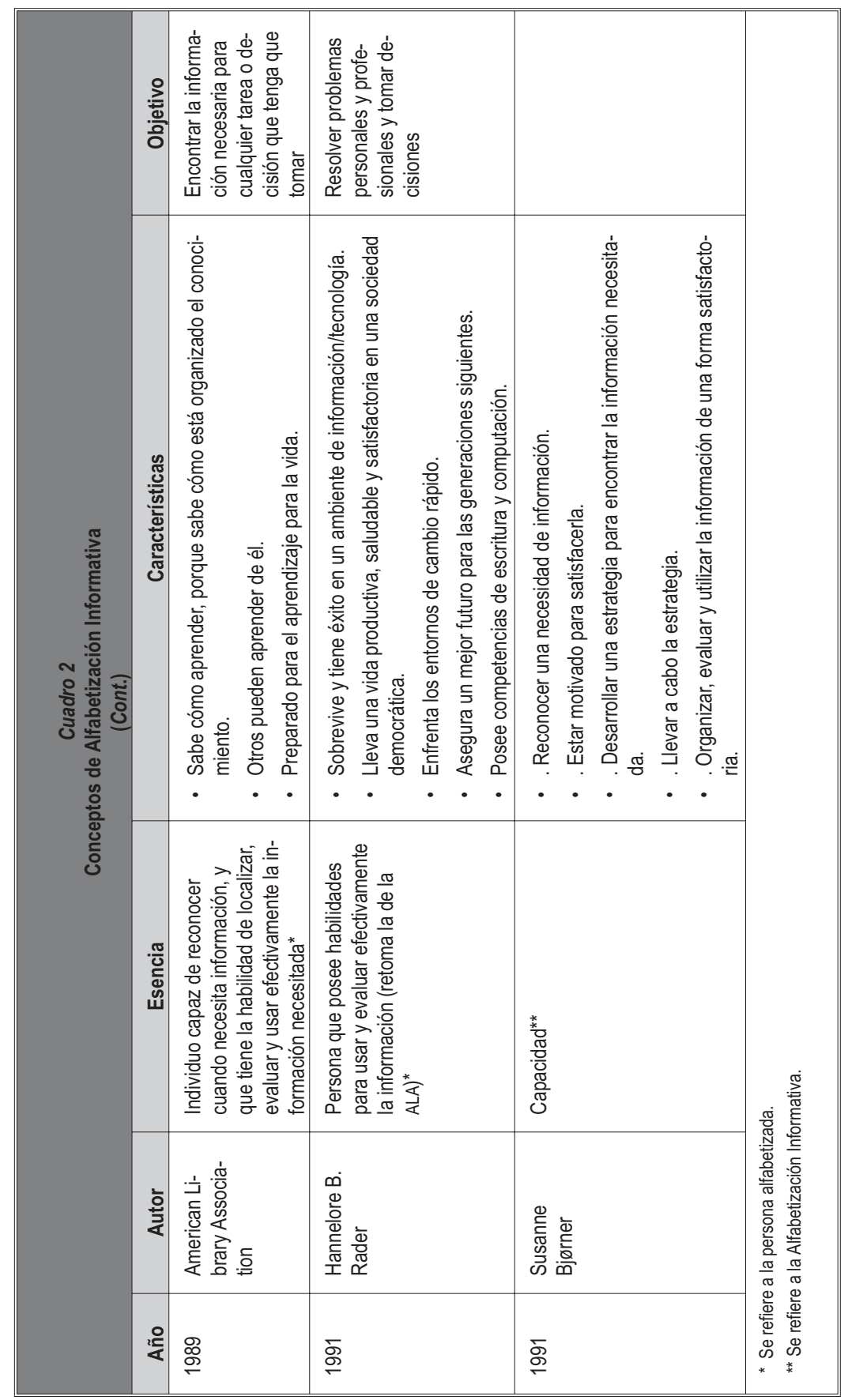




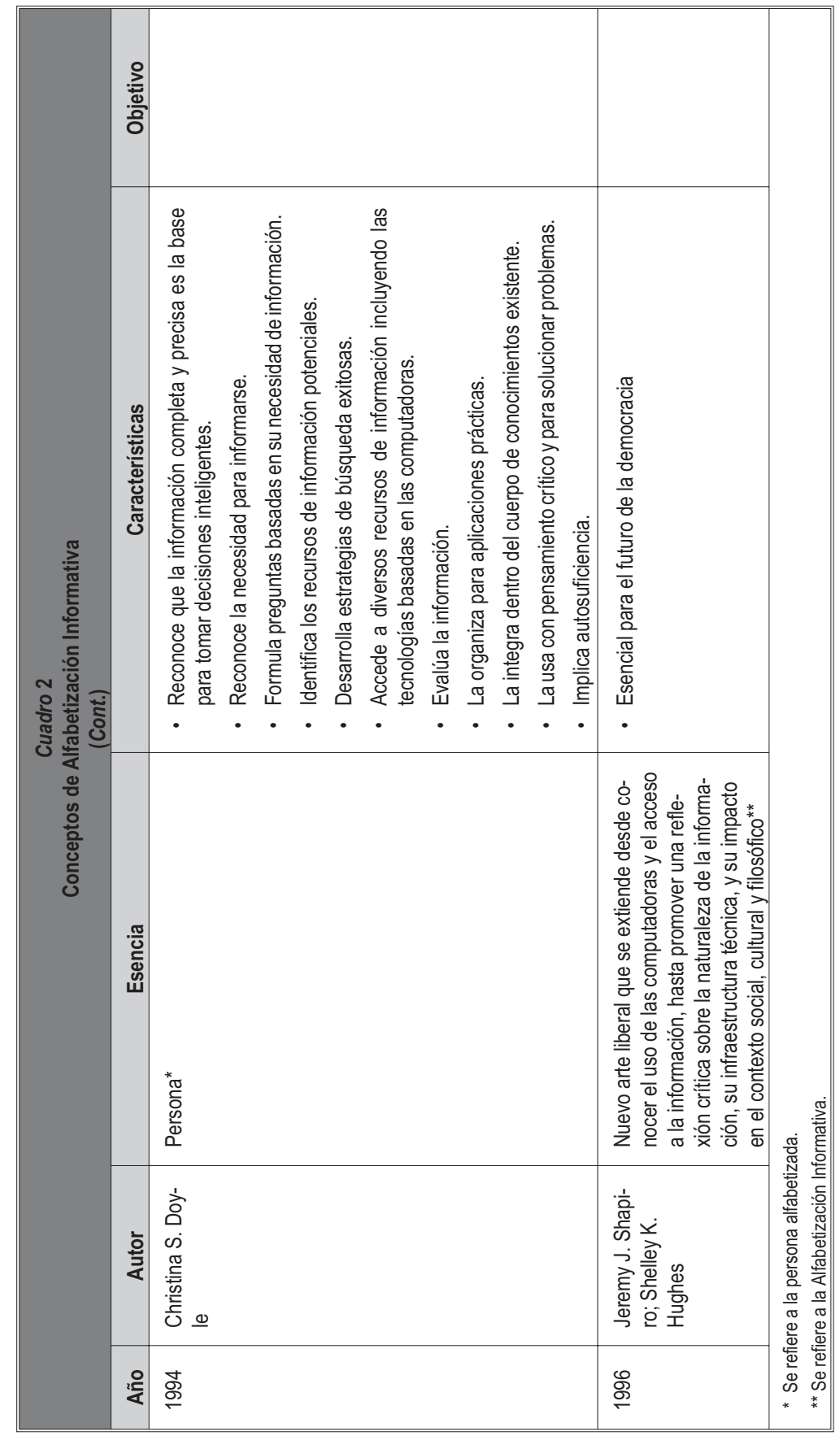




\begin{tabular}{|c|c|c|c|c|c|}
\hline & 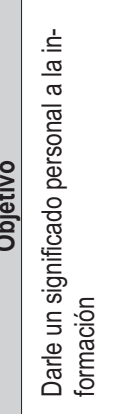 & & 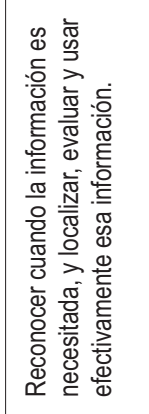 & 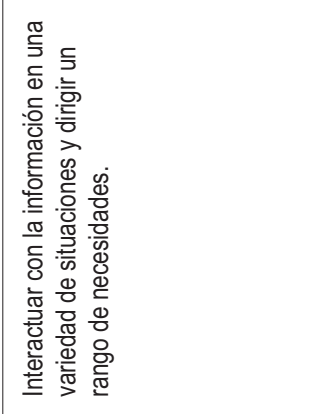 & \\
\hline 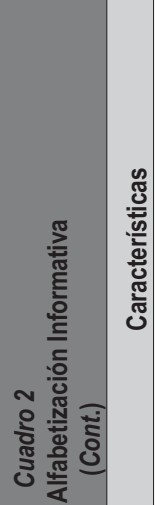 & |ֶ: & 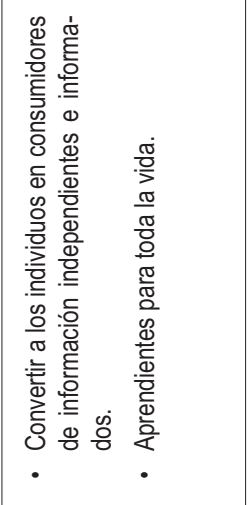 & 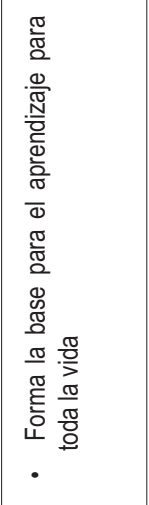 & 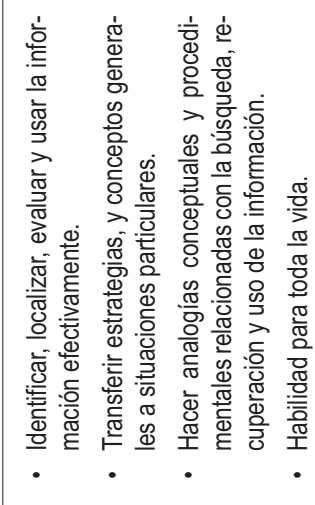 & \\
\hline 离 & 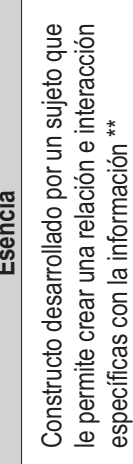 & 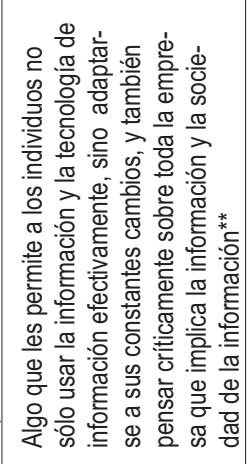 & 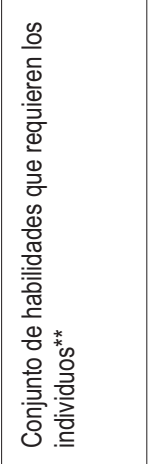 & 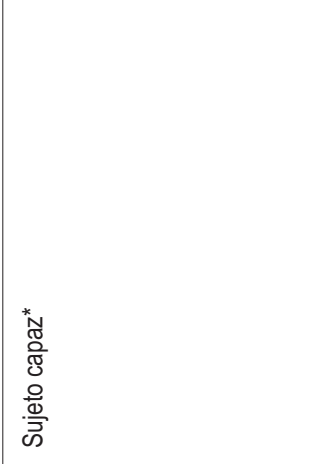 & 我 \\
\hline & 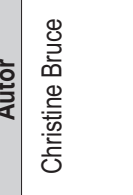 & 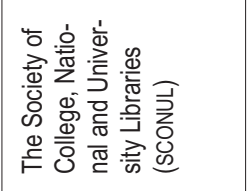 & 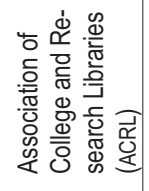 & 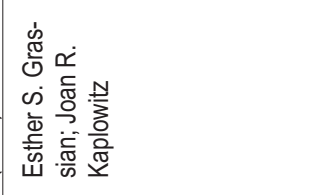 & 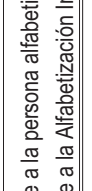 \\
\hline & 量唄 & 㟢 & ర్ & চ্ণ্ণ & \\
\hline
\end{tabular}




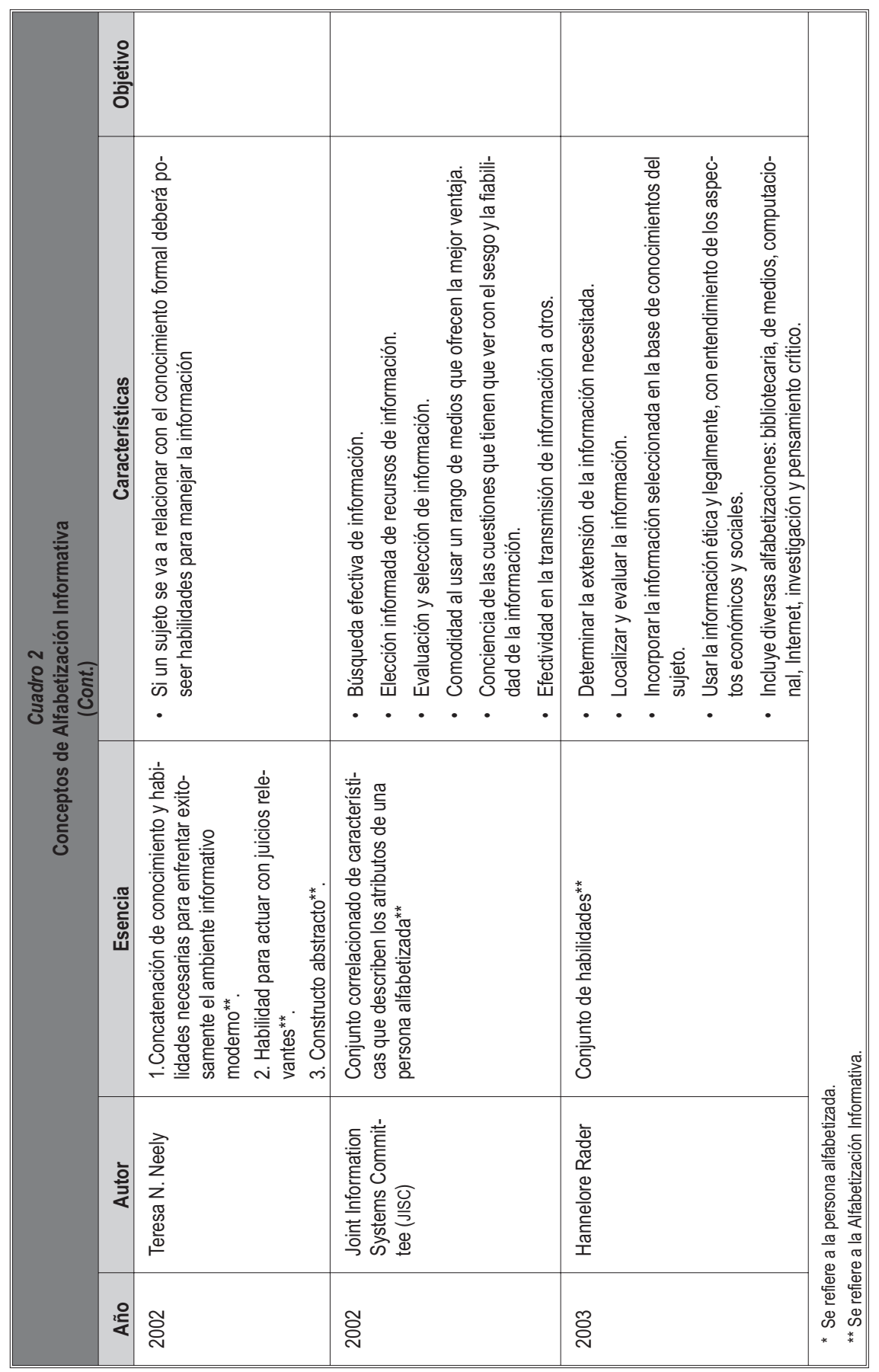




\section{Esencia (¿Qué es?)}

En cuanto a la forma, la mayoría de conceptos (11 de ellos) atiende al proceso, es decir, a la frase Alfabetización Informativa y el resto (5) al sujeto producto de ese proceso. Esta gran diferencia se debe a que se dejaron en el camino una buena cantidad de documentos que retomaban la definición de la ALA, que se refiere a la persona alfabetizada.

El examen se inicia con los conceptos de la AI como proceso, puesto que tiene mayor validez tanto lingüística como epistemológicamente. La esencia de los conceptos de AI se explica en dos partes, la primera representa el término o términos que le dan su identidad y la segunda la especialidad de esa identidad. En la primera parte se destacan ocho identidades:

1. Habilidad.

2. Capacidad.

3. Conjunto integrado de habilidades y conocimientos (Breivik, 1985); más procesos de pensamiento y actitudes (Kuhlthau, 1987).

4. Concatenación de conocimiento y habilidades.

5. Conjunto correlacionado de características.

6. Nuevo arte liberal.

7. Constructo desarrollado por un sujeto.

8. Algo.

El análisis puntual de cada uno de estos términos o frases nos lleva a determinar que existen diversas significaciones de AI. Existe un consenso tácito entre todos los estudiosos del tema al circunscribir las representaciones dentro de un marco pedagógico, de enseñanza y de 
aprendizaje, por lo que las acepciones se darán desde este marco.

La habilidad se refiere a la disposición, facilidad y comodidad que muestra algún individuo para desarrollar y/o realizar tareas (físicas o mentales) y resolver problemas en áreas de actividad determinadas. El desarrollo de habilidades se logra con la concurrencia de tres elementos: la capacidad, más el hábito, más el conocimiento del proceso a seguir; y se consolida mediante la eliminación de actividades inútiles y el reforzamiento de las actuaciones eficaces. Las habilidades pueden ser de diferentes tipos y niveles, que van desde las más sencillas, de carácter manual, hasta las más complejas de corte intelectual. La realización de las actividades requiere eficiencia y se espera de ellas un resultado específico, atendiendo a ciertos grados de satisfacción previstos.

En esta conceptuación resalta la introducción de la palabra capacidad que es otra de las que aparece como esencia, ésta hace alusión a la cualidad estable que tienen los sujetos y que les permite efectuar un acto físico o mental. Como una forma de capacidad está la cognitiva, entendida como:

[...] la suma de funciones neurológicas, intelectuales $\mathrm{y}$ mentales que posee un individuo para generar conocimiento. Los elementos cognitivos que permiten la construcción de conocimiento son los siguientes: percepción, memoria, representación mental, aprendizaje, deducción conceptual, solución de problemas, planificación y formas de decisiones estratégicas, (Perrone y Propper, 2007, p. 77). 
Lo anterior nos lleva a establecer que la habilidad es un estadio cognitivo complejo, puesto que requiere tener la capacidad para realizar una acción, la cual tendrá que reforzarse hasta lograr los resultados que cubrirán ciertas especificaciones para que puedan ser evaluados satisfactoriamente; es decir, la habilidad incluye a la capacidad, por lo que se prefiere el término habilidad para conceptuar a la AI.

Viene ahora la explicación del conjunto integrado de babilidades, conocimientos, procesos de pensamiento y actitudes, es conveniente emplear la palabra conjunto, puesto que existen diversos tipos y niveles de habilidades o capacidades. Ahora bien, en la propia definición de habilidades se establece que además de la capacidad se requiere el conocimiento del proceso a seguir, lo que hace innecesaria la mención del término conocimientos, ya que éstos están implícitos en el desarrollo de las habilidades.

Kuhlthau (1987) plantea en su concepción los procesos de pensamiento y los circunscribe a dar significado y aprehender (acomodar un nuevo conocimiento en el entramado cognitivo) la nueva información. De acuerdo con lo expresado anteriormente, relacionado con la capacidad cognitiva, podría creerse que los procesos de pensamiento están demás, sin embargo, debe especificarse en el concepto que se acepte y/o construya.

Esta misma autora integra las actitudes, éstas ya habían sido introducidas por Breivik en 1985 como condición para que se produjera el conjunto de habilidades y conocimientos, pero no como parte de la esencia de la AI. Las actitudes se refieren a las reacciones que una per- 
sona expresa ante un fenómeno determinado, están formadas por tres tipos de elementos: afectivo cognitivo ${ }^{4}$ y conductual. ${ }^{5}$ Estos elementos imprimen cierto significado en el sujeto, por lo que actúa en consecuencia ante determinada situación. La AI debe generar ciertas actitudes, por lo que es conveniente integrarlas a la delimitación conceptual.

En cuanto al conjunto correlacionado de características resulta demasiado genérico, pues una característica es un rasgo peculiar de una persona en cualquier circunstancia y no refiere en forma inmediata a sus habilidades, procesos mentales o actitudes.

Es un poco aventurado concebir a la AI como un nuevo arte liberal, porque no es un arte, aunque su consecuencia lleve a los sujetos a tomar decisiones y resolver problemas en forma autónoma y figurativamente a "ser libres".

Es interesante la forma en que concibe Bruce (1997) a la AI, constructo desarrollado por un sujeto. El término constructo remite a la teoría cognitiva del aprendizaje, y a toda la corriente cognitiva de la Bibliotecología y las Ciencias de la Información, su acepción puede derivarse tanto de la teoría de la personalidad (constructo personal) como de la tendencia pedagógica del constructivismo (constructo cognitivo). La primera nos dice que es una categoría descriptiva que utiliza cada individuo

3 Se relaciona con los sentimientos y estados de ánimo.

4 Se aplica a los procesos y actividades mentales.

5 Conjunto de acciones que permiten adaptarse a una realidad. 
para organizar los acontecimientos y datos del medio, y que representa su manera particular de construir el mundo, el sistema de categorías deviene de procesos mentales y es el que determina su percepción del mundo y sus acciones; y la segunda afirma que es la asimilación y el acomodo de nueva información en su cadena de conocimientos.

Como se puede apreciar ambos significados serían válidos para la construcción del concepto de AI, sin embargo, no se retomará porque estas ideas ya están contenidas en el desarrollo de habilidades y procesos de pensamiento, además resulta una denominación demasiado especializada que sería poco entendible en términos generales. Como se ha enfatizado, se debe tender a generar una definición que sea entendida y aceptada por profesionales de diversas disciplinas, así como tomadores de decisiones de los sectores gubernamentales, empresariales y de la industria, lo que haría poco práctica su adopción. Por último, algo es un término tan amplio que resulta inoperante su utilización.

Recapitulando, la frase que de acuerdo con el Cuadro 2, representa la primera parte de la esencia de la AI es un conjunto de habilidades, procesos de pensamiento y actitudes.

Analicemos ahora la segunda parte de la esencia, la especialidad. Las definiciones que la contenían fueron sólo tres:

- Nuevo arte laboral: el uso de las computadoras; acceso a la información; reflexión crítica sobre la naturaleza de la información; su infraestructura técnica; su impacto en el contexto social, cultural y filosófico. 
- Constructo: crear una relación e interacción específicas con la información.

- Algo: no sólo usar la información y la tecnología de información; adaptarse a constantes cambios; pensar críticamente sobre la empresa de la información y de la sociedad de la información.

Como se puede observar, en términos generales se expresan aquí las habilidades y los procesos de pensamiento que ya han sido abordados. Aparece como nuevo elemento la reflexión o pensamiento crítico. Esta idea se introduce en la AI con Breivik (1985), quien dice que el desarrollo de habilidades y conocimientos se hará mediante una mirada crítica y evaluativa, aunque estaba tácitamente expresado desde Zurkowski, cuando expresa que la gente podrá moldear soluciones a sus problemas con la información.

El pensamiento crítico es una construcción mental razonable y reflexiva que se dirige sobre cierto aspecto, pregunta o problema y que permite decidir qué creer y qué hacer para resolverlos. Se basa en un cuestionamiento permanente y profundo sobre el fenómeno o problema, que implica observar, interpretar, analizar, inferir, evaluar y explicarlo, es decir, un sujeto que posee pensamiento crítico: juzga, decide y resuelve. Su importancia radica en que un pensador crítico puede explicar lo que piensa y el proceso que realizó para llegar a ese pensamiento o juicio; y aplicar sus razonamientos a ellos mismos para mejorar o sostener sus opiniones, por lo que se convierten en autorregulables.

Esta última cualidad le confiere al pensamiento crítico el carácter de meta-cognición, un proceso de orden supe- 
rior que consiste en aplicarle el pensamiento al acto de pensar, y se reflexiona sobre lo pensado en forma permanente, lo que permite mejorar las tareas intelectuales y asegurar su buena ejecución; es decir, permite aprender a aprender (uso consciente de estrategias de aprendizaje), de aquí que este tipo de pensamiento se considere como un proceso de orden superior.

Las características básicas del pensamiento crítico son:

- Actividad reflexiva, basada en preguntas, de orden meta-cognitivo.

- Dialógico, se da mediante un proceso interactivo. (Vezzosi, M., Disponible en: http://dspace-unipr.cilea.it/bitstream/1889/91/2/BP100\%20Vezzosi.pdf, consulta: 23 de mayo del 2010).

Esta aproximación conceptual aclara puntualmente la relevancia de lograr el desarrollo de un pensamiento crítico, durante y como resultado de la AI, y de integrarlo a su concepto.

En cuanto al alcance de la AI, las definiciones enfatizan la necesidad de mirar en forma holística el fenómeno información, desde su naturaleza hasta su impacto dentro de un contexto actual, se precisan en los dos elementos restantes del estudio de las definiciones, las características y el objetivo.

\section{Características (¿Cómo es?)}

Las características que aparecen en el Cuadro 2, son principalmente los atributos que la AI genera en un sujeto. En general existen coincidencias, sobresalen las relacionadas con la solución de problemas y el aprendizaje 
para toda la vida. La primera situación tiene que ver con el pensamiento crítico, los sujetos que desarrollan este pensamiento connaturalmente resuelven problemas, por lo que esto se debe expresar claramente dentro de los procesos considerados en la esencia.

En cuanto al aprendizaje para toda la vida, la Federación Internacional de Asociaciones Bibliotecarias (International Federation of Library AssociationsIFLA) lo define como "todas las actividades de aprendizaje que tienen un propósito determinado emprendido en una base progresiva con el objetivo de aumentar el conocimiento, las habilidades y la competencia”. Este aprendizaje puede lograrse de diferentes maneras: formal (sistemas de educación escolarizada), o informal (entrenamiento dentro de la estructura de movimientos sociales). La conexión con la AI es que "dependen de métodos de trabajo que desarrollan la habilidad individual de buscar información y desarrollar conocimiento activa e independientemente" (The role of libraries in lifelong learning, 2004, h. 3), por lo que este rasgo se debe incluir también en el concepto final.

Todas las características presentadas se relacionan con el pensamiento crítico, ya que además de resolver problemas, se deben hacer juicios y tomar decisiones. A continuación se listan los atributos que concede la $\mathrm{AI}$ a los sujetos:

- Leer para entender y aprender, y escribir para comunicar.

- Aprender conceptos y comunicar ideas.

- Reconocer una necesidad de información y aceptarla. 
La Alfabetización Informativa como un proyecto nacional

- Desarrollar estrategias para encontrar la información que se necesita.

- Determinar la extensión de la información necesitada.

- Localizar y evaluar la información.

- Elegir el recurso más adecuado.

- Organizar y utilizar la información en forma satisfactoria.

- Incorporar la información seleccionada a la base de conocimientos del sujeto.

- Usar la información ética y legalmente, con entendimiento de los aspectos económicos y sociales.

- Comunicar o transmitir ideas a otros.

En un concepto no es necesario incluir este listado de habilidades, sino integrarlo posteriormente.

El análisis de esta parte nos arroja que se debe enfatizar en la definición el desarrollo del pensamiento crítico y el aprendizaje para toda la vida.

\section{Objetivo (¿Para qué?)}

El tercer y último elemento examinado es el objetivo, para qué le sirve a un sujeto poseer un conjunto de habilidades, procesos de pensamiento (pensamiento crítico) y buenas actitudes. Este rubro aparece solo en tres definiciones, y como una deriva de la otra (Tessemer, 1983; Breivik, 1985; Kuhlthau, 1987) resultan exactamente igual. Aparecen sólo dos estadios de la relación entre la información y el usuario, acceder y evaluarla, efectivamente, lo que demostrará que se ha logrado alcanzar el nivel y el grado de habilidad requeridos para hacerlo, 
por último todo esto debe ser de acuerdo con una necesidad dada.

Hasta aquí, pareciera que ya se ha delimitado el concepto de AI; sin embargo, se debe dar un paso atrás y revisar la esencia. La generación de definiciones requiere establecer el significado de cada palabra, en este caso Alfabetización e Informativa, si atendemos a esta premisa el significado de alfabetización se corresponde con el conjunto de habilidades, procesos de pensamiento y actitudes, proposición que no resulta verdadera.

La alfabetización es la acción educativa, sistematizada destinada a proveer los conocimientos básicos de lectura, escritura y cálculo indispensables para integrarse y desenvolverse en la sociedad, cuyo objetivo es que los "ciudadanos de un país alcancen un nivel cultural suficiente para ocuparse, dentro de la comunidad natural, de las tareas que les incumben con garantías de éxito" (Diccionario de la educación, 1983 p. 130).

Esta acepción resulta real y válida para la generación del concepto que nos ocupa. La llevamos a la AI y agregamos los elementos establecidos como esencia, características y objetivo, con lo que tenemos que la Alfabetización Informativa es la acción educativa sistematizada destinada a proveer a los sujetos de un conjunto de babilidades, procesos de pensamiento, como el pensamiento critico, $y$ actitudes que le permitan acceder, evaluar y usar efectivamente la información, para cubrir una necesidad dada. Esta acción deberá promover que aprendan a aprender y generar aprendizajes para toda la vida.

En esta aproximación conceptual están incluidos explícita o implícitamente todos los elementos necesarios 
y suficientes para entender la alfabetización informativa como proceso. Cabe destacar que dicha acción no se refiere exclusivamente a recursos tecnológicos, sino de cualquier tipo y soporte.

Salta ahora la pregunta ¿por qué nombrarla alfabetización? Existe una gran polémica a este respecto, puesto que en estricto sentido la AI provee de habilidades superiores a las básicas. Como ya se anotó, el origen de la frase se ubica en EUA, y se debió a dos causas. La primera tiene que ver con la idea de alfabetización para ese país, allí se entiende como la habilidad individual para escribir, leer y hablar inglés, y para razonar y resolver problemas a niveles de destreza necesarios para funcionar en el empleo y en la sociedad, con esto los ciudadanos de ese país podrán alcanzar sus metas personales y desarrollar conocimiento y potencialidad. En esta acepción aparece el pensamiento crítico, representado por razonar y solucionar problemas para funcionar en la sociedad, de aquí que se hablara de alfabetización.

La segunda causa deviene de su escenario social, el cual desde finales de la década de los setenta ha estado permeado por la aplicación de las tecnologías en todos los aspectos de la vida diaria. El Comité sobre Alfabetización Informativa de la ALA estudia esta situación y a finales de los ochenta genera el reporte titulado The importance of Information Literacy to Individuals, Business, and Citizenship: Opportunities to develop Information Literacy. En este documento el Comité ubica tres factores que se estaban presentando en ese momento en la sociedad norteamericana: 
- La rápida generación y expansión de la información, a partir del uso de la tecnología: almacenamiento, organización y acceso.

- El advenimiento y consolidación de la Sociedad de la Información.

- El derecho a la información para que la vida de los ciudadanos se enriqueciera económica, social y educativamente, lo que conllevaría a aumentar su calidad de vida.

Como se puede apreciar, estaba explícitamente expresada la información y sobretodo la consolidación de la Sociedad de la Información, así que dicha alfabetización tendría que ser sobre la información.

En cuanto al análisis de las definiciones de persona alfabetizada, se circunscribe al hecho de que es el sujeto quien recibirá la acción de la AI. Y que muestran solamente los atributos que deberán poseer, los cuales fueron retomados cuando se explicaron las características de la AI, por lo que quedan contenidas en el concepto que se generó.

\section{LA ALFABETIZACIÓN INFORMATIVA COMO UN PROYECTO NACIONAL}

La indefinición conceptual ha llevado a que exista una gran confusión en cuanto a cómo nombrar las acciones que sobre el uso adecuado de la información se planean, en dónde empieza y en dónde acaba la AI, y si es válido hablar de la evolución de otros procesos semejantes como la formación de usuarios, o la instrucción biblio- 
La Alfabetización Informativa como un proyecto nacional

gráfica. El concepto generado precisa qué es, cómo es y para qué sirve, se requiere especificar ahora su alcance.

La AI corresponde más a un proceso nacional que a una propuesta particular de alguna institución educativa, esto se justifica básicamente por dos razones: recomendaciones de la ALA e interés internacional.

\section{Recomendaciones de la ALA}

En el mismo documento en el que esta Asociación establece la definición de persona alfabetizada (The importance of information literacy to individuals, business, and citizenship opportunities to develop information literacy, 1989) la ALA sugiere seis recomendaciones para generar proyectos de AI, a saber:

1. Reconsiderar las maneras en que se ha organizado la información institucionalmente; reestructurado su acceso y definido su papel en las vidas de todos los ciudadanos (casa, comunidad y trabajo). Esta recomendación pretende ampliar los conceptos que se tienen acerca del conocimiento y la información, dentro del nuevo y dinámico ambiente de información. Las metas a alcanzar son: comunicar el poder del conocimiento; desarrollar en cada ciudadano el sentido de responsabilidad para adquirir conocimiento; y adquirir conocimiento que promueva un mejor uso de la información y las tecnologías con las que aquél se genera y distribuye. Y alude a las habilidades que se requieren para saber cuándo se tiene una necesidad de información; y para reunir, evaluar, interpretar, analizar, y sintetizar esa información. 
2. Formar una Coalición de Alfabetización Informativa. Esta Coalición estaría dirigida por la ALA, en coordinación con otras agencias y organizaciones nacionales para promover la AI. Esta Coalición debería estar organizada por un comité consultivo formado por destacadas figuras públicas de la bibliotecología, la educación, los negocios y el gobierno, y tendría las siguientes funciones:

- Promover la alfabetización informativa.

- Monitorear, reportar y reconocer los esfuerzos que tanto individuos como instituciones hacen para promover la alfabetización informativa y el aprendizaje basado en los recursos de información.

> Obtener recursos.

3. Emprender proyectos de investigación y demostración relacionados con la información y su uso. La intención sería desarrollar e implementar una agenda nacional de investigación sobre diversos temas, tales como: efectos sociales de la lectura; lugar que ocupa la información impresa; variaciones en el uso de información por disciplina; los efectos que la enseñanza de habilidades informativas tiene en la actuación y retención de los estudiantes; y el papel que pueden jugar las habilidades en información en el desarrollo económico y social de las minorías, entre otros.

4. Asegurar un ambiente que conduzca a los estudiantes de cada estado a convertirse en alfabetizados. Esto debería ser realizado por los Departamentos de Estado de Educación, las Comisiones de Educación Supe- 
rior y los Consejos Académicos del Gobierno. Entre las estrategias que se plantean destacan:

- Incorporar la alfabetización informativa en los currículos de instituciones educativas de todos los niveles.

- Incorporar en la preparación profesional y en la capacitación de los docentes la importancia del aprendizaje basado en los recursos de información.

> Incluir las competencias de alfabetización informativa en los exámenes de evaluación del estado.

5. Modificar la formación de los profesores y las expectativas de actuación docente. Este requerirá incluir aspectos relacionados con la alfabetización informativa y con el aprendizaje basado en los recursos de información, los profesores deberán utilizar un conjunto cada vez mayor de recursos de información. Para desarrollar esta recomendación se sugieren varias acciones, entre las que destaca promover las habilidades de: pensamiento investigativo; pensamiento crítico; de planteamiento y solución de problemas; y para el manejo de la información en todas sus formas y soportes (bases de datos especializadas, redes de aprendizaje, materiales de consulta, libros de texto, revistas, periódicos, entre otros). Asimismo, se enfatiza que los profesores deberían promover y esperar que sus alumnos se conviertan en alfabetizados informativamente.

6. Promover el entendimiento entre la relación de la alfabetización informativa y los temas de la Conferencia de la Casa Blanca sobre Biblioteca y Servicios 
de Información, esto fomentaría que el público en general se diera cuenta de la importancia de la AI (American Library Association, 1989).

Tanto el origen del proceso como las anteriores recomendaciones demuestran que la alfabetización informativa debe ser una estrategia educativa nacional con miras a resolver problemas sociales y en la que se comprometan a participar todos los sectores, actores e instancias necesarias, tanto gubernamentales como privados.

\section{INTERÉS INTERNACIONAL}

Como resultado de los esfuerzos que ha hecho EUA, diferentes instancias internacionales están reconociendo su trascendencia y han lanzado declaraciones y proclamas, cuya finalidad es extender su influencia en los países o regiones geográficas en las que aún no lo han hecho, a continuación se describen en orden cronológico cada una de las propuestas.

2000

La Unesco establece el Programa de Información para todos (Information for All Programme-IFAP http:// www.unesco.org/new/en/com munication-and-information/intergovernmental-programmes/informationfor-all-programme-ifap/), éste es un programa intergubernamental cuya finalidad es promover el acceso universal a la información y el conocimiento, para lograr el desarrollo y la construcción de Sociedades del Conocimiento. Entre las opciones que presenta el sitio de este Programa está una que corresponde a la Alfabetización 
Informativa. Cabe mencionar que este programa reemplazó al Programa General de Información y que se le dio un carácter más específico e inclusivo al dirigirlo hacia los sujetos. El IFAP funciona mediante Comités Nacionales de los países que están desarrollando estrategias, planes y programas relacionados con la AI.

\section{2}

La Federación Internacional de Asociaciones de Bibliotecarios (International Federation of Library Associations-IFLA) crea la Sección de Alfabetización Informativa, cuyo objetivo es "impulsar la cooperación internacional para el desarrollo de la educación en alfabetización informativa en todos los tipos de bibliotecas e instituciones de información" (disponible en http:// www.ifla.org/en/information-literacy, [consulta: 13 de abril del 2010]).

\section{3}

En la Reunión de Expertos en Alfabetización Informativa, organizada por la Comisión Nacional sobre Bibliotecas y Ciencia de la Información de EUA, y apoyada por la UNESCO, los participantes, representantes de 23 países, generaron The Prague Declaration "Towards an Information Literate Society". Este documento enfatiza que la creación de la Sociedad de la Información es un elemento clave para que las naciones, instituciones, comunidades e individuos se desarrollen económicamente en el siglo XXI, y resalta el hecho de que la AI debe ser un proyecto que comprometa a todos los sectores de la so- 
ciedad, y que lleve al gobierno de cada país a crear programas interdisciplinares sólidos que promuevan y generen programas de AI. El análisis de esta propuesta nos lleva a concluir que retoman así lo sugerido por la ALA en 1989, al considerar a la AI como un proyecto nacional incluyente que debería beneficie a todos los integrantes de una población o ciudadanía.

\section{5}

Durante el Coloquio de Alto Nivel sobre Alfabetización Informativa y Aprendizaje para toda la vida, realizado en la Biblioteca de Alejandría, se proclamó que:

[...] la AI y el aprendizaje para toda la vida son los faros de la Sociedad de la Información que iluminan los caminos hacia el desarrollo, la prosperidad y la libertad. (Beacons of the Information Society: The Alexandria Proclamation on Information Literacy and Lifelong Learning, disponible en: http://archive.ifla.org/III/wsis/BeaconInfSoc.html, [consulta: 12 de mayo del 2010]).

Por otro lado, se enfatizó el papel que debe jugar el aprendizaje para toda la vida, ya que "posibilita que los individuos, comunidades y naciones logren sus metas y aprovechen las oportunidades emergentes del ambiente global". Se estableció que se tendrán que generar programas que permeen todos los niveles escolares, incluyendo la educación continua, la educación informal para adultos y jóvenes, y a todos los sectores de la población. Y por último se resaltó, muy puntualmente, que para que esto se logre los países tendrán que invertir recursos económicos cuya ganancia será crear un 
La Alfabetización Informativa como un proyecto nacional

bien público que los dirigirá hacia la Sociedad de la Información.

\section{6}

Derivado de las anteriores declaraciones, los profesionales de la información y de la educación de España reunidos en el Seminario de Trabajo "Biblioteca, aprendizaje y ciudadanía: la alfabetización informacional", emitieron el documento Bibliotecas por el aprendizaje permanente: Declaración de Toledo sobre la Alfabetización Informacional (Alfin). El objetivo de este documento fue marcar las líneas prioritarias y de actuación sobre la situación de la AI en ese país, y realzar la importancia de los profesionales de la información en este tipo de experiencias; sin embargo, dejan fueran temas importantes como la necesidad de que los proyectos o programas de AI se manejen a nivel gubernamental.

A partir de estas propuestas, en algunos países de América Latina ha surgido el interés por generar y aplicar programas de AI, entre los más entusiastas y participativos se cuentan: Cuba, Chile (ambos pertenecen al Programa de Información para Todos de la Unesco) y Colombia. Éste último ha creado un sitio que provee toda la información, tanto retrospectiva como actualizada sobre AI a nivel internacional, el sitio se denomina Alfabetización Informacional -ALFIN/Colombia, (disponible en http://alfincolombia.blogspot.com/2009/ 12/el-conocimiento-y-reconocimiento-de-los.html, [consulta: 30 de mayo del 2010]). 


\section{CONCLUSIONES}

Es imperativo tomar conciencia de la transcendencia de integrar la Alfabetización Informativa a la agenda de las estrategias básicas para lograr que todos los ciudadanos de un país se integren a la Sociedad de la Información. El manejo adecuado de los recursos y herramientas de información permitirá el desarrollo democrático y equitativo de un país.

A pesar de estas afirmaciones existe una gran controversia en cuanto al significado puntual de este proceso. Tras analizar una serie de definiciones generadas a través de las últimas cinco décadas, se establece una en la que concurren sus elementos más característicos, así la AI es la acción educativa sistematizada destinada a proveer a los sujetos de un conjunto de habilidades, procesos de pensamiento, como el pensamiento crítico, y actitudes que le permitan acceder, evaluar y usar efectivamente la información, para cubrir una necesidad dada. Esta acción deberá promover que aprendan a aprender y generar aprendizajes para toda la vida.

\section{OBRAS CONSULTADAS}

American Association of School Librarians. Information literacy standards for student learning: standards and indicators, disponible en http://www.ala.org/ala/mgrps/divs/ aasl/aaslarchive/pubsarchive/informationpower/InformationLiteracy Standards_final.pdf, [consulta: 12 de diciembre del 2010]. 


\section{La Alfabetización Informativa como un proyecto nacional}

American Library Association. Presidential Committee on Information Literacy: Final Report, The importance of in formation literacy to individuals, business, and citizenship opportunities to develop information literacy, disponible en http:// www.ala.org/ala/acrl/acrlpubs/whitepapers/presidential.htm, [consulta: 12 de marzo del 2010].

A Nation at Risk (1983), disponible en: http://www2.ed.gov/ pubs/NatAtRisk/index.html, [consulta: 8 de mayo del 2010].

The Association of College and Research Libraries, Information Literacy Competency Standards for Higher Education, Chicago: American Library Association, 2000, 20 p.

Australian and New Zealand Information Literacy Framework: principles, standards and practice (2004), Adelaide: Australian and New Zealand Institute for Information Literacy, $52 \mathrm{p}$.

Beacons of the Information Society: The Alexandria Proclamation on Information Literacy and Lifelong Learning, disponible en http://archive.ifla.org/III/wsis/BeaconInfSoc. html, [consulta: 24 de marzo del 2010].

Behrens, S. J. (1994), “A conceptual analysis and historical overview of Information Literacy", en College and Research Libraries, pp. 309-322, July.

Bibliotecas por el aprendizaje permanente: Declaración de Toledo sobre la Alfabetización Informacional (Alfin), Documento en pdf.

The big blue: information skills for students, disponible en http://www.library.mmu.ac.uk/bigblue/pdf/finalreportful.pdf, [consulta: 10 de agosto del 2009]. 
Tendencias de la Alfabetización Informativa en Iberoamérica

Breivik, P. S., Information literacy: revolution in the library, New York: American Council on Education, c1989, 250 p.

Bruce, C. (1997), The seven faces of information literacy, Adelaide, Australia: Auslib. 203 p.

Council of Australian University Librarians. Information Literacy Standards, disponible en http://www.caul.edu.au/ caul-doc/InfoLitStandards2001.doc, [consulta: 10 de agosto del 2009].

Doyle, C. S. (1994), Information literacy in an information society a concept for the information age, Syracuse, New York: ERIC Clearinghouse on Information \& Technology, Syracuse University, 80 p.

Eisenberg, M. B.; Lowe, C. A.; Spitzer, K. L.( c2004), Information literacy: essential skills for the information age, Wetsport, Connecticut: Libraries Unlimited, 405 p.

Grassian, E. S.; Kaplowitz, J. R. (2001), Information Literacy Instruction: theory and practice. New York: Neal-Schuman Publishers, Inc., 468 p.

Hempel, C.G. (c1988), Fundamentos de la formación de conceptos en ciencia empírica, Madrid: Alianza Editorial, 124 p.

IFLA, disponible en http://www.ifla.org/en/information-literacy, [consulta: 13 de abril del 2010].

Implementación de programas de alfabetización informativa: contextos y experiencias (2006), Jesús Cortés, Berenice Mears, comp. Ciudad Juárez, Chihuahua: Universidad Autónoma de Ciudad Juárez, Library Outsourcing Services.

Information and IT literacy: enabling learning in the 21st century (2003), Ed. Martin Allan and Hannelore Rader, London: facet publishing, $284 \mathrm{p}$. 


\section{La Alfabetización Informativa como un proyecto nacional}

Information Literacy: An International State of the Art Report (2007), Coord. Jesus Lau, IFLA, Information Literacy Section, disponible en www.uv.mx/usbi ver/unesco, [consulta: 23 de enero del 2010]

Kuhlthau, C. C. (1987), Information Skills for an Information Society: a review of research, Syracuse, New York: Syracuse University.

National Information Literacy Awareness Month, 2009: a proclamation, disponible en http://www.whitehouse.gov/ the press office/Presidential-Proclamation-NationalInformation-Literacy-Awareness-Month/ [consulta: $22 \mathrm{de}$ enero del 2010].

Neely, T. Y., Sociological and psychological aspects of information literacy in bigher education, Lanham: The Scarecrow Press, Inc., 2002.

Perrone, G.; Propper, F. V., Diccionario de educación, Buenos Aires: Alfagrama, 2007.

The Prague Declaration, "Towards an Information Literate Society" (2003), disponible en http://portal.unesco.org/ci/ en/files/19636/11228863531PragueDeclaration.pdf/

PragueDeclaration.pdf, [consulta: 8 de febrero del 2010].

Rader, H. (1991), "Information literacy: a revolution in the library”, en $R Q, 25-29$, Fall, 1991.

Shapiro, J. J.; Shelley, K. H. (1996), Information literacy as $l i$ beral art: enlightenment proposals for a new curriculum, disponible en: http://net.educause.edu/apps/er/review/review Articles/31231.html, [consulta: 22 de enero, 2010]. 
Tendencias de la Alfabetización Informativa en Iberoamérica

The Society of College, National and University Libraries, Briefing paper: Information skills in higher education, disponible en http://www.sconul.ac.uk/groups/information_literacy/papers/Seven_pillars2.pdf, [consulta: 10 de agosto del 2010].

The Society of College, National and University Libraries, Learning Outcomes and Information Literacy, disponible en http://www.sconul.ac.uk/groups/information literacy/papers/outcomes.pdf, [consulta: 10 de mayo del 2010].

Vezzosi, M., Critical thinking and reflective practice: the role of information literacy, disponible en: http://dspaceunipr.cilea.it/bitstream/1889/91/2/BP100\%20Vezzosi. pdf, [consulta: 23 de mayo del 2010].

Weber, S.; and B. Johnston (2000), "Conceptions of information literacy: new perspectives and implications", en Journal of Information Science, 26 (6): 381-397.

Zurkowski, P. (1974), The information service environment relationships and priorities, National Commission on Libraries and Information Science, Related Paper Number Five. 


\title{
Las Políticas de Información en el marco de los estudios sobre la alfabetización informativa
}

\author{
EGBERT J. SÁNCHEZ VANDERKAST \\ Universidad Nacional Autónoma de México
}

\section{INTRODUCCIÓN}

G n el Foro Mundial de Educación (Dakar, 2000) se Urealizó la primera consulta sobre el lanzamiento de una iniciativa mundial sobre alfabetización. Este escenario sirvió para organizar el plan de acción para la década denominada de la "Alfabetización para Todos".

La proclama de una década sobre alfabetización informativa se debió a que ésta:

Continúa siendo un desafío cuantitativo y cualitativo mayor para los países en desarrollo y para los desarrollados.

Es un derecho humano fundamental, una necesidad básica de aprendizaje y clave para aprender a aprender. 
La batalla por la alfabetización requiere esfuerzos intensivos, sostenidos y focalizados, más allá de programas, proyectos o campañas de corta duración.

Favorece la identidad cultural, la participación democrática y la ciudadanía, la tolerancia y el respeto por los demás, el desarrollo social, la paz y el progreso. ${ }^{1}$

De acuerdo con lo anteriormente mencionado la alfabetización informativa se vuelve un instrumento para fortalecer la justicia social, para empoderar a las personas y elevar la dignidad humana.

El advenimiento de las tecnologías de información y de comunicación, TIC, ha propiciado la revisión del concepto de alfabetización informativa dada la sobreabundancia de recursos informativos disponibles de manera electrónica y el acceso libre o comercial.

En un balance realizado por los nueve países más poblados del mundo, entre ellos México, reconocieron que existe un "[...]analfabetismo masivo en algunos países [y es] un gran desafío [que sigue] pendiente". ${ }^{2}$ Debido a ello

1 Naciones Unidas. (2000), Alfabetización para todos: Década de las Naciones Unidas para la Alfabetización (2003-2010), Documento, junio de 2000 , p. 5, consulta 23 de noviembre de 2010, en http://www.fronesis.org/immagen/rmt/documentosrmt/ UN_Decada_Alfabetizacion.pdf.

2 Naciones Unidas. (2000), Alfabetización para todos: Década de las Naciones Unidas para la Alfabetización (2003-2010). Documento, junio de 2000. p. 7. Consulta 23 de noviembre de 2010. En http://www.fronesis.org/immagen/rmt/documentosrmt/ UN_Decada_Alfabetizacion.pdf 
Las Políticas de Información en el marco de los estudios ...

se propusieron en Dakar nuevas metas a alcanzar para el periodo 2000 al 2015. Entre ellas se encuentran, “[...] asegurar la satisfacción de las necesidades de aprendizaje de jóvenes y adultos a través del acceso equitativo a programas apropiados de aprendizaje de habilidades para la vida y para la ciudadanía, y mejorar todos los aspectos de la calidad de la educación y asegurar la excelencia de todos, de modo que todos logren resultados de aprendizaje reconocidos y medibles, especialmente en torno a la alfabetización, el cálculo y las habilidades esenciales para la vida". ${ }^{3}$ Estos dos puntos tienen una relación muy estrecha con los principios básicos de la Declaración de Praga (2003) que entre sus recomendaciones para formular una política de alfabetización en información (Alfin) manifestó que tendría que "[...]ver la posibilidad de incluir la Alfin dentro de la Década de la Alfabetización de las Naciones Unidas (2003-2015)". 4

Con miras a cumplir los objetivos propuestos en Jomtien (1990-2000), y Dakar (2000-2015), el concepto

3 Naciones Unidas. (2000), Alfabetización para todos: Década de las Naciones Unidas para la Alfabetización (2003-2010), documento, junio de 2000, p. 8, consulta 23 de noviembre de 2010 , en http://www.fronesis.org/immagen/rmt/documentosrmt/UN_Decada_Alfabetizacion.pdf.

4 Declaración de Praga (2003), Hacia una sociedad alfabetizada en información. (traducción: Critobal Pasadas Ureña, Grup de Trebal Alfincat), consultado el 23 de noviembre de 2010, en http://sol-e.com/plec/archivos/Docs_Bibliografias/Declaraci_Praga_castellano.pdf. 
de alfabetización para todos nos lleva a diseñar “[...]políticas activas y esfuerzos colectivos no sólo para alfabetizar sino para lograr que las personas y grupos alfabetizados hagan usos significativos de ese conocimiento como medio de expresión, comunicación y aprendizaje permanente". 5

A partir de esta visión renovada se desprende que la alfabetización es entendida como:

1. Un proceso de aprendizaje que dura y se perfecciona a lo largo de toda la vida.

2. El desarrollo de la expresión y la comunicación tanto oral como escrita, dentro de una visión del lenguaje como totalidad (hablar, escuchar, leer, escribir).

3. La compresión de que no existe un método único o universal para alfabetización informativa..

4. Un proceso a todo lo ancho del currículo escolar.

5. Una responsabilidad conjunta del Estado y la sociedad civil.

Además, la alfabetización informativa está asociada con instrumentos convencionales pero también con instrumentos modernos (papel y lápiz, teclados y las tecnologías digitales, [las TIC] etc.). ${ }^{6}$ En México, una de las iniciativas que fue promovida por la Universidad Autónoma de Ciudad Juárez, la RENABIES (Red Nacio-

5 Naciones Unidas (2000), Alfabetización para todos: Década de las Naciones Unidas para la Alfabetización (2003-2010), documento, junio de 2000, p. 10, consulta 23 de noviembre de 2010, en http://www.fronesis.org/immagen/rmt/documentosrmt/ UN_Decada_Alfabetizacion.pdf. 
Las Políticas de Información en el marco de los estudios ...

nal de Bibliotecas de Instituciones de Educación Superior) y el CONPAB-UPES (Consejo Nacional para Asuntos Bibliotecarios de las Universidades Públicas Estatales) fue la propuesta para establecer una política a nivel institucional nacional sobre el desarrollo de habilidades informativa, que se presentó en 1997 en el marco del "Encuentro Nacional sobre Programas de Desarrollo de Habilidades Informativas". La idea central de este encuentro fue reunir información sobre las experiencias mexicanas relativa a la temática. Las declaratorias emanadas de dichos encuentros estuvieron principalmente dirigidas a las instituciones de educación superior. Sin embargo, la alfabetización informativa como una iniciativa no ha sido promovida en todo el sistema educativo nacional, ni a un nivel informal. Por tanto sería importante realizar algunas reflexiones en el marco de Educación para Todos (EPT), la década de "Alfabetización para Todos" y las acciones a nivel nacional.

6 Naciones Unidas (2000), Alfabetización para todos: Década de las Naciones Unidas para la Alfabetización (2003-2010), Documento, junio de 2000, p. 11, consulta 23 de noviembre de 2010 , en http://www.fronesis.org/immagen/rmt/documentosrmt/ UN_Decada_Alfabetizacion.pdf.

7 Desarrollo $\overline{d e}$ habilidades informativas en instituciones de educación superior (2000), Ciudad Juárez, Chihuahua: Universidad Autónoma de Ciudad Juárez, p.8. 


\section{ALFABETIZACIÓN INFORMACIONAL}

La Alfabetización informacional o Alfabetización en información conocida también por sus siglas ALFIN, surge como un concepto durante la década de los setenta y fue paulatinamente madurando en cuanto a su contenido hasta convertirse en objeto de estudio de la bibliotecología y de los estudios de la información.

La Reunión de Expertos en Alfabetización en Información celebrada en Praga en 2003, fue uno de los eventos cumbre donde se hicieron propuestas concentradas en seis principios básicos y tres recomendaciones para diseñar una política nacional sobre alfabetización informacional (ALFIN).

Llama la atención que entre los puntos tratados el énfasis se haya puesto en los derechos humanos básicos, la promoción de la tolerancia y en la promoción de la democracia, como a continuación se manifiesta:

$\checkmark$ La ALFIN abarca el conocimiento de las propias necesidades y problemas con la información,... y forma parte del derecho humano básico al aprendizaje a lo largo de toda la vida.

$\checkmark(\ldots)$ la promoción de la tolerancia y la comprensión mutua gracias al uso de la información en contextos diferentes multiculturales y multilingües.

$\checkmark$ Los gobiernos deben desarrollar programas potentes de promoción de la ALFIN en todo el país como un paso necesario para cerrar la brecha digital por medio de la creación de una ciudadanía al- 
Las Políticas de Información en el marco de los estudios ...

fabetizada en información, una sociedad civil eficaz y una fuerza de trabajo competitiva. ${ }^{8}$

La promoción de ALFIN de una u otra manera tiene implicaciones trascendentales en la cultura democrática de los países y podría tener como consecuencia una ciudadanía mejor informada para la toma de decisiones, y una mayor participación ciudadana en la vida pública y personal.

La creación de una sociedad de la Información resulta clave para el desarrollo social, político y económico. Además, una política nacional sobre alfabetización informacional debería trascender la concepción de la sociedad de la información y hablar de sociedades del conocimiento, ya que según el Informe Mundial de la Unesco, la sociedad de la información se basa en el progreso tecnológico mientras que la sociedad del conocimiento comprende dimensiones sociales, éticas y políticas mucho más amplias, como la diversidad cultural, lingüística y los mundos sociales pluriculturales y se propone conseguir una cohesión social.

Las sociedades del conocimiento se basan principalmente en los derechos fundamentales del hombre, a saber:

8 Declaración de Praga (2003), Hacia una sociedad alfabetizada en información, (traducción: Cristóbal Pasadas Ureña. Grup de Trebal Alfincat), consultado el 23 de noviembre de 2010, en ( http://sol-e.com/plec/archivos/Docs_Bibliografias/Declaraci_ Praga_castellano.pdf. 
1. La libertad de opinión y de expresión.

2. El derecho a la educación.

3. El derecho a tomar parte libremente en la vida cultural de la comunidad, a gozar de las artes, y a participar en el progreso científico y en los beneficios que de ello resulte.

En este tenor la alfabetización informacional es una manera de hacer efectivos los derechos fundamentales mencionados y de generar así capital social, desarrollo sustentable, acceso a la educación, igualdad en el acceso a la información y la participación en la constitución de sociedades más democráticas.

Sin embargo llama la atención el contexto tan diferente en que se encuentra cada sociedad. Esto impide que se pueda hablar, propiamente dicho, de una sociedad, debido a que cada sociedad consta de múltiples mundos sociales. En México la promoción de una política nacional sobre alfabetización informativa ha sido vinculada sobre todo con los retos de las instituciones de educación superior, IES.

La Declaratoria sobre Habilidades Informativas en Instituciones de Educación Superior de México de 1997, manifiesta que hay que:

$\checkmark$ Desarrollar una política institucional y nacional adecuada para el mejoramiento de la calidad de los sistemas informativos y bibliotecarios... 
Las Políticas de Información en el marco de los estudios ...

$\checkmark$ Establecer un plan nacional para el desarrollo de habilidades informativas (DHI), que coordine esfuerzos y facilite la colaboración inter-institucional en los diferentes niveles educativos, así como crear programas sobre DHI como parte de la planeación curricular. ${ }^{9}$

Se percibe aquí que el diseño de una política sobre la temática está relacionado con la calidad en general de los sistemas bibliotecarios a nivel nacional, y pone énfasis en la formulación de un plan nacional y la creación de programas sobre el desarrollo de habilidades informativas, DHI.

Mientras que la Declaratoria sobre la Función de la Biblioteca en Modelos Educativos Orientados al Aprendizaje emitida en 1999, en el marco del segundo Encuentro Nacional de Programas Universitarios de Desarrollo de Habilidades Informativas, destacaba la necesidad de contar con un programa de desarrollo de colecciones basado en un conocimiento suficiente de los intereses y necesidades de su comunidad.

En ese mismo encuentro se propuso entre las estrategias a seguir "[...] estructurar a corto plazo un programa nacional de educación de usuarios, de carácter permanente en las IES". ${ }^{10}$ No basta con tener un programa de

9 Desarrollo de habilidades informativas en instituciones de educación superior (2000), Ciudad Juárez, Chihuahua: Universidad Autónoma de Ciudad Juárez, p.133.

10 La instrucción de usuarios ante los nuevos modelos educativos (2000), Ciudad Juárez, Chihuahua: Universidad Autónoma de Ciudad Juárez, p.159. 
DHI, a la par es necesario tener colecciones, sean estas electrónicas o impresas, útiles para los usuarios.

Con la aprobación del documento "Declaratoria sobre las Normas sobre la Alfabetización Informativa en Educación Superior" al finalizar el tercer Encuentro sobre Habilidades Informativas del 2002, se da el primer paso para el desarrollo de normas sobre las competencias informativas en educación superior para evaluar las destrezas adquiridas por los usuarios en el uso de las colecciones.

Todo lo anterior deja entrever lo complejo que ha sido proponer políticas de ALFIN en las instituciones de enseñanza superior. Ahora, la situación problemática se sitúa en cómo articular una política nacional a este respecto en cada mundo social.

\section{LOS MUNDOS SOCIALES, MUNDOS DE VIDA}

La sociedad está inmersa en la actualidad en una dinámica de globalización y por consiguiente tiene que atender las exigencias que marcan los actores de un mundo globalizado, y simultáneamente atender la complejidad interna y las demandas de los otros mundos sociales que integran la sociedad o comunidad nacional. Como cada uno de los mundos sociales aporta su propia complejidad por lo cual hay que trazar políticas para homogeneizar las acciones y la toma de decisiones.

Fue la sociología la que empezó a hablar de "mundos sociales" para referirse a estos micro entornos que influyen y marcan las pautas para hacer una política. 
Las Políticas de Información en el marco de los estudios ...

A principios de siglo, Luckmann ${ }^{11}$ se refería a estos micro entornos como "mundos de vida" del hombre, los cuales tienen una relación estrecha con el espacio y el tiempo. Este enfoque pone el énfasis en el individuo y la vida cotidiana. Sostiene que existen diversos mundos sociales o comunidades que se suman y conforman una sociedad, y que estos mundos están entrelazados el uno con el otro. Esta idea de mundo de vida y mundo social se puede extrapolar al diseño de una política nacional de ALFIN ya que ésta no se encuentra separada, ni es independiente del gran todo socialmente hablando.

Lo anterior se encuentra sustentado en los estudios realizados por Elfreda Chatman, ${ }^{12}$ quien desde la perspectiva de la investigación bibliotecaria ha realizado trabajo de campo en diversos mundos sociales como son los trabajadores de cierta clase social, los pobres, los grupos de bajo ingreso económico, los de bajo ingreso que tienen habilidades técnicas, los conserjes, las mujeres mayores, las mujeres jubiladas, las comunidades virtuales, los libreros, y las feministas, para apuntalar una teoría sobre la pobreza de información, y sostiene que no se puede hablar de una sociedad, sino más bien de varios mundos.

De acuerdo con Unruh un mundo social abarca "[...] todas aquellas personas y las organizaciones cuya actividades son necesarias para producir cualquier tipo de

11 Benita Luckmann, "The small life-world of modern man", en Social Research, vol. 3, 1970, pp.580-582.

12 Véase la obra de Elfreda Chatman (1985, 1986, 1987, 1990, 1991, 1995, 1996, 1999 y 2001). 
evento y de objetos tangibles que ese mundo produce y que se distinguen por las características de ese mundo". ${ }^{13}$ Estas formas de organización social no pueden ser definidas de manera precisa en un espacio geográfico formal o de manera estricta. De acuerdo con lo anterior, los límites imaginarios de los mundos sociales deberían estar determinados por la interacción y la comunicación que trasciende y transgrede todo lo formal, así como también las tradiciones que delínean una organización. Con el transcurrir de los años este fenómeno de mundos sociales, ha sido nombrado de manera distinta; algunos ejemplos son: redes de contacto; comunidades parte de otras comunidades; ecología de juegos; colegios invisibles; sistemas de conductas; ć́rculos sociales; sistemas de actividades y subculturas.

Aun cuando varios términos son utilizados para denominar los mundos sociales, cada uno de ellos comprende elementos que están relacionados con fenómenos que incluyen algunas desviaciones detectadas y que tienen características estructurales distintas; sin embargo cuentan con elementos de interacción que los unen en unidades de organizaciones sociales.

Por ello al hablar de "mundo social" se puede estar uno refiriendo a una forma de organización social que de un modo plausible, aunque inimaginable, crea una visión común, la visión del mundo que abarca todo el entorno que gira alrededor del actor social.

13 David Unruh, The nature of the social worlds. Pacific sociological Review, vol.23, no. 3, 1980. p.279. 
Las Políticas de Información en el marco de los estudios ...

Algunas características de un mundo social como organización social son:

1. La identificación voluntaria que consiste en ser parte de un mundo social por voluntad propia, se distingue de otras unidades de organización social que son formales.

2. Involucramiento parcial; se demuestra que este involucramiento es inherente al carácter amorfo del grupo, y no sólo una consecuencia de una tendencia.

3. Múltiple identidad; un actor, una organización, un evento, una práctica, un apoyo, pueden participar en diferentes mundos a la vez. Mientras giran alrededor del autor.

4. Interacción mediada; los mundos sociales no dependen de la mediación. Sin embargo es una manera de conectarse con otros actores, organizaciones, eventos y prácticas en otros espacios.

A partir de lo anteriormente mencionado el establecimiento de un plan de acción nacional debería de conocer el qué y el para qué se necesita la información y el dónde encontrarla (sea en el formato que sea), y cómo evaluarla, utilizarla y comunicarla. En pocas palabras, se debe trazar un plan de acción con estrategias que ayuden a los miembros de los mundos sociales a divulgar sus características sociales y también sus necesidades de información.

Además se deberían considerar los cuatro aspectos básicos en los que Chatman fundamenta su propuesta teórica que son: 
1. Normas sociales; entender lo bueno y lo malo de un mundo social, principalmente cómo se dan las conductas sociales en ese mundo, la ideología, la vestimenta, la forma de actuar y la conducta aceptable en ese mundo específico.

2. Visión del mundo; la manera de percibir la estructura del mundo de "afuera". La visión de los miembros de un mundo social pequeño sobre sus prioridades, la participación en la sociedad tradicional, sus conocimientos acerca de los mundos, y de sus normas.

3. Tipos sociales; ¿cómo son percibidos y definidos en el mundo social tradicional, los de "afuera"? La dinámica social de cada pequeño mundo social.

4. Patrones de conducta informativos: ¿cómo buscan información y sus canales para allegarse de la información requerida? La búsqueda puede ser formal a través de una biblioteca.

Burnett y Jaeger ${ }^{14}$ basándose en la obra de Chatman, consideran que en cualquier mundo social los procesos de acceso e intercambio de información también forman parte de las actividades cotidianas, ya que la información que buscan es la que les permitirá para entender las situaciones en su mundo, las que giran alrededor de

14 G. Burnett y Jaeger, P.T. (2008), "Small worlds, life worlds and information: the ramification of the information behavior of social groups in public policy and the public sphere", en Information Research, vol. 13, núm. 2, june, recuperado en http://informationr.net/ir/13-2/paper346.html, consulta el 23 de agosto de 2010. 
Las Políticas de Información en el marco de los estudios ...

ellos, y las normas establecidas para darle identidad a su pequeño grupo y que los distingue de otros grupos.

Considerando las perspectivas mencionadas, en México podemos reconocer a las sociedades tradicionales, las sociedades pluri-culturales y las sociedades lingüísticas que se encuentran dispersas a lo largo de todo el territorio nacional formando parte de la sociedad mexicana. Además, habrá que sumar las tribus urbanas que son "[...] toda una serie de movimientos y expresiones culturales, regularmente juveniles y colectivas, que se rebasan, se rechazan, se marginan, se enfrentan o trascienden la cultura institucional[...]"15 y se aprecian en todas las grandes urbes de México.

\section{HACIA UNA POLÍTICA DE INFORMACIÓN EN ALFABETIZACIÓN INFORMATIVA}

Atherton ${ }^{16}$ manifiesta que una política de información es la formulación o declaración general de intención que ayuda a traducir los objetivos de los programas en realizaciones suministrando pautas administrativas para la toma de decisiones y su ejecución.

15 Karl Heinz Hillemann (2001), Diccionario enciclopédico de Sociología, Barcelona: Herder, p. 957.

16 P. Atherton (1978), Manual de sistemas y servicios de información, Paris: Unesco, p.53. 
Por otro lado Marta Dosa ${ }^{17}$ percibe una política de información como un plan para desarrollar servicios, fuentes y recursos de información, y a utilizarlos más eficazmente.

Destacan en las propuestas de los autores los términos estrategias, programas y planes que se encuentran ligados a la toma de decisiones y la administración. Y por tanto reflejan que una política está encaminada a generar resultados a partir de una planeación sistemática de largo plazo.

En este sentido coincido con Rowlands y Turner ${ }^{18}$ en que una política puede ser considerada como un proceso por etapas que comprende:

1. El diseño; abarca la gestación (el reconocimiento del problema, la definición de su naturaleza, y el diagnóstico de algunas de sus causas así como propuestas de medidas de solución), y la formulación de un plan o política.

2. La implantación; que comprende la adopción y/o adaptación del plan y su implementación.

3. La tercera etapa; la evaluación de los resultados.

17 M. Dosa, Farid, M. y Vasarhelyi, P. (1989), From informal gatekeeper to information counselor: emergence of a new professional role, Hague: FID. p.29.

18 I. Rowlands y Turner, P. (1996), "Models and frameworks for Information Policy Research", en Rowlands, I. Understanding Information Policy: proceedings of a workshop held at Cumberland Lodge, New Providence, NJ: Bowker - Saur, pp. 46-60. 
Las Políticas de Información en el marco de los estudios ...

En este proceso intervienen elementos tanto sociales, como culturales, políticos y organizacionales.

\begin{tabular}{|c|c|c|c|c|}
\hline \multicolumn{5}{|c|}{$\begin{array}{c}\text { Cuadro } 1 \\
\text { Etapas del proceso de una política }\end{array}$} \\
\hline \multicolumn{2}{|c|}{ Diseño } & \multicolumn{2}{|c|}{ Implementación } & \multirow{2}{*}{ Evaluación } \\
\hline & & $\rightarrow$ & - & \\
\hline $\begin{array}{l}\text { Reconocimiento de proble- } \\
\text { mas y la gestación de posi- } \\
\text { bles medidas de solución. }\end{array}$ & $\begin{array}{l}\text { Formulación de la } \\
\text { política o del plan. }\end{array}$ & $\begin{array}{l}\text { Adopción y/o } \\
\text { Adaptación de la } \\
\text { política. }\end{array}$ & $\begin{array}{l}\text { Implantación } \\
\text { de la política. }\end{array}$ & $\begin{array}{l}\text { Evaluación de } \\
\text { los resultados. }\end{array}$ \\
\hline $\begin{array}{l}\text { Reconocimiento de proble- } \\
\text { mas y la gestación de posi- } \\
\text { bles medidas de solución. }\end{array}$ & $\begin{array}{l}\text { Formulación de la } \\
\text { política o del plan. }\end{array}$ & $\begin{array}{l}\text { Adopción y/o } \\
\text { Adaptación de la } \\
\text { política. }\end{array}$ & $\begin{array}{l}\text { Implantación } \\
\text { de la política. }\end{array}$ & $\begin{array}{l}\text { Evaluación de } \\
\text { los resultados. }\end{array}$ \\
\hline
\end{tabular}

No obstante lo anteriormente mencionado, algunas políticas son formuladas a raíz de una necesidad, una demanda de las comunidades o bien una crisis por la que atraviesan las instituciones, en este caso las bibliotecarias. El diseño de una política de información en alfabetización informativa, en algunos casos llamado plan o programa, ayuda a entender el contexto social, económico, organizativo y político, así como también la toma de decisiones, para posteriormente trazar las estrategias e implementarlas o adoptarlas y alcanzar las metas deseadas, además de hacer una constante evaluación de la ejecución de las estrategias y los logros obtenidos.

En relación con lo anterior, Ponjuan (1993: 44) realizó una diferenciación entre una política y un plan señalando que "un plan sólo dice lo que se hará durante un 
tiempo para lograr ese objetivo (...) apunta hacia las actividades (...) tiene que ver con el ¿¿cómo?”. ${ }^{19}$

Sin embargo, no se debe perder de vista que un plan o documento de planeación también es considerado como "[...]el diseño que se realiza hoy para la acción de mañana: para decirlo de alguna manera como un mapa de carretera; la orientación de los pasos a dar, empezando por ahora, y su continuación hacia el futuro". ${ }^{20}$

Dada la complejidad que representa implementar una política nacional de Alfabetización Informativa, lo más conveniente sería trazar planes de acción para enfrentar la amplia gama de mundos sociales que existen a nivel nacional, la variedad de los sectores de la sociedad tradicional y las diversas sociedades pluri- culturales, multiétnicas y multilingües que deben ser atendidas.

A este respecto Medina Giopp y Mejía Lira ${ }^{21}$ opinan que eventualmente un plan podría constar de uno o varios documentos escritos que describan el escenario deseado y las consecuencias previstas en las actividades concernientes a la organización. Sin embargo los planes se diferencian entre sí de acuerdo con el "[...]tipo de actividades, el área organizacional, e nivel de decisión y el

19 G. Ponjuan Dante (1993), "Las políticas nacionales de información en el contexto latinoamericano. El caso de Cuba”, en Ciencias de la Información, 24. (1). p.44.

20 Véase R. Stueart y J. T. Eastlick (1981) y R. Stueart y B. Moran (1987 al 2002).

21 A. Medina Giopp y Mejía Lira, J. (1993), El control en la implantación de la política pública, México: Plaza y Valdés. 
Las Políticas de Información en el marco de los estudios ...

flujo de información de referencia". ${ }^{22}$ Puesto que no es lo mismo un plan de desarrollo que un plan de acción, este último podrá constar de una amplia gama de planes, diferenciados por una especificidad de sus variables, su temporalidad y/o grado de discrecionalidad.

Por tanto al realizar un análisis minucioso de la naturaleza y las características de los planes se puede determinar si se trata de políticas, normas, reglas, objetivos, estrategias, proyectos, programas o presupuestos.

Medina Giopp y Mejía Lira plasman esta idea en la figura de la página siguiente.

La jerarquización de planes pone a la misión o el propósito en la cúspide de la pirámide y al presupuesto como la base de ésta.

La misión o el propósito de un plan se encuentran vinculados a la ideología, a un plan nacional de desarrollo, a un programa propuesto a nivel internacional o a declaratorias basadas en consensos, inmersas en un entorno determinado, sea éste de índole pública o privada del sector educativo, social o cultural; y de una comunidad determinada que persigue una ideología y/o prácticas afines, y que tienen una función social básica en la sociedad.

Las estrategias son en algunas ocasiones entendidas como un plan de acción, documento en el que se plantean "[...]los objetivos básicos a largo plazo [...] y la adopción de los cursos de acciones y la asignación de los

22 A. Medina Giopp y Mejía Lira, J. (1993), op. cit. p.77. 
Tendencias de la Alfabetización Informativa en Iberoamérica

Figura 1

Jerarquía de Planes

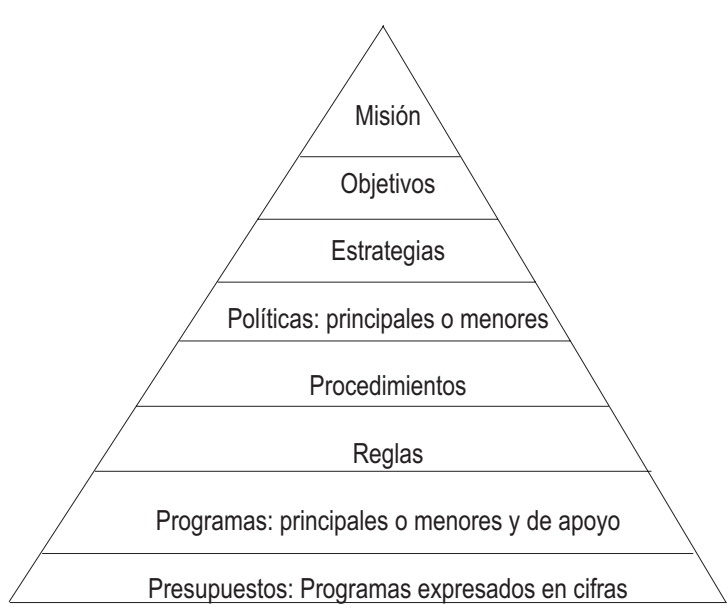

Fuente: Medina Giopp, A. y Mejía Lira, J., El control en la implantación de la política pública, México: Plaza y Valdés, 1993. p. 78.

recursos necesarios para su cumplimiento". ${ }^{23}$ Mientras que un procedimiento propone el mejor modo de "[...] ]ejecutar una actividad o tarea específica; enumerando los detalles a realizar; e indican la mejor manera de

23 H. Koontz y Weihrich, H. (2004), Administración: una perspectiva global. 12a. Ed. México: McGraw Hill. p.126. 
Las Políticas de Información en el marco de los estudios ...

cumplir con ciertas tareas”. ${ }^{24}$ Es decir, marcan una secuencia cronológica de las acciones que sirven de guía para realizar las actividades de manera detallada.

Tanto Koontz y Weihrich, ${ }^{25}$ como Medina Giopp y Mejía Lira, ${ }^{26}$ coinciden en que los planes constituyen en un proceso formal de la planeación, constituyen un método racional para el cumplimiento de objetivos preseleccionados.

Es decir, desde el ángulo estricto de la planificación se trata de un proceso planificador que incita a los tomadores de decisiones a poner en marcha el mencionado proceso de manera global, donde sean los actores quienes intervengan para fijar los objetivos y evaluar los progresos según sus criterios.

En síntesis, un plan es un documento por escrito que sirve de guía, apunta hacia dónde se desean dirigir las acciones, re-direcciona el impacto de los cambios, minimiza el desperdicio y la redundancia, y simultáneamente apuntala normas para aplicar el control.

Para poner en marcha las actividades de un plan en muchas ocasiones los recursos de distinta índole, como

24 P. Atherton (1978), Manual de sistemas y servicios de información, París: Unesco. p.53.

25 Véase H. Koontz y Weihrich, H. (2004), Administración: una perspectiva global, 12a. Ed. México: McGraw Hill. y H. Koontz y Weihrich, H. (2007), Elementos de administración: un enfoque internacional. $7^{\mathrm{a}}$. Ed. México: McGraw-Hill Interamericana.

26 A. Medina Giopp, A. y Mejía Lira, J. (1993), El control en la implantación de la política pública, México: Plaza y Valdés. 
por ejemplo los económicos, son necesarios. La carencia de ellos puede limitar o impedir que se abstenga la calidad o el desarrollo adecuado.

\section{A MANERA DE CONCLUSIÓN}

Diseñar una política nacional de alfabetización informativa involucra a muchos y diversos actores sociales, políticos y culturales.

Cada uno de ellos debe asumir el compromiso de sacar adelante una política consensuada que a su vez derive en planes de acción alcanzables en cuanto a su implementación. Un factor decisivo en la implementación de los diferentes planes de acción en distintos niveles, sectores y mundos sociales dependería del presupuesto.

En caso de no existir un programa expresado en cifras y/o en costos, o de no trabajarlo simultáneamente en el documento de planeación sería difícil augurarle al plan o programa un desarrollo sano.

La tarea no es fácil dadas las dimensiones sociales del país. Los entornos extra-sociales como las declaraciones mundiales de la Unesco y de la conferencia mundial sobre la Juventud entre otros, más otros factores no mediatos como el envejecimiento de la población, ponen el énfasis en buscar los instrumentos útiles para generar tanto el capital social como el cultural. 
Las Políticas de Información en el marco de los estudios ...

\section{OBRAS CONSULTADAS}

Atherton, P. (1978), Manual de sistemas y servicios de información, París: Unesco, 1978.

Burnett, G. y Jaeger, P.T. (2008), "Small worlds, life worlds and information: the ramification of the information behavior of social groups in public policy and the public sphere", en Information Research, vol. 13, núm. 2, june, recuperado en http://informationr.net/ir/13-2/paper346. html, consulta el 23 de agosto de 2010.

Chatman, E. A. (1985a), "Low income and leisure: Implications for public library use", en Public Libraries, vol. 24, pp. 34-36.

Chatman, E. A. (1985b), "Information, mass media use and the working poor", en Library E Information Science Research, vol. 7. pp. 97-113.

Chatman, E. A. (1986), "Diffusion theory: a review and test of a conceptual model in information diffusion", en Journal of the American Society for Information Science and Technology, vol. 37. pp. 377-386.

Chatman, E. A. (1987a), "The information world of low-skilled workers", en Library E Information Science Research, vol. 9. pp. 265-283.

Chatman, E. A. (1987b), "Opinion leadership, poverty and information sharing”, en Reference Quarterly, vol. 26. pp. 341-353.

Chatman, E. A. (1990), “Alienation theory: application of a conceptual framework to a study of information among janitors", en Reference Quarterly, vol. 29. pp. 355-368. 
Chatman, E. A. (1991a), "Life in a small world: application of gratification theory to information seeking behavior", en Journal of the American Society for Information Science and Technology, vol. 42. pp. 438-449.

Chatman, E. A. (1991b), "Channels to a larger world: older women staying in contact with the great society", en $L i$ brary E Information Science Research, vol. 13, pp. 281-300.

Chatman, E. A. (1996a), "The impoverished world of outsiders", en Journal of the American Society for Information Science and Technology, vol. 47. pp. 83-92.

Chatman, E. A. (1996b), "Social context and culture: linking use and digital libraries", 1996, en Digital Libraries Workshop, recuperado http://is.gseis.ucla.edu/research/dig_libraries/chatman.html, consulta el 28 de septiembre de 2010.

Chatman, E. A. (1999), "A theory of life in the round", en Journal of the American Society for Information Science and Technology, vol. 50. pp.207-217.

Chatman, E. A. y Pendleton, V. (1995), "Knowledge gap, information seeking behavior and the poor", en Reference Librarian, vol. 49-50. pp.135-145.

Declaración de Praga. (2003), Hacia una sociedad alfabetizada en información, (traducción: Critobal Pasadas Ureña. Grup de Trebal Alfincat), consultado el 23 de noviembre de 2010, en (http://sol-e.com/plec/archivos/Docs_Bibliografias/

Declaraci_Praga_castellano.pdf .

Desarrollo de habilidades informativas en instituciones de educación superior (2000), Ciudad Juárez, Chihuahua: Universidad Autónoma de Ciudad Juárez. 
Las Políticas de Información en el marco de los estudios ...

Dosa, M., Farid, M. y Vasarhelyi, P. (1989), From informal gatekeeper to information counselor: emergence of a new professional role, Hague: FID.

Instrucción de usuarios ante los nuevos modelos educativos (2000), Ciudad Juárez, Chihuahua: Universidad Autónoma de Ciudad Juárez, p.159

Karl Heinz Hillemann (2001), Diccionario enciclopédico de Sociología. Barcelona: Herder, p. 957.

Koontz, H. y Weihrich, H. (2004), Administración: una perspectiva global, 12a. Ed. Mexico : McGraw Hill.

Koontz, H. y Weihrich, H. (2007), Elementos de administración: un enfoque internacional, $7^{\mathrm{a}} \mathrm{Ed}$. México:McGraw-Hill Interamericana.

Luckmann, B. (1970), “The small life-world of modern man”, en Social Research, vol. 3. 1970, pp. 580-596.

Medina Giopp, A. y Mejía Lira, J. (1993), El control en la implantación de la política pública, México: Plaza y Valdés.

Naciones Unidas (2000), Alfabetización para todos: Década de las Naciones Unidas para la Alfabetización (2003-2010), documento, junio de 2000, p. 5, consulta 23 de noviembre de 2010, en http://www.fronesis.org/immagen/rmt/documentosrmt/UN_Decada_Alfabetizacion. pdf.

Normas sobre alfabetización informativa en educación superior: declaratoria, (2004), Ciudad Juárez, Chih.: UACJ, Dirección General de Información y Acreditación.

Ponjuan Dante, G. (1993), "Las políticas nacionales de información en el contexto latinoamericano. El caso de Cuba”, Ciencias de la Información 24, 1 (1993): 43-47. 
Rowlands, I. y Turner, P. (1996), "Models and frameworks for Information Policy Research", pp. 46-60, en Rowlands, I. Understanding Information Policy: proceedings of a workshop held at Cumberland Lodge, New Providence, NJ: Bowker - Saur.

Stueart, R. y Eastlick, J. T. (1977), Library Management, Littleton, Colo.: Libraries Unlimited.

Stueart. R. y Eastlick, J. T. (1981), Library Management, 2a. ed. Littleton, Colo.: Libraries Unlimited.

Stueart, R. y Moran, B. (1998), Gestión de Bibliotecas y Centro de Información, (traducción de la $4^{\mathrm{a}}$. Edición en inglés de 1993), Barcelona: Pages Editores.

Stueart, R. y Moran, B. (1987), Library Management, 3a. edición, Littleton, Colo.: Libraries Unlimited.

Stueart, R. y Moran, B. (1993), Library and Information Center Management, 4a. ed. Englewood, Colo.: Libraries Unlimited.

Stueart, R. y Moran, B. (1998), Library and Information Center Management, 5a. ed. Englewood, Colo.: Libraries Unlimited.

Stueart, R. y Moran, B. (2002), Library and Information Center Management, 6a. ed. Greenwood Village, Colo.: Libraries Unlimited.

Stueart, R. y Moran, B. (2007), Library and Information Center Management, 7a. ed. Greenwood Village, Colo.: Libraries Unlimited.

Unruh, D. (1980), "The nature of the social worlds", en Pacific sociological Revierw, vol.23, núm. 3, 1980. 


\title{
A Alfabetização Informativa e a inclusção na sociedade da informação
}

\author{
EMIR JOSÉ SUAIDEN \\ Instituto Brasilero de Información de Ciencia y Tecnología
}

\section{INTRODUÇÃO}

N a sociedade industrial a riqueza era gerada pela informacionais trabalharam muito com as metodologias quantitativas: número de usuários, número de consultas, número de empréstimos domiciliares, etc.

$\mathrm{Na}$ sociedade da informação a riqueza é propiciada pela produção do conhecimento. Riqueza nos dois casos significa a geração de emprego e renda e a melhoria da qualidade de vida. Nesta nova sociedade as unidades de informação passam a ter suas responsabilidades aumentadas, pois para medir o impacto da informação é necessário usar metodologias qualitativas.

Apesar da revolução de Gutenberg, grande parte da população da América Latina e do Caribe, ainda hoje, 
não tem acesso aos livros e as bibliotecas e a informação reinante é a informação oral, pois devido ao analfabetismo e principalmente a baixa qualidade do ensino as populações citadas não têm como ler e, principalmente, interpretar a informação bibliográfica. É importante ressaltar que os países da América Latina e Caribe com maior capacidade de formar um público leitor tiveram uma maior facilidade em utilizar a revolução tecnológica. O Brasil obteve o 53 lugar, em uma lista de 65 países, numa prova internacional que avaliou a capacidade de leitura de estudantes com 15 anos. Além da leitura, o Pisa (Programa Internacional de Avaliação de Alunos) também avaliou as habilidades dos estudantes em matemática e ciências. $\mathrm{O}$ exame, que é aplicado a cada três anos, é divulgado pela OCDE (Organização para a Cooperação e Desenvolvimento Econômico). Juntos, os países que participam do Pisa representam aproximadamente $90 \%$ da economia mundial. No Pisa 2009, o foco da análise foi a leitura. Nesse ranking, o Brasil obteve 412 pontos -a China, primeira colocada, chegou a 556 pontos-. Foram avaliados diversos aspectos na leitura, como a capacidade de reflexão, avaliação e interpretação dos alunos, por exemplo. De acordo com os pesquisadores, o Brasil teve um grande ganho na nota de leitura nos últimos anos. Apesar disso, o país ainda fica atrás de Chile (44) Uruguai (47), Trinidad e Tobago (51) e Colômbia (52). Por outro lado, o Brasil conseguiu ficar à frente da Argentina (58) e do Peru (63).

A oralidade da informação, plenamente justificada por inúmeros pesquisadores, na verdade, dá vazão a manipulação e desinformação. Essas populações, muitas ve- 
A Alfabetização Informativa e a inclusção na sociedade da ...

zes são manipuladas e desinformadas, pois não conseguem avaliar a informação oral. Isso cria o processo de dependência informacional. $\mathrm{O}$ sujeito que é dependente informacional jamais será um produtor de informação. Os motivos alegados são muitos. Mas os principais se referem a falta de infra-estrutura informacional, composta com bibliotecas infantis, bibliotecas escolares e bibliotecas públicas.

Com a falta de bibliotecas escolares na América Latina e no Caribe os estudantes invadiram as poucas bibliotecas públicas existentes e isso criou o fenômeno da escolarização da biblioteca pública. A biblioteca pública foi incapaz de atender os demais segmentos da comunidade, tais como o pequeno e médio empresário, o comércio, os aposentados, etc.

Nos estudos sobre visibilidade institucional a unidade de informação aparece com visões antagônicas. Uma do profissional da informação que acredita que o livre acesso à informação é o caminho natural para a inclusão social e a outra da comunidade que vê a unidade de informação elitizada e somente propícia para estudantes e jovens.

Sem visibilidade a unidade de informação, na sociedade industrial não conseguiu participar da agenda do governo e muito menos criar uma política de informação. A informação jamais foi vista como insumo de transformação.

\section{A SOCIEDADE DA INFORMAÇÃO}

O desenvolvimento dos países da América Latina e do Caribe dependem cada vez mais das suas possibilidades de gerar o conhecimento e as competências necessárias 
pra impulsionar a inovação econômica e social, assim como para aumentar seu efeito no crescimento econômico, a inclusão social e a sustentabilidade ambiental. Tudo isso em um contexto em que é necessário redefinir a relação entre mercado, Estado e sociedade que prevaleceu durante três décadas e não conseguiu responder aos desafios do desenvolvimento e fechar as brechas produtivas e sociais (CEPAL, 2010 a).

$\mathrm{Na}$ nova fase de recuperação econômica após a crise financeira, os países da região enfrentam importantes desafios e oportunidades no âmbito da sociedade da informação, entendida como o sistema econômico e social onde o conhecimento e a informação constituem fontes fundamentais de bem estar e progresso. Surge um cenário onde os países da região podem crescer mais e melhor somente se renovarem suas estratégias de desenvolvimento com igualdade gerando bases mais sólidas de crescimento e maiores níveis de inclusão social em um contexto de um novo ciclo tecnológico baseado nas tecnologias de informação e comunicação. Elas oferecem uma nova oportunidade de utilizar seu potencial transformador para agregar valor a atividade econômica, os serviços públicos e a organização social.

No final da década de oitenta, especialistas começaram a prenunciar que se acabava a sociedade pós industrial e que se dava inicio uma nova sociedade conhecida como sociedade da informação. Previam, esses especialistas, que a sociedade da informação seria uma sociedade de compartilhamento de recursos e uma sociedade que acabaria com as desigualdades sociais. Pouco tempo depois surgiram as principais críticas a nova sociedade. 
A Alfabetização Informativa e a inclusção na sociedade da ...

Criticavam abertamente que a sociedade da informação aumentaria as desigualdades sociais e que era uma sociedade feudal na medida em que os donos do poder seriam os donos dos meios de comunicação.

Os governos da América Latina e do Caribe começaram no novo século a implantar sociedade da informação de forma e entendimentos bastantes variados. Alguns achavam que bastavam distribuir computadores no sistema educacional para incluir a população na nova sociedade, outros fortaleceram os meios de comunicação e poucos resolveram criar infra-estrutura informacional adequada.

A sociedade industrial comprovou que não bastava construir bibliotecas e que o grande desafio era a construção de um público leitor. Uma coisa está alinhada a outra, mas a questão da cultura leitora só é viável na América Latina e no Caribe através da aplicação de metodologias envolvendo a competência informacional.

De qualquer maneira a indicação de eficiência de uma sociedade da informação somente é comprovavel na medida em que os indicadores demonstram que o processo de inclusão das pessoas antes marginalizadas está aumentando. Na medida em que há o aumento da inclusão outros indicadores começam a surgir como a diminuição da violência e a maior oportunidade da geração de emprego e renda para as pessoas marginalizadas do processo de desenvolvimento.

Portanto o acesso às tecnologias de comunicação e informação, a produção de conteúdos, a melhoria da infraestrutura informacional (composta de bibliotecas infantis, escolares, publicas, especializadas e universi- 
tárias); a aplicação de metodologias de alfabetização informacional e a compreensão de que a inclusão na sociedade da informação tem um grande significado na melhoria da qualidade de vida, são as questões mais relevantes na formulação de políticas públicas.

Numa sociedade da informação, onde tanto a falta de informação quanto a explosão informacional, podem representar fatores de exclusão, surge o papel cada vez mais fundamental do profissional da informação. A formação desse profissional deve dar privilégios para as áreas de tecnologias da informação e comunicação, inclusão social e alfabetização informativa.

Nesse novo contexto, cabe ao profissional da informação ser um profissional competente em informação, pois terá que conduzir uma política de inclusão social para as pessoas marginalizadas e ao mesmo tempo atuar na formação de pesquisadores, bem como atuar no processo da melhoria da produção científica e a conseqüente visibilidade internacional. As palavras chaves passam a ser: aprender a aprender, saber agir, saber fazer, alfabetizar informacionalmente, enfim construir um mundo com mais equidade social.

Os desafios maiores são na área da inclusão social. Como incluir na sociedade da informação pessoas marginalizadas que muitas vezes não sabem nem que tipo de informação necessitam? Não sabem reconhecer quando precisam de informação. Não sabem validar a informação? São muitas vezes totalmente dependentes da informação oral e por isso são totalmente manipulados na busca da informação. 
A Alfabetização Informativa e a inclusção na sociedade da ...

Por outro lado, num nível percentual bem menor da população da região, encontramos pessoas que têm competência informacional. São os usuários mais críticos do sistema informacional. São produtores de informação. Tem capital intelectual suficiente para não dependerem do texto escrito e, muitas vezes, agrega valor a palavra impressa.

\section{ALFABETIZAÇÃO INFORMATIVA}

O processo de busca e avaliação da informação tem sido estudado há muito tempo por especialistas da área de ciência da informação. O grande obstáculo passa a ser o contingente ainda grande de analfabetos ou analfabetos funcionais da América Latina e do Caribe, pois sem uma formação educacional adequada essas pessoas não possuem condições intelectuais para avaliar a busca e, principalmente, a compreensão da informação.

$\mathrm{Na}$ verdade cada revolução, ou cada nova inovação, traz no seu bojo a questão da exclusão. Quando Gutenberg inventou a imprensa, trouxe novas condições para aperfeiçoar a produção cultural, educacional e científica. Ao mesmo tempo surgiram os analfabetos e iletrados que jamais tiveram acesso à inovação de Gutenberg. A revolução tecnológica, apesar dos inúmeros benefícios trouxe também a questão dos excluídos da sociedade da informação. Todo esse processo acabou validando, cada vez mais, a questão da alfabetização informativa que hoje, em muitos países é considerada tão importante quanto a alfabetização educacional.

Inicialmente a informação era considerada propriedade da matéria. Mensagem, documento ou recurso in- 
formacional, qualquer material simbólico publicamente disponível. Hoje, no entanto, a informação é o que é capaz de transformar estruturas de imagem, estímulo que altera a estrutura cognitiva do receptor.

Tradicionalmente a necessidade de informação era o estado de necessidade de algo que o investigador chama de informação, focada no que o sistema possui, e não no que o usuário precisa. $\mathrm{Na}$ investigação alternativa a necessidade de informação se realiza quando a pessoa reconhece que existe algo errado em seu estado de conhecimento e deseja resolver essa anomalia, estado de conhecimento insuficiente para lidar com incerteza, conflito e lacunas em uma área de estudo ou trabalho (Dervin e Nila, 1986, p.17).

Para Choo, 2006, pode-se usa a informação em três áreas básicas: na criação de significados para o entendimento do seu ambiente de atuação; na construção de conhecimentos para suprir lacunas de conhecimento e desenvolver novas competências e na tomada de decisões para escolher formas de ação. A geração e transformação da informação são moldadas pela cultura e especificação de regras, rotinas e papeis. Informações e significados são forjados nos pensamentos, sentimentos e ações dos indivíduos, em um processo cíclico. A administração do ciclo da informação gera mais informação, que por sua vez gera conhecimento, que subsidia a estratégia fornecendo base para a ação, e que fornece o feedback necessário para recomeçar o processo. Assim, a administração da informação deve ser vista como a administração de uma rede de processos que adquirem, 
A Alfabetização Informativa e a inclusção na sociedade da ...

criam, organizam, distribuem e usam a informação num ciclo contínuo.

Há uma relação entre as necessidades de informação e as competências informacionais. Para Miranda (2007) as necessidades de informação estariam relacionadas com os aspectos cognitivos, emocionais e situacionais. Os cognitivos estão relacionados com o saber, os emocionais com o saber-agir e os situacionais com o saber-fazer. Todos eles são importantes na questão da competência informacional.

Os estudos orientados para o usuário nas abordagens mais recentes vêem a informação como uma construção subjetiva, em que o valor da informação reside no relacionamento que o usuário constrói entre si mesmo e determinada informação. Portanto, devem ser examinados as preferências e necessidades cognitiva e psicológicas do indivíduo e também como elas afetam a busca e os padrões de comunicação da informação. Isso envolve a busca dos motivos que geram as necessidades informacionais e de como essas necessidades são percebidas, representadas, definidas e vivenciadas. Também envolve atender como a informação ajuda o usuário a avaliar os resultados do uso, impacto, benefícios e contribuição para o desempenho (CHOO, 2006).

$\mathrm{Na}$ verdade a alfabetização informativa deve ser implantada na América Latina e no Caribe como uma política de Estado, na medida em que a sua implantação pode colaborar definitivamente para acabar com os problemas das desigualdades sociais, proporcionar a geração de emprego e renda, capacitar e melhorar a formação de investigadores e aumentar a produção científica. 
Os casos mais complexos estão relacionados com o emprego e a utilização da alfabetização informativa nas zonas rurais, nas zonas marginalizadas onde, até hoje, há um índice expressivo de problemas relacionados com o analfabetismo e a desnutrição infantil. Geralmente nesses casos o indivíduo tem dificuldades para saber e compreender qual é a sua necessidade informacional, pois ele só entende a informação oral e para ele a informação bibliográfica, digital ou virtual não tem nenhum sentido.

Mesmo depois de ser alfabetizado ele vai encontrar dificuldades para se tornar um leitor e para interpretar o texto escrito. Este é o momento para utilizar as metodologias de mediação da informação e a metodologia etnográfica. É necessário um esforço intelectual para que não seja somente uma inclusão precária e sim uma inclusão definitiva na sociedade da informação.

\section{AS BOAS PRÁTICAS}

É possível perceber um marcante crescimento nos programas e projetos de inclusão digital e social no Brasil nos últimos anos. Parte resultado do avanço tecnológico impulsionado pelo progresso da industria da informática e parte pelo desenvolvimento de metodologias, sistemas de avaliação e consolidação da Ciência da Informação, que tem acontecido na academia e nos institutos de pesquisa.

No Brasil a Ciência da Informação, particularmente por meio da Alfabetização Informacional, tem contribuído fortemente para o êxito dos programas de inclusão digital que a utilizam. Nesse sentido colocaremos 
A Alfabetização Informativa e a inclusção na sociedade da ...

como exemplo dois projetos que estão focados nos seus fundamentos interdisciplinares.

O primeiro é a Escola Digital Integrada -EDI, resultado de uma pesquisa de doutorado defendida na Universidade de Brasília. Essa pesquisa foi transformada em Lei pelo Governo do Distrito, vencedora de um premio nacional de Inclusão Digital e deu origem a uma Organização da Sociedade Civil de Interesse Publico-OSCIP (terceiro setor).

Trata-se de uma metodologia de mediação da informação que utiliza a aprendizagem informacional como base do seu desenvolvimento. A experiência piloto da EDI foi implantada, em 2002, em uma escola publica do Distrito Federal com 2.870 alunos, 150 professores e 30 funcionários, que atende ensino fundamental, médio e supletivo. Foi criada uma sala com 30 computadores, conectados em banda larga, 2 coordenadores e 6 monitores. $\mathrm{O}$ projeto atendia a toda comunidade escolar, embora tenham sido selecionados 44 dos 292 matriculados no primeiro ano do ensino médio para compor a turma experimental.

Esses alunos permaneciam na escola três vezes por semana no contra turno e trabalhavam novos conteúdos como: fontes de informação; tecnologia e sociedade; empreendedorismo; cidadania e identidade cultural; educação artística e oficina literária.

O projeto atuou na melhoria da infra-estrutura informacional da escola, fortalecendo e automatizando a biblioteca; reforçando a radio comunitária existente de maneira incipiente e ampliando a videoteca. 
Foi desenvolvido um sistema de avaliação para acompanhar e mensurar os resultados alcançados. Dentre os indicadores selecionados um dos mais impactantes foi o percentual de alunos aprovados no primeiro vestibular. A media de aprovação da escola oscilava entre 3,5 e 4\%, ao final do $3^{\circ}$ ano de trabalho o resultado foi surpreendente, $68.9 \%$ dos alunos participantes do projeto foram aprovados. Outros indicadores importantes foram os níveis de violência na escola, a melhora no relacionamento com a família, a qualidade dos textos produzidos, dentre outros.

Atualmente a EDI esta implantada em outros estados brasileiros, gerou um software educacional, um produto social e tem servido de base para outros projetos de inclusão e a realização de pesquisas que resultaram em 17 dissertações e 12 teses sobre o tema. $\mathrm{O}$ seu êxito deve-se muito a utilização de metodologias como a etnográfica, pesquisação e alfabetização informacional.

Um segundo exemplo de boas praticas acontece com o Projeto Corredor Digital. Trata-se de uma iniciativa do Instituto Brasileiro de Informação em Ciência e Tecnologia - IBICT, instituto de pesquisa do Ministério de Ciência e Tecnologia do Brasil. Esse projeto faz parte do Programa de Inclusão Social do Instituto que utiliza aprendizagem informacional como base para o desenvolvimento dos conteúdos e capacitações que realiza.

A primeira experiência foi a implantação do Corredor Digital Indígena, em 2007, em 3 aldeias da etnia Tukano no Alto rio Negro, na Amazônia. Foram produzidos conteúdos impressos, um software e uma capacitação presencial de 12 professores indígenas das 
A Alfabetização Informativa e a inclusção na sociedade da ...

aldeias Balaio, Taracua e Paricachoeira, nas dependências do IBICT.

A partir dessa experiência criamos o Corredor Digital Rural, em parceria com a Secretaria de Educação do Distrito Federal, em 2008, onde implantamos 18 laboratórios com 10 máquinas cada, 1 TV de plasma de 42 polegadas, data show, moveis, e capacitação de 180 professores. Foram desenvolvidos conteúdos e material especifico para o publico alvo e o acompanhamento esta sendo realizado por meio de comunidades de prática.

Dentro desse programa temos o Corredor Digital Urbano, cuja experiência primeira esta se dando na Biblioteca Nacional de Brasília - BNB. Foi criado um espaço com 10 equipamentos, mesas e cadeiras para crianças menores de 6 anos, livros infantis, uma videoteca e material para atividades de leitura. As escolas agendam sua participação e algumas delas têm sido muito pro ativas e desenvolvido ações nas próprias escolas e a equipe da BNB acompanha. Um dela criou um jornalzinho mensal e em 10 de dezembro de 2010 serão lançados "Livros Digitais" uma coletânea literária de um grupo de alunos dessa escola.

No próximo ano estaremos atuando em conjunto com o Programa Casa Brasil que foi criado na Presidência da Republica e que esta sendo transferido para o IBICT. A Casa Brasil esta estruturada em módulos e propicia a conexão de vários saberes. As atividades realizadas devem articular temas e ações diversas. Sua estrutura e funcionamento se dá da seguinte forma; cada unidade tem 20 computadores conectados à Internet e abriga atividades livres e oficinas temáticas. $\mathrm{O}$ acesso à tecnologia mostra como é possível ajudar a resolver questões coti- 
dianas da comunidade; uma Sala de leitura que tem por objetivo fomentar leitura, produção e compartilhamento de textos e oferecer atividades culturais, como encontros literários, oficinas de criatividade, saraus, rodas de leitura, orientação a pesquisas e empréstimo domiciliar de livros; um auditório, destinado a encontros, reuniões e divulgação do que é produzido na unidade Casa Brasil e na comunidade, com no mínimo 50 lugares e equipamentos audiovisuais, como caixas acústicas, tela e canhão de projeção; Laboratório de divulgação da ciência, tem por objetivo popularizar e divulgar a ciência, por meio de apropriação científica e tecnológica e de produções culturais e artísticas, estimulando interesses e curiosidades; Laboratório de informática, trabalha com montagem e manutenção de equipamentos de informática, possibilitando a exploração de microcomputadores e de seus componentes para desenvolver atividades que tratem de recondicionamento e reciclagem das máquinas, incluindo novos significados e usos para tecnologias; Estúdio multimídia, destinado a criação, gravação e tratamento de conteúdos audiovisuais, produção e compartilhamento de conteúdos para Internet e programação com ferramentas e linguagens livres. É equipado com computadores, câmeras fotográfica e de vídeo digitais, gravador digital portátil, mesa de som, reprodutor de VHS e SVHS e microfones e Oficina de rádio, estimula a produção de conteúdos para rádio livre, web rádio e outros tipos de transmissão pública de conteúdos em linguagem radiofônica, com programação montada livremente pelos programadores. Oferece oficinas de produção de conteúdo de áudio, comunicação comuni- 
A Alfabetização Informativa e a inclusção na sociedade da ...

tária, web rádio e podcasting. Incentiva a produção de mídias abertas de interesse público, com cunho comunitário, educativo, informativo, cultural e artístico.

Finalmente a alfabetização informativa tem sido cada vez mais vista e entendida como uma ferramenta importante na ampliação da sociedade da informação, especialmente em regiões como a América Latina e o Caribe.

\section{CONCLUSÃO}

No século XXI houve uma nova descoberta da importância da ciência da informação para proporcionar o acesso das populações menos favorecidas para a sociedade da informação. Este processo demonstra que o profissional da informação deve estar capacitado para utilizar metodologias de alfabetização informacional, mediação da informação concomitantemente com as tecnologias de informação e comunicação.

Neste cenários de novas descobertas, cabe ao profissional da informação saber trabalhar com destreza para proporcionar à sua comunidade mecanismos de geração de emprego e renda para diminuir as desigualdades sociais ainda reinantes na América Latina e no Caribe.

Inovação, passa a ser a palavra de referência, pois devemos inovar para proporcional mais facilidades de acesso ao livro e as novas tecnologias. Tanto a informação bibliográfica, como a informação digital e virtual, podem proporcionar facilidades nunca então conhecidas nas práticas de inclusão digital para a inclusão social. As novas gerações tem muita facilidade em trabalhar com a informação eletrônica, já as da terceira idade tem mais facilidades em trabalhar com a informação docu- 
mental. Cabe ao profissional da informação elaborar um diagnóstico sobre o estado da arte da sua comunidade e colocar em prática. Muitas vezes será necessário segmentar a comunidade para o avanço do processo de inclusão na sociedade da informação.

As boas práticas comprovam que a alfabetização informativa é tão importante como a alfabetização educacional. A busca da informação se bem avaliada é um processo que pode conduzir as populações marginalizadas para as questões da equidade social.

\section{REFERÊNCIAS BIBLIOGRÁFICAS}

CEPAL, Las TIC para el crecimiento y la igualdad: renovando las estratégias de la sociedad de la información, Lima, CEPAL, 2010.

Choo, Chun Wei, A organização do conhecimento: como as organizações usam a informação para criar significado, construir conhecimento e tomar decisões, São Paulo, Editora Senac, 2003.

Dervin, B. Nilan, M., "Information needs and uses", en Annual Review of Information Science and Tecnology., ARIST, New York, v.21, p.3-33, 1986.

Miranda, Silvânia, "Como as necessidades de informação podem se relacionar com as competências informacionais", en Ciência da Informação, Brasília, v.35, n.3, set-dez, 2006. 


\title{
Estado del arte de la Alfabetización Informacional en Colombia
}

\author{
Alejandro URIBE TIRADO \\ Universidad de Antioquia
}

\section{INTRODUCCIÓN}

Dara iniciar el desarrollo de este texto es necesario en

1 primer lugar hacer varias precisiones terminológicas, conceptuales y contextuales que sirvan como acuerdo (desde la perspectiva de este trabajo), para facilitar la compresión del mismo y la identificación de las características comunes y divergentes que esta temática de la alfabetización informacional ha tenido, tiene y seguirá teniendo en Colombia. Estas precisiones se enmarcan entonces considerando el título que se le ha dado a este trabajo:

\section{Estado del arte}

En este texto se asume como comprensión de "estado de la arte" lo que proponen Vélez Restrepo y Galeano Marín (2002), retomando diferentes autores, respecto a que "un estado del arte es... una investigación sobre la producción -investigativa, teórica o metodológica- exis- 
tente acerca de determinado tema para develar desde ella, la dinámica y lógica presentes en la descripción, explicación o interpretación que del fenómeno en cuestión hacen los teóricos o investigadores".

Entender de esta manera un "estado del arte" implica, siguiendo estas mismas autoras (Vélez Restrepo y Galeano Marín, 2002), considerar diferentes estrategias ${ }^{1}$ para ubicar esa producción -más allá de lo sólo documental/impreso- y considerar así desde la perspectiva/enfoque cualitativo, entre otros: los estudios de caso, los grupos de discusión, la observación participativa y el análisis de contenidos (Andréu, 2000; Piñuel, 2002; Porta y Silva, 2003; Salinas, 2006; Solís Valdespino, 2008, etc.), ${ }^{2}$ y más específicamente de contenidos Web, de contenidos Digitales, (Wan-Ying Lin, 2000; McMillan, 2000; Strijbos et al, 2005; Herring, 2010, etc.).

Desde esta perspectiva es claro finalmente que todo "estado del arte" es una aproximación en un momento, de un grupo de personas (investigadores) y con determi-

1 "Las estrategias se conciben como modelos o patrones de procedimiento investigativo... Una estrategia investigativa combina enfoques, produce o recoge información de diversas fuentes y a través de distintos procedimientos, confronta y valida resultados obtenidos por diversas vías, produciendo una interpretación del problema particular que investiga y ocupan una posición de puente entre los enfoques y técnicas de investigación" (Triangulación).

2 Ver en: http://www.investigacioncualitativa.cl/2008/02/anlisis-de-contenido. html y http://132.248.242.3/publica/archivos/libros/metodos_cualitativos.pdf 
Estado del arte de la Alfabetización Informacional en ...

nadas fuentes-estrategias concretas, que en ningún momento puede presumir que allí está toda la producción sobre un tema, pero sí puede garantizar un trabajo sistemático que busca ser lo más amplio y profundo posible.

Alfabetización informacional (o..., entendido como...)

Respecto a la alfabetización informacional como término (su forma de expresarlo) durante las últimas 3 décadas de desarrollo de la information literacy (Pinto, Cordon y Gomez, 2010) ha habido múltiples discusiones en diferentes idiomas sobre cuál es el término más adecuado desde diferentes perspectivas lingüísticas y de traducción para expresarlo.

En el caso del español ésta ha sido también una realidad con posiciones divergentes como la de Gómez Hernández (alfabetización informacional) o Marzal (alfabetización en información), o variaciones como las de Cortés y Lau (desarrollo de habilidades informativas), o posiciones sustentadas en la tradición bibliotecológica y determinadas perspectivas educativas como las de Naranjo Vélez y otros (formación-educación de usuarios)

A este respecto, desde este trabajo se asume una posición pragmática en cuanto a que en campos de conocimiento recientes los acuerdos terminológicos son procesos en construcción, en los que en muchas ocasiones no se llega a posiciones de acuerdo. Por tanto, es asumido como término el de "alfabetización informacional -ALFIN-” acogiendo la posición de Gómez Hernández (2007), validada a su vez por el uso, que en cuestiones idiomáticas, terminológicas, finalmente es la que tiene más peso, ya que en español cuando se hace una búsque- 
da de los diferentes términos relativos a esta temática ${ }^{3}$ es el de "alfabetización informacional" el más utilizado considerando el contexto hispanoamericano, ${ }^{4}$ e igualmente en el caso colombiano. ${ }^{5}$

Unido a lo anterior, en el desarrollo de la alfabetización informacional los últimos treinta años ha habido diferentes propuestas, como definición (su forma de entenderla), que de manera directa e indirecta han buscado conceptualizarla. En muchos casos en nuestros contextos (latinoamericano, hispanoamericano, iberoamericano) se han asumido traducciones literales de las definiciones en habla inglesa más reconocidas (ALA, CILIP, SCONUL, CAUL), ${ }^{6}$ no obstante ha habido propuestas de determinados autores que han buscado darle una defini-

3 Alfabetización informacional, Alfabetización en información, Alfabetización informativa, Desarrollo de Habilidades Informativas (DHI), Competencias informacionales, Competencias en información, Competencias informativas, Formación de usuarios para la búsqueda de información, etcétera.

4 Por ejemplo, usando Google Scholar, como herramienta para comparar la frecuencia de uso de estos términos se encuentra (a Febrero/2010) para los términos en español: 991 documentos con la expresión "alfabetización informacional”, 180 con "desarrollo de habilidades informativas"; 499 con "alfabetización en información"; 191 con "alfabetización informativa"; 214 con "competencias informacionales"; 97 con "competencias en información"; 110 con "competencias informativas", y finalmente, 367 con "formación de usuarios" + "búsqueda de información".

5 Depurando los resultados generales de Hispanoamérica para "Colombia" y ".co", utilizando de nuevo como fuentes Google Scholar y el repositorio E-lis, el término "alfabetización informacional" es el mayoritario. 
Estado del arte de la Alfabetización Informacional en ...

ción "propia”, que complemente y amplíe, y en algunos casos, contextualice dichas definiciones provenientes de contextos anglosajones.

Desde este trabajo, continuando con una posición pragmática, se asumió la necesidad de ir más allá de las definiciones "sintéticas" muy propias del contexto anglosajón y retomar las fortalezas-potencialidades de gran parte de las definiciones-descripciones sobre alfabetización informacional de los últimos años, buscando generar una descripción amplia del término que abarque toda su complejidad. ${ }^{7}$

Por tanto, desde este texto se entiende por alfabetización informacional (Uribe Tirado, 2008, 2009, 2010):

El proceso de enseñanza-aprendizaje que busca que un individuo o un colectivo, gracias al acompañamiento profesional y de una institución educativa o bibliotecológica y utilizando diferentes estrategias didácticas y ambientes de aprendizaje (modalidad presencial, "virtual" o mixta -blended learning-), alcance las competencias (conocimientos, habilidades $\mathrm{y}$ actitudes) en lo informático, comunicativo e informativo, que le permitan, tras identificar sus necesidades de información, y utilizando diferentes formatos, medios y recursos físicos, electrónicos o digitales, poder localizar, seleccionar, recuperar, or-

6 Ver: http://www.informationliteracy.org.uk/Information_literacy_definitions/Definitions.aspx y http://dis.shef.ac.uk/ literacy/definitions.htm .

7 Ver comentarios sobre esta propuesta de definición-descripción de ALFIN en: http://medina-psicologia.ugr.es/biblioteca/mod/ forum/discuss.php?d=27 . 
ganizar, evaluar, producir, compartir y divulgar (Comportamiento Informacional) en forma adecuada y eficiente esa información, con una posición crítica y ética a partir de sus potencialidades (cognoscitivas, prácticas y afectivas) y conocimientos previos (otras alfabetizaciones-Multialfabetismo/Literacias), y lograr una InterAcción apropiada con otros individuos y colectivos (práctica cultural-inclusión social), según los diferentes roles y contextos que asume (niveles educativos, investigación, desempeño laboral o profesional), para finalmente con todo ese proceso, alcanzar y compartir nuevos conocimientos y tener las bases de un aprendizaje permanente (lifelong learning) para beneficio personal, organizacional, comunitario y social (evitando la brecha digital e informacional) ante las exigencias de la actual sociedad de la información.

\section{COLOMBIA}

Tratar de presentar un "estado del arte" sobre la "alfabetización informacional" en un contexto concreto, en este caso el de un país, es un propósito investigativo grande que implica un proceso de indagación continuo. En el caso de este texto, ese proceso se basa en el trabajo docente e investigativo que los últimos cinco años se ha venido realizando desde la Escuela Interamericana de Bibliotecología de la Universidad de Antioquia (Medellín-Colombia), y el grupo de investigación "Información, Conocimiento y Sociedad" que ha permitido, especialmente en el último año y medio, con los estudios doctorales sobre esta temática, hacer un proceso sistemático para detectar esa producción relacionada con la ALFIN considerando: los artículos y ponencias que autores colombianos han 
Estado del arte de la Alfabetización Informacional en ...

publicado sobre este tema; los trabajos de tesis a nivel de pregrado y posgrado; los proyectos de investigación; los programas y proyectos planeados y/o implementados en diferentes tipologías de instituciones educativas y bibliotecas; los recursos web $(1.0$ y 2.0$)$ que tratan y han tratado esta temática, y los procesos de acompañamiento a la formación de profesionales de la información sobre ALFIN en diferentes ciudades y redes-colectivos.

No obstante, como lo implica un "estado del arte", y se mencionó anteriormente, no incluye todo lo producido, por tanto es, siguiendo una metáfora: una fotografía panorámica desde un momento, un ángulo y un fotógrafo específico, que da cuenta en gran medida de ese paisaje, pero que no es todo el paisaje.

\section{METODOLOGÍA Y RESULTADOS}

Teniendo en cuenta las tres consideraciones anteriores en relación con el título de este trabajo es posible presentar ahora la metodología que se siguió en el proceso investigativo que enmarca este trabajo, y sus resultados específicos.

En primer lugar es necesario indicar que se eligieron como estrategias (métodos/técnicas e instrumentos): la investigación documental, el análisis de contenidos Web-Digitales, la entrevista formación observación participante, y las encuestas virtuales.

\section{Investigación documental}

Respecto a la investigación documental se realizó un trabajo de búsqueda y recuperación de información que 
implicó durante varios meses el rastreo de fuentes de información que permitieran ubicar lo que se ha publicado sobre el tema de la alfabetización informacional en Colombia los últimos años.

En concreto se consultaron: los repositorios INFOLIT Global y E-lis, las bases de datos referenciales REDALYC y LATININDEX, específicas del contexto iberoamericano y las bases de datos científicas de trayectoria $\mathrm{y}$ alcance internacional (ISI, SCOPUS, ERIC, EBSCO-FUENTE ACADEMICA; ESMERALD, etc.), lo que permitió identificar gran parte de la producción (publicaciones-investigaciones-propuestas formativas-objetos de aprendizaje) de lo que se ha hecho y está haciendo en ALFIN en Colombia.

Tras la organización, depuración (duplicados) y sistematización de esos resultados de búsqueda, se logró la ubicación y el análisis (Ficha de ampliada de contenidos bibliográficos -Anexo 1) de la siguiente producción relacionada directa e indirectamente con la alfabetización informacional en Colombia: ${ }^{8}$

Artículos y Ponencias:

- Formación de usuarios de la Información y procesos formativos: hacia una conceptuación, (Naranjo Vélez, 2003).

8 Para ubicar estas referencias, puede consultar Línea de tiempo ALFIN/Colombia http://www.dipity.com/alfincolombia/ Además de: http://alfincolombia.blogspot.com/2009/09/quese-ha-publicado-sobre-alfin-desde_05.html y 
Estado del arte de la Alfabetización Informacional en ...

- Internet, software libre, brecha digital y analfabetismo informacional. Una reflexión y discusión pendiente en la Universidad, (Uribe Tirado, 2005).

- La alfabetización informacional, un prerrequisito y campo de acción para la e-inclusión y la gestión del conocimiento en red en las universidades, (Uribe Tirado, 2005).

- Evolución y tendencias de la formación de usuarios en un contexto latinoamericano: resultados de la investigación, (Rendón Giraldo, Naranjo Vélez y Giraldo Arredondo, 2005).

- La fluidez de la información en la era digital, (Cortés S., 2006).

- Programa de Alfabetización en Información del Sistema de Bibliotecas sede Bogotá de la Universidad Nacional de Colombia, (Ardila y Martínez, 2006).

- Acceso, conocimiento y uso de Internet en la Universidad de Antioquia: modelo de diagnóstico y caracterización, (Uribe Tirado et al., 2007).

- Los bibliotecólogos y bibliotecarios, agentes lideres en la formación de estudiantes y comunidades para el acceso a información de calidad utilizando Internet, (Uribe Tirado, 2007).

- Introducción al Desarrollo de Habilidades Informativas-Information Literacy, (Machett Penagos, 2007).

- La alfabetización múltiple: reto de las bibliotecas, (Giraldo, 2007).

- Implicaciones sociales y culturales de la Alfabetización Informacional, (Mesa, 2007).

- Las habilidades informativas en el contexto de la formación profesional, (Ordóñez, 2007). 
Tendencias de la Alfabetización Informativa en Iberoamérica

- Acerca de la Alfabetización Informacional y el papel de la academia, (Naranjo Vélez, 2007).

- Programa de formación y orientación de los alumnos, (Tinjacá, 2007).

- La investigación en la biblioteca escolar: una estrategia para el desarrollo de la ALFIN, (Vélez de Monchaux, 2007).

- La brecha digital, no solo conectividad. La Socio, Info e Infraestructura Informacional una triada necesaria para los análisis en la sociedad de la información, (Uribe Tirado, 2007).

- De la didáctica y otras acciones para la formación de usuarios en bibliotecas universitarias, (Naranjo Vélez, 2007).

- Experiencia de un programa de formación de usuarios como apoyo al proceso de enseñanza-aprendizaje universitario en el Sistema de Bibliotecas de la Universidad de Antioquia, (Gil Jaramillo, 2008).

- Competencias informacionales en estudiantes universitarios: Una reconceptualización, (Marciales Vivas et al., 2008).

- La formación en competencias tecnológicas e informacionales de futuros bibliotecólogos aprovechando la plataforma educativa Moodle: caso Escuela Interamericana de Bibliotecología Universidad de Antioquia 2007-2008, (Castaño Muñoz y Uribe Tirado, 2008).

- Hacia una formación de usuarios de la información en entornos locales, (Rendón Giraldo y Herrera Cortés, 2008). 
Estado del arte de la Alfabetización Informacional en ...

- El conocimiento y reconocimiento de los modelos de comportamiento informacional. Un aspecto necesario para los servicios de información Web 2.0 y la Alfabetización Informacional-DHI desde las bibliotecas, (Uribe Tirado, 2009).

- Interrelaciones entre veinte definiciones-descripciones del concepto de alfabetización informacional: Propuesta de macro-definición, (Uribe Tirado, 2009).

- Formación de habilidades y competencias informacionales en entorno virtual, Caso Universidad del Rosario, Colombia, (Lisowska, 2009).

- Mitos, realidades y preguntas de investigación sobre los 'nativos digitales': una revisión, (Cabra Torres y Marciales Vivas, 2009).

- Intranets, repositorios, alfabetización digital e informacional... Estrategias cubanas para evitar la brecha digital, replicables y adaptables en otros contextos iberoamericanos, (Uribe Tirado, Zayas Mujica y Fernández Valdés, 2009).

- La Alfabetización Informacional en la Universidad. Descripción y Categorización según los Niveles de Integración de ALFIN, Caso Universidad de Antioquia, (Uribe Tirado, 2010).

- Avances y perspectivas de ALFIN en Iberoamérica. Una mirada desde la publicación académico-científica y la web 1.0 y 2.0., (Uribe Tirado, 2010).

- Perfiles de la competencia informacional en estudiantes de primer semestre de carreras técnicas y profesionales, (Marciales Vivas et al, 2010). 
Tendencias de la Alfabetización Informativa en Iberoamérica

- La formación y los estándares-competencias en alfabetización informacional para estudiantes universitarios. Una mirada contextualizadora desde los postulados de la teoría de la actividad y la acción mediada, (Uribe Tirado, 2010).

- El proyecto INFOLIT Global y su importancia para las instituciones bibliotecarias y educativas de Colombia para la enseñanza-aprendizaje de competencias informacionales/Alfabetización Informacional, (Uribe Tirado, 2010).

- Alfabetización Informacional (ALFIN) en la Red Capital de Bibliotecas Públicas de Bogotá, (Fino Garzón, 2010).

- Asignaturas para el desarrollo de competencias en el manejo de información y uso de TIC, (Menéndez y Mesa, 2010).

- Formación cívica y ciudadana mediada por las tecnologías de la información y la comunicación-TIC: una experiencia de alfabetización informacional con contenidos locales, (Bedoya, 2010).

- La formación en competencias informacionales (alfabetización informacional) una necesidad imperante en la educación colombiana, (Uribe Tirado, 2010).

- Uso de los sistemas de información documental en la educación superior: estado del arte, (Naranjo Vélez, 2010).

- Competencias informacionales en estudiantes universitarios, (Marciales Vivas et al, 2010).

- Presencia, tendencias y aspectos diferenciadores de la formación sobre derechos de autor en la alfabetización informacional en el ámbito universitario, (Uribe Tirado, 2010). 
Estado del arte de la Alfabetización Informacional en ...

- Modelo académico para el desarrollo de habilidades informacionales: caso del departamento de ciencia de la información de la pontificia universidad javeriana, (Mesa, 2010).

- Alfabetización Informacional desde la Universidad de La Salle: Retos y Oportunidades, (Gómez Dueñas, 2010).

- El desarrollo de competencias informacionales desde la Biblioteca Pública: caso de la Red de Capital de Bibliotecas Públicas, (Sierra Escobar, 2010).

- La emancipación a través del conocimiento como objetivo en el diseño curricular de programas de alfabetización informacional, (Machett, 2010).

- El desarrollo de habilidades informativas como componente del programa de Animación a la lectura Biblioteca Escuela PALBE, (Carrerro Gómez, 2010).

- La formación en alfabetización informacional en la Escuela Interamericana de Bibliotecología: Competencias para ser alfabetizados y competencias para ser alfabetizadores, (Uribe Tirado y Castaño Muñoz, 2010).

Libros:

- Evolución y Tendencias de la Formación de Usuarios en un Contexto Latinoamericano, (Naranjo Vélez et al, 2006).

- Acceso, conocimiento y uso de internet en la Universidad: Modelo de diagnóstico y caracterización, (Uribe Tirado et al. 2008).

- MUFUS-Modelo de formación de usuarios de la información, (Naranjo Vélez et al, 2009). 
Tendencias de la Alfabetización Informativa en Iberoamérica

Trabajos de grado en pregrado:

- Búsquedas especializadas en la Web en texto completo puestas a disposición en el catálogo público Olib 7 del Sistema de Bibliotecas de la Universidad de Antioquia,. Recurso impreso, Escuela Interamericana de Bibliotecología, Universidad de Antioquia, (Zapata Patiño/Arredondo Hernández -Dir.-, 2000).

- Creación de indicadores para los estándares de alfabetización informativa propuestos por la ALA, como modelo de medición de las habilidades en el uso de la información, por parte de los estudiantes de grado $11^{\circ}$ : estudio de caso aplicado a los colegios Pureza de María y San Bartoloméla Merced, recurso electrónico, Pontificia Universidad Javeriana-Bogotá, (Lugo y Mesa/ Hinestrosa -Dir.-, 2003).

- Evaluación de servicios en línea en el ámbito de las bibliotecas universitarias desde la perspectiva del manejo de indicadores de gestión y la usabilidad. recurso impreso y electrónico, Escuela Interamericana de Bibliotecología, Universidad de Antioquia, (Arias Sanchez./Pineda Gaviria.-Dir.-, 2004).

- Competencias en el manejo de información: Guía metodológica y didáctica para docentes y estudiantes de educación básica primaria de Bogotá, Recurso electrónico, Universidad de La Salle-Bogotá, (Ruíz/Peña -Dir.-, 2005).

- Diseño de un instrumento de evaluación para el programa de formación de usuarios en el acceso, uso y gestión de la información del departamento de bibliotecas de la Universidad de Antioquia, recurso electrónico, Escuela Interamericana de Bibliotecología, Universidad de 
Estado del arte de la Alfabetización Informacional en ...

Antioquia, (Gallo Builes/Pineda Gaviria -Dir.-, 2005).

- Diagnóstico de las competencias en información de los estudiantes de VII semestre de la carrera de Ciencia de la Información-Bibliotecología de la Pontificia Universidad Javeriana, recurso electrónico, Pontificia Universidad Javeriana, (Valderrama/Mesa -Dir.-, 2006).

- Propuesta de un programa de formación de usuarios para estudiantes y profesores de la Facultad de Odontología de la Universidad de Antioquia, recurso electrónico, Escuela Interamericana de Bibliotecología. Universidad de Antioquia, (Llano Ochoa/NaranjoVélez -Dir.-, 2007).

- Diseño de un programa de desarrollo de habilidades informativas: estudio de caso aplicado al taller de Internet para personas mayores de la red de bibliotecas Colsubsidio, recurso electrónico, Pontificia Universidad Javeriana-Bogotá, (Machett/Vélez de Monchaux -Dir.-, 2008).

Tesis de especialización, maestría y doctorado:

- El bibliotecólogo como promotor de la lectura y sus bases pedagógicas, (Naranjo Vélez, 2003)-TM.

- Acceso, conocimiento y uso de las herramientas especializadas de internet entre la comunidad académica, cientifica, profesional y cultural de la Universidad de Antioquia, (Uribe Tirado, 2004)-TE.

- Diseño, implementación y evaluación de una propuesta formativa en alfabetización informacional mediante un ambiente virtual de aprendizaje a nivel universitario: caso Escuela Interamericana de Bibliotecología, Universidad de Antioquia, (Uribe Tirado, 2008)-TM. 
Tendencias de la Alfabetización Informativa en Iberoamérica

- La traducción de la transferencia de información para los estudiantes de ciencia de la información en Colombia, (Naranjo Vélez, 2008... -en proceso de desarrollo-)-TD.

- Lecciones aprendidas en programas de alfabetización informacional en universidades de Iberoamérica, (Uribe Tirado, 2009... -en proceso de desarrollo-)-TD.

Modelos, niveles y estándares

- Lineamientos y Directrices para la Formación de Usuarios de la Información, (Naranjo Vélez et al, 2006).

- Modelo Gavilán, (EDUTEKA, 2006).

- Modelo integrador de 7 macro-competencias de ALFIN, (Uribe Tirado, 2008).

- Modelo de Formación de usuarios de la Información MOFUS, (Naranjo Vélez et al, 2009).

- Niveles de incorporación de ALFIN en universidades y Escuelas/Facultades de Bibliotecología/Documentación/Ciencia de la Información, (Uribe Tirado, 2010).

\section{Eventos}

- Alfabetización informacional: desafíos y posibilidades. XVII Encuentro de Bibliotecas de Cajas de Compensación Familiar, (Bogotá, 2007).

- II Congreso Internacional de Investigación en Ciencia de la Información, (Medellín, 2009).

- BiblioTic 2010, Segundo Encuentro de Bibliotecas en Tecnologías de la Información y la Comunicación, (Medellín, 2010).

- Jornada académica, "La alfabetización informacional: aprendizaje para la vida”, (Bogotá, 2010). 
Estado del arte de la Alfabetización Informacional en ...

\section{Análisis de contenidos Web-Digitales}

El análisis de los sitios Web de las bibliotecas es una estrategia que desde la perspectiva del análisis de contenidos Web-Digitales permite identificar la relevancia y desarrollos que desde las bibliotecas dan a la formación como servicio fundamental y transversal ante los requerimientos de la Sociedad de la Información en los distintos niveles educativos y tipologías de bibliotecas.

Para la realización de esta estrategia se generó una Ficha de registro y análisis de los contenidos Web-Digitales-Anexo 2- de las bibliotecas universitarias, públicas y mixtas (Cajas de Compensación) colombianas, a partir de la utilización de distintos directorios-sistemas de información:

- Sistema Nacional de Información de la Educación Superior. Ministerios de Educación-Colombia: http://snies.mineducacion.gov.co/men/sniesBasico/ consultarInstitucionesRegistradas.jsp.

- Directorio nacional de bibliotecas públicas: http:// www.bibliotecanacional.gov.co/?idcategoria $=$ 28981.

- Red Nacional de Bibliotecas de Cajas de Compensación Familiar: http://blogs.comfenalcoantioquia. com/redbibliotecascajas/

Tras la elaboración de la ficha de registro y análisis se identificó, como se muestra en la Tabla 1 (Síntesis de Programas/Procesos de ALFIN y/o de Formación de Usuarios identificados tras el análisis de las sitios web de las bibliotecas universitarias colombianas) para el caso de las bibliotecas universitarias (ver página siguiente). 
Por tanto considerando los niveles 1 y 2 de ALFIN propuestos, se destacan desde la información Web-Digital que presentan, los casos de:

A nivel 2 de ALFIN:

- Universidad de Antioquia-Medellín.

- Universidad del Rosario-Bogotá. ${ }^{10}$

- Universidad de La Sabana-Bogotá. ${ }^{11}$

- Pontificia Universidad Javeriana-Bogotá. ${ }^{12}$

A nivel 1 de ALFIN:

- Universidad de los Andes-Bogotá. ${ }^{13}$

- Universidad San Buenaventura-Cali. ${ }^{14}$

- Pontificia Universidad Javeriana-Cali. ${ }^{15}$

- Universidad ICESI-Cali. ${ }^{16}$

9 http://formacionbiblioteca.udea.edu.co/moodle/course/ category.php? $\mathrm{id}=6$.

10 http://www.urosario.edu.co/Biblioteca/ur/Informacion/ Biblioteca-Antonio-Rocha-Alvira-\%287\%29/.

11 http://biblioteca.unisabana.edu.co/capacitacion.htm.

12 http://www.javeriana.edu.co/biblos/capacitacion/ capacitacion.htm.

13 http://biblioteca.uniandes.edu.co/Servicios/capacitacion. php.

14 http://www.usb.edu.co/index.php?option=com_content\& task $=$ view \&id $=474 \&$ Itemid $=45$.

15 http://www.javerianacali.edu.co/Paginas/Servicios/ Biblioteca/Biblioteca_Index.aspx .

16 http://www.icesi.edu.co/biblioteca/servicios_formacion_ usuarios.php . 


\begin{tabular}{|c|c|c|c|c|}
\hline \multirow{6}{*}{ 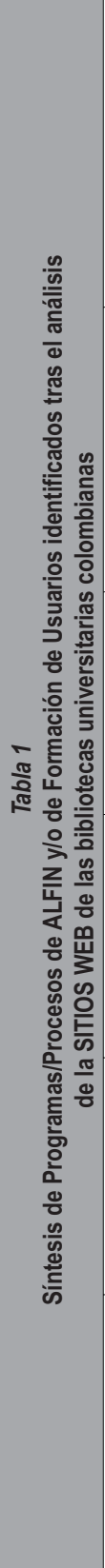 } & 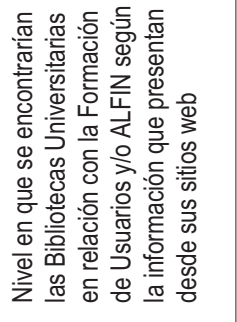 & 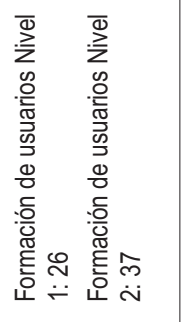 & 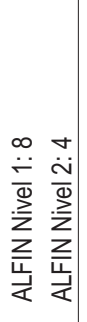 & \multirow{6}{*}{ 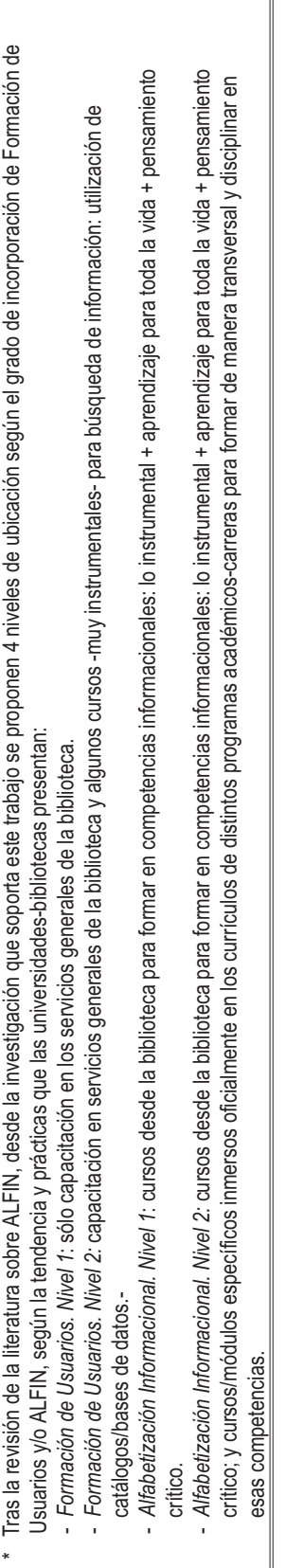 } \\
\hline & 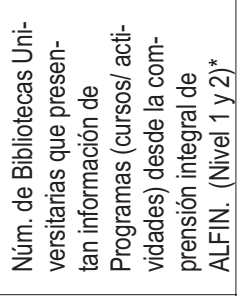 & & 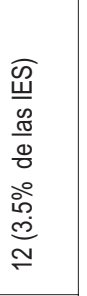 & \\
\hline & 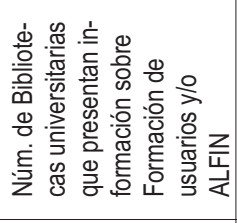 & 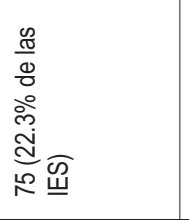 & & \\
\hline & 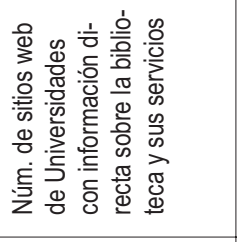 & 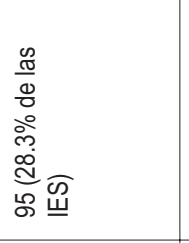 & & \\
\hline & 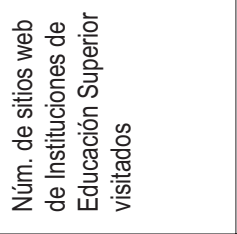 & 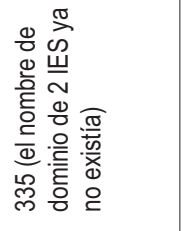 & & \\
\hline & 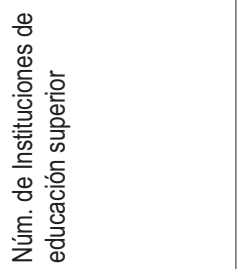 & 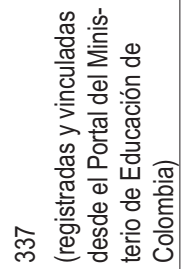 & & \\
\hline
\end{tabular}


- Pontificia Universidad Javeriana-Cali. ${ }^{17}$

- Universidad ICESI-Cali. ${ }^{18}$

- Universidad del Tolima-Ibagué. ${ }^{19}$

- Universidad del Norte-Barranquilla. ${ }^{20}$

- Universidad de Manizales-Manizales. ${ }^{21}$

- Universidad Nacional de Colombia-Palmira. ${ }^{22}$

En el caso de las bibliotecas públicas tras la consulta del directorio específico para esta tipología de bibliotecas, se encontró que únicamente las bibliotecas principales ubicadas en las grandes ciudades (Bogotá, Medellín, Cali, Barranquilla) contaban con sitio web propio.

De estas, solo la red de bibliotecas del Banco de la República y su sede principal la Biblioteca Luis Ángel Arango, ${ }^{23}$, la Red de bibliotecas y parques-bibliotecas de Medellín y Área Metropolitana ${ }^{24}$ y la Red de Bibliotecas de Bogotá-BIBLIORED ${ }^{25}$ presentaban información refe-

17 http://www.javerianacali.edu.co/Paginas/Servicios/ Biblioteca/Biblioteca_Index.aspx .

18 http://www.icesi.edu.co/biblioteca/servicios_formacion_ usuarios.php .

19 http://desarrollo.ut.edu.co/tolima/hermesoft/ portal/home_5/htm/cont0.jsp?rec=not_15843.jsp .

20 http://www.uninorte.edu.co/biblioteca/secciones.asp? $\mathrm{id}=35$.

21 http://umanizales.edu.co/ biblio/induccion.htm .

22 http://www.virtual.unal.edu.co/unvPortal/courses/CoursesViewer.do? reqCode $=$ view OfFacultys .

23 http://www.banrepcultural.org/actividadeseducativas.htm

24 http://www.reddebibliotecas.org.co/sites/Bibliotecas/ Paginas/Bibliotecas.aspx 
Estado del arte de la Alfabetización Informacional en ...

rente a aspectos formativos, pero centrados principalmente en el Nivel 2 de formación de usuarios (las bibliotecas pertenecientes a las dos primeras) o iniciando acciones para alcanzar el Nivel 1 de ALFIN (el caso de Bibliored).

En el caso de las bibliotecas de Cajas de Compensación Familiar (mixtas), con una situación semejante a las bibliotecas públicas, se encontraron desarrollos centrados en los Niveles de formación de usuarios, y se destacaron en el nivel 2, más próximo a ALFIN, los procesos formativos de las bibliotecas pertenecientes a: COMFENALCO-Medellín, ${ }^{26}$ COMFAMA-Medellín, ${ }^{27}$ COMFAMILIAR-Barranquilla ${ }^{28}$ y COLSUBSIDIO-Bogotá. ${ }^{29}$

No obstante, en el caso de estas bibliotecas de tipo mixto (público-privadas) se destacan los programas de formación que desde el Servicio de Información Local de COMFENALCO se han realizado con una perspectiva más de ALFIN considerando las competencias informa-

25 http://www.biblored.org.co/es/programas/formacionusuarios.

26 http://www.comfenalcoantioquia.com/bibliotecas/ InicioBibliotecas/tabid/1565/Default.aspx .

27 http://www.comfama.com/contenidos/servicios/Bibliotecas/ Bibliotecas.asp .

28 http://www.comfamiliar.co/opencms/opencms/comfamiliar/ Servicios/CCultural/Portafolio/servicios-bibliotecarios.html.

29 http://www.colsubsidio.com/porta_serv/educacion/ bibliotecas3.html . 
cionales para la gestión de información (de trámites gubernamentales y de empleo) para los ciudadanos. ${ }^{30}$

En definitiva, tanto en el caso de las bibliotecas públicas y de Cajas de Compensación Familiar desde el análisis de sus sitios web, es evidente aún la concepción y preocupación más por la alfabetización digital-informática que por la informacional, que aunque necesaria y paso previo y complementario, se queda corta considerando la necesidad de formación para toda la vida, pensamiento crítico y cumplimiento del derecho universal de acceso a la información que conlleva la alfabetización informacional.

En el caso de las bibliotecas escolares la situación de esta tipología de bibliotecas en el país es muy poco desarrollada, ya que en las instituciones de educación primaria y secundaria pertenecientes al sector estatal, las bibliotecas públicas, desde el Plan Nacional de Lectura y Bibliotecas, ${ }^{31}$ han centrado todos los esfuerzos en la creación y dotación de éstas, y deja que sean ellas (las bibliotecas públicas), las que cubran las necesidades escolares.

En las instituciones de educación primaria y secundaria de tipo privado, la realidad de las bibliotecas tampoco tiene grandes desarrollos, pues sólo se destacan algunas instituciones que han asumido la perspectiva de CREA (Centro de Recursos para la Enseñanza y el Aprendizaje), pero en la mayoría de los casos son biblio-

30 http://www.conexionciudad.com/Programas/tabid/235/ language/es-ES/Default.aspx .

31 http://www.bibliotecanacional.gov.co/?idcategoria $=27535$. 
Estado del arte de la Alfabetización Informacional en ...

tecas tradicionales cuando éstas existen, o se ha asumido que las bibliotecas personales (de cada familia + Internet) o las salas de informática de la institución cubren las necesidades de información, aunque con muy poca o nula formación en alfabetización informacional.

Sin embargo es necesario destacar a nivel escolar un caso particular en el país, y es el de las instituciones escolares que han sido asesoradas y tenido espacios de formación, especialmente en la región del Valle del Cauca (Cali), gracias al trabajo de la Fundación Gabriel Piedrahita Uribe que ha desarrollado el Modelo GAVILÁN. ${ }^{32}$

\section{Entrevistas-Formación-Observación participante}

Continuando con el interés de lograr desde diferentes estrategias (métodos/técnicas e instrumentos) la triangulación de información sobre esta temática, se aprovecharon diferentes espacios y medios para conocer más el desarrollo de Colombia desde diferentes niveles educativos y tipologías de bibliotecas relacionadas con la alfabetización informacional.

En este sentido, por un lado, se utilizaron las entrevistas semi-estructuradas para conocer la situación de algunas de las principales universidades del país:

- Universidad de Antioquia

- Universidad del Rosario-Bogotá

- Universidad de La Sabana-Bogotá

- Pontificia Universidad Javeriana Bogotá

32 http://www.eduteka.org/modulos/1/258 . 
- Universidad de los Andes-Bogotá

- Universidad ICESI-Cali

- Universidad Nacional de Colombia-Palmira

Esto permitió confirmar la situación de los desarrollos en ALFIN que desde los sitios Web de estas instituciones se informaba, y que las ubicaba en un Nivel de desarrollo 1 y 2 en ALFIN.

Además, aprovechando la organización de diferentes espacios de formación en esta temática, se tuvo la oportunidad de conocer la situación de conocimientos, habilidades y actitudes (competencias) por parte de los profesionales de la información que estaba a cargo de bibliotecas y servicios en bibliotecas universitarias, públicas y de Cajas de Compensación en relación con la ALFIN, y observar participativamente, en el campo, el desarrollo de sus programas de formación:

- Taller: "La alfabetización informacional desde las bibliotecas” BiblioTic 2010 (Bibliotecas universitarias y públicas de Colombia),

- Taller: "Competencias Informacionales para el Aprendizaje" (bibliotecas sedes Universidad Nacional de Colombia: Bogotá, Medellín, Manizales, Palmira, Amazonía, San Andrés),

- Conferencia-Taller: "La Alfabetización informacional al servicio de las Bibliotecas" (Bibliotecas universitarias, públicas y de Cajas de Compensación de Colombia),

- Conferencia-Taller: "Impacto de las nuevas tecnologías en el mundo. Realidades, Retos y Perspectivas para las Bibliotecas" (Bibliotecas Cajas de Compensación de Colombia) y 
Estado del arte de la Alfabetización Informacional en ...

- Taller: El benchmarking, una estrategia clave para diseñar Programas-Proyectos de Formación en Competencias Informacionales-Alfabetización Informacional (Bibliotecas universitarias y públicas de Colombia).

Estas dos estrategias permitieron identificar y reconfirmar la situación de las bibliotecas universitarias que sí tienen adelantos en ALFIN, la carencia de programas y proyectos en la gran mayoría de bibliotecas del país, y el mayor énfasis que existe en la formación en lo digital-informático que en la de lo informacional.

A su vez quedó claro que la formación de los profesionales de la información en esta temática es muy poca, ya que en los casos de egresados de antes del 2005 en las cuatro Facultades/Escuelas/ Departamentos que ofrecen formación bibliotecológica en el país (Escuela Interamericana de Bibliotecología Universidad de Antioquia-Medellín, ${ }^{33}$ Departamento de Ciencia de la Información Pontificia Universidad Javeriana-Bogotá, ${ }^{34}$ Departamento de Sistemas de Información y Documentación Universidad de La Salle-Bogotá ${ }^{35}$ y Universidad del Quindío -a distancia-) el tema de la formación,

33 http://formacionbiblioteca.udea.edu.co/moodle/course/view. php?id=97 y http://aprendeenlinea.udea.edu.co/lms/moodle/ course/category.php?id $=16$

34 http://www.alfintic.tk/-http://www.javeriana.edu.co/cyl/ website/dep ciencias infor/serv acad.htm

$35 \mathrm{http}: / /$ sisinfo.lasalle.edu.co/index.php?option = com_content $\&$ task $=$ view $\&$ id $=217 \&$ Itemid $=230$ 
las tecnologías y su interrelación en la ALFIN no estaba muy presente en sus currículos, ya que sólo a partir de los últimos años se han iniciado procesos de transformación curricular, que en las tres primeras universidades, con varias asignaturas obligatorias y electivas (entre dos y tres) han ido incorporando aspectos relacionados con la ALFIN, pero dichos estudiantes sólo están recientemente egresando, por lo que el impacto de esta formación en las distintas tipologías de bibliotecas apenas está empezando a notarse. ${ }^{36}$

Transformación curricular que tiene interrelación con el hecho de que esta temática sólo en este último quinquenio ha comenzado a tener presencia como tal y como línea de investigación, reflejadas en diferentes proyectos.

A este respecto consultando los sitios web de las cuatro Facultades/Escuelas/Departamentos que ofrecen formación bibliotecológica, y además el Sistema de Información de Grupos e Investigaciones de Colombia (COLCIENCIAS-Plataforma SCIENTI-Colombia), ${ }^{37}$ se ubica que es en la Universidad de Antioquia (Grupo Información, Conocimiento y Sociedad $)^{38}$ y la Pontificia Universidad Javeriana-Bogotá en asociación con la Universidad Industrial de Santander (Grupo Aprendizaje y So-

36 http://www.biblored.org.co/files/programacionweb.pdf

37 http://www.colciencias.gov.co/scienti/

38 http://201.234.78.173:8080/gruplac/jsp/visualiza/visualizagr. jsp?nro $=00000000008625$. 
Estado del arte de la Alfabetización Informacional en ...

ciedad de la Información) ${ }^{39}$ en donde se están dando en forma directa desarrollos y aportes teórico-conceptual y aplicados desde la investigación, referentes a la Alfabetización Informacional, las Competencias Informacionales y/o la Formación de Usuarios, pues a este respecto no hay entre estos grupos y sus investigadores acuerdos terminológicos.

A su vez, fue posible identificar otros grupos de investigación, ${ }^{40}$ que aunque con una tendencia aún más marcada hacia la alfabetización digital-informática y a la incorporación y apropiación de las TIC y los recursos de información para el aprendizaje y el e-learning, trabajaban en forma indirecta relacionados con la ALFIN desde la definición-descripción amplia que este trabajo propone sobre alfabetización informacional.

\section{Encuestas virtuales}

Considerando la estrategia seguida en este trabajo, se generaron dos tipos de espacios para la consulta sobre los desarrollos de programas y proyectos de ALFIN, las bibliotecas universitarias públicas, y las Cajas de Compensación Familiar de Colombia.

39 http://201.234.78.173:8080/gruplac/jsp/visualiza/visualizagr. jsp?nro $=00000000001836$.

40 Ver otros grupos con trabajos indirectos: http:alfincolombia. blogspot.com/2009/10/grupos-de-investigacion-colombianosque.html. 
Así, aprovechando los eventos formativos mencionados anteriormente, se consultó (diagnóstico previo-de entrada) a sus participantes sobre su nivel de formación y experiencia(s) como profesionales en la temática de la alfabetización informacional y la realidad de la incorporación de este servicio fundamental y transversal en sus respectivas bibliotecas, ${ }^{41}$ teniendo la participación de 50 profesionales de la información de distintas ciudades de Colombia vinculados a diferentes tipologías de bibliotecas. En este caso, sus respuestas confirmaron los bajos niveles de formación en esta temática y el inicio, en la mayoría de las bibliotecas, de procesos para pasar de los tradicionales programas de formación de usuarios, a programas de alfabetización informacional de formación en competencias informacionales para el aprendizaje a lo largo de la vida.

Por otra parte, al centrarse en la realidad de las bibliotecas universitarias, ${ }^{42}$ se tuvo una consulta en la que participaron 82 instituciones de educación superior de Colombia, en la que se obtuvieron los siguientes resultados, que evidencian la situación de desarrollo de ALFIN a nivel 1 y 2 de algunas bibliotecas, y el deseo de iniciar estos procesos en un buen porcentaje de las restantes, y la ausencia (preocupante) de formación en cualquier nivel.

41 Ver cuestionario: http://www.surveymonkey.com/s/ MCCQ8KD.

42 Ver cuestionario: http://www.surveymonkey.com/s/ ALFIN-LeccionesAprendidas. 


\section{Figura 1}

Pregunta 3. Universidades colombianas.

Presencia o no de Programa de F.U. y/o ALFIN

Si se entiende por:

Formación de Usuarios "a la capacitación para el uso de los servicios de información que ofrece la Biblioteca / Facultad-Escuela-Instituto"

- Alfabetización Informacional "a la formación en competencias -conocimientos, habilidades y actitudes para buscar, recuperar, organizar, utilizar, divulgar y reelaborar la información de interés en diferentes formatos, fuentes y servicios (internos y externos) para generar nuevo conocimiento y pensamiento critico, mediante cursos desde la biblioteca y/o como temáticas permanentes inmersas en cursos y/o actividades curriculares especificas de distintos programas académicos-carreras"

Considera que actualmente la labor formativa que dicha Biblioteca / Facultad-Escuela-Instituto ofrece a sus usuarios se orienta más a cuál(es) tendencia(s):

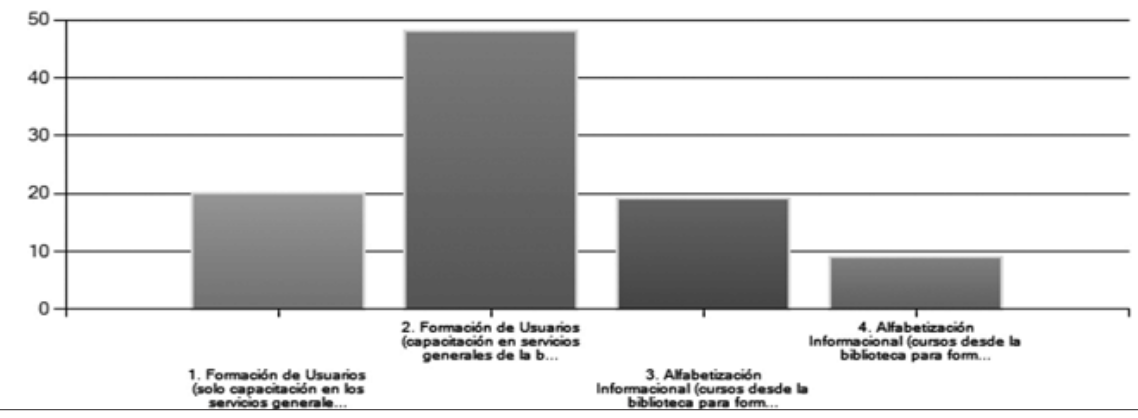

Figura 2

Pregunta 4a. Universidades colombianas. Nombre del Programa de formación.

Capacitacion de Usuarios Capacitaciones Especializadas

Taller Formación de Usuarios

Taller de familiarización con la gestión de iniciativas de Alfabetización Informacional Introducción a la Alfabetización Informacional Competencias en eluso de la información Capacitación en estrategias de búsqueda de información Alfabetización informacional y capacitación a usuarios

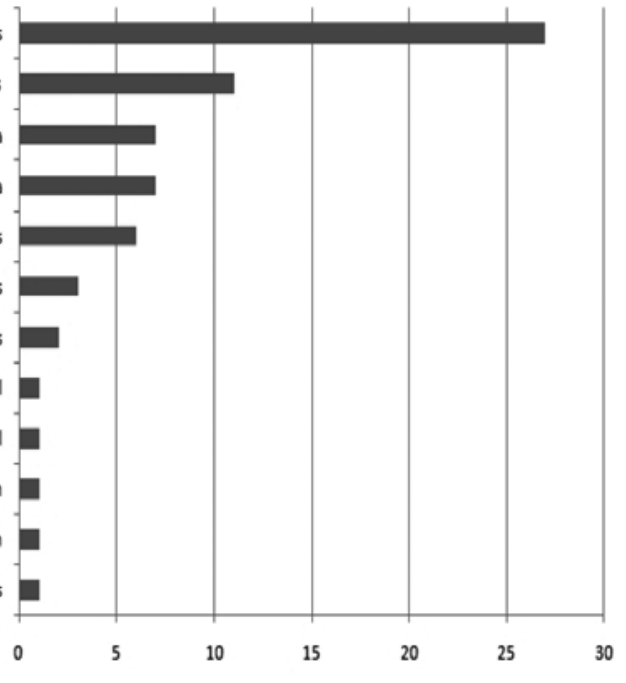


Figura 3

Pregunta 4b. Universidades colombianas. Año de creación del Programa de formación

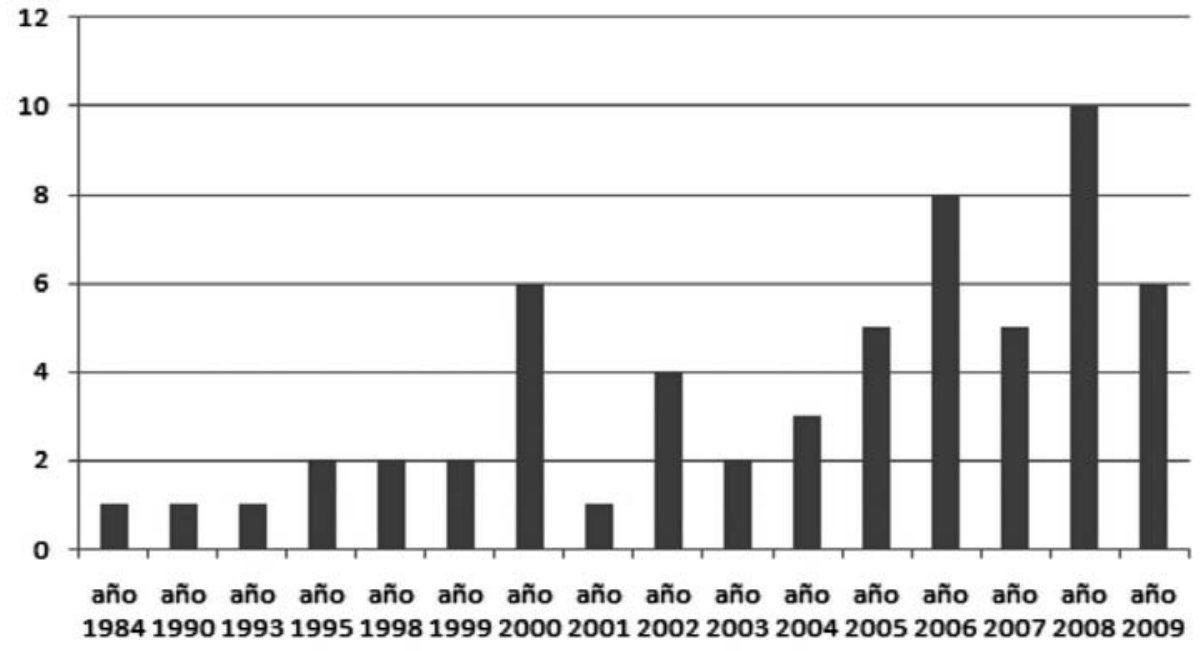

\section{Figura 4}

Pregunta 5. Universidades colombianas. Información y recursos web del Programa de Formación

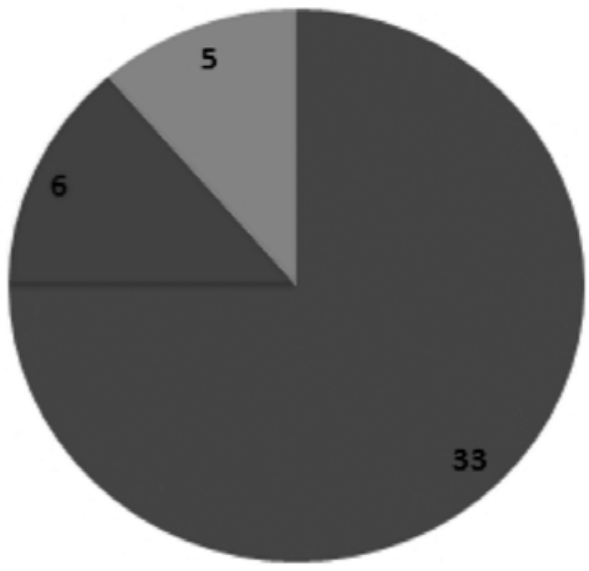

Sitio web del Programa

Sitio Web Plataforma

Sitio Web 2.0 


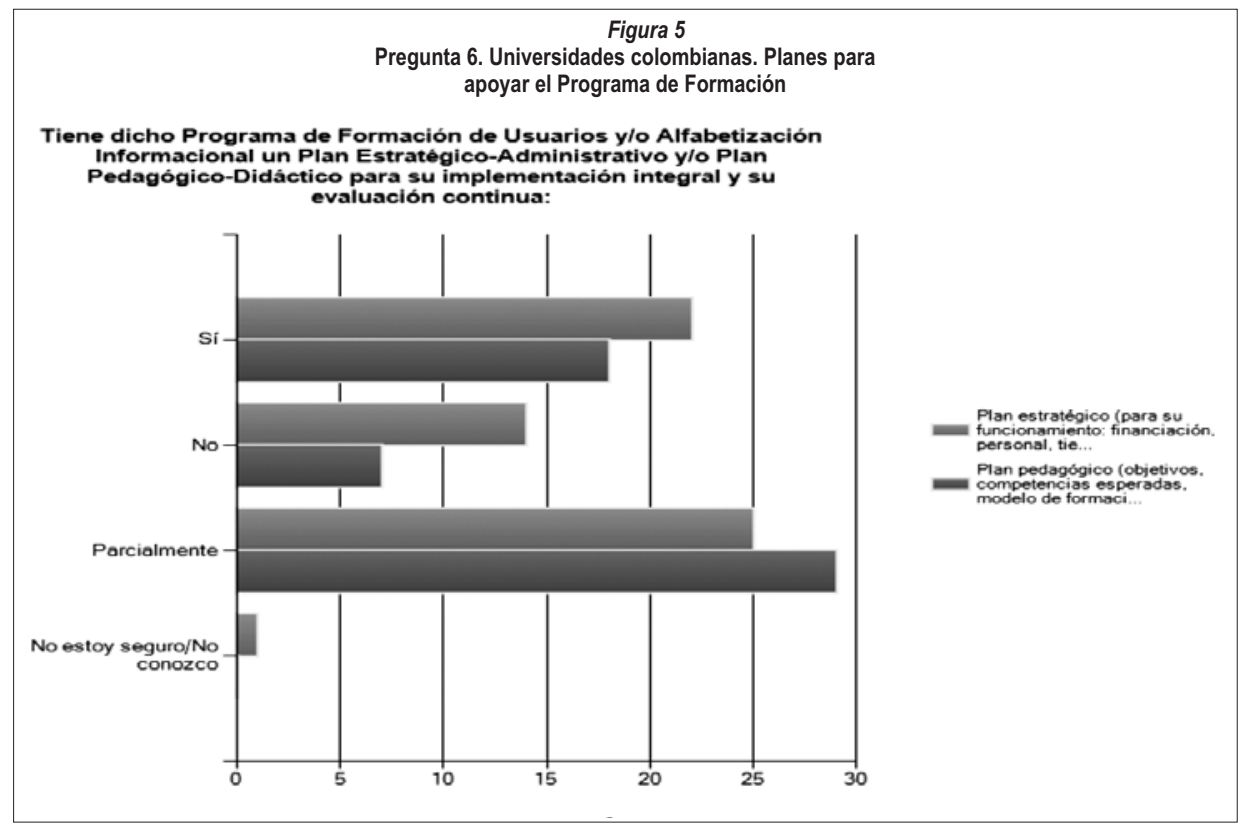

Figura 6

Pregunta 7. Universidades colombianas. Año de implementación de Planes para apoyar el Programa de Formación

Si su respuesta anterior (No. 5) es Sí o PARCIALMENTE. Desde qué periodo aproximadamente se estaría realizando ese Plan:

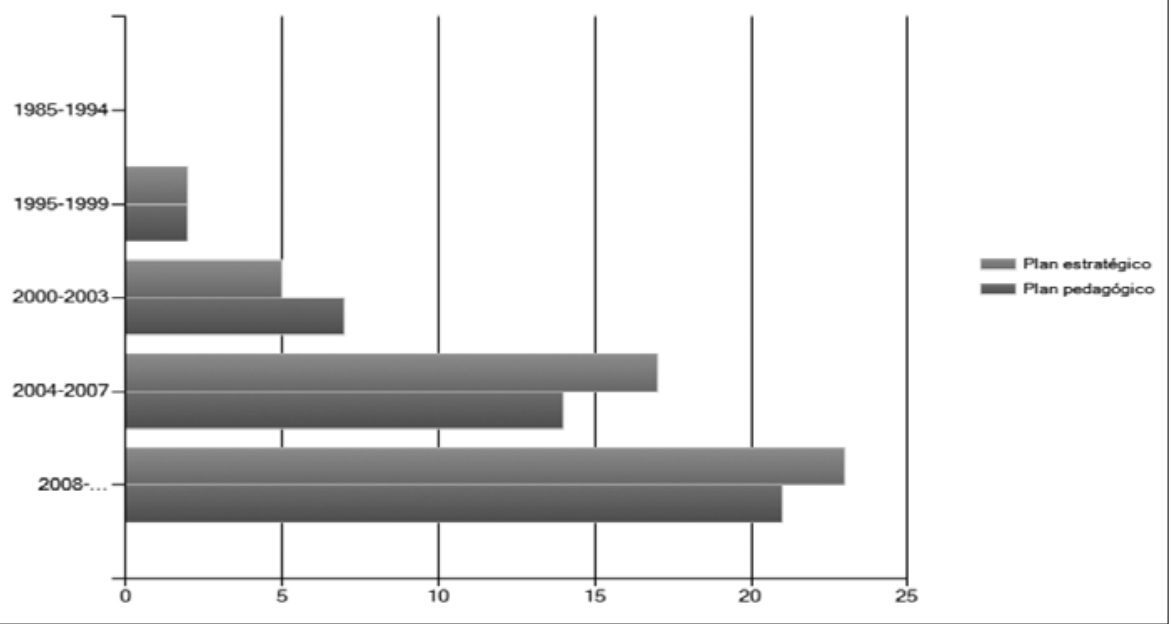


Figura 7

Pregunta 8. Universidades colombianas.

Cursos/Actividades que constituían
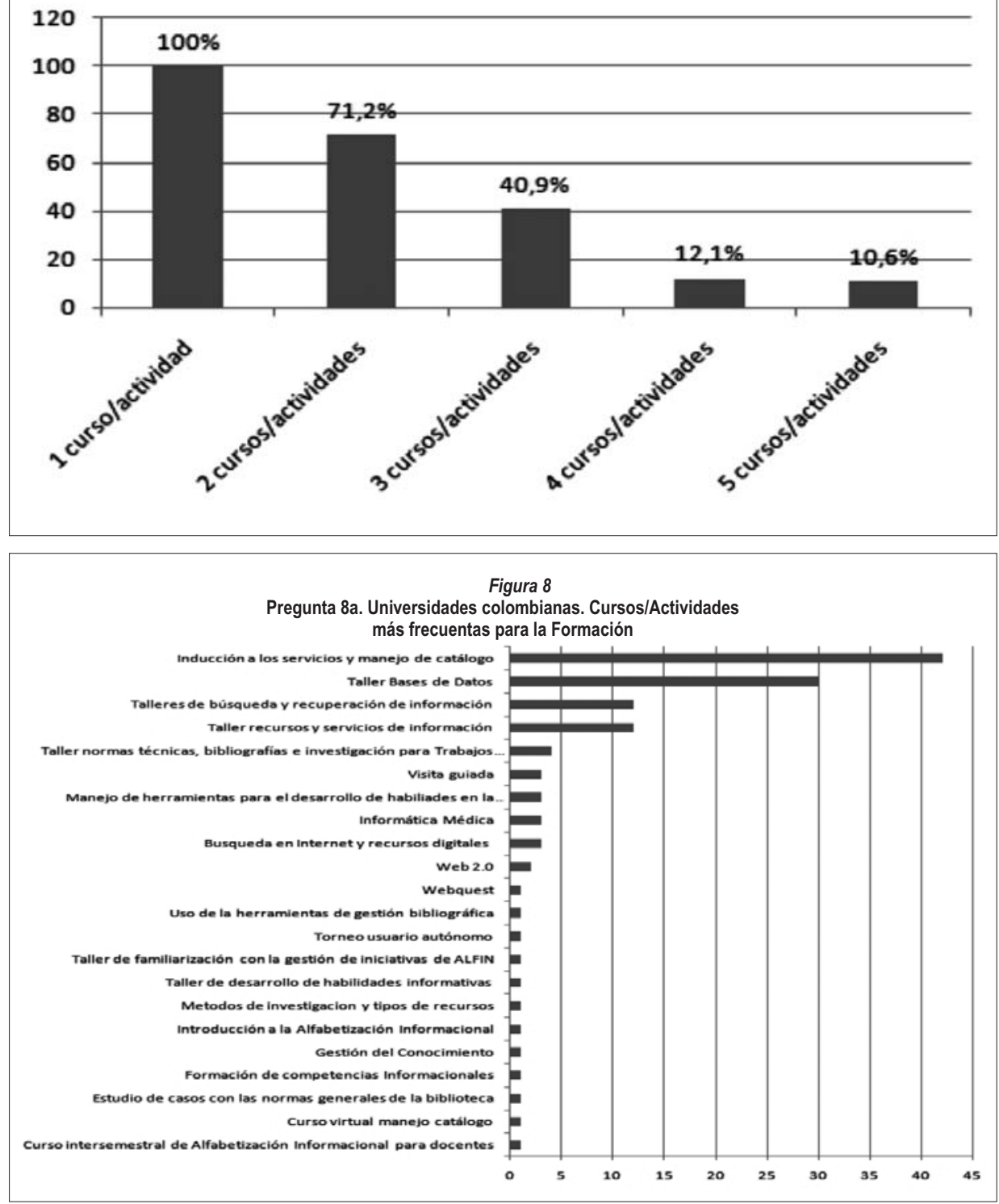


\section{Figura 9}

Pregunta 8b. Universidades colombianas. Públicos a los que se dirige la Formación

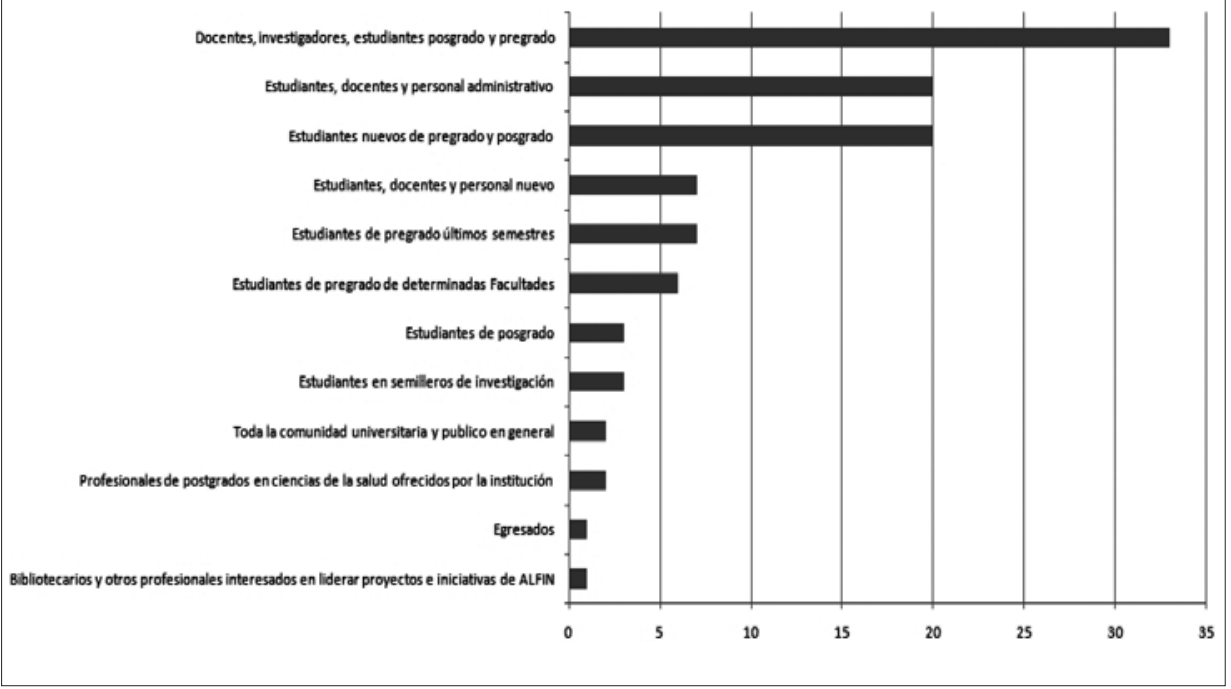

Figura 10

Pregunta 8c. Universidades colombianas.

Promedio de horas de formación

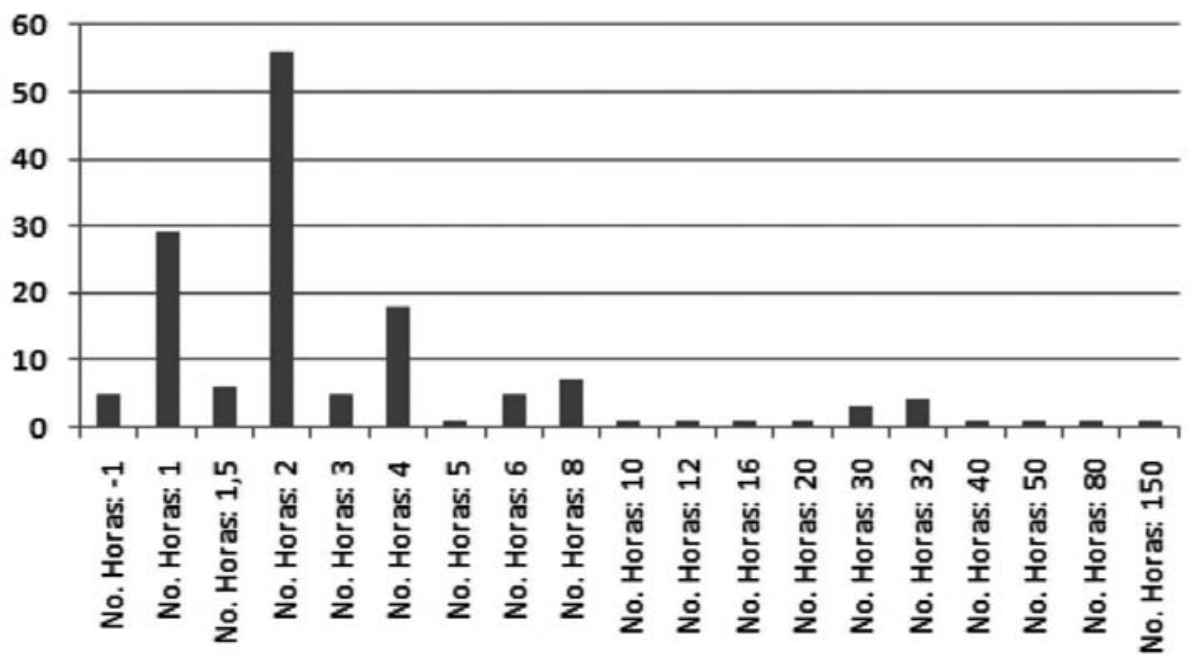


Figura 11

Pregunta 8d. Universidades colombianas.

Última actividad de Formación

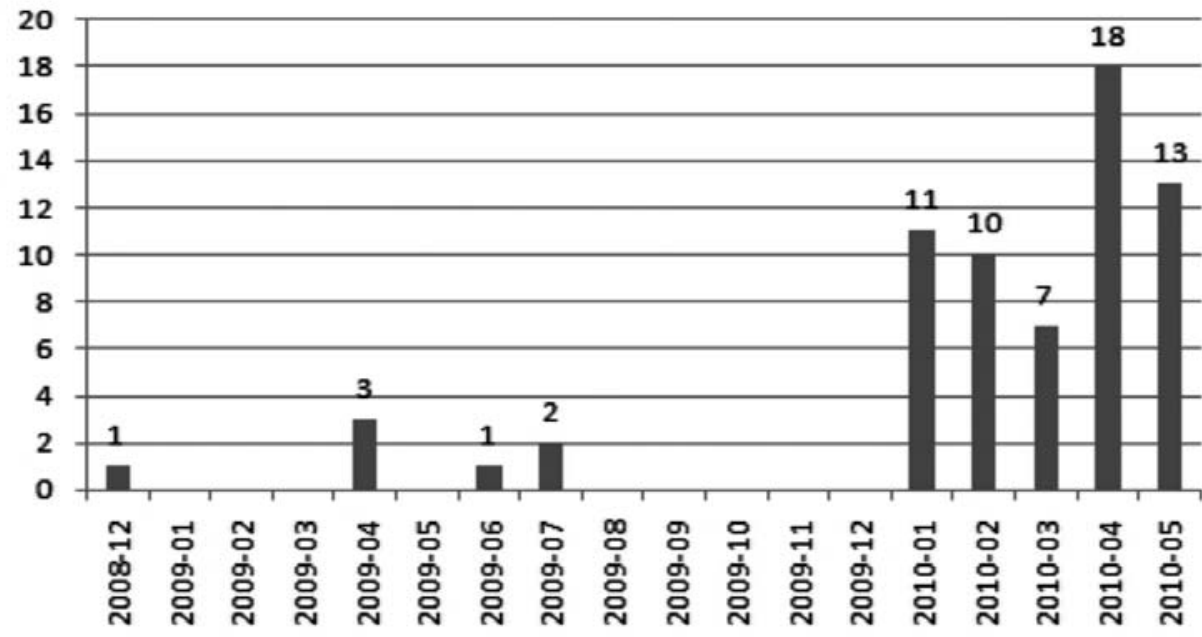

Figura 12

Pregunta 12. Universidades colombianas: Auto-evaluación

de niveles de desarrollo de F.U. y/o ALFIN

Si se entiende por:

- Formación de Usuarios "a la capacitación para el uso de los servicios de información que ofrece la Biblioteca / Facultad-Escuela-Instituto"

- Alfabetización Informacional "a la formación en competencias -conocimientos, habilidades y actitudes para buscar, recuperar, organizar, utilizar, divulgar y reelaborar la información de interés en diferentes formatos, fuentes y servicios (internos y externos) para generar nuevo conocimiento y pensamiento critico, mediante cursos desde la biblioteca y/o como temáticas permanentes inmersas en cursos y/o actividades curriculares especificas de distintos programas académicos-carreras"

Considera que actualmente la labor formativa que dicha Biblioteca / Facultad-Escuela-Instituto ofrece a sus usuarios se orienta más a cuál(es) tendencia(s):

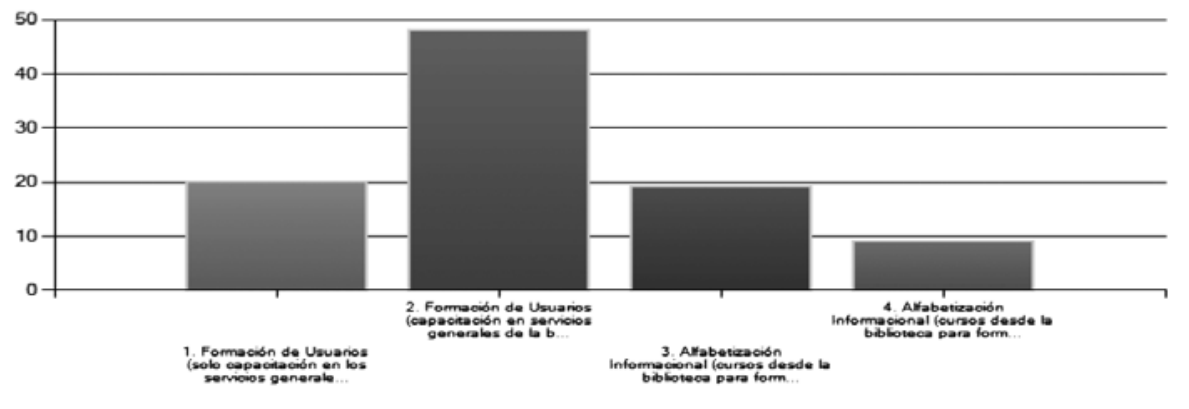


Estado del arte de la Alfabetización Informacional en ...

Conectando estos resultados con la estrategia de análisis de contenidos Web-Digital presentan informaciones de sumo interés para esta investigación, que podemos resumir en los siguientes puntos:

- La convocatoria a participar en esta encuesta virtual se hizo directamente vía e-mail a varias instancias de las 337 IES (Instituciones de Educación Superior) colombianas. Finalmente respondieron 83 instituciones $-25 \%-$, pero de éstas, 13 indicaron al llegar a la tercera pregunta (Figura 1) que no tenían ningún programa de formación, ni desde la perspectiva de Formación de Usuarios ni mucho menos desde la perspectiva de ALFIN. Quedaron así 70 instituciones, las cuales al auto-clasificarse en los cuatro niveles propuestos (Figura 12) nos indicaron que un $70 \%$ de ellas estaban en los niveles de Formación de Usuarios más que de Alfabetización Informacional, lo cual concuerda con resultados del análisis hecho a los sitios web (Tabla 1). Esta auto-clasificación, se validaba a su vez, al analizar los resultados de otras dos preguntas (figuras 2 y 8), donde las inducciones, las visitas guiadas, la capacitación en el uso del catálogo y en bases de datos de manera instrumental, como parte de un programa tradicional de Formación de Usuarios eran las prácticas mayoritariamente más comunes, e incluso en el hecho de que muchas de estas bibliotecas no tenían más de 2 cursos/actividades de formación (figuras 7, 8, 10 y 11).

- Aunque la Formación de Usuarios tradicional en las bibliotecas universitarias tiene una trayectoria de varias décadas, un porcentaje muy alto de las IES colom- 
bianas participantes, indicaron que su programa no tenía más de 5 años de desarrollo (figuras 3 y 6), ni presentaban estructuras de planeación, sobre todo pedagógicas (figuras 5 y 6), lo cual permite visualizar el atraso que habría en este tema, y lo cual también revalida algunos de los resultados ya presentados años atrás desde la investigación "Evolución y tendencias en la formación de usuarios en América Latina" (Naranjo Vélez et al, 2006). ${ }^{43}$

- Respecto a la posible calidad e innovación pedagógica de los Programas, el hecho de no haber, o no en forma completa, planes pedagógicos, ni uso extensivo de nuevas tecnologías para apoyar el aprendizaje (plataformas-Web 2.0), y de que eran escasas las horas de formación en promedio para apoyar la formación en esta temáticas (figuras 4, 5, 6, 8 y 9), evidencia que la formación de usuarios tradicional es la que persiste mayoritariamente en las bibliotecas universitarias colombianas, además que tal formación, no siempre se da en forma permanente-continua (Figura 12).

\section{ANÁLISIS Y CONCLUSIONES}

Tras la aplicación de las 4 estrategias de indagación mencionadas en el ítem anterior y los resultados particulares de cada una, es posible hacer una generalización que dé

43 http://bibliotecologia.udea.edu.co/formausuarios/parte1/55. htm. 
Estado del arte de la Alfabetización Informacional en ...

cuenta del estado actual de la alfabetización informacional en Colombia respondiendo a los siguientes puntos:

\section{Tendencias teóricas}

En este aspecto es necesario indicar que sólo los últimos 5 años se han comenzado a presentar aportes teórico-conceptuales basados en las labores de docencia e investigación que se desarrollan en forma particular en algunas de las Escuelas/Facultades donde se imparten estudios de bibliotecología, a nivel de pregrado y posgrado, apoyados y unidos a grupos de investigación.

En este aspecto es necesario destacar la labor de investigadores como Edilma Naranjo Vélez, Nora Elena Rendón, Gloria María Marciales Vivas y Alejandro Uribe Tirado, quienes son los que tienen una mayor producción académica-científica con propuestas concretas a nivel de modelos, niveles, definiciones ydescripciones sobre la ALFIN y sus distintas interrelaciones: con los usuarios, la tecnología, la pedagogía y didáctica, el e-learning, etcétera.

Sin embargo la continua labor de sólo estos investigadores y los grupos a los que pertenecen, evidencia que la alfabetización informacional es aún, como línea y proyecto de investigación, una temática incipiente en Colombia, que no está presente en las cuatro Escuelas/Facultades, y en otras disciplinas (grupos disciplinarios e interdisciplinarios), que se relacionarían con la ALFIN, por tener poco o nulo reconocimiento.

A su vez, teniendo en cuenta toda la producción ubicada respecto a: artículos y ponencias, libros, tesis, trabajos de grado, modelos, niveles y estándares, además de 
Tendencias de la Alfabetización Informativa en Iberoamérica

eventos; es notorio que esta producción ha estado viviendo un crecimiento -influenciada por eventos académico/investigativos concretos- que sin embargo refleja poco a poco importancia y concientización sobre esta temática que en determinadas bibliotecas, escuelas/facultades, universidades, etc. se está viviendo, aunque aún falta mucho por hacer, aprender y compartir, si consideramos todas las bibliotecas e instituciones educativas del contexto colombiano, y lo comparamos con los desarrollos de otros contextos iberoamericanos, y sobre todo, mundiales (Figura 13).

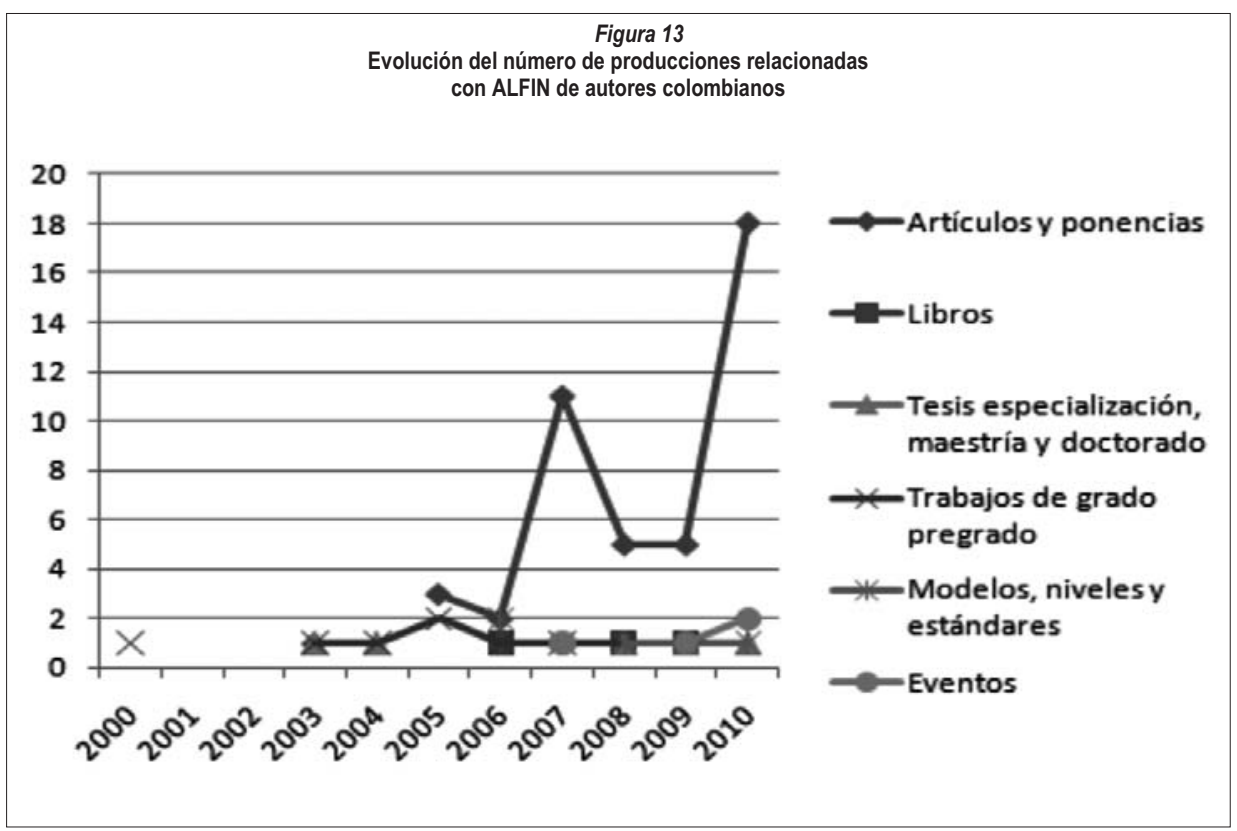


Estado del arte de la Alfabetización Informacional en ...

\section{Políticas estatales y/o nacionales}

Retomando los resultados de las 4 estrategias seguidas y adicionando a éstos el análisis de documentos fundamentales a nivel educativo y de bibliotecas en Colombia:

- Plan Decenal de Educación 2006-2016. ${ }^{44}$

- Plan Nacional de Lectura y Bibliotecas. ${ }^{45}$

- Ley Nacional de Bibliotecas. ${ }^{46}$

- Plan Nacional de Ciencia y Tecnología. ${ }^{47}$

- Plan Nacional de TIC 2008-2019. ${ }^{48}$

Resulta claro que en Colombia la formación en alfabetización informacional no es vista aún con claridad como una estrategia fundamental a nivel educativo, por las bibliotecas y la investigación.

Como se evidencia en dichos documentos, y en los pocos casos encontrados donde se está alcanzando niveles de ALFIN (1 ó 2), la preocupación sigue más encaminada hacia la infraestructura física, las colecciones, el equipamiento de tecnologías, la incorporación a las aulas y la generación de redes científicas pero no a un aspecto específico como a las competencias informacionales. Respecto de esta formación, el alcance y la concepción están muy determinadas por la preocupación de la alfabetización informacional desde la perspec-

44 http://www.plandecenal.edu.co/html/1726/w3-channel.html.

45 http://www.bibliotecanacional.gov.co/?idcategoria $=28574$.

46 http: $/ /$ www.mincultura.gov.co/?idcategoria $=29073$.

47 http://www.colciencias.gov.co/programas_estrategias.

48 http://www.colombiaplantic.org.co/. 
tiva de la brecha digital centrada en cuestiones de acceso-infraestructura que de la infoestructura (Uribe Tirado, 2007).

Esto implica la necesidad de jugar un papel divulgativo y proactivo por parte de las bibliotecas, docentes, investigadores, grupos y universidades que tienen adelantos a este respecto que implique ir ganando espacios para el posicionamiento y la discusión de esta temática como tema fundamental y transversal en la educación, los servicios bibliotecológicos y la investigación y generación de ciencia, de nuevos conocimientos que un país en "vías de desarrollo", como Colombia, debe afrontar cuanto antes.

\section{Programas y Niveles educativos}

Como se presentó en los resultados de las cuatro estrategias mencionadas, el mayor desarrollo se observa es en el caso de la educación superior y de las bibliotecas universitarias, si se compara con los programas y proyectos concretos de las bibliotecas públicas o escolares.

Sin embargo, aun en el caso de las bibliotecas universitarias, los programas y proyectos concretos de ALFIN son todavía muy pocos teniendo en cuenta que las instituciones categorizadas en el nivel 1 ó 2 de ALFIN, en el universo amplio de instituciones de educación superior colombianas, alcanzaría a ser de $3.5 \%$, porcentaje que en el caso de las bibliotecas públicas y escolares sería casi nulo hablando porcentualmente.

Esto implica la necesidad de generar diferentes estrategias, especialmente de divulgación y de hacer trabajo en red, que permitan el posicionamiento de esta temáti- 
Estado del arte de la Alfabetización Informacional en ...

ca, el aumento de la formación de los profesionales de la información, el reconocimiento de los impactos de los programas de ALFIN ya en proceso y la concientización de la importancia de las competencias informacionales, entre otros.

Es tomando en cuenta esta perspectiva que el inicio y desarrollo de los recursos Web 2.0, denominados ALFIN/ Colombia (http://alfincolombia.blogspot.com), se ha convertido en un potencializador de esas dos estrategias (divulgación y trabajo en red), al generar diferentes recursos para compartir información, dar a conocer lo que se está haciendo tanto a nivel local y nacional como internacional, y el proponer aportes a la Alfabetización Informacional desde el contexto colombiano, y un Iberoamericano (con los recursos Web ALFIN/Iberoamérica), ${ }^{49}$ lo cual durante el primer año de existencia de estos recursos (8 de septiembre de 2009 -Día Mundial de la Alfabetización-) ha sido reconocido por expertos de todo el mundo, ${ }^{50}$ Taller de formadores de ALFIN de UNESCO,${ }^{51}$ Sección de INFOLIT de IFLA, ${ }^{52}$ entre otros.

Es por ello que este trabajo quiere finalizar indicando que en el tema de la alfabetización informacional, Colombia, como un todo, tiene aún un desarrollo incipien-

49 http://alfiniberoamerica.blogspot.com.

50 http://information-literacy.blogspot.com/search/label/ Colombia.

51 http://medina-psicologia.ugr.es/biblioteca/course/view.php? $\mathrm{id}=3$.

52 http://www.ifla.org/files/information-literacy/newsletters/ february-2010.pdf . 
te, pero desde ese desarrollo incipiente hay personas, propuestas e instituciones que están realizando una labor destacada y en crecimiento que es necesario e importante compartir en el contexto nacional, para apoyar el impulso de ALFIN en el país, pero a su vez, valorando lo propio, ser aporte a otros profesionales, países y contextos, al movimiento ALFIN-INFOLIT (information literacy) a nivel mundial.

\section{REFERENCIAS BIBLIOGRÁFICAS}

Andréu, J. (2000), Las técnicas de análisis de contenido; una revisión actualizada, Centro de Estudios Andaluces. http://public.centrodeestudiosandaluces.es/pdfs/S20010 3.pdf, (consultado: febrero 1 de 2010).

Castaño Muñoz, W.; Uribe Tirado, A. (2008), La formación en competencias tecnológicas e informacionales de futuros bibliotecólogos aprovechando la plataforma educativa Moodle: caso Escuela Interamericana de Bibliotecología Universidad de Antioquia 2007-2008, X Congreso Nacional de Bibliotecología y Ciencias de la Información, Bogotá, (Colombia), http://eprints.rclis.org/15197/, (Consultado : junio 15 de 2009).

Cortés, J.; Lau, J. (2000), Desarrollo de Habilidades Informativas en Instituciones de Educación Superior, México: UACJ, 132p.

Gómez Hernández, J.A. (2007), “Alfabetización informacional: cuestiones básicas", en Anuario ThinkEPI, pp. 43-50, http://www.thinkepi.net/alfabetizacion-informacionalcuestiones-basicas, (consultado: septiembre 22 de 2009). 
Estado del arte de la Alfabetización Informacional en ...

Herring, S.C. (2010), "Web content analysis: Expanding the paradigm", en J. Hunsinger, M. Allen, \& L. Klastrup (Eds.), The International Handbook of Internet Research (pp. 233-249), Berlín: Springer Verlag, Preprint: http: //ella.slis.indiana.edu/ herring/ webca.2008.pdf, (consultado: febrero 1 de 2010).

Marzal, M.A. (2008), "Evolución conceptual de la alfabetización en información a partir de la alfabetización múltiple en su perspectiva educativa y bibliotecaria", en Investigación Bibliotecológica: archivonomía, bibliotecología e información, (CUIB-México). No. 47.

McMillan, S. J. (2000), “The Microscope and the Moving Target: The Challenge of Applying Content Analysis to The World Wide Web", en Journalism and Mass Communication Quarterly, 77(1): 80-98.

Naranjo Vélez, E. (2003), "Formación de usuarios de la Información y procesos formativos: hacia una conceptuación", en Investigación Bibliotecológica, UNAM-México. 18, p. $33-60$.

Naranjo Vélez, E. et. al. (2006), Evolución y Tendencias de la Formación de Usuarios en un Contexto Latinoamericano, Medellín: CICINF-EIB, Universidad de Antioquia, 256 p.

Naranjo Vélez, E. et. al. (2009), MUFUS-Modelo de formación de usuarios de la información, Medellín: CICINF-EIB Universidad de Antioquia, $148 \mathrm{p}$.

Pinto, M.; Cordon, J.A.; Gómez. R. (2010), “Thirty years of Information Literacy (1977-2007): a terminological, conceptual and statistical analysis”, en JOLIS, 42:1 3-19. 
Piñuel, J.L. (2002), "Epistemología, metodología y técnicas del análisis de contenido", en Estudios de Sociolingüística 3(1), 2002, pp. 1-42, http://web.jet.es/pinuel.raigada/ A.Contenido.pdf, (consultado: febrero 1 de 2010).

Porta, L.; Silva, M. (2003), La investigación cualitativa: El Análisis de Contenido en la investigación educativa, Red Nacional Argentina de Documentación e Información Educativa, http://www.uccor.edu.ar/paginas/REDUC/ porta.pdf, (consultado: febrero 1 de 2010).

Rendón Giraldo, N.; Naranjo Vélez, E.; Giraldo Arredondo, C. (2005), "Evolución y tendencias de la formación de usuarios en un contexto latinoamericano: resultados de la investigación", en Revista Interamericana de Bibliotecología, vol.28, n.2, pp. 43-86, http://www.scielo.org.co/ $\mathrm{pdf} / \mathrm{rib} / \mathrm{v} 28 \mathrm{n} 2 / \mathrm{v} 28 \mathrm{n} 2$ a03.pdf, (consultado: diciembre 5 de 2009).

Strijbos, J. W., Martens, R. L., Prins, F. J., \& Jochems, W. M. G. (2006), "Content analysis: What are they talking about?", en Computers and Education, 46, 29-48.

Uribe Tirado, A. (2005), "La alfabetización informacional, un prerrequisito y campo de acción para la e-inclusión y la gestión del conocimiento en red en las universidades", en XII Congreso Internacional de Educación Electrónica, Virtual y a Distancia TELEDUMED. http://eprints.rclis.org/ 15064/, (consultado: diciembre 15 de 2009).

Uribe Tirado, A. (2007), "La brecha digital, no solo conectividad. La Socio, Info e Infraestructura Informacional una triada necesaria para los análisis en la sociedad de la información”, en THINKepi, http://eprints.rclis.org/8563/, (consultado: diciembre 15 de 2009). 
Estado del arte de la Alfabetización Informacional en ...

Uribe Tirado, A. (2008), Diseño e implementación y evaluación de una propuesta formativa en alfabetización informacional mediante un ambiente virtual de aprendizaje a nivel universitario: caso Escuela Interamericana de Bibliotecología, Universidad de Antioquía, Maestría en Ingeniería, Línea Informática Educativa, Universidad EAFIT (Colombia).

Uribe Tirado, A. (2009), "El conocimiento y reconocimiento de los modelos de comportamiento informacional.Un aspecto necesario para los servicios de información Web 2.0 y la Alfabetización Informacional-DHI desde las bibliotecas”, en Memorias XVI Coloquio Internacional de Bibliotecarios, Guadalajara, México, Feria Internacional del Libro FIL.

Uribe Tirado A. (2009), "Interrelaciones entre veinte definiciones-descripciones del concepto de alfabetización informacional: propuesta de macro-definición”, en Acimed. 20(4), http://bvs.sld.cu/revistas/aci/vol20_4_09/aci0110 09.htm, (consultado: noviembre 13 de 2009).

Uribe Tirado, A. (2010), "La Alfabetización Informacional en la Universidad. Descripción y Categorización según los Niveles de Integración de ALFIN. Caso Universidad de Antioquia”, en Revista Internamericana de Bibliotecología. Vol. 33 Núm. 1, enero-junio de 2010.

Uribe Tirado, A. (2010), "Avances y perspectivas de ALFIN en Iberoamérica. Una mirada desde la publicación académico-científica y la web 1.0 y 2.0", en Congreso INFO 2010, Cuba, http://eprints.rclis.org/18597/, (consultado: junio 1 de 2010). 
Tendencias de la Alfabetización Informativa en Iberoamérica

Uribe Tirado, A. (2010), "El proyecto INFOLIT Global y su importancia para las instituciones bibliotecarias y educativas de Colombia para la enseñanza-aprendizaje de competencias informacionales/Alfabetización Informacional", en Segundo Encuentro de Bibliotecas y Tecnologías de la Información y la Comunicación, BIBLIOTIC-Medellín 2010, http://www.bibliotic.info/, (consultado: junio 1 de 2010).

Velez Restrepo, O.L.; Galeano Marín, M.E. (2002), Investigación cualitativa, Estado del arte, Universidad de Antioquia.

Weare, C.; Lin, W.-Y. (2000), "Content analysis of the World Wide Web: Opportunities and challenges”, en Social Science Computer Revierw, 18(3): 272-292. 


\title{
La Alfabetización en Información: una necesidad desde la educación primaria
}

\author{
ANA MARÍA REUSCH HEVIA \\ Universidad de Playa Ancha, Chile
}

\section{INTRODUCCIÓN}

E

1 siglo XXI demanda para la escuela, más allá de la alfabetización tradicional que ha sido hasta ahora una de sus funciones fundamentales, otras competencias básicas, muchas de las cuales tienen relación directa con la información disponible. Junto a la lectoescritura están, por ejemplo, las siguientes: el desarrollo del habla y la escucha; la búsqueda y el análisis; la resolución de problemas; el pensamiento crítico, y la capacidad de encontrar información, seleccionarla y ser capaz de utilizarla de manera apropiada, entre otras.

Si bien desde hace ya bastantes años se viene hablando de la necesidad de aprender a aprender, hoy más que nunca ello cobra vigencia y se convierte en un imperativo para la educación, tal como lo manifiesta la UNESCO cuando plantea las características de la educación para el 2010, el aprendizaje debiera ser un proceso continuo, 
flexible e innovador, que fomente el desarrollo de habilidades y capacidades.

La Alfabetización en Información (ALFIN) aparece entonces como una respuesta a las nuevas concepciones pedagógicas del siglo XXI y al aprendizaje durante toda la vida, aparejada al desarrollo de las nuevas tecnologías de la información y las comunicaciones (TIC). Una alfabetización que es vista como la capacidad de las personas para acceder, evaluar y usar la información efectiva y éticamente, en un mundo donde la información es creciente, compleja y en la mayoría de los casos está muy dispersa.

Es precisamente en el ámbito de la educación donde se evidencian las continuas dificultades con que se encuentran profesores y estudiantes para acceder a la información debido al gran desarrollo de los recursos y a la poca estructuración de éstos; en ocasiones no saben que hacer frente a este nuevo abanico de posibilidades. De allí la necesidad de plantear estrategias que les permitan ser autosuficientes en los procesos de aprendizaje, y aprender habilidades y competencias para localizar, evaluar y utilizar la información que necesitan, desde los primeros niveles educativos.

Parece necesario adaptarse al nuevo entorno de la sociedad de la información y del conocimiento, cambiando el enfoque del aprendizaje memorístico por el de un aprendizaje significativo, basado en el desarrollo de habilidades múltiples. Y donde se aprenden conceptos claves como la formación a lo largo de toda la vida, generación de conocimiento e información y otros. En este aspecto, la alfabetización tanto informativa como digi- 
La Alfabetización en Información: una necesidad para la ...

tal, es un requisito básico de el aprendizaje para toda la vida, común a todas las disciplinas y presente en todos los niveles educativos, donde se forman los futuros ciudadanos.

Los ciudadanos requieren conocimientos y habilidades de nuevo tipo para desempeñarse en el complejo mundo actual y ejercer una ciudadanía activa. Instituciones como el US National Research Council, y su Comité sobre Alfabetización de la Información, Informática y Telecomunicaciones, han mostrado interés por crear programas que promuevan en los estudiantes la capacidad de ser autosuficientes y críticos frente a la nueva explosión de contenidos, preparándolos para tener un rol activo como ciudadanos en la sociedad del conocimiento.

Hasta el momento en Chile no se ha implementado ninguna política pública que tenga relación con la Alfabetización en Información. Existen experiencias, estudios e investigaciones acerca de esta temática, pero están orientados a la educación superior; sin embargo, las carencias relacionadas con el manejo de información, así como la insuficiencia en la consolidación de las prácticas de ALFIN se pueden detectar en todos los niveles de la educación.

Una reciente investigación realizada en Chile, se refiere por primera vez al ámbito de la Alfabetización en Información y la educación primaria. Reusch (2009), la autora emplea en ella distintas técnicas cualitativas, tales como el Método Delphi, en su versión panel de expertos Entrevistas en Profundidad, Grupos de Discusión 
Triangular y Observación no Participante, para abordar la temática.

Esta investigación da cuenta de los aportes que puede hacer la ALFIN desde la educación primaria y muestra la necesidad de formar a los estudiantes en habilidades de información desde temprana edad, para que se conviertan en eficaces aprendices en la era de la información y, por ende, en ciudadanos de la sociedad del conocimiento.

\section{ALFABETIZACIÓN EN INFORMACIÓN Y DESAFÍOS}

Al revisar la bibliografía disponible puede comprobarse que en la actualidad es en los Estados Unidos de Norteamérica, el Reino Unido y Australia donde la Alfabetización en Información tiene mayor fuerza. Resulta interesante verificar, también, que organismos internacionales como Unesco, o la Comunidad Europea, al discutir el fenómeno de la sociedad del conocimiento están promoviendo el uso masivo y estratégico de las TIC, pero junto con ello recomiendan el desarrollo e integración de las habilidades y competencias informacionales en los procesos educativos, así como en todo el quehacer humano.

En América Latina, en tanto, la ALFIN ha empezado a colocarse en la agenda de distintos países, y es posible apreciarla en trabajos de investigadores cubanos, brasileños, mexicanos y chilenos. En nuestro país Gladys Matus, es una reconocida experta en el tema y se ha destacado por el permanente fomento de la Alfabetización en Información. 
La Alfabetización en Información: una necesidad para la ...

En palabras de Matus (2004) la Alfabetización en Información es uno de los grandes desafíos que enfrenta nuestra sociedad contemporánea, mucho más en el ámbito de América Latina, donde el esfuerzo por el mejor acceso y uso de la información es una constante.

La misma autora ha señalado:

La mayor relevancia de esta nueva alfabetización radica en que los nuevos códigos propuestos por la mundialización de las economías, la cultura y en especial por los efectos en la información de las tecnologías, implican el imperativo por el manejo de estos códigos a nivel de todos los ciudadanos; para ello es indispensable desarrollar habilidades tales como las de reconocer las necesidades de información, saber establecer estrategias para localizarla, acceder a ella, seleccionarla desde el vastísimo mundo de información presente, evaluarla, comunicarla y crear nueva información, (Matus, 2005:1).

Gómez (2005), uno de los expertos españoles en el tema de Alfabetización en Información, ha hecho recientemente una crítica a las políticas de desarrollo de la llamada sociedad de la información, al sostener:

Ha primado por parte de los gobiernos la alfabetización tecnológica o digital, y aspiramos a lograr una mayor presencia de la ALFIN, pues la comprensión y evaluación de la información es una condición para una auténtica apropiación social de las herramientas tecnológicas que mediatizan el acceso y uso de la información.

Así lo han entendido los profesionales de la información y de la educación del Estado español, quienes tras reunirse en Toledo el 3 de febrero de 2006, emitieron la 
Declaración de Toledo sobre la Alfabetización Informacional (ALFIN), donde entre otras cosas señalan:

Estamos inmersos en una sociedad del conocimiento, en la que debemos aprender durante toda la vida y desarrollar habilidades para usar la información de acuerdo a objetivos personales, familiares y comunitarios. Así lo afirman organismos internacionales en numerosas declaraciones y, de igual forma, lo asumen los profesionales de la información a través de instituciones como IFLA y manifiestos como la "Declaración de Praga: hacia una sociedad alfabetizada en información" y la "Declaración de Alejandría sobre la alfabetización informacional y el aprendizaje a lo largo de la vida."

La misma Declaración de Toledo sostiene que "la Alfabetización Informacional es una herramienta esencial para la adquisición de competencias en información, así como para el desarrollo, participación y comunicación de los ciudadanos," y afirma a la vez que el sistema educativo obligatorio es la base inicial para obtener capacitación en el uso de la información.

\section{DEMANDAS DEL SIGLO XXI}

La información en la sociedad actual es infinita, incierta y con fecha de caducidad. Ello influye determinantemente en la educación, donde se hace patente esta realidad. En los centros de enseñanza se relativizan los contenidos enseñados, que cada día son más heterogéneos, y las escuelas se encuentran con la demanda de enseñar a vivir, a formar a los futuros ciudadanos. 
La Alfabetización en Información: una necesidad para la ...

Ante esta realidad, los autores se preguntan si los actuales patrones de enseñanza, currículos vigentes y valores imperantes tienen validez o no en la formación de estos futuros ciudadanos, ésos que se están formando hoy en las escuelas.

Monereo y Pozo (2001) sostienen que "a menudo la escuela enseña contenidos del siglo XIX con profesores del siglo XX a alumnos del siglo XXI", y se preguntan si el conocimiento social de los ciudadanos debe reducirse sólo a la educación cívica.

Y agregan: "se imparten bastantes contenidos que resultan obsoletos y no responden a los avances de las investigaciones que se desarrollan en cada disciplina. Por otra parte, estén o no actualizados sus contenidos, cada vez está menos claro cuál es la función de cada una de esas disciplinas en la formación de los futuros ciudadanos".

Hay que tener en cuenta que los profesores que hoy se desempeñan en las aulas se han formado mayoritariamente en una escuela tradicional, que ha privilegiado, por ejemplo, el aprendizaje de memoria y la acumulación de datos sobre el máximo de temas posible.

No obstante los estudiantes de hoy deben hacer frente a los problemas del siglo XXI, interpretar, adaptarse o, en su caso, transformar el mundo en el que les toca vivir. Y el contexto en el que están inmersos es el de chats, teléfonos celulares, videojuegos, música, modas, deportes, elementos que apenas tienen cabida en las aulas.

Benito (2000) formula una ácida crítica que puede ser compartida en países de nuestro continente: "encontramos argumentos que destacan que caminamos hacia una 
sociedad de la incomunicación y la marginación, cultural y económica; encontramos unos parámetros educativos (currículum, rol de los docentes, organización de los centros) regidos por principios de la sociedad industrial; y sobre todo, encontramos muchos niños y jóvenes desmotivados, que no desean aprender los contenidos que se les imponen, ni en la manera que se le ofrecen" (Benito, 2000: 20).

Pareciera que esta disociación entre la vida y la escuela es una situación insalvable. De ahí que cada día adquiere más fuerza la preocupación de los especialistas acerca de la necesidad de que los alumnos tengan habilidades y competencias para vivir, y no sólo sobrevivir, en este siglo.

\section{BIBLIOTECA ESCOLAR Y ALFIN}

Frente a una realidad como la descrita, que preocupa a los actores y las escuelas, y ante la cual se plantean diferentes alternativas y soluciones en distintas latitudes, el rol de la biblioteca escolar aparece como relevante, si es capaz de hacer suyo el paradigma actual y de asumir un papel activo en cuanto a la Alfabetización en Información.

La biblioteca tiene, como el centro de recursos de información documental, en todas sus especialidades y soportes, una responsabilidad clave. Por ello debe ser un servicio básico que les dé a sus usuarios, tanto de modo autónomo, como en programas docentes más amplios y colaborativos. Sin embargo, aún son muchos quienes creen que la biblioteca debe cumplir sólo funciones de tipo tradicional. 
La Alfabetización en Información: una necesidad para la ...

La escuela ya no es la depositaria privilegiada del saber, ni tampoco dispone como antaño de los únicos instrumentos para producir y sistematizar el saber. Sus bibliotecas se han ido quedado obsoletas y se están quedando atrás en la promoción de la nueva alfabetización que demanda la sociedad de la información.

Teniendo en cuenta las características de la sociedad actual, resulta un imperativo replantearse, entre otros, los conceptos de alfabetización, instrucción formal y acceso a la información. Así lo expresa Benito:

Replantear el acceso a la información, porque sin una adecuada preparación de los escolares para aprovechar los instrumentos que la sociedad actual les ofrece para obtener información, desarrollando su capacidad para seleccionarla y organizarla, les obstaculizamos su adaptación a las nuevas demandas. (Benito, 2000: 22).

Es donde en esta perspectiva la biblioteca escolar adquiere un rol protagónico, tal como lo estipula el mismo autor:

La biblioteca escolar, entendida como centro de información y recursos en diversos formatos, es el lugar ideal de aprendizaje tanto para el desarrollo de habilidades de comprensión de textos y autorregular el aprendizaje, como para el manejo de las herramientas tecnológicas que facilitan la localización, procesamiento y comunicación de la información, (Benito, 2000: 118). 


\section{REALIDAD CHILENA}

En Chile, el Ministerio de Educación ha dado a conocer sus principios orientadores acerca de las bibliotecas escolares: "Creemos que un país que pretende caminar firmemente hacia el desarrollo, debe contar con bibliotecas de calidad en cada una de sus escuelas y liceos, un espacio de información, formación y recreación para todos los miembros de la comunidad educativa”.

En el Manual "La Biblioteca Escolar: hacia un Centro de Recursos para el Aprendizaje (CRA)”, del propio Ministerio de Educación, se sostiene:

[...] las bibliotecas escolares han experimentado cambios cualitativos importantes en los últimos años, constituyéndose en verdaderos Centros de Recursos para el Aprendizaje (CRA), que cumplen un destacado rol en el sistema educativo como apoyo a la implementación del currículum y como espacios generadores de instancias de aprendizaje.

El mismo documento agrega:

El CRA en la enseñanza básica de nuestro país, se plantea hoy un gran desafío: generar su espacio y transformarlo en un soporte efectivo para el aprendizaje de los alumnos, entregando asimismo a los profesores las herramientas necesarias que les permitan enriquecer y diversificar sus estrategias de enseñanza.

Sin embargo, todos estos planteamientos acerca de la importancia de los CRA en el sistema educativo distan bastante de la realidad de las escuelas chilenas en cuanto a bibliotecas y los CRA, la ayuda es aún precaria, tal 
La Alfabetización en Información: una necesidad para la ...

como ha quedado de manifiesto en la mencionada investigación.

Al año 2008 los Centros de Recursos para el Aprendizaje (CRA) cubrían un 47\% del total de establecimientos que imparten educación primaria. En el período 2005-2008 se pasó de un $6 \%$ a un $47 \%$ de cobertura. En cuanto al número de títulos distribuidos por niño, aun se considera insuficiente (3,2 por niño), ya que está muy por debajo de los estándares internacionales. En efecto, de acuerdo con las recomendaciones IFLA/UNESCO 2002, se debe disponer de 10 títulos por alumno, cifra que corresponde al estándar que el Ministerio de Educación chileno ha establecido.

Para dimensionar el tamaño de nuestro problema de educación resulta necesario referirse a algunos datos estadísticos oficiales. Según la Dirección de Presupuestos, en 2008 existía un total de 8.363 establecimientos que impartían enseñanza primaria y 2.186 que impartían enseñanza secundaria; de estos últimos más de dos tercios $(68 \%)$ son particulares subvencionados, mientras que de los que imparten educación primaria, la mayor parte (61\%) son municipales o públicos.

Por otra parte, el número de alumnos, según la matrícula de los establecimientos que imparten primaria y secundaria, alcanzaba el año 2008 a 3.151.852, la mayoría de los cuales $(70 \%)$ estudiaba el nivel de la enseñanza primaria.

En cuanto a los docentes, la dotación total ascendía a 217.291, de los cuales el 62\% correspondía a docentes de enseñanza primaria. 


\section{RED ENLACES Y ALFABETIZACIÓN DIGITAL}

En Chile la educación obligatoria es de 12 años: ocho años de educación primaria (llamada educación básica), cuatro años de educación secundaria (llamada educación media). En el sistema coexisten la educación privada, particular-subvencionada y municipalizada o pública (escuelas y liceos), a los que acuden los estudiantes de menores ingresos económicos.

Dentro de América Latina, Chile está muy avanzado en cuanto a penetración de Internet y de PC (computadoras). La agenda digital de Chile es, posiblemente, la mejor en el continente. Según un estudio del Foro Económico Mundial (FEM) sobre competitividad tecnológica, Chile se ubica en el sitio 31, de 122 países analizados. En esa lista aparece como el país más aventajado de la región, seguido por México, en el puesto 49.

En el marco de la Reforma Educacional, Chile posee desde 1992 una política de informática educativa, llamada "Red Enlaces", adscrita al Ministerio de Educación, que favorece a la educación básica y media subvencionada; desde entonces Enlaces ha consolidado una gran red computacional y contribuido a ampliar las oportunidades y el acceso de docentes y estudiantes, y de la comunidad educativa a las nuevas tecnologías de información y comunicación (TIC) en el país.

Es así como el gobierno, a través del Ministerio de Educación, ha dotado a los establecimientos educacionales de equipos computacionales, subsidio a la conectividad, recursos educativos digitales y asistencia técnica o pedagógica, con grandes logros en cuanto a la alfabetización digital. 
La Alfabetización en Información: una necesidad para la ...

Según Hepp (2003), el proyecto Enlaces ha intentado integrar las TIC en el sistema educativo, especialmente para mejorar los aprendizajes, pero también para ofrecerles a los niños y jóvenes las herramientas que les permitan navegar con soltura en el espacio digital y, por ende en la sociedad de la información.

Al respecto, el promedio nacional de alumnos por computador ha evolucionado drásticamente desde el año 2000, y bajado de 70 a 13 alumnos por computador.

Frente a estos avances en cuanto a implementación tecnológica en el ámbito de la educación, no se visualizan esfuerzos explícitos en relación con la formación en información en los procesos escolares, en el supuesto de que se requiere en forma creciente que los estudiantes aprendan a desarrollar habilidades y competencias en el acceso, uso y comunicación de la información -en las más diversas fuentes y formatos- desde los primeros años de escolaridad.

\section{Carencias en escuelas chilenas}

Las reformas educativas que se han emprendido en Chile, al igual que en diversos países latinoamericanos han apuntado, entre otros aspectos, a modificar los currículos en la dirección del aprendizaje constructivo y significativo. Los cambios van en la dirección planteada por el paradigma cognitivo, donde la persona y el ciudadano son reflexivos, críticos y creadores; sin embargo hasta el momento no se han visto sus frutos.

Así queda en evidencia que en las escuelas chilenas hay aún mucho camino que recorrer al respecto. En efecto en Chile existen diversas carencias que afectan especialmen- 
te a las escuelas municipalizadas o públicas. En éstas se concentran los estudiantes de menores recursos, quienes son los que en general tienen los peores resultados, y están todavía lejos del ideal de calidad y equidad que se han propuesto los gobiernos para la educación.

Como dan cuenta diversos estudios, la ineficacia de las escuelas pobres podría estar, precisamente, en la alta segregación que posee el sistema escolar chileno, donde hay escuelas que concentran mayoritariamente alumnos pobres y otras que tienen sólo alumnos ricos.

La Corporación Municipal de Valparaíso (Chile) -a la cual pertenecen las escuelas donde realizó el trabajo de campo de esta investigación- atiende en sus escuelas a estudiantes que pertenecen en muchos casos a sectores vulnerables; sus esfuerzos están dirigidos a avanzar en distintos aspectos en los que se constatan carencias y debilidades, tales como de infraestructura, estilos de dirección, trabajo en equipo, capacidades docentes, desarrollo de capacidades culturales e incorporación de padres $\mathrm{y}$ apoderados al proceso educativo.

No obstante, y a pesar de que la misión de dicha Corporación contempla la formación de los estudiantes como personas y ciudadanos críticos, constructores y creativos, se pudo comprobar en las escuelas la inexistencia de programas de Alfabetización en Información, que les enseñen a los alumnos de enseñanza básica (primaria) el uso de la información documental y su transformación en conocimiento y su comunicación.

Por una parte los profesores de estas escuelas desconocen la ALFIN, así como también el nuevo rol que puede asumir la biblioteca escolar; y son testigos de que sus 
La Alfabetización en Información: una necesidad para la ...

estudiantes, en general, "copian y pegan" la información de Internet a la hora de hacer una tarea. Sus intereses y expectativas sobre la sala Enlaces -donde se encuentran los equipos computacionales- no coinciden con la de los alumnos, que prefieren el chat, Messenger o Fotolog.

Los escolares, por su parte, tienen baja comprensión lectora y se muestran desmotivados para investigar; $y$ no cuentan con las habilidades informacionales que requiere su nivel educativo. Si bien son capaces de determinar una fuente de información, acceder a Internet y, en ciertas ocasiones utilizar su criterio personal para evaluar la información obtenida, el problema básico es que estas habilidades se usan en forma aislada y no como parte de un proceso cognitivo regular y conciente.

El resultado es que, más allá de las repercusiones en los aprendizajes específicos, los estudiantes carecen de habilidades que les servirán más adelante para su vida cotidiana de ciudadanos.

\section{APORTES DE LA ALFIN A LA EDUCACIÓN}

Si bien en la educación de hoy juegan un rol importante tanto las TIC como las bibliotecas escolares, la Alfabetización en Información debería ir de la mano de ambas, pues aparece como un fenómeno indispensable, ya que puede conducir a los estudiantes, desde las primeras etapas escolares, a tomar conciencia de la necesidad de buscar información, acceder a ella, utilizarla y, sobre todo, a crear nueva información. 
La realidad muestra que los estudiantes se encuentran con constantes dificultades para acceder a la información, debido al gran desarrollo de los recursos y la poca estructuración de éstos, y que no saben hacer frente a este nuevo abanico de posibilidades. De ahí que resulte fundamental plantear nuevas estrategias que les permitan ser autosuficientes en los procesos de aprendizaje y los dote de habilidades y competencias para localizar, evaluar y utilizar la información que necesitan.

La Alfabetización en Información puede jugar, por esto, un rol determinante en la educación primaria, a pesar de que se trata de un fenómeno emergente, y su importancia no llega a sertodavía percibida por la comunidad escolar.

Así lo manifestaron los expertos que integraron el panel virtual de expertos -tras la aplicación del Método Delphi, contemplado en el diseño de la investigaciónquienes señalaron que los aportes más significativos que puede hacer la Alfabetización en Información a la educación son los siguientes: en primer lugar, formar alumnos autónomos en cuanto a la búsqueda de información, que sepan qué información es la que necesitan, dónde conseguirla, qué hacer con ella, desde las primeras etapas de la educación; en síntesis, aprender a aprender durante toda la vida.

$\mathrm{Y}$, en segundo lugar, les permite desenvolverse en la vida, desarrollando competencias de comprensión lectora, pensamiento crítico, resolución de problemas, habilidades para analizar y sintetizar, y de comunicación.

De la participación de los expertos también se pudo establecer que desde la educación primaria los estudian- 
La Alfabetización en Información: una necesidad para la ...

tes pueden desarrollar distintas habilidades como las siguientes: habilidad de reconocer la necesidad de información y ser capaces de expresarla en forma clara; asimismo, localizar la información que necesitan en fuentes impresas o digitales, conociendo los recursos para llegar a esas fuentes, tales como bibliotecas o Internet. También, la habilidad para saber qué hacer con toda la información localizada: para analizar y sintetizar textos en distintos formatos, comparar, evaluar, analizar, extraer citas, respetar el derecho de autor, crear nueva información y comunicarla.

\section{ALFIN PARA LA EDUCACIÓN PRIMARIA}

Los antecedentes recogidos en esta investigación han hecho posible la elaboración de un programa de curso de Alfabetización en Información destinado específicamente para los estudiantes de enseñanza primaria.

Pero antes de referirnos a él, parece importante concordar alguna definición sobre Alfabetización en Información. En este sentido, coincidimos con Gómez Hernández (2000) cuando dice que la ALFIN se refiere “[...]a las competencias, aptitudes, conocimientos y valores necesarios para acceder, usar y comunicar la información en cualquiera de sus formas, con fines de estudio, investigación, o ejercicio profesional. Entendemos la ALFIN como el conocimiento y la capacidad de usar de modo reflexivo e intencional el conjunto de conceptos, procedimientos y actitudes involucrados en el proceso de obtener, evaluar, usar y comunicar la información a través de medios convencionales y electrónicos" (Gómez Hernández, 2000: 171). 
El mismo autor ha señalado que es necesario instruir a los ciudadanos en la Alfabetización en Información, "[...]principalmente por las instituciones mediadoras en los procesos del conocimiento y la información, las bibliotecas, los archivos, los servicios de documentación, así como el sistema educativo como responsable de la educación formal desde la educación infantil hasta la universidad" (Gómez Hernández, 2000:7).

Para que ello ocurra $-y$ tal como se sostiene en las conclusiones de la investigación- se demanda un trabajo conjunto entre profesores y bibliotecólogos. Los espacios para la ALFIN son las bibliotecas escolares y las aulas. Por ende, el primer paso para la ejecución de un programa de curso de Alfabetización en Información en las escuelas debiera darse en el sentido de preparar a ambos profesionales para que desarrollen habilidades instruccionales orientadas a la enseñanza de la ALFIN.

El programa de Alfabetización en Información que se propone para alumnos de educación primaria contempla las siguientes etapas:

1. Elaboración de un diagnóstico cuantitativo sobre habilidades tecnológicas de los niños.

2. Diagnóstico cualitativo que determine sus habilidades informacionales y sus motivaciones. Para que el programa tenga éxito es muy importante que surja de las motivaciones de los alumnos; esto permitirá un mayor interés por aprender.

3. Creación de actividades que les permitan aprender los principales contenidos del curso. Y plantear estos contenidos mediante el uso de herramientas impresas y digitales. 
La Alfabetización en Información: una necesidad para la ...

4. Evaluación de los resultados del curso de forma cuantitativa y cualitativa.

Se trata de un curso teórico-práctico orientado a introducir a los alumnos en el proceso de búsqueda y selección de información para realizar sus trabajos de investigación.

El objetivo del curso apunta a que los estudiantes conozcan los principales procesos, etapas e importancia de la Alfabetización en Información, permitiendo que se formen, desde el nivel primario, como personas autónomas, con las habilidades y conocimientos necesarios para insertarse en la sociedad del conocimiento.

El programa del curso pone énfasis en los siguientes contenidos:

- La sociedad de la información y su implicación para los niños y jóvenes.

- Las distintas Fuentes de Información: Impresas y Virtuales.

- Las mejores formas de acceder a esas fuentes.

- Las estrategias de búsqueda de Información de Calidad.

\section{PROGRAMA DE ALFIN}

El programa de curso que se propone incluye, en detalle, las siguientes unidades temáticas:

Unidad I: La Sociedad de la Información y las Tecnologías

- Importancia de la información y del conocimiento

- Importancia de la investigación

- Las tecnologías y su uso por parte de los niños 
Tendencias de la Alfabetización Informativa en Iberoamérica

- Alfabetización digital y Alfabetización en Información

Unidad II: Alfabetización en Información

- La necesidad de información

- Lectura comprensiva

- Fuentes de Información e importancia de citarlas

- Etapas y técnicas para acceder, seleccionar, evaluar y usar información.

Unidad III: Aprender a aprender

- Búsqueda de información en documentos impresos

- Búsqueda de información digital

- Recuperación de información

- Selección e incorporación al conocimiento

Esta propuesta de curso permitirá que los alumnos de enseñanza primaria se formen como estudiantes autónomos y tengan las habilidades y conocimientos necesarios para insertarse adecuadamente en el mundo de hoy.

\section{CONCLUSIONES Y DESAFÍOS}

Las demandas de la sociedad del conocimiento son crecientes y plantean nuevos desafíos en todo orden de cosas, debido a los nuevos paradigmas y al creciente desarrollo de las Tecnologías de Información y Comunicación (TIC), las que también alcanzan al ámbito de la educación.

Las carencias relacionadas con el manejo de la información, así como la insuficiencia en la consolidación de 
La Alfabetización en Información: una necesidad para la ...

las prácticas de ALFIN son una realidad en todos los niveles de la educación. El desarrollo de la Alfabetización en Información debe ser considerado como un pilar básico en la educación, desde el nivel primario, ya que conduce a los futuros ciudadanos a acceder, seleccionar y utilizar la información, pudiendo también crear nueva información de su autoría y no sólo copiarla.

Un curso de ALFIN en la escuela primaria debiera comprometer a toda la comunidad escolar y desarrollarse en forma paralela a la alfabetización digital. El espacio para desarrollar la Alfabetización en Información debe ser tanto la sala de clases como la biblioteca escolar.

Los requerimientos del mundo globalizado interpelan a los sistemas educativos de los distintos países latinoamericanos para que formen a los futuros ciudadanos, no sólo en el uso de la tecnología, sino también en las habilidades y competencias que exige la sociedad del conocimiento.

\section{BIBLIOGRAFÍA}

Basulto, E., Mohar, F., De La Figal, A., Bermello, L., \& García, J. (2008), “Estrategia de Alfabetización Informacional para los estudiantes de la carrera de Ingeniería Agrícola que cursan el Plan de Estudios D." Pedagogía Universitaria, 13(5), 14-40, [en Línea]: http://search.ebscohost.com.

Benito Morales, F. (2000), "Nuevas necesidades, nuevos problemas. Fundamentos de la alfabetización en información”, en José A. Gómez Hernández (coord..) Estrategias y modelos para enseñar a usar la información, pp.11-74, Murcia: Editorial KR. 
Tendencias de la Alfabetización Informativa en Iberoamérica

Comité Sobre Alfabetización de la Información, Informática y Telecomunicaciones. US National Research Council, recuperado el 21 de octubre de 2009, de: http://www.nap. $\mathrm{edu} / \mathrm{catalog} / 6482 . \mathrm{html}$.

Declaración de Toledo, (2006), recuperado el 24 de julio de 2006, de http://travesia.mcu.es/S_ALFIN/ficheros/ Declaracion_Toledo.pdf.

Delors, J. (1989). La educación encierra un tesoro. Madrid: UNESCO.

Evaluación del Programa de Recursos Educativos Centros de Recursos de Aprendizaje (CRA) elaborado por la Dirección de Presupuestos (DIPRES), recuperado el 14 de septiembre de 2010, de http://www.bibliotecas-cra.cl/uploadDocs/201 003121120080.MinutaejecutivaEPG.pdf.

Foro Económico Mundial (FEM), Índice Global de Competitividad 2009-2010, recuperado el 19 de septiembre de 2009, de http://www.incae.edu/ES/clacds/noticias/PANAMA WEF2009_Com_Prensa.pdf.

Gómez Hernández, J. (2000), "La Alfabetización Informacional y la Biblioteca Universitaria", en Estrategias y Modelos para enseñar a usar la información, 7, Murcia: KR.

Gómez Hernández, J. (2005), Alfabetización Informacional: cuestiones básicas. Recuperado el 25 de noviembre de 2005, de http://thinkepi.net/repositorio/alfabetizacioninformacional-cuestiones-basicas/.

Gómez Hernández, J. (2005). Alfabetización Informacional: cuestiones básicas, recuperado el 25 de noviembre de 2005, de http://thinkepi.net/repositorio/alfabetizacioninformacional-cuestiones-basicas/. 
La Alfabetización en Información: una necesidad para la ...

Hepp, P. (2003), "Enlaces: El programa de informática educativa de la reforma educacional chilena", en Cristian Cox. (ed), Políticas educacionales en el cambio de siglo. La reforma del sistema escolar en Chile, Santiago: Ediciones Universitarias.

La Biblioteca Escolar hacia un centro de recursos para el aprendizaje (CRA), $2^{\circ}$ Edición, diciembre de 2005, [en Línea]: http://www.bibliotecascra.cl/docs/recursos/Manual Biblioteca Escolar.pdf.

Matus Sepúlveda, G. (2005), "Qué se ha investigado en Chile respecto a Habilidades de Información", en Seminario "Desarrollando profesionales con Habilidades de Información desde la Educación Superior", Valparaíso: Universidad de Playa Ancha.

Matus Sepúlveda, G. (2004), Alfabetización en Información: una experiencia en la Universidad de Playa Ancha, recuperado el 19 de mayo de 2005, de http://www.sje.cl/cra/ bilbiodocencia/7/7_pdf.

Monereo y Pozo (2001), Competencias para convivir con el siglo XXI. recuperado el 14 de septiembre de 2010 de, http://www.scribd.com/doc/12975732/Monereo-PozoCompetencias-para-convivir-con-el-siglo-XXI .

Red Enlaces (2010), recuperado el 12 de septiembre de 2010, de http://www.enlaces.cl/index.php?t $=44 \& \mathrm{i}=2 \& \mathrm{cc}=$ $13168 \mathrm{tm}=2$.

Reusch Hevia, Ana María (2009), Alfabetización en Información en la Formación de Ciudadanos para la Sociedad del Conocimiento en la Educación Básica Municipalizada de la Comuna de Valparaíso, Valparaíso, Universidad de Playa Ancha, (Tesis de Doctorado). 


\title{
ALFIN para alumnos de educación primaria: propuesta de modelo y perspectivas de aplicación
}

\author{
GuADALUPE VEGA DÍAZ \\ El Colegio de México \\ SYLVIA ROJAS-DRUMMOND \\ Facultad de Psicología de la UNAM
}

\section{CONTEXTO}

ada vez se hace más necesario que las competencias para usar la información se promuevan en los sujetos en edades tempranas, porque es importante que los individuos se beneficien en su vida escolar y que cuenten con las habilidades, los conocimientos y las actitudes que les permitan participar de manera informada en la solución de problemas. Sin embargo, en México los resultados de diversas pruebas han mostrado que los alumnos de educación primaria tienen deficiencias para localizar, evaluar, comprender y usar la información (Instituto Nacional para la Evaluación de la Educación, [INEE], 2005). De manera puntual, en las pruebas aplicadas por la Secretaría de Educación Pública de México ([SEP], 2007), así como en las de la Organización para la 
Cooperación y el Desarrollo Económico, las pruebas PISA ([OCDE], 2001, 2003, 2007), se ha detectado que los alumnos mexicanos se ubican en los niveles más bajos de los países miembros, en lo que toca a la comprensión lectora y a la valoración de la información. Estos bajos niveles, en parte, pueden atribuirse a que los alumnos no han desarrollado sus habilidades y conocimientos para usar la información (Cuevas-Cerveró, 2005).

En México, en el año 2009 se publicaron los planes y programas de estudio para educación básica, los cuales, a partir del tercer grado, incluyen como un objetivo de aprendizaje el fortalecimiento de las competencias para el manejo de la información. Estas competencias son: “[...]la búsqueda, identificación, evaluación, selección y sistematización de la información, [...] pensar, reflexionar, argumentar y expresar críticas; [...] analizar, sintetizar, utilizar y compartir información" (Secretaría de Educación Básica [SEB], 2009:12).

Desde nuestra perspectiva la inclusión de las competencias para el manejo de la información en los programas de educación básica es un avance importante, sin embargo, se observa que en dichos programas hay confusiones conceptuales, por ejemplo no se explicitan qué son y ni cómo se aplican las estrategias de búsqueda; tampoco se explicitan los criterios e indicadores para evaluar la información. Es decir, son presentadas de manera superficial, sin que medie una noción clara de los conceptos, las habilidades y las actitudes que están implícitas.

Se considera que la situación anterior es el reflejo de un problema más amplio, y que justamente se relaciona 
ALFIN para alumnos de educación primaria: propuesta de ...

con el desconocimiento de los procesos involucrados en el fortalecimiento de las competencias en información en alumnos de este nivel. Este problema se vincula también con la carencia de bibliotecas escolares y con la ausencia de profesionales de la información que se encarguen del diseño e implementación de servicios de información especializados para los alumnos y docentes de educación básica.

\section{LA PERSPECTIVA SOCIOCULTURAL DEL APRENDIZAJE}

Desde nuestra perspectiva la promoción de las competencias en información debe fundamentarse en perspectivas teóricas del aprendizaje y en evidencias empíricas que permitan comprender cómo los alumnos de educación primaria usan la información. Para esta investigación hemos retomado la perspectiva sociocultural como marco teórico del aprendizaje. Esta perspectiva enfatiza que el aprendizaje es un proceso social que se basa en la participación activa de los sujetos en la solución de los problemas de una comunidad (cfr. Palicsar, 1998).

La perspectiva sociocultural implica que el aprendizaje es situado, ya que el pensamiento, los instrumentos y los signos tienen propiedades funcionales en relación al contexto y a las prácticas de una comunidad en las que es significativo un conocimiento.

En una comunidad el conocimiento está distribuido de manera diferenciada entre sus integrantes, por lo que hay participantes expertos y periféricos. El rol de los expertos es guiar el aprendizaje y ayudar a los participan- 
tes periféricos a alcanzar niveles superiores de conocimiento y a apropiarse de los conocimientos y artefactos de una comunidad. Por su parte los periféricos se asumen como aprendices que observan y analizan los acontecimientos, tratando de no perturbar las actividades de la comunidad (Daniels, 2001/2003).

Vygostky considera que para poder ayudar a los aprendices a pasar a los niveles superiores de conocimiento es importante conocer su zona de desarrollo próximo [ZDP], la cual es definida como:

[...] la distancia entre el nivel real de desarrollo, determinado por la capacidad de resolver independientemente un problema; y el nivel de desarrollo potencial, determinado a través de la resolución de un problema bajo la guía de un adulto o en colaboración con otro compañero más capaz (Vygostky, 1979: 113).

Para pasar a un nivel superior de conocimiento, los expertos dan andamiaje a los aprendices, esto es les proporcionan apoyo cognitivo para ayudarlos a resolver tareas que no podrían resolver solos. El andamiaje requiere de la realización de actividades significativas para los sujetos, de tal forma que se sientan involucrados y motivados a participar. Otro concepto fundamental dentro de la perspectiva sociocultural es la apropiación, que se entiende como el proceso mediante el cual una persona hace suyo el conocimiento, lo interpreta, lo comprende y lo transforma a partir de su propia experiencia (Daniels, 2001/2003). 
ALFIN para alumnos de educación primaria: propuesta de ...

En la perspectiva sociocultural, el lenguaje es un instrumento cultural que posibilita los procesos de andamiaje y de apropiación para la construcción del conocimiento. Se considera que es mediante el análisis del lenguaje que podemos reconocer los cambios cognitivos en los aprendices. De acuerdo con Newman, Griffin y Cole (1991) los cambios cognitivos pueden ocurrir en cuestión de minutos, meses, o incluso años.

\section{EL CONCEPTO DE ALFABETIZACIÓN INFORMA- TIVA DESDE LA PERSPECTIVA SOCIOCULTURAL}

La alfabetización informativa [ALFIN] es un término traducido del inglés (information literacy), que ha evolucionado de acuerdo con las aproximaciones teóricas y las prácticas derivadas de su aplicación en diferentes contextos. En sus orígenes la ALFIN hace referencia a una serie de atributos que deben poseer los individuos en el marco de la sociedad de la información, estos atributos son:

[...] el alfabeta reconoce cuándo necesita información, tiene la habilidad para localizarla, evaluarla y

1 El término information literacy fue utilizado por primera vez por Zurkowski en 1974, para referirse a los conocimientos y las habilidades que los individuos deberían tener en relación con las tecnologías de la información, incluyendo el manejo del software, Gómez-Hernández (2007) afirma que su traducción gramatical correcta es alfabetización informacional. En este estudio se utiliza el término alfabetización informativa como sinónimo del de alfabetización informacional. 
usarla efectivamente para satisfacer sus necesidades de información [...] finalmente, una persona alfabetizada en el uso de la información es quien sabe cómo aprender a aprender. Conoce cómo aprender porque conoce cómo se organiza el conocimiento, cómo encontrar información y cómo usarla. Es una persona preparada para el aprendizaje continuo porque puede encontrar la información para contestar preguntas, realizar una tarea o tomar decisiones (American Library Association [ALA], 1989).

Esta forma de concebir la ALFIN ha sido ampliamente aceptada en diferentes ámbitos y niveles educativos. Sin embargo desde principios del siglo XXI se ha conformando una nueva conceptualización del término. En ésta se plantea que la ALFIN más que un conjunto de atributos personales, se refiere al uso de la información en las prácticas de una comunidad; es decir se la vincula con una perspectiva más sociocultural (Vega, 2009, Bawden 2002; Licea y Gómez, 2002; Lloyd, 2005, 2006), al respecto Llyod afirma que la ALFIN:

[...] es una práctica cultural que se explora con otros y que adquiere significado a partir de las prácticas cotidianas. Enriquece la práctica social a partir de la habilidad para conectarse con la información, para usarla y para producir significados en interacciones formales e informales. Además de ello, se involucra para conocer el uso de la información en el desarroIlo social, textual y físico de un contexto (2006: 570).

Acorde con lo anterior la ALFIN se constituye a partir de las relaciones sociales y las experiencias individuales en contextos determinados, en donde conviven sujetos con diferentes niveles de conocimiento; los cuales se 
ALFIN para alumnos de educación primaria: propuesta de ...

van moviendo en las organizaciones a partir de la comprensión colectiva de la práctica y de la negociación de significados. Para alcanzar dicha comprensión, Lloyd afirma que es necesario interactuar en cada escenario por periodos largos, ya que en cada contexto hay diferentes actividades, símbolos, artefactos y personas que comparten información y ayudan a otros a aprender el qué, el cómo y el para qué.

En el mismo sentido que Lloyd, en el Congreso de la International Federation of Library Associations and Institutions ([IFLA], 2005), la ALFIN fue vinculada con el aprendizaje para toda la vida en dos sentidos: por un lado en la comprensión crítica de la información para la participación activa en la resolución de problemas, y, por otro, para la creación de nuevo conocimiento y productos culturales. En dicho Congreso también se consideró que la alfabetización informativa era crucial para aumentar las ventajas competitivas de los individuos, ya que fue considerada como un elemento clave para el acceso, uso y creación de contenidos para el desarrollo económico, la educación, la salud y los servicios humanos.

De acuerdo con lo anterior, la ALFIN puede ser conceptualizada como un proceso de aprendizaje complejo, dinámico y transversal dirigido a que los individuos sean capaces de conocer y aprender en diferentes contextos a partir de su participación y experiencia con información en las comunidades en las que están vinculados.

Este proceso de aprendizaje se caracteriza por ser continuo y situado, además de que se constituye a partir de la información que se obtiene de fuentes físicas, sociales, textuales y contextuales. Esta información se en- 
laza con las prácticas cotidianas a fin de producir significados para una comunidad. Estos significados son interiorizados por los individuos y transformados para producir avances y modificaciones en el proceso y en los conocimientos originales.

Esta forma de conceptualizar la ALFIN se relaciona con la alfabetización funcional (Vega 2000; y RojasDrummond, Albarrán, Vega, Zúñiga y Vélez, 2005); es decir con los conocimientos y habilidades que emergen de las demandas sociales en un determinado momento histórico y en situaciones específicas.

\section{DISEÑO DE LA INVESTIGACIÓN}

Acorde con lo anterior en esta investigación se retoma el concepto de ALFIN desde una perspectiva sociocultural. El objetivo es obtener evidencias para comprender los procesos de apropiación de las competencias en el uso de la información de los alumnos de sexto año de educación primaria. Estas evidencias, junto con el marco teórico son la base para construir un modelo de ALFIN para este nivel educativo.

La investigación se integró con 2 estudios en los que participaron alumnos de sexto año de escuelas primarias del D. F., de los ciclos escolares: 2004-2005 y 2005-2006. Estos alumnos participaron en un programa de innovación educativa denominado "Aprendiendo Juntos". En este programa se promovieron habilidades sociales, cognoscitivas, psicolingüísticas y tecnológicas, incluyendo de manera central la ALFIN. En el programa los niños trabajaron en tríadas para realizar investigaciones escolares sobre temas de su interés. Para ello realizaron procesos 
ALFIN para alumnos de educación primaria: propuesta de ...

de búsqueda, evaluación, comprensión, síntesis e integración de información de diversas fuentes incluyendo las tecnologías de la información y la comunicación [TIC]. Durante la promoción de estos procesos los alumnos dialogaron para tomar decisiones y para ponerse de acuerdo sobre las diversas actividades a realizar en torno a sus investigaciones. Al final del trabajo toda la información fue integrada en un texto, y a partir de este texto los alumnos prepararon una conferencia multimedia. Las conferencias fueron presentadas al final del ciclo escolar ante padres de familia, maestros, alumnos y directivos, así como otros miembros de la comunidad local.

\section{Participantes}

En cada estudio participaron diferentes alumnos de entre 11 y 12 años, de sexto grado de educación primaria. Los alumnos fueron organizados en tríadas. Para el estudio se seleccionó una triada focal al azar (ver Tabla 1).

\begin{tabular}{||l|c|c|c||}
\hline \multicolumn{4}{|c||}{ Estudios, grupos, alumnos y tríadas focales. } \\
\hline \multicolumn{1}{||c||}{ Estudios } & \multicolumn{1}{|c||}{ Número de grupos } & $\begin{array}{c}\text { Núm. de } \\
\text { alumnos }\end{array}$ & Tríadas focales \\
\hline $\begin{array}{l}\text { Estudio apropiación de la } \\
\text { ALFIN (Ciclo escolar 2004- } \\
\text { 2005) }\end{array}$ & 2 grupos de aplicación & 50 & $\begin{array}{l}\text { Tríada focal 3 } \\
\text { Tríada focal 4 }\end{array}$ \\
\hline $\begin{array}{l}\text { Estudio comparativo } \\
\text { (Ciclo escolar 2005-2006) }\end{array}$ & $\begin{array}{l}\text { 2 grupos } \\
\text { (1 de aplicación y 1 testigo) }\end{array}$ & 98 & Tríada focal 5 \\
\hline
\end{tabular}




\section{Colección y análisis de datos}

A las triadas focales seleccionadas se les dio seguimiento a lo largo del ciclo escolar mediante la videograbación de las interacciones dialógicas de las tres tríadas focales. Estas videograbaciones fueron analizadas con el método de la etnografía de la comunicación de Hymes (1972).

El método de la etnografía de la comunicación tiene sus fundamentos en la investigación antropológica alrededor de los estudios lingüísticos de grupos específicos. Hymes (1964, 1964a) es uno de los primeros autores en definir los conceptos alrededor de este tipo de estudios. Para él la comunicación sigue una serie de patrones regulares que posibilitan la comprensión entre los hablantes de una cultura. Estos patrones ocurren en los diferentes niveles de comunicación (tanto sociales como de grupo e individuales). Saville - Troike (2003) considera que estos patrones también dependen de factores como el grupo social al que se pertenece, la edad, el género, entre otros.

Hymes sugiere tres unidades de análisis relacionadas jerárquicamente: la situación, el evento y el acto comunicativo. Saville-Troike (2003) describe cada una de las unidades de la siguiente forma:

- La Situación Comunicativa. Es el contexto en el que tiene lugar el fenómeno comunicacional. Ésta puede referirse a uno o varios escenarios o también puede comprender varias actividades realizadas en uno o varios momentos; por ejemplo una fiesta o reunión de trabajo. 
ALFIN para alumnos de educación primaria: propuesta de ...

- El Evento Comunicativo. Éste se determina por cada uno de los propósitos específicos que completan una tarea, por ejemplo, la selección del tema para elaborar un texto expositivo. En el evento los participantes comparten el mismo tópico de diálogo, las reglas de interacción y el mismo escenario. Asimismo, los eventos pueden ser discontinuos puesto que en ocasiones son interrumpidos o suspendidos por otros acontecimientos; por ejemplo, cuando recibimos una llamada en medio de una conversación.

- El Acto Comunicativo se refiere a las interacciones específicas, por ejemplo, hacer una broma o presentar un argumento. Éstas incluyen tanto manifestaciones verbales como no verbales. A partir de la identificación de los actos comunicativos es posible inferir los procesos cognitivos que llevan a cabo los individuos al resolver un problema, de tal forma que el conjunto de actos refleje los procesos de apropiación.

Cabe señalar que este método ya ha sido aplicado en México para hacer investigaciones de la conversación en el aula (Vega 2009, Mazón, 2006; Rojas-Drummond, Mazón, Fernández y Wegerif, 2006).

\section{Resultados}

Para analizar el lenguaje se aplicó el método etnográfico de la comunicación a los diálogos que sostuvieron los alumnos de las tríadas del estudio 1 y se comparó con los obtenidos en la tríada del estudio 2. El método seleccionado atiende las recomendaciones de diversos autores para realizar estudios que permitan una comprensión 
Tendencias de la Alfabetización Informativa en Iberoamérica

profunda del comportamiento informativo de los sujetos (Wilson, 2008; Candela, 2006, Lindauer, 2008 y Bilal, 2002). Los datos que se reportan corresponden a los diálogos que los alumnos sostuvieron en las diferentes sesiones del programa "Aprendiendo Juntos", cada intervención fue contabilizada como un turno (ver Tabla 2).

\begin{tabular}{||c|c|c|c||}
\hline \multicolumn{4}{|c|}{ Tabla 2 } \\
\hline Estudios & Tríadas & Número de sesiones & $\begin{array}{c}\text { Número de } \\
\text { turnos }\end{array}$ \\
\hline Estudio 1 & Tríada focal 3 & 6 & 674 \\
\hline & Tríada focal 4 & 8 & 902 \\
\hline Estudio 2 & Tríada focal 5 & 6 & 569 \\
\hline
\end{tabular}

De acuerdo con la propuesta de Hymes (1972), a continuación se presenta el análisis siguiendo el orden jerárquico de las unidades de análisis.

\section{Situaciones comunicativas}

En este estudio se identificaron cinco situaciones comunicativas que estuvieron presentes en las tres tríadas, estas fueron: I. Elegir el tema de investigación; II. Identificar las fuentes de información; III. Elaborar el resumen; IV. Elaborar la conferencia y V. Elaborar la presentación. Lo que se observó es que las situaciones comunicativas explicitaban el vínculo entre los procesos de ALFIN y los productos escritos, intermedios y finales, que los alumnos elaboraron para realizar su investigación. 
ALFIN para alumnos de educación primaria: propuesta de ...

\section{Eventos comunicativos}

Se identificaron nueve eventos comunicativos, los cuales están relacionados con interacciones dialógicas que tenían propósitos similares. Estos propósitos son: A. Seleccionar un tema; B. Organizar el tema; C. Buscar información; D. Evaluar información; E. Sintetizar información; F. Administrar archivos; G. Integrar información; H. Editar información e I. Comunicar información. En cada una de las tríadas se presentaron los tipos de eventos “A” a la "H”. En la tríadas 4 y 5 , además se presentó el evento I. Comunicar información (ver Gráfica 1).

Gráfica 1. Tipos y número de eventos comunicativos

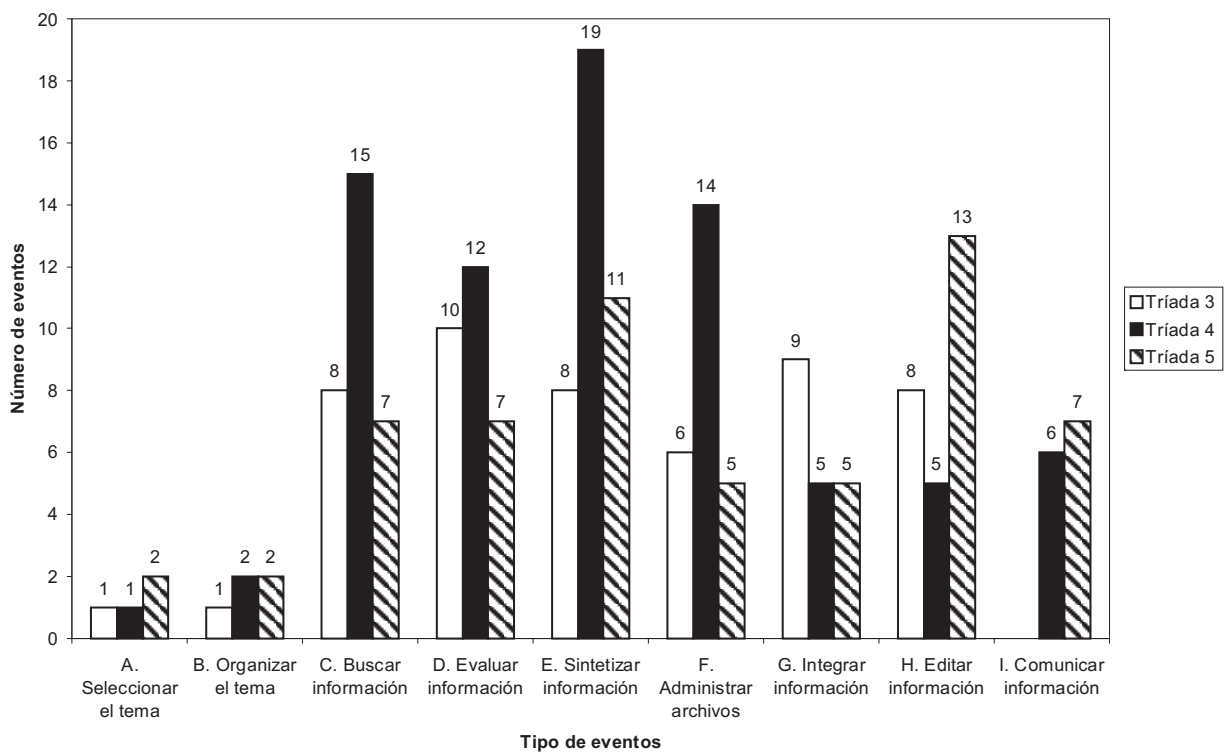


La cantidad de interacciones dialógicas para cada evento comunicativo fue diferente para cada una de las tríadas focales. Hubo eventos que tuvieron una o dos interacciones: A. Seleccionar el tema; B. Organizar el tema. Eventos que tuvieron entre cinco y nueve interacciones: $G$. Integrar información e I. Comunicar información. Por último hubo eventos en los que se presentaron de siete a 19 interacciones, estos son: C. Buscar información, D. Evaluar información, E. Sintetizar información, F. Administrar archivos y H. Editar información.

\section{Actos comunicativos}

Los actos comunicativos fueron entendidos como un conjunto de diálogos que siguen una congruencia discursiva en relación al logro de propósitos específicos. En total se encontraron 41 tipos de actos comunicativos. A partir de estos actos fue posible identificar los procesos cognitivos y procedimentales específicos que los alumnos llevaron a cabo de manera conjunta, para apropiarse de la ALFIN. También se observaron aspectos actitudinales que estuvieron presentes en el proceso, sin embargo estos últimos no se incluyen en este estudio. Es importante señalar que fue al nivel de actos comunicativos en donde se observaron diferencias notables entre los procesos desarrollados por los alumnos de las tríadas focales.

Los actos comunicativos se presentaron de manera iterativa, es decir, en ciclos sucesivos de ida y de regreso dirigidos a alcanzar la meta planteada. A continuación se presenta el listado completo de los actos comunicativos identificados a lo largo de todas las videograbaciones. 
ALFIN para alumnos de educación primaria: propuesta de ...

Actos comunicativos

1. Organizar la actividad

2. Explorar la información

3. Proponer temas de investigación

4. Elegir tema de investigación

5. Justificar el tema de investigación

6. Aplicar estructuras textuales para organizar el tema

7. Justificar las estructuras

8. Identificar fuentes de información

9. Cotejar las preguntas o las estructuras de investigación

10.Diseñar estrategias de búsqueda

- Identificar los términos de búsqueda

- Identificar el tipo de búsqueda

11. Aplicar estrategias de búsqueda

- Buscar en orden alfabético

- Buscar por frases

- Buscar por palabras clave

- Buscar en orden alfabético

> Sinónimos

> Homónimos

> Palabras relacionadas (más especificas)

- Palabras relacionadas (más generales)

- Buscar utilizando operadores boleanos

- Buscar por URL

- Navegar

- Preguntarle a un especialista

12. Explorar documentos recuperados en la búsqueda

13. Refinar estrategias de búsqueda 
- Limitar la búsqueda (temas, fechas, etc.)

- Ampliar la búsqueda (temas, fechas, etc.)

14. Aplicar criterios de valoración

- Valorar temática,

- Valorar la autoridad

- Valorar la veracidad

- Valorar la suficiencia

- Valorar la audiencia

- Valorar el formato

15. Explorar la información

- Leer, de manera exploratoria, un listado de documentos

- Leer, de manera exploratoria, las fuentes de información

16. Comparar dos o más documentos

17. Elegir el o los documentos

18. Justificar la valoración

19. Proponer estrategias de síntesis

20. Leer, de manera profunda el documento elegido

21. Co-construir el texto

- Identificar ideas principales y secundarias

- Proponer una idea o frase para el texto

- Ampliar una idea o frase para el texto

- Complementar la idea o frase para el texto

- Copiar partes del texto

- Dictar partes del texto

- Escribir el texto

22. Auto-revisar el texto

- Leer el texto elaborado 
ALFIN para alumnos de educación primaria: propuesta de ...

- Verificar la información del texto

- Identificar las inconsistencias y/o las omisiones

- Corregir, completar o reformular el texto

23. Justificar la estrategia de síntesis

24. Buscar/localizar archivos

25. Abrir/guardar archivos

26. Instalar software

27. Identificar los elementos de la conferencia escrita

28. Estructurar el texto de la conferencia

29. Justificar el contenido de la conferencia

30. Identificar los elementos de las diapositivas

31. Formatear las diapositivas

- Formatear el texto y las letras

- Buscar fondo y colores

- Evaluar y seleccionar el fondo y los colores más apropiados.

- Buscar imágenes

- Evaluar y seleccionar imágenes

- Insertar imágenes

32. Revisar las diapositivas

- Leer las diapositivas

- Verificar la información de las diapositivas

- Identificar las inconsistencias y/o las omisiones

- Corregir, completar o reformular el texto de las diapositivas 33. Justificar el contenido de las diapositivas

34. Delimitar el tema de investigación

35. Proponer preguntas de investigación

36. Opinar sobre el texto o el tema

37. Copiar información 
38. Mostrar partes del documento o imágenes

39. Explicar el tema de investigación a terceros

36. Opinar sobre el texto o el tema

40. Compartir puntos de vista

41. Organizar la presentación

Algunos de los actos estuvieron compuestos por unidades de análisis más específicas a las que denominamos sub-actos. Tal es el caso de los actos 11, 14 y 21, entre otros.

De los 41 tipos de actos comunicativos identificados, 21 de ellos se presentaron en las tres tríadas focales. Estos actos se presentan en la Tabla 3.

Un aspecto importante es que la presencia de los actos listados en la Tabla 3, no estuvo condicionada por la temática seleccionada, los tipos de preguntas de investigación, la cantidad de interacciones dialógicas, ni por las fuentes de información utilizadas. Esto nos permite afirmar que son la base del proceso de apropiación. De los 20 actos comunicativos restantes, 11 presentaron dos de las tres tríadas focales. Estos actos se pueden apreciar en la Tabla 4.

$\mathrm{Al}$ analizar con detalle estos 11 actos comunicativos, se encontró que su presencia estuvo condicionada por las preguntas de investigación, por la forma en la que los alumnos se relacionaron para tomar decisiones y por los procesos colaborativos para solucionar problemas. 
ALFIN para alumnos de educación primaria: propuesta de ...

\begin{tabular}{|l||}
\hline \multicolumn{1}{|c||}{$\begin{array}{c}\text { Tabla } 3 \\
\text { tríadas focales }\end{array}$} \\
\hline 1. Organizar la actividad \\
\hline 2. Explorar información \\
\hline 4. Elegir tema de investigación \\
\hline 6. Aplicar estructuras textuales para organizar el tema \\
\hline 7. Justificar las estructuras \\
\hline 9. Cotejar preguntas o estructura del tema de investigación \\
\hline 10. Diseñar estrategias de búsqueda \\
\hline 11. Aplicar estrategias de búsqueda \\
\hline 12. Explorar documentos recuperados en la búsqueda \\
\hline 13. Refinar estrategias de búsqueda \\
\hline 14. Aplicar criterios de valoración \\
\hline 15. Explorar la información \\
\hline 17. Elegir el o los documentos \\
\hline 20. Leer de manera profunda el documento elegido \\
\hline 21. Co-construir el texto \\
\hline 22. Auto-revisar el texto \\
\hline 24. Buscar/localizar archivos \\
\hline 25. Abrir/guardar archivos \\
\hline 30. Identificar los elementos de las diapositivas \\
\hline 31. Formatear las diapositivas \\
\hline 32. Auto-revisar las diapositivas \\
\hline
\end{tabular}


Tendencias de la Alfabetización Informativa en Iberoamérica

Tabla 4

Actos que se presentaron en dos de tres tríadas focales

\begin{tabular}{||l|c|c|c||}
\hline \multicolumn{1}{|c|}{\begin{tabular}{|} 
Actos \\
comunicativos
\end{tabular}} & \multicolumn{2}{c|}{ Estudio 1 } & Estudio 2 \\
\cline { 2 - 4 } & Tríada focal 3 & Tríada focal 4 & Tríada focal 5 \\
\hline 3. Proponer temas de investigación & $\mathrm{X}$ & & $\mathrm{X}$ \\
\hline 5. Justificar el tema de investigación & $\mathrm{X}$ & & $\mathrm{X}$ \\
\hline 8. Identificar fuentes de información & $\mathrm{X}$ & & $\mathrm{X}$ \\
\hline 16. Comparar dos o mas documentos & $\mathrm{X}$ & & $\mathrm{X}$ \\
\hline 19. Proponer estrategias de síntesis & $\mathrm{X}$ & & $\mathrm{X}$ \\
\hline 23. Justificar la estrategia de síntesis & $\mathrm{X}$ & & $\mathrm{X}$ \\
\hline 35. Proponer preguntas de investigación & & $\mathrm{X}$ & $\mathrm{X}$ \\
\hline 37. Copiar información & & $\mathrm{X}$ & $\mathrm{X}$ \\
\hline 38. Mostrar partes del documento o imágenes & & $\mathrm{X}$ & $\mathrm{X}$ \\
\hline 39. Explicar el tema de investigación a terceros & & $\mathrm{X}$ & $\mathrm{X}$ \\
\hline 41. Organizar la presentación & & $\mathrm{X}$ & $\mathrm{X}$ \\
\hline
\end{tabular}

Es decir que la presencia de estos 11 actos no dependen de las características de los contextos, por ejemplo de la disponibilidad de la información, ya que los alumnos de la tríada focal 4 tenían acceso a las mismas fuentes de información que los alumnos de la tríada focal 3. Lo que se observó es que las interacciones estuvieron vinculadas a la toma de decisiones y los procesos colaborativos para la solución de problemas. Por último hubo nueve actos comunicativos que sólo estuvieron presentes en una de las tres tríadas (Tabla 5). 
ALFIN para alumnos de educación primaria: propuesta de ...

\begin{tabular}{||l|c|c|c||}
\hline \multicolumn{4}{|c||}{$\begin{array}{c}\text { Tabla 5 } \\
\text { Actos que se presentaron en una de las tríadas } \\
\text { focales de los estudios 1 y 2 }\end{array}$} \\
\hline \multicolumn{1}{|c|}{ Actos comunicativos } & Estudio 1 & Estudio 2 & \\
\hline 3. Proponer temas de investigación & Tríada focal 3 & Tríada focal 4 & Tríada focal 5 \\
\hline 5. Justificar el tema de investigación & $X$ & & $X$ \\
\hline 8. Identificar fuentes de información & $X$ & & $X$ \\
\hline 16. Comparar dos o mas documentos & $X$ & & $X$ \\
\hline 19. Proponer estrategias de síntesis & $X$ & & $X$ \\
\hline 23. Justificar la estrategia de síntesis & $X$ & & $X$ \\
\hline 35. Proponer preguntas de investigación & & & $X$ \\
\hline 37. Copiar información & & $X$ & $X$ \\
\hline 38. Mostrar partes del documento o imágenes & & $X$ & $X$ \\
\hline 39. Explicar el tema de investigación a terceros & & $X$ & $X$ \\
\hline 41. Organizar la presentación & & $X$ & $X$ \\
\hline
\end{tabular}

Estos nueve actos corresponden a: i) demandas específicas de los proyectos de investigación de los alumnos (acto 26$)$; ii) procesos que se derivaron de las reflexión sobre el tema o los procesos de la ALFIN (actos 18, 33 y $34)$; iii) la necesidad de aclarar la tarea (actos 27, 28 y 34 ) y iv) la presencia de una mayor interacción dialógica entre tríadas (actos 36 y 40).

Estos actos comunicativos representan situaciones específicas en donde hubo procesos más reflexivos en la solución de problemas, tales como justificar, opinar o 
Tendencias de la Alfabetización Informativa en Iberoamérica

compartir puntos de vista sobre la información que estaban valorando.

\section{Dinámica de los actos comunicativos}

Como ya se mencionó antes, algunos de los actos comunicativos eran más complejos que otros debido a que se desagregaban en sub-actos. Los actos comunicativos que se detectaron como más complejos fueron: 10. Diseñar estrategias de búsqueda; 11 . Aplicar estrategias de búsqueda; 13. Refinar estrategias de búsqueda; 14. Aplicar criterios de valoración; 15. Explorar la información, 21. Co-construir el texto; 22. Auto revisar el texto; 31. Formatear las diapositivas, y por último 32. Auto-revisar las diapositivas. Se identificó que los sub-actos se presentaban de manera iterativa, cíclica y recursiva. Para ilustrar lo anterior se toman los actos comunicativos 10. Diseñar estrategias de búsqueda, 11. Aplicar estrategias de búsqueda, 12 Explorar los documentos recuperados en la búsqueda y 13. Refinar estrategias (Tabla 6). Cabe señalar que en el acto 12 no se observaron sub-actos.

Como se puede observar en la Tabla 6 en el acto comunicativo 11 se detectaron seis sub-actos, que se refieren a estrategias de búsqueda que los alumnos aplicaron para obtener la información para su investigación. Las interrelaciones que se identificaron en estos tres actos comunicativos se presentan en la Figura 1. 
ALFIN para alumnos de educación primaria: propuesta de ...

\begin{tabular}{|c|c|}
\hline \multicolumn{2}{|c|}{$\begin{array}{c}\text { Tabla } 6 \\
\text { Dinámica de los actos comunicativos } 10,11,12 \text { y } 13\end{array}$} \\
\hline \multirow{2}{*}{$\begin{array}{l}\text { Acto comunicativo } 10, \\
\text { Diseñar estrategias de búsqueda }\end{array}$} & Sub-actos \\
\hline & $\begin{array}{l}\text { Identificar los términos de búsqueda. } \\
\text { Identificar el tipo de búsqueda }\end{array}$ \\
\hline \multirow{7}{*}{$\begin{array}{l}\text { Acto comunicativo } 11 \text {, } \\
\text { Aplicar estrategias de búsqueda }\end{array}$} & Sub-actos \\
\hline & Buscar en orden alfabético \\
\hline & Buscar por frases \\
\hline & Buscar por operadores boleanos \\
\hline & Buscar por URL \\
\hline & Navegar \\
\hline & Preguntar a un especialista \\
\hline \multirow{3}{*}{$\begin{array}{l}\text { Acto comunicativo } 13 \text {, } \\
\text { Refinar estrategias de búsqueda }\end{array}$} & Sub-actos \\
\hline & Limitar (temas, fechas, etc.) \\
\hline & Ampliar (temas, fechas etc.) \\
\hline
\end{tabular}

Figura 1

Actos comunicativos en el evento comunicativo C. Buscar información.

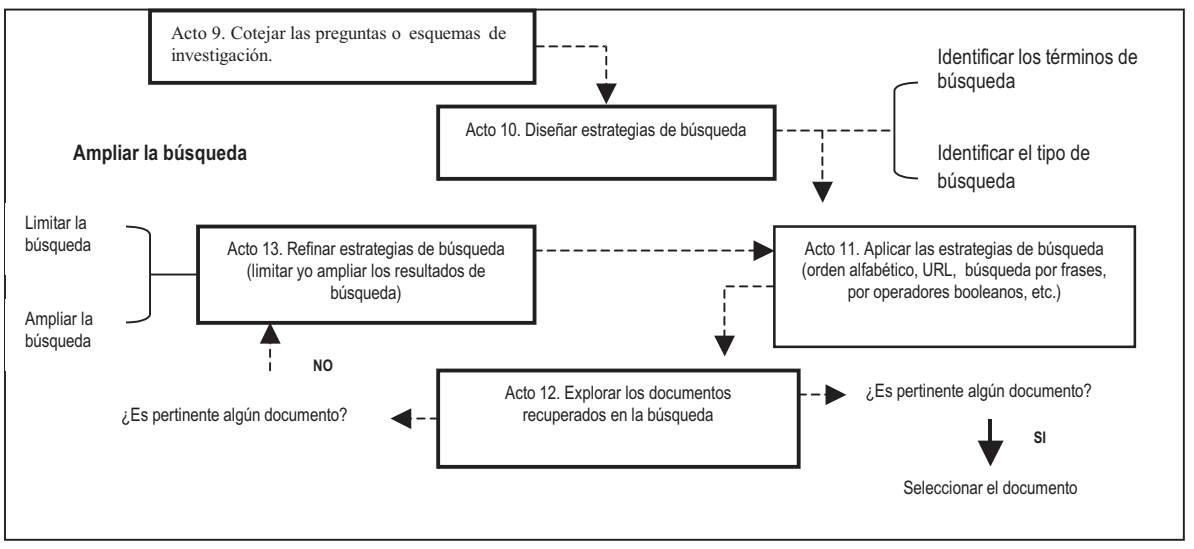


En la Figura 1 se observa que los alumnos primero cotejaron sus preguntas de investigación o sus esquemas, para a partir de ello diseñar sus estrategias de búsqueda (actos 9 y 10). Como parte de las estrategias de búsqueda identificaron los términos más adecuados y seleccionaron el tipo de búsqueda que realizarían. Estas estrategias estuvieron determinadas por los conocimientos previos de los alumnos sobre su tema, así como por las experiencias al buscar información para su investigación.

Al aplicar la estrategia de búsqueda (acto 11), los alumnos obtenían listados de resultados o una serie de documentos que tenían que ser valorados. La valoración consistía en el cotejo de los documentos o del listado de resultados con las preguntas de investigación (acto 12), este cotejo se realizó a partir de una lectura de tipo exploratoria

Dependiendo de la valoración, los documentos eran seleccionados o no. Si no eran seleccionados los alumnos refinaban sus estrategias de búsqueda (acto 13). Este proceso implicó dos acciones generales, limitar o ampliar la búsqueda de información. Para ampliar la búsqueda utilizaban términos más generales (por ejemplo buscar el tema de las focas en zoología); también utilizaban sinónimos, otras fuentes de información u otras estrategias de búsqueda. En el caso de la limitación los alumnos utilizaban términos más específicos (peletería de focas, en lugar de focas), también incluían más términos o datos relacionados con el contexto, fechas, países, etc. Para ilustrar una interacción dialógica a continuación se presenta un ejemplo para explicitar cómo se obtuvieron los datos reportados. 
ALFIN para alumnos de educación primaria: propuesta de ...

Figura 2

Esquema de la tríada focal 3

\section{El fin del mundo}

Causas

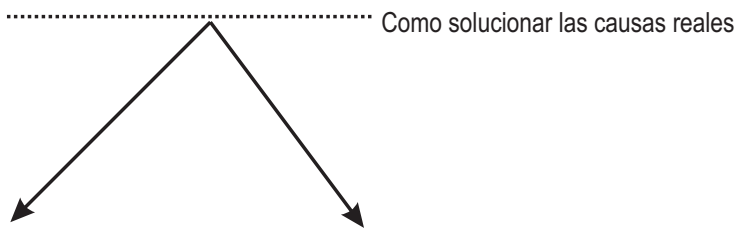

De la naturaleza

Depende del hombre

Ejemplo de análisis aplicando el método de la etnografía de la comunicación

El ejemplo corresponde a la tríada focal 3, la cual ha seleccionado el tema "Causas del fin del mundo". Los alumnos elaboraron un esquema de comparación-contraste para identificar las causas provocadas por el hombre y las que son de origen natural. El esquema que los alumnos elaboraron está representado en la Figura 2.

El esquema nos permite anticipar que los alumnos llevaran a cabo procesos de búsqueda y evaluación de la información, en los que emitirán juicios de valor sobre lo que están leyendo. Al respecto se presenta un diálogo que sostuvieron en la sesión 4, en el cual la conversación se centra en la comprensión de los criterios de valoración. 
- Tríada focal 3

- Sesión 4

- Situación comunicativa: II. Identificar fuentes de información

- Eventos comunicativos: C. Búsqueda de información y D. Evaluación de la información

\section{Diálogo 1}

En estos eventos los alumnos no elaboraron documentos, sólo se pusieron de acuerdo en las características de la información que van a buscar. Los alumnos se encuentran en el aula de medios, está iniciando la sesión y se acomodan para iniciar la actividad. Tienen una computadora y su esquema de investigación. El facilitador se acerca:

329 Facilitador: Ayer, estuvimos con otros niños, la mayoría toma lo primero que está a la mano, sin verificar si es verdad o mentira ¿Se imaginan qué pasaría si tomamos información que no es verdadera?

330 Oscar: Ya ni modo [risas].

331 Facilitador: ¡Cómo! ¿Ya ni modo? [risas], ¿Qué pasaría si lo que decimos no es verdad? Entonces la gente va a pensar que nuestro trabajo está mal. Podemos confundir a las personas o dar información falsa.

332 Oscar: Pero ahí te viene la lógica, no vas a poner cosas que no.

333 Marta: Pero ¿cómo saber qué es lógico?

334 Facilitador: Sí, muy buena pregunta ¿cómo sabemos qué es lógico? 
ALFIN para alumnos de educación primaria: propuesta de ...

335 Oscar: Revisando la información.

336 Irma: Que no tenga punto com.

337 Marta: Luego los papás también se equivocan.

338 Facilitador: A ver... ¿Cómo podemos saber si la información que tenemos es buena o no? Es importante lo que dices. Pero ¿cómo podemos saber?

339 Oscar: Buscando más información y comparando.

340 Marta: Le dices a tu papá y a tu tío y ves quien tiene razón.

341 Facilitador: Sí comparamos información entre dos páginas en Internet o entre dos revistas, luego tienes que decidir. ¿En qué aspectos de las fuentes nos fijamos para evaluar la información?

342 Oscar: Si es punto org

343 Facilitador: Si es de Internet en la terminación, ¿en qué otra cosa?

344 Irma: Si es punto $\mathrm{mx}$

345 Facilitador: Todo eso son terminaciones. Aparte de las terminaciones ¿en qué otra cosa nos fijamos?

346 Oscar: En el nombre de la página.

347 Facilitador: Sí, pero ¿qué es lo más importante?

348 Irma: Que tenga lo que quieres encontrar, si no para qué lo buscas.

349 Facilitador: Muy bien, y eso qué es ...

350 Oscar: El tema.

351 Facilitador: Si tienes razón el tema es una de las cosas más importantes 
En el diálogo 3, el facilitador primero sensibiliza a los alumnos sobre la importancia de evaluar la información (turnos 329 y 331). Luego, Oscar propone usar la "lógica" para evaluar la información (turnos 332-335). Más adelante aclara, que la lógica consiste en comparar la información de dos o más fuentes (acto comunicativo 16. Comparar dos o más documentos, turnos 338-342). Para Marta, la búsqueda de información incluye la consulta a personas (acto comunicativo 11. Aplicar estrategias de búsqueda, sub-acto preguntar a un especialista, turno 341). El facilitador revisa e insiste en los criterios de evaluación de autoridad (acto comunicativo 14. Aplicar criterios de valoración", sub-acto, valorar la autoridad, turnos 343-346) y el relativo a la temática (348-351).

\section{Propuesta DE MODELO ${ }^{2}$}

A partir de los resultados empíricos obtenidos por la investigación se elaboró una propuesta de modelo el cual puede ser útil para comprender y promover los procesos de apropiación de la ALFIN, así como para establecer la normatividad necesaria para su evaluación. El modelo retoma los elementos esenciales de la perspectiva sociocultural en la forma en la que se promovieron en el progra$\mathrm{ma}$ "Aprendiendo Juntos". Estos elementos se

2 Para un análisis detallado de los modelos de comportamiento informativo consulte Wilson (2005). También puede consultarse el análisis sobre modelos de comportamiento en la búsqueda de información de Hernández, Ibáñez, Valdéz y Vilches (2007). 
ALFIN para alumnos de educación primaria: propuesta de ...

relacionan con los conceptos mencionados en los apartados de conceptos y con el marco teórico de este trabajo.

$\mathrm{El}$ primer proceso que se retoma en el modelo (ver figura 2) se refiere a la comprensión holística, integrada y articulada de todo el proceso de ALFIN. En este sentido, se parte de que los alumnos son capaces de identificar problemas de información asociados a prácticas que se presentan en los escenarios de la escuela o de la vida cotidiana. Estos escenarios son fuentes ricas de exploración para los alumnos, quienes encuentran en la ALFIN un proceso que los lleva, en primer término, a reconocer que tienen necesidades de información relacionadas con lo que desean conocer o aprender (cognitivas), con lo que sienten o piensan (afectivas) y con su salud o su organismo (fisiológicas).

En el modelo las prácticas sociales y necesidades de información están representadas en la parte superior del modelo (Figura 2, elementos I. Prácticas sociales y II. Necesidades de información). ${ }^{3}$

El siguiente proceso es el relativo a los principios que permiten una participación social, en términos de la negociación de significados ${ }^{4}$ y del respeto a las posiciones e ideas de los demás sobre un tema. Este conjunto de principios está relacionado con la colaboración (Figura 2,

3 Los números romanos y las letras mayúsculas de los procesos de ALFIN son usados con fines de descripción y no representan una secuencia.

4 Entendida como los procesos para ponerse de acuerdo y lograr una comprensión común de un concepto o tarea, ente otras. 


\section{Tendencias de la Alfabetización Informativa en Iberoamérica}

Figura 2

Modelo para guiar los procesos de apropiación de la

ALFIN [elaborado por Vega, 2009)

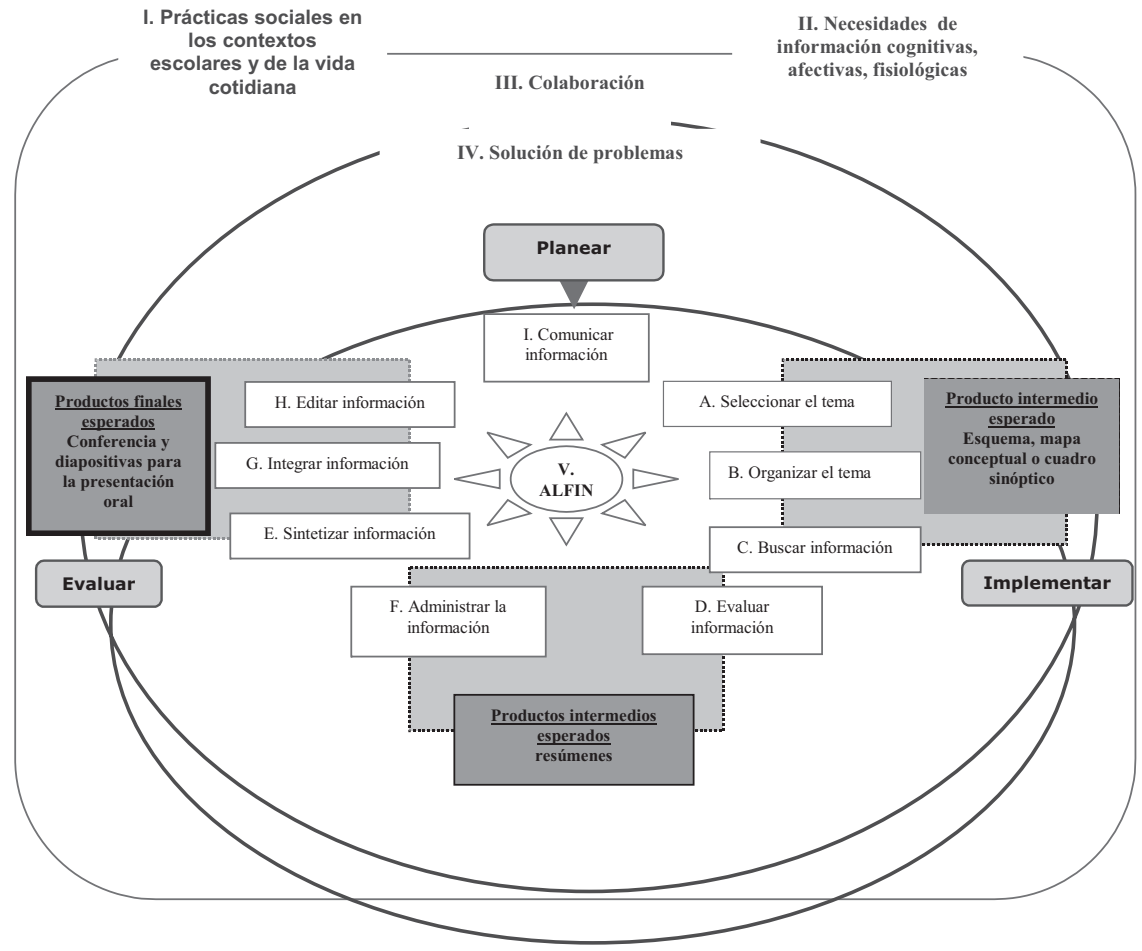

Supervisar 
ALFIN para alumnos de educación primaria: propuesta de ...

elemento III. Colaboración), y sus objetivos son enriquecer las formas de interacción en el aula, así como fortalecer la comunicación entre los alumnos en la construcción del conocimiento. Estos principios se basan en la propuesta de Mercer (1997), sobre la promoción del habla exploratoria en el aula.

A partir de los principios de habla exploratoria se pretende que los alumnos participen activamente en diálogos amplios que les permitan articular, reflexionar y modificar su comprensión de la realidad. El fundamento es que los alumnos, al trabajar en colaboración, toman decisiones razonadas y que los problemas a resolver se centran en los intereses y necesidades de todos los integrantes.

Otro conjunto elemento del modelo es el IV. Solución de problemas. En este caso primero se enfatizan los procesos de planeación, implementación, supervisión y evaluación. Posteriormente se analizan las estrategias específicas para estructurar el problema mediante la identificación de los elementos clave y su representación gráfica. Se continúa con el análisis de las diferentes alternativas de solución en las que se involucran las fuentes de información disponibles. Luego se aborda la implementación incluyendo la supervisión continua, la corrección y el acondicionamiento del plan inicial a las situaciones imprevistas. Finaliza con la valoración del proceso en relación con la meta planteada, así como la identificación de los aspectos de la resolución del problema que son susceptibles de ser aplicados en otros problemas similares. 
Como parte de las habilidades de solución de problemas, se propone que los alumnos desarrollen un proyecto que vincule las necesidades de información derivadas de las prácticas sociales de las comunidades en las que participan. Este proyecto constituye una iniciación a los métodos de investigación y se compone de una serie de procesos en los que se incorpora el uso funcional, la información para fortalecer la oralidad y la lecto-escritura. La oralidad se promueve en función de la conversación argumentada y la comunicación de las ideas. La lecto-escritura se fortalece en función de la comprensión y producción de diferentes tipos de textos, entre los que sobresalen los de tipo expositivo.

El proyecto tiene metas parciales que, en el caso del modelo, se relacionan con el desarrollo de productos escritos que los sujetos elaboran para elaborar un texto integrado. Los productos se elaboran a partir de las diferentes experiencias con información, la cuales se explicitan en el elemento V. Alfabetización informativa [ALFIN]. Los procesos que están involucrados son:

\section{Elegir el tema}

La elección del tema es un proceso en el que los alumnos tienen la oportunidad de expresar sus necesidades de información de manera abierta y a partir de sus propias visiones del mundo. En principio la selección del tema debe atender a dos aspectos, primero que sea de interés para ellos, y segundo, que sea de interés para resolver un problema o comprender una situación de su comunidad. Con ello, se busca que los alumnos se sientan motivados a investigar y comprender los diferentes textos. 
ALFIN para alumnos de educación primaria: propuesta de ...

En nuestro estudio se detectó que los contextos, escolar y de la vida cotidiana, influyeron de manera importante en la selección de los temas de investigación de los alumnos. Lo que desde nuestra perspectiva significa que sus temas estaban derivados de interés por participar en prácticas sociales, tales como el cuidado del medio ambiente, o de situaciones que afectaban su sentido de seguridad, entre otros. Este interés se incrementa en la medida que los alumnos toman conciencia de que su participación en el planteamiento de soluciones está relacionada con el análisis e interpretación de la información adecuada.

\section{Organizar el tema}

En este proceso los alumnos elaboran una representación gráfica (esquema, mapa conceptual, etc.) sobre lo que quieren aprender sobre el tema que han elegido. Para orientar la organización del tema, se promueve el uso de las estructuras que subyacen en los textos de tipo expositivo, tales como la definición, la colección, el mecanismo de problema-solución o el de comparacióncontraste y de causa-efecto (Meyer, 1984; Horowitz 1985; Sánchez 1993).

Una vez que han realizado la representación gráfica de su tema los alumnos elaboran una serie de preguntas para expresar lo que desean investigar. En el proceso de organización del tema, se presta particular atención a los términos, frases y preguntas de investigación elaboradas por los alumnos, dado que éstos guían, de manera flexible y dinámica, la búsqueda, la evaluación y la síntesis de la información (Novak y Gowin, 1984/1988). 
También son importantes para orientar la elaboración de los diferentes productos escritos (resúmenes, conferencia y diapositivas).

\section{Buscar información}

Este proceso consiste en diseñar y aplicar estrategias de búsqueda para recuperar información útil de las fuentes de información impresos y electrónicos. Existen cinco aspectos que pueden afectar este proceso, estos son: 1) el dominio de la temática a buscar, 2) las características de la tarea, 3) las características de la fuente de información, 4) el medio en el que se desarrolla la investigación y 5) los requerimientos de búsqueda (Marchionni, 1995).

El dominio de la temática se relaciona con los requerimientos de búsqueda y se refieren al repertorio de términos y conceptos relacionados con el tema de investigación, que el alumno utilizará para buscar información. En un inicio, éste repertorio se construye a partir de los conocimientos previos de los alumnos, y se va enriqueciendo conforme avanzan en su investigación, a la par que mejoran sus estrategias de búsqueda y son más hábiles para identificar las fuentes de información adecuadas.

En relación con las características de las fuentes de información La recuperación de la información incluye la identificación de estas fuentes, así como el diseño, aplicación y refinamiento de estrategias de búsqueda para obtener información pertinente y relevante. Entre las estrategias que se promueven se encuentran la recuperación por índices, por campos (autor, título, tema, idioma, etc.), y por herramientas específicas de cada recurso 
ALFIN para alumnos de educación primaria: propuesta de ...

de información (por ejemplo, los operadores boleanos en el caso de los recursos electrónicos).

En el caso del medio en el que se desarrolla la búsqueda, se observa que la mejora en la selección de términos y en las estrategias de búsqueda sea o se vea favorecida con la interacción que se establece con las fuentes electrónicas. Ya que a partir de esta interacción los alumnos pueden ensayar diferentes términos y evaluar los resultados para determinar si las fuentes de información y los términos empleados son adecuados.

\section{Evaluar la información}

Este proceso implica el establecimiento y aplicación de juicios de valor sobre los documentos recuperados. En la valoración inciden los conocimientos previos, los criterios aplicados y, de manera importante, la situación y el contexto en el que se evalúa. Acorde con ello, en el Módulo de ALFIN, la evaluación que se promueve se basa en explicitar algunos de los criterios de valoración de la información propuestos por Wang y Soergel (1998) que son pertinentes para educación primaria.

Estos criterios se abordan a partir de los elementos de un documento, tales como el autor, título, pie de imprenta y formato en el que se publica. Estos elementos son relacionados con tres criterios de evaluación, tales como el de temática (título, tabla de contenido y contenido del documento), autoridad (autor, editorial y editor) y actualidad (fecha de publicación o de última revisión). 
Los criterios vinculan los requerimientos de la investigación, en este sentido las preguntas planteadas al inicio de su investigación juegan un papel importante, ya que cada pregunta desencadena procesos de evaluación diferentes. Al respecto se considera que hay tres clases de valoración de información: 1) la referente a los hechos, 2) la relacionada con la identificación del punto de vista correcto y, 3) la que se refiere al análisis y escrutinio de los datos (Limberg y Sundín, 2006). En el primer caso las preguntas son de tipo factual (¿cuándo ocurrió?, ¿quién intervino?, etc.). En el segundo las preguntas requieren de la valoración crítica (¿cuáles son las causas?, ¿qué puntos de vista son los más objetivos?, etc.). En el último caso, consideramos que las preguntas son explicativas (¿por qué ocurren ciertos fenómenos?, ¿cuál es la justificación?).

\section{Sintetizar la información}

En este proceso se solicita a los alumnos que elaboren resúmenes con la información que han seleccionado. Se considera que en los procesos de síntesis el alumno tiene una participación activa en la construcción de representaciones mentales de lo leído para identificar las ideas principales a partir de sus conocimientos sobre el lenguaje, sus conocimientos previos y su conocimiento sobre el mundo; de modo tal que pueda enlazar la información previa con la recién adquirida. Además, la comprensión de un texto está vinculada con los propósitos del lector, puesto que mientras más claro tenga el objetivo, mejor podrá planificar sus lecturas y lo que extraerá de ellas. 
ALFIN para alumnos de educación primaria: propuesta de ...

Para modelar las estrategias de síntesis e integración de la información se promueven las propuestas de Van Dijk y Kintsch (1983), sobre las macroestructuras textuales; éstas se definen como la "representación abstracta de la estructura global del significado del texto". En otras palabras, son las representaciones mentales que nos permiten seguir la coherencia de un texto y conocer el contenido global de un mensaje. El conocimiento de las macroestructuras de un texto permite generar una representación de los textos relacionada con procesos de síntesis, como:

- Supresión. Es la operación mental para descartar la información de poca importancia, que está repetida o que no es relevante para los propósitos del lector.

- Generalización. En esta operación se realizan agrupaciones conceptuales a partir de esquemas de clasificación de los contenidos, y se propone un término supraordenado que las abarque.

- Construcción. En este proceso, la operación mental es la inferencia del contenido del texto de manera global. Es decir, la información del texto se sustituye por la que el lector va proponiendo conforme a sus conocimientos previos y el contexto que lo rodea.

Estas estrategias son útiles tanto para la comprensión lectora como para la elaboración de textos. En el modelo se reconoce que el proceso de síntesis tiene diferentes niveles de dificultad, en el primero los alumnos tienen que sintetizar su propio conocimiento en un esquema que represente el tema a investigar. En el segundo sintetizan diferentes textos, en el tercer nivel sintetizan la información de los textos que resumieron y por último, 
sintetizan los resultados de la investigación para presentarlos ante una audiencia.

\section{Administrar información}

Un proceso paralelo a la comprensión lectora es el registro ordenado de las fuentes de información. En el Módulo "Aprendiendo Juntos", se promueve el uso del estilo bibliográfico básico que incluye los siguientes elementos como autor, título, edición, lugar de publicación, editorial y año. En el caso de las revistas, además de los elementos anteriores se consigna el número de volumen, número y el año de la publicación. Para los recursos electrónicos de Internet, se incluye la dirección electrónica y la fecha de consulta. Con ello se busca más que una norma específica, que los alumnos sean conscientes sobre la pertinencia de ofrecer al lector datos relativos a las fuentes que leyeron o consultaron para elaborarlo, brindando así la oportunidad de localizarlos y fortaleciendo en los alumnos, el respeto a los derechos de autor.

\section{Integrar información}

La integración de la información consiste en la confección de un texto coherente a partir de los diferentes resúmenes que elaboraron. Para elaborar dicho texto los alumnos se apoyan en las representaciones gráficas de su tema o en las preguntas de investigación que elaboraron.

Para elaborar este texto los alumnos aplican las macroestructuras textuales descritas anteriormente. La elección de la macroestructura, desde nuestro punto de vista, se vincula con las preguntas de investigación. Por 
ALFIN para alumnos de educación primaria: propuesta de ...

ejemplo si las preguntas requieren discernimiento crítico, entonces los alumnos necesitarían comparar datos y hacer generalizaciones sobre lo que están leyendo, mientras que en las preguntas de tipo factual la macroestructura empleada puede ser, principalmente, de supresión.

\section{Editar información}

Este proceso tiene como objetivo que los alumnos elaboren los auxiliares visuales en los que se auxiliarán o auxiliaron para exponer los hallazgos de su investigación. Estos auxiliares pueden ser diapositivas, carteles, láminas, etc. La estructura de los auxiliares se basa en el orden propuesto por el esquema inicial, enfatizando las preguntas de investigación y las respuestas que encontraron a sus dudas.

De manera más específica, los auxiliares que elaboren los alumnos deben incluir: título, nombre del equipo, participantes, introducción, objetivo, preguntas de investigación, resultados de la investigación y conclusiones. De manera deseable se incluyen imágenes. Sonidos, videos, maquetas, juguetes, etc. que puedan enriquecer la presentación.

\section{Comunicar información}

Uno de los productos de los alumnos es una conferencia multimedia en la que los alumnos, además de los textos, integran otros elementos, como sonido, imágenes, dibujos, animaciones, etcétera. 
El objetivo es que los resultados de la investigación se vean, no como parte de una calificación, sino como una oportunidad para expresar sus inquietudes e intereses ante un público amplio interesado en los hallazgos del proyecto de investigación. La audiencia para las conferencias se compone de los integrantes de la comunidad a la que pertenece el alumno, y puede estar compuesta por otros alumnos, maestros, padres de familia y autoridades de la escuela, entre otros asistentes. Se considera que esta forma de comunicación, permite que los alumnos centren su motivación en el hecho de que tal información puede contribuir en la búsqueda de soluciones de manera informada.

Cabe señalar que los procesos de comunicación son constantes a lo largo de todo el proceso de ALFIN, y que éstos constituyen la base del análisis que se presenta. Sin embargo en este caso la comunicación se refiere al acto de presentar los resultados de su investigación a otros.

\section{CONCLUSIONES}

Uno de los principales problemas para promover la ALFIN en los alumnos de educación básica es que hay pocas evidencias sobre cómo se origina y se promueve su apropiación. Es común que se fragmente el proceso de ALFIN, y que se analicen sus componentes de manera aislada, lo que sacrifica la naturaleza dinámica del proceso como un todo. También es común que se analice el comportamiento informativo de los sujetos, desligado del contexto en el cual éste se origina, o que se realicen estudios basados en entrevistas o cuestionarios que recogen las percepciones o los puntos de vista de los sujetos de es- 
ALFIN para alumnos de educación primaria: propuesta de ...

tudio, en un momento dado, sin dar seguimiento a las prácticas, acciones y a la aplicación reflexiva de la ALFIN, (cfr. Vega, 2009). En contraparte, el modelo que se propone es una contribución a la comprensión holística e integrada de los procesos involucrados en la ALFIN. El propósito aquí es que esta comprensión sirva de apoyo para diseñar programas de alfabetización informativa eficaces y fundamentados teórica y empíricamente.

La comprensión holística del proceso de la ALFIN incluye la identificación de las metas parciales para el logro de un objetivo general, así como la determinación de los roles de los participantes en el proceso y de sus formas de ser y de conocer a partir de su participación informada en una comunidad. Acorde con ello, los fines de la alfabetización informativa no se relacionaron con el uso de la información por sí misma, sino que se vincularon con las habilidades y conocimientos que son necesarios para fortalecer la valoración crítica de la información, la toma de decisiones y la elaboración de propuestas, entre otros fines.

En esta investigación se observó que la apropiación de la ALFIN es un proceso cuya complejidad radica tanto en la diversidad de actores y procesos que están involucrados, como en las múltiples interacciones dialógicas que son posibles. En este sentido el método etnográfico de la comunicación, permitió presentar un acercamiento a los tipos de interacciones y a la dinámica que se presenta en ellos. 


\section{REFERENCIAS}

American Library Association, Presidential Committee on Information Literacy, [ALA.PCIL], (1989), Final report, recuperado el 10 de julio de 2006, en http://www.ala.org/ ala/acrl/acrlpubs/whitepapers/presidential.htm\#.

Association of College and Research Libraries [ACRL], (2003), Information literacy competency standards, performance indicators and outcomes, recuperado el 1 de abril del 200, en http://www.ala.org/acrl/ilstandardlo.html .

Bawden, D. (2002), "Revisión de los conceptos de alfabetización informativa y alfabetización digital", en Anales de Documentación, 5, 361-408.

Bilal, D. (2004), "Research children's information seeking on the Web", en M.K. Chelton, y C. Cool (Eds.), Youth information seeking-behavior: Theories, models, and issues (pp. 271-291), Lanham, MD: The Scarecrow Press.

Candela, A. (2006), "Corrientes teóricas sobre el discurso en el aula", en Revista Mexicana de Investigación Educativa, 6 (12), 317-333

Cuevas Cerveró, A. y Vives, J. (2005), “La competencia lectora en el estudio PISA: un análisis desde la alfabetización en información", en Anales de Documentación, 8, 51-70.

Cuevas Cerveró, G. y García Quismodo, M.A. (2007), “La competencia lectora como modelo de alfabetización en información”, en Anales de Documentación, 10, 49-70.

Daniels, H. (2001/2003), Vygotsky y la pedagogía, México, D.F.: Paidós.

Gómez-Hernández, J. A. (2007), Alfabetización informativa: Cuestiones básicas, Anuario Think EPI, 43-50. 
ALFIN para alumnos de educación primaria: propuesta de ...

Hernández-Salazar, P. Ibañez Marmolejo, M., Valdez Hernández, G. y Vilches Malagón, C. (2008), Análisis de modelos de comportamiento en la búsqueda de información, en Ci. Inf., Brasília, 36 (1), 136-146.

Horowitz, R. (1985), “Patterns of texts: Part 1", en Journal of Reading, 28(5), 448-454.

Hymes, D. (1964), "Linguistics approaches”, Part 2, Transcultural studies in cognition", en American Anthropologist, New Series, 66(3), 6-56.

Hymes, D. (1964a), "Ethnography of communication", en American Anthropologist, New Series, 66(6), 1-34.

Hymes, D. (1972), "Models of interaction in language and social life", en Gumperz and Hymes, D. (Eds.), Directions in Sociolinguistics: The ethnography of communication, (pp. 35-71), London: Basil.

Instituto Nacional para la Evaluación de la Educación [INEE], (2005), “QQué resultados obtuvieron las entidades en las pruebas nacionales de comprensión lectora y matemáticas?", Colección de folletos: los temas de la evaluación, 11, México, D.F.: INEE.

International Federation of Library Associations and Institutions, [IFLA], (2005), Declaración de Alejandría sobre la alfabetización informativa y el aprendizaje a lo largo de la vida, Adoptado el 9 de noviembre de 2005. National Forum on Information Literacy, recuperado el 4 de mayo del 2007, en www.ifla.org/III/wsis/AlexandriaManifesto-es.html .

Licea de Arenas, J. y Gómez Hernández, J. A. (2002). "La alfabetización en información en las universidades", en Revista Investigación Educativa, 20(2), 469-486. 
Limberg, L. y Sundin, O. (2006), "Teaching information seeking: Relating information literacy eduction to theories of information behaviour", en Information Research, 12 (1), recuperado el 10 de noviembre del 2008, de http://informationr. net/ir/12-1/paper280.html .

Lindauer, B. G. (2006), "Los tres ámbitos de evaluación de la alfabetización informativa", en Anales de Documentación, 9 (6), 69-81.

Llyod, A. (2005), "No man (or woman) is an island: Information literacy affordances and communities of practice", en The Australian Library Journal, 54 (3), 230-238.

Lloyd, A. (2006), "Information literacy landscapes: An emerging picture", en Journal of Documentation, 62(5), 570-583.

Marchionini, G. (1995), Information seeking in electronic environments, Cambridge: Cambridge University Press.

Mazón, N. (2006), Fortalecimiento del uso del habla exploratoria y la producción de macroestructuras de textos expositivos a través de una innovación educativa, (Tesis doctoral, Universidad Nacional Autónoma de México, Facultad de Psicología, 2006).

Mercer, N. (1997), La construcción guiada del conocimiento, Barcelona: Paidós.

Meyers, E. M. (2007), "From activity to learning: Using cultural historical activity theory to model school library programmes and practices", en Information Research, 12(3), recuperado el 10 de noviembre del 2008, de http://informationr.net/ir/12-3/paper313.html . 
ALFIN para alumnos de educación primaria: propuesta de ...

México, Secretaría de Educación Pública [SEP], (2007), Evaluación Nacional del Logro Académico en Centros Escolares, Sistema de Consulta de Resultados de la Prueba ENLACE, México, D.F.: SEP, recuperado el 8 de mayo del 2007, en http://www.snie.sep.gob.mx/enlace.asp .

México, Secretaría de Educación Pública, Subsecretaría de Educación Básica [SEB], (2009), Plan de estudios 2009. Educación básica. Primaria, 2da. Edición. México, D.F.: SEP, Subsecretaría de Educación Básica, Dirección General de Desarrollo Curricular, recuperado el 23 de octubre del 2009, de http://basica.sep.gob.mx/reformaintegral/ sitio/pdf/generalizacion_P_estudios.pdf .

Newman, D., Griffin, P. y Cole, M. (1991), La zona de construcción del conocimiento: trabajando por un cambio cognitivo en la educación, Madrid: Morata.

Novak, D. y Gowin, B. (1984/1988), Aprendiendo a aprender, Barcelona: Martínez Roca.

Organización para la Cooperación y el Desarrollo Económico [OCDE], (2001), Knowledge and skills for life: First results from PISA 2000, París: OCDE.

Organización para la Cooperación y el Desarrollo Económico [OCDE], (2002), Adams and Margaret Wu (Eds.), PISA: Technical Report, R.. París: OCDE

Organización para la Cooperación y el Desarrollo Económico [OCDE], (2003), PISA: Assessment framework: Mathematics, reading, science and problem solving knowledge and skills, París: OCDE.

Palincsar, A. S. (1998), "Social constructivism perspectives on teaching and learning”, en Annual Revier of Psychology, 49, 345-375. 
Rojas-Drummond, S. M., Albarrán, D., Vega, G., Zúñiga, M. y Vélez, M. (2006), "Learning togheter: The creation of communities of inquiry supported by ICT, en MirandaNet e-Journal, recuperado el 17 de noviembre del 2006, en http://www.mirandanet.ac.uk/internat/mexico.htm

Rojas-Drummond, S. M., Mazón, N., Fernández, M. y Wegerif, R. (2006), "Explicit reasoning, creativity and co-construction in primary school children's collaborative activities", en Journal of Thinking Skills Creativity, 1(2), 84-94.

Sánchez, E. (1993), Los textos expositivos, Madrid: Santillana.

Saville-Troike, M. (2003), The ethnography of communication: An introduction. (3rd ed.), Malden, Ma.: Blackwell.

Van Dijk, T. A. (1983), La ciencia del texto, Barcelona: Paidós.

Vega Díaz, G. (2010), Alfabetización informativa: estudio sobre su apropiación en alumnos de primaria, (Tesis doctoral, Universidad Nacional Autónoma de México, Facultad de Psicología).

Vega Díaz, G. (2000), "Instrucción de usuarios y alfabetización informativa” (pp. 25-36), en J. Lau y J. Cortés (Compiladores), Desarrollo de habilidades informativas en instituciones de educación superior, Ciudad Juárez, Chih., México: UACJ.

Vygotsky, L. S (1979), El desarrollo de los procesos psicológicos superiores, Barcelona: Crítica.

Wang, P. y Soergel, D. (1998), "A cognitive model of document use during a research project”, Study I. Document selection, en Journal of the American Society for Information Science, 49(2), 53-99. 
ALFIN para alumnos de educación primaria: propuesta de ...

Wilson, T. D. (2005), "Evolution in information behavior modeling: Wilson's model”, en E. Fisher, S. Erdelez and L. Mckechnnie (Eds.), Theories of information behavior (pp. 31-36), Medford, NJ: Information Today.

Wilson, T. D. (2008), "Activity theory and information seeking", en Annual Reviere of Information Science and Technology, 42, 119-161.

Zurkowski, Paul (1974), The Information service environment - relationships and priorities, Washington, D.C.: National Commission on Libraries and Information Science, (ERIC Clearinghouse on Information Resources, Service No. ED 100391). 
Experiencias de formación de usuarios $y$ de babilidades informativas en Educación Superior 


\title{
La formación de usuarios en el Centro de Enseñanza de Lenguas Extranjeras de la UNAM: una experiencia de trabajo de más de diez años
}

\author{
JESÚS VALDEZ RAMOS \\ Centro de Enseñanza de Lenguas Extranjeras de la UNAM
}

\section{INTRODUCCIÓN}

\begin{abstract}
P ara escribir sobre los hechos y sucesos del pasado reciente el lugar común es recurrir al relato cronológico, en esta ocasión y para contar lo que ha sucedido en la biblioteca del Centro de Enseñanza de Lenguas Extranjeras (CELE) de la UNAM se pretende rebasar este lugar común y hacer una reflexión sistemática sobre el trabajo relacionado con la formación de usuarios que se ha desarrollado en la biblioteca del CELE. Esta tarea tiene varias implicaciones, por una parte, haber sido testigo y actor participante de los hechos y por otra poner una prudente distancia para que el producto de la reflexión resulte lo más objetivo posible. Éste será el reto que tiene frente a sí el autor de esta colaboración.
\end{abstract}


El propósito de esta colaboración es presentar los antecedentes, rasgos característicos y evolución del Programa de Formación de Usuarios (PFU) de la biblioteca del Centro de Enseñanza de Lenguas Extranjeras (CELE) de la Universidad Nacional Autónoma de México (UNAM). La información y datos que contiene este documento están organizados de la siguiente forma, primero se presenta el marco institucional y las características en las que se desarrolló el PFU. Segundo se describe el PFU, sus antecedentes y características. Tercero se señalan los perfiles de los participantes en el Programa. Cuarto se analizan las acciones didácticas y las consecuencias que éstas tuvieron en los estudiantes que participaron en el PFU. Quinto se señalan las características de diseño que distinguen a algunos de los materiales didácticos que fueron utilizados en el PFU. Sexto se muestran los resultados de dos tipos de evaluación que se utilizaron en el PFU. Y séptimo se presentan algunas consideraciones finales sobre la experiencia que se ha tenido en más de diez años del PFU.

\section{LA INSTITUCIÓN Y SUS CARACTERÍSTICAS}

El CELE de la UNAM se funda en 1966 y desde su creación se ha dedicado a la planeación, programación y enseñanza de cursos de lenguas extranjeras dirigidos principalmente a los estudiantes universitarios de nivel profesional y de posgrado de la UNAM. Actualmente su misión es desarrollar e impulsar la enseñanza y el aprendizaje de lenguas extranjeras en diferentes modalidades; la certificación, la formación y actualización de recursos humanos; la investigación en linguiística aplicada y la ex- 
La formación de usuarios en el Centro de Enseñanza de ...

tensión y difusión de la cultura y las lenguas que imparte a través de servicios de calidad a la sociedad mexicana en general y a la comunidad de la UNAM en particular.

Se imparten quince lenguas extranjeras diferentes: alemán, francés, inglés, italiano, portugués, ruso, japonés, árabe, catalán, coreano, chino, griego moderno, hebreo, rumano y sueco. La población de alumnos que asiste es de 7500 estudiantes que se inscriben cada semestre. A través de los cursos que se imparten en el CELE, se provee a los alumnos de una herramienta profesional y cultural indispensable para nuestro mundo globalizado, tomando en cuenta sus motivaciones, marcos de referencia nacionales e internacionales, enfoques y modalidades pedagógicas novedosas. Desde hace más de veinte años, el CELE realiza estudios e investigaciones en lingüística aplicada, a través del departamento de lingüística aplicada, que cuenta con seis áreas de investigación, y un seminario permanente de lingüística aplicada.

El CELE es una de las sedes del programa de posgrado en Lingüística de la UNAM, en donde se imparten la maestría en lingüística aplicada y el doctorado en lingüística. Asimismo se imparten la especialización en la enseñanza del español como lengua extranjera a distancia y el curso de formación de profesores de lenguas-culturas (CFPL-C), para inglés, francés, alemán, italiano, japonés, griego moderno, náhuatl, maya y purépecha.

En 1980 se instaló la biblioteca del CELE. Misma que en memoria de uno de los fundadores del CELE, en 1984 tomó el nombre de "Stephen A. Bastien". La biblioteca es una biblioteca tradicional y virtual, que ofrece un acervo y servicios de información de vanguardia. 


\section{EL PROGRAMA DE FORMACIÓN DE USUARIOS: ANTECEDENTES Y CARACTERÍSTICAS}

\section{Antecedentes}

En 1981 se puede ubicar el antecedente más remoto sobre acciones relacionadas con la formación de usuarios en la biblioteca, se trata de la tesis de María Guadalupe Olalde Ramos, ella fue la primera coordinadora de la biblioteca y elaboró y puso en práctica un modelo para la creación de un servicio de referencia especializado en lingüística, a través del cual se ofrecía un servicio para la elaboración de bibliografía especializada en lingüística.

Durante el periodo comprendido entre el año de 1982 a 1986, se inicia la sistematización de actividades específicas para la formación de usuarios a través de dos actividades al menos. Por una parte, visitas guiadas presenciales para los estudiantes del posgrado en lingüística $\mathrm{y}$ del curso de formación de profesores. Y por otra, charlas sobre el uso de índices impresos especializados como Lingusitic Language Behavior Abstrac, Educational Resources Information Center y Modern Language Association, en los cursos de metodología de investigación y en algunos cursos de escritura de textos académicos en inglés.

En 1987 se incorpora una herramienta de las tecnologías de información y la comunicación, se trata del video. En ese año se produce, en colaboración con TV-UNAM, el programa de video Bienvenidos a la biblioteca. Este programa, que tiene una duración de 18 minutos, es una pequeña ficción en la que a través de una visita a la biblioteca hecha por un estudiante, se 
La formación de usuarios en el Centro de Enseñanza de ...

muestran las colecciones y servicios que ofrece la biblioteca.

A partir de la experiencia que se tuvo con la producción del programa de video Bienvenidos a la biblioteca, en 1989 se iniciaron los trabajos del proyecto Diseño y producción de material didáctico en video para la enseñanza de lenguas en la UNAM. ${ }^{1}$ Dicho proyecto, actualmente vigente, desde su inicio ha estado financiado por el Programa de Apoyo a Proyectos para la Innovación y Mejoramiento de la Docencia (PAPIME) de la UNAM. El proyecto es una iniciativa colectiva de docentes e investigadores de diferentes dependencias de la UNAM que tiene entre sus objetivos el diseño y producción de videos para promover el uso adecuado de obras de consulta, específicamente de diccionarios bilingües y monolingües en trece lenguas diferentes.

En el marco de este proyecto se produce un programa multimedia, particularmente interesante por su diseño y población meta, se trata de un programa que promueve el uso de los recursos y servicios que ofrece la mediateca del CELE, espacio diseñado para el aprendizaje autodirigido de lenguas extranjeras.

En el periodo comprendido entre el año 2000 a 2003 se imparten una serie de talleres presenciales sobre el uso de índices especializados en lingüística y enseñanza

1 Para más información sobre el proyecto PAPIME Diseño y producción de material didáctico en video para la enseñanza de lenguas en la UNAM, se puede visitar la siguiente dirección: http://dla. cele.unam.mx/terminologia/jesus_valdez/index.html 
de lenguas. Los talleres se impartieron a estudiantes del posgrado en lingüística (UNAM), el curso de formación de profesores, profesores de asignatura del CELE y estudiantes de diferentes programas de licenciatura en enseñanza de lenguas de algunas universidades públicas de los estados circunvecinos con la ciudad de México.

Asimismo se imparte un curso presencial sobre el uso de recursos electrónicos de consulta e información sobre lingüística, éste es el antecedente y punto de partida para el diseño del programa de formación de usuarios de la biblioteca.

\section{El programa de formación de usuarios (PFU)}

En noviembre de 2004 inicia el PFU, cuyo objetivo general es formar a la comunidad del CELE para el desarrollo de habilidades informativas con el propósito de resolver problemas en materia de información, a través del uso de los recursos de información electrónica que ofrecen la biblioteca Stephen A. Bastien y el sistema de bibliotecas de la UNAM. El PFU está integrado por una serie de acciones didácticas, tales como, vistas guiadas, presenciales y virtuales, así como cursos y talleres que se imparten en dos modalidades: presencial y en línea.

A través del PFU se promueven aprendizajes significativos y el alumno aprende a aprender. Además se resuelven problemas prácticos a los que se enfrentará durante sus estudios y en su vida como profesional de la lingüística y de la enseñanza de lenguas. Enseguida se presentan dos imágenes, una se refiere a la descripción general del PFU y la otra es el modelo de diseño que se utilizó para planear las acciones del PFU. Veamos: 
La formación de usuarios en el Centro de Enseñanza de ...

Figura 1

Programa de formación de usuarios en línea

\section{Programa de Formación de Usuarios en línea}

\section{Módulo 2}

\section{Curso de}

Formación de

Profesores de

Lenguas-Culturas

\section{Módulo 3}

Posgrado en lingüística.

- Estudiantes de la

maestria en

lingüistica aplicada

- Estudiantes de la

maestría en

lingúistica hispánica

Estudiantes del

doctorado en

lingüistica

\section{Módulo 6}

Usuarios Externos:

- Estudiantes y

profesores de

las licenciaturas

de Lingûistica,

Enseñanza de

Lenguas, Letras

Modernas y

áreas afines

Descripción general del Programa de Formación de Usuarios en línea

La estructura del PFU en línea está compuesta por ocho módulos y cada módulo contiene diferentes actividades que a continuación se describen:

- Módulo1. Sesión inicial: Este módulo contiene: nociones básicas y fue diseñado para la comunidad académica del CELE y para usuarios externos, e incluye a los estudiantes de las licenciaturas en lingüística, enseñanza de lenguas, letras modernas y áreas afines. 
Asimismo este módulo se ofrece en línea, en la siguiente dirección http://ced.cele.unam.mx/moodle/course/view.php?id=53, es de acceso libre para todos los usuarios de la biblioteca Stephen A. Bastien.

- Módulo 2. Herramientas de investigación. Este módulo forma parte de las materias de tronco común del Curso de Formación de Profesores de Lenguas-Culturas (CFPL-C) que se imparte en el CELE de la UNAM. Este módulo se ha impartido a las últimas cuatro generaciones, es decir de 2006 a 2010. El diseño del módulo contempla dos sesiones presenciales y seis sesiones en línea. El acceso es restringido y está abierto sólo para los estudiantes inscritos en el CFPL-C. Para más información se puede consultar la siguiente dirección : http://ced.cele.unam.mx/moodle/file. $\mathrm{php} / 66 /$ modulo/indice.html.

- Módulo 3. Uso de herramientas electrónicas de información para estudiantes del posgrado en lingüística de la UNAM. Este módulo se encuentra en la fase de diseño de contenidos y está dirigido a los estudiantes de nuevo ingreso del posgrado en lingüística, es decir maestría en lingüística aplicada, lingüística hispánica y el doctorado en lingüística. Se les ha impartido de forma presencial un taller a los estudiantes de las últimas siete generaciones del posgrado en lingüística y se han editado dos manuales de ejercicios para los estudiantes que asisten a dicho taller. Los manuales se pueden consultar en las siguientes direcciones: http://www.cele.unam.mx/biblioteca/pdfs/cuader- 
La formación de usuarios en el Centro de Enseñanza de ...

nodetrabajo.pdf y http://www.cele.unam.mx/ biblioteca/pdfs/sitiosweb.pdf.

- Módulo 4. Este módulo está diseñado para los estudiantes que asisten a los diferentes diplomados impartidos por el CELE. Actualmente se han impartido una serie de talleres para el diplomado de traducción de textos especializados y para la especialización sobre la enseñanza del español como lengua extranjera. Se han utilizado como materiales de apoyo el manual de ejercicios que se encuentra disponible para su consulta en la siguiente dirección: http://www.cele. unam.mx/biblioteca/pdfs/cuadernodetrabajo.pdf.

- Módulo 5. Este módulo ha sido creado para los docentes que imparten cursos de lenguas extranjeras en el CELE. Hasta ahora se ha impartido al menos en tres ocasiones, durante los periodos inter semestrales, como talleres de actualización. Para el taller herramientas electrónicas de información: un apoyo al profesor de idiomas, se ha diseñado un manual de ejercicios que se puede consultar en la siguiente dirección electrónica: http://www.cele.unam.mx/ biblioteca/pdfs/herramientas06.pdf.

- Módulo 6. Este módulo ha sido diseñado para los usuarios externos, es decir, estudiantes de las licenciaturas en lingüística, enseñanza de lenguas, letras modernas y áreas afines, que visitan la biblioteca y solicitan información y orientación para el uso de los recursos electrónicos de información y los servicios que se ofrecen en la biblioteca. De este módulo se han impartido diferentes talleres y se han elaborado dos manuales de ejercicios que han servido de apoyo para 
la impartición de estos talleres. El contenido de los manuales se puede consultar en las siguientes direcciones electrónicas: http://www. cele.unam.mx/ biblioteca/pdfs/uabc.pdf y http://www.cele.unam. $\mathrm{mx} / \mathrm{biblioteca/pdfs/uaem.pdf.}$

- Módulos 7 y 8. Se encuentran en la fase de diseño de los contenidos. Estos modulos estarán dedicados a la evaluación de los módulos primero y tercero, los enfoques y procedimientos de evaluación se diseñarán de acuerdo al tipo de usuario. Este módulo es de autoevaluación para los módulos quinto y sexto, y estará diseñado para evaluar el aprendizaje de los usuarios externos de la biblioteca. Sin embargo se han llevado a cabo acciones de evaluación de forma sistemática y para propósitos de acreditación del módulo 2 Herramientas de Investigación. En la sección 6 de este documento se muestran con detalle el proceso y resultados de la evaluación.

\section{Modelo para el diseño del Programa de Formación de Usuarios}

Para establecer un patrón que regule el proceso de las actividades del PFU, se propuso un modelo de diseño para el PFU. Dicho modelo se presenta y explica de forma sucinta a continuación:

En la Figura 2, se presenta el modelo, en dicha figura se ilustra el proceso de diseño del PFU, se trata de un rectángulo en que se encuentran en los extremos los conceptos: la definición del contexto institucional, es decir el entorno en el que se desarrolla el PFU, y el concepto de articulación de creencias, a saber los supuestos teóricos que se 
La formación de usuarios en el Centro de Enseñanza de ...

Figura 2

Modelo para el diseño del Programa de Formación de Usuarios

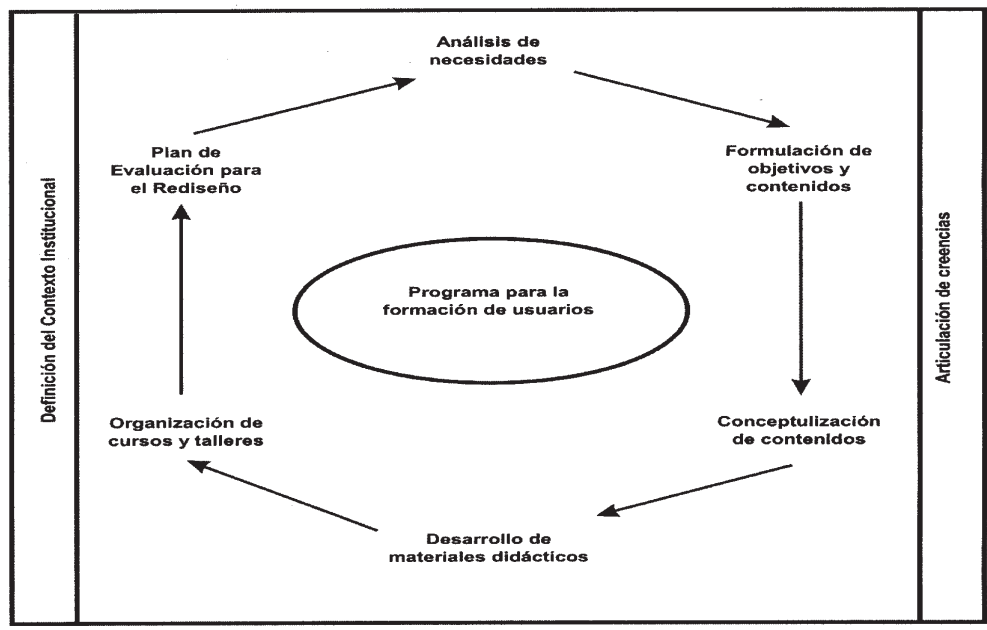

(Elaborado por Vega, 2009)

tomaron en cuenta en el diseño del PFU. Al interior del rectángulo, se encuentra una elipse que dice Programa para la Formación de Usuarios y alrededor de éste, una serie de conceptos y flechas que giran en el sentido de las manecillas del reloj. Los conceptos son: análisis de necesidades, formulación de objetivos y contenidos, diseño de los contenidos didácticos, desarrollo de materiales, organización de los cursos, evaluación y rediseño del programa, dichos conceptos son las etapas del proceso de diseño y la operación del PFU.

La gestión del PFU a partir de este modelo de diseño se puede considerar como una estructura flexible que ha permitido generar algunos productos, como materiales didácticos y el diseño de cursos y talleres, entre otros. 
La puesta en marcha del PFU y su operación estuvo integrada originalmente por cinco etapas:

- Presentación del proyecto ante las autoridades del CELE.

- Convenio de colaboración con el Centro Universitario de Investigaciones Bibliotecológicas de la propia UNAM, para recibir asesoría de la doctora Patricia Hernández Salazar, investigadora especialista del área de formación de usuarios.

- Entrevistas con profesores que imparten algunos de los módulos del CFPL-C y el posgrado en Lingüística.

- Impartición de talleres a los estudiantes del CFPL-C y del posgrado en lingüística.

- Sesiones de evaluación interna

\section{LOS PARTICIPANTES Y SUS PERFILES}

La población que ha participado en el PFU ha sido diversa. Por una parte, incluye a estudiantes de los cursos de lenguas, estudiantes de los cursos y diplomados que se imparten en el CELE, más estudiantes del posgrado en lingüística de la UNAM. Incluye también a profesores de los cursos, diplomados y del posgrado que se imparte en el CELE, y usuarios externos de la biblioteca, es decir, estudiantes y profesores de escuelas y facultades de lenguas de universidades públicas y privadas de los estados circunvecinos a la ciudad de México, como la Universidad Autónoma del Estado de México, Universidad Autónoma del Estado de Morelos, Universidad Autónoma de Tlaxcala y la Universidad Autónoma del Estado de Hidalgo, entre otras. Además, cuenta con un equipo de tres bibliotecólogos, un in- 
La formación de usuarios en el Centro de Enseñanza de ...

geniero de cómputo, un diseñador especialista en contenidos didácticos en línea y un pedagogo.

\section{LAS ACCIONES Y SUS CONSECUENCIAS}

Ante tal diversidad de participantes en el PFU la biblioteca ha respondido con diferentes acciones, tales como charlas introductorias, visitas guiadas -presenciales y virtuales-, talleres presenciales sobre uso de recursos electrónicos especializados en lingüística y enseñanza de lenguas, talleres presenciales como prerrequisito para los estudiantes del posgrado en lingüística y el diseño del módulo curricular "Herramientas de Investigación”, que se imparte en línea y forma parte de los módulos obligatorios del CFPL-C del CELE.

Las acciones didácticas del PFU se pueden caracterizar de la siguiente forma: primero, están diseñadas para el desarrollo de habilidades informativas que permiten al estudiante establecer una relación proactiva en procesos de la asimilación, la creación y la transmisión del conocimiento, característica similar a la que se reconoce en las Normas sobre alfabetización informativa en educación superior: declaratoria. (2004) editadas por la Universidad Autónoma de Ciudad Juárez. Y segundo tienen una gradación, es decir van de lo fácil a lo difícil, describiendo paso a paso los procedimientos para la búsque$\mathrm{da}$, recuperación, análisis y evaluación de la información, y promoviendo el descubrimiento paso a paso de las diferentes herramientas de información electrónicas.

Las consecuencias de las acciones realizadas han sido múltiples y detonadoras de procesos creativos e integradores. ¿Por qué múltiples? Porque han promovido el 
uso intensivo de recursos y servicios de información que ofrece la biblioteca, porque han incidido en un grupo amplio y diverso de usuarios y porque han integrado los recursos electrónicos de información al trabajo cotidiano de la comunidad de usuarios de la biblioteca.

¿Por qué detonadoras de procesos creativos integradores? Porque se ha conformado un equipo multidisciplinario para el diseño y elaboración de materiales didácticos utilizando TIC, porque han promovido un avance orientado hacia la formación de usuarios en línea y porque han iniciado un cambio para reconocer el papel del bibliotecario como docente, desde la biblioteca y a partir de los recursos de información que posee este espacio.

\section{LOS MATERIALES DIDÁCTICOS Y SU DISEÑO}

El desarrollo de los materiales didácticos para el PFU ha sido un trabajo de diseño, creación colectiva y colaboración multidisciplinaria. De esta manera, para el desarrollo de los materiales didácticos se tomaron en cuenta dos aspectos importantes y que caracterizan a los manuales de trabajo, cuadernos de ejercicios, CD ROM y actividades, tareas y foros del módulo en línea. El primer aspecto se refiere a las bases teóricas del aprendizaje significativo, así todos los ejercicios y actividades que están presentes en los materiales didácticos señalados, tienen una relación directa con algunos temas que se imparten en los cursos a los que asisten los usuarios de la biblioteca sobre el aprendizaje de una lengua extranjera, descripción lingüística y didáctica de las lenguas y psicolinguística. El segundo aspecto es el uso de las normas 
La formación de usuarios en el Centro de Enseñanza de ...

sobre alfabetización informativa en educación superior, para la redacción de los objetivos generales y particulares que se incluyeron en los materiales didácticos diseñados.

En los materiales didácticos se presentan contenidos temáticos de dos tipos, básicos y secundarios. Los básicos se refieren a la adquisición y desarrollo de habilidades para la búsqueda, recuperación, análisis y evaluación de la información de recursos electrónicos de información especializados en la enseñanza de lenguas y lingüística. Los secundarios se refieren al uso y aplicación de recursos electrónicos de información en diferentes tareas académicas, como los que se mencionan a continuación: los catálogos de la biblioteca, las bases de datos especializadas en lingüística y enseñanza de lenguas, las obras de consulta en línea, las revistas electrónicas de texto completo, los sitios web, los sitios con información sobre asientos bibliográficos y los derechos de autor.

Algunos ejemplos de estos materiales son los que se mencionaron en la sección "Descripción general del Programa de Formación de Usuarios en línea" de este documento y el Manual básico para la búsqueda y recuperación de información en $C D$ - $R O M$, entre otros (ver Figura 3).

2 Normas sobre alfabetización informativa en educación superior: declaratoria. (2004), Cortés, Jesús et a,. México: Universidad Autónoma de Ciudad Juárez, Dirección General de Información y Acreditación. 
Tendencias de la Alfabetización Informativa en Iberoamérica

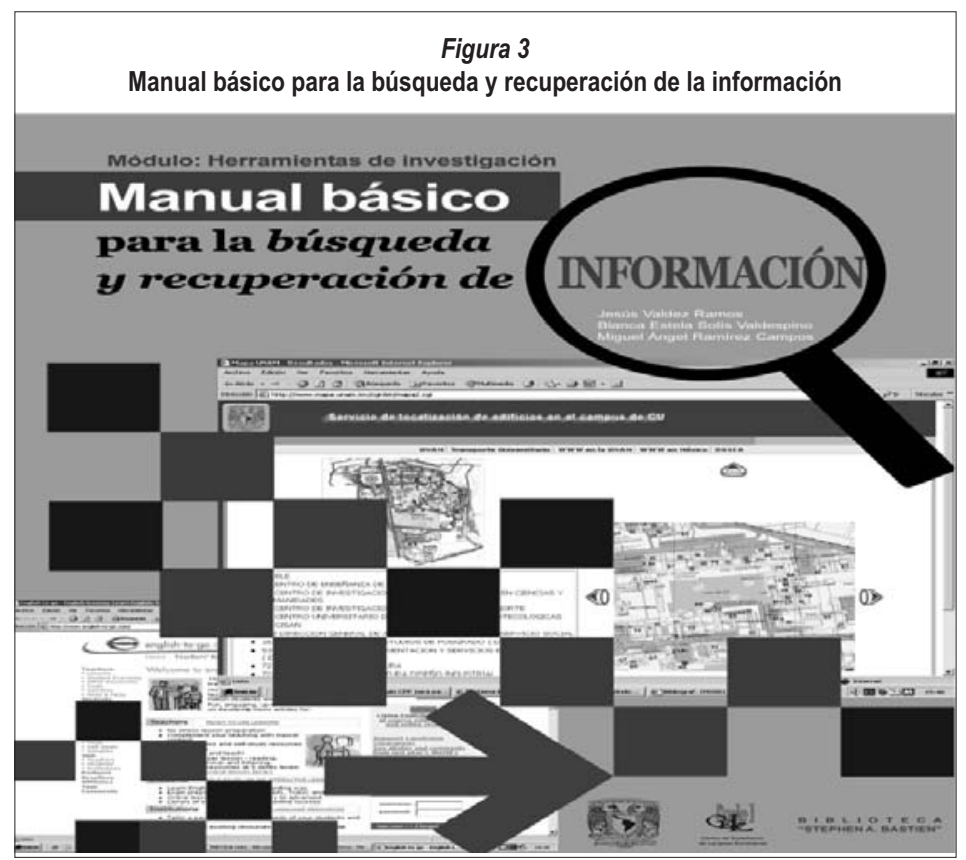

\section{LOS RESULTADOS Y SU EVALUACIÓN}

Evaluar los resultados de un programa de formación de usuarios es una tarea compleja. La evaluación es un proceso que realimenta y mejora las actividades y el diseño de materiales del PFU, entre otras acciones. Es una de las formas a través de las cuales se orienta al bibliotecario y al estudiante hacia la reflexión de la experiencia de enseñanza y de aprendizaje en la que participan. 


\section{La formación de usuarios en el Centro de Enseñanza de ...}

\begin{tabular}{||l|c|c|l||}
\hline \multicolumn{4}{|c|}{ Uso de fuentes de información } \\
\hline $\begin{array}{c}\text { Indicador 1 } \\
\begin{array}{c}\text { Tipos de } \\
\text { fuentes de } \\
\text { información }\end{array}\end{array}$ & $\begin{array}{c}\text { Generación 2005 } \\
\text { (muestra de 21 trabajos } \\
\text { finales) }\end{array}$ & $\begin{array}{c}\text { Generación 2006 } \\
\text { (muestra de 23 traba- } \\
\text { jos finales) }\end{array}$ & $\begin{array}{c}\text { Generación 2007 (muestra de 17 } \\
\text { trabajos finales) }\end{array}$ \\
\hline $\begin{array}{l}\text { Fuentes de } \\
\text { información } \\
\text { consultadas }\end{array}$ & $\begin{array}{l}\text { Formatos } \\
\text { Impresos: 19 libros que } \\
\text { fueron editados en las dé- } \\
\text { cadas de los años sesen- } \\
\text { ta a los años ochenta. } \\
\text { Electrónicos: } 9 \text { direccio- } \\
\text { nes electrónicas de dife- } \\
\text { rentes sitios sin respaldo } \\
\text { académico, que aparecen } \\
\text { en la página web de la bi- } \\
\text { blioteca. }\end{array}$ & $\begin{array}{l}\text { Formatos } \\
\text { Impresos: 27 libros edi- } \\
\text { tados en su mayoría a fi- } \\
\text { nales de los años } \\
\text { noventa a la fecha. } \\
\text { Electrónicos: 4 direccio- } \\
\text { nes electrónicos de re- } \\
\text { cursos electrónicos que } \\
\text { aparecen en la página } \\
\text { web de la biblioteca. }\end{array}$ & $\begin{array}{l}\text { Formatos } \\
\text { Impresos: 69libros editados a partir de } \\
\text { la década de los noventa a la fecha, } \\
\text { además de 24 artículos publicados en } \\
\text { revistas impresas y 4 ponencias pre- } \\
\text { sentadas en congresos relacionados } \\
\text { con la enseñanza de lenguas. } \\
\text { Electrónicos: 26 direcciones electró- } \\
\text { nicas de las cuales 18 corresponden a } \\
\text { revistas electrónicas, 6 a sitios web } \\
\text { que aparecen en la página web de la } \\
\text { biblioteca, 1 a bases de datos y 1 a un } \\
\text { e-book. }\end{array}$ \\
\hline
\end{tabular}

\begin{tabular}{|c|c|c|c|}
\hline \multicolumn{4}{|c|}{$\begin{array}{c}\text { Tabla } 2 \\
\text { Estructura del documento final }\end{array}$} \\
\hline $\begin{array}{l}\text { Indicador } 2 \\
\text { Estructura del } \\
\text { documento final }\end{array}$ & $\begin{array}{l}\text { Generación } 2005 \\
\text { (muestra de } 21 \\
\text { trabajos finales) }\end{array}$ & $\begin{array}{l}\text { Generación } 2006 \\
\text { (muestra de } 23 \\
\text { trabajos finales) }\end{array}$ & $\begin{array}{l}\text { Generación } 2007 \\
\text { (muestra de } 17 \\
\text { trabajos finales) }\end{array}$ \\
\hline $\begin{array}{l}\text { Portada } \\
\text { Índice } \\
\text { Introducción } \\
\text { Hipótesis } \\
\text { Metodología } \\
\text { Resultados } \\
\text { Conclusiones } \\
\text { Bibliografía }\end{array}$ & $\begin{array}{l}4 \text { trabajos finales que } \\
\text { sí contaron con los } \\
\text { elementos sugeridos } \\
\text { en el apartado de re- } \\
\text { portes académicos }\end{array}$ & $\begin{array}{l}8 \text { trabajos finales que sí contaron } \\
\text { con los elementos sugeridos en el } \\
\text { apartado de reportes académicos }\end{array}$ & $\begin{array}{l}17 \text { trabajos finales que sí } \\
\text { contaron con los elemen- } \\
\text { tos sugeridos en el apar- } \\
\text { tado de reportes } \\
\text { académicos }\end{array}$ \\
\hline
\end{tabular}


Tendencias de la Alfabetización Informativa en Iberoamérica

\begin{tabular}{||c|c|c|c||}
\hline \multicolumn{4}{|c|}{$\begin{array}{c}\text { Normas para elaboración de } \\
\text { citas y referencias }\end{array}$} \\
\hline $\begin{array}{c}\text { Indicador 3 } \\
\text { Normas de estilo } \\
\text { bibliográfico para } \\
\text { trabajos finales }\end{array}$ & $\begin{array}{c}\text { Generación 2005 } \\
\text { (muestra de 21 } \\
\text { trabajos finales) }\end{array}$ & $\begin{array}{l}\text { Generación 2006 } \\
\text { (muestra de 23 } \\
\text { trabajos finales) }\end{array}$ & $\begin{array}{c}\text { Generación 2007 } \\
\text { (muestra de 17 trabajos } \\
\text { finales) }\end{array}$ \\
\hline $\begin{array}{l}\text { Citas bibliográficas } \\
\text { y bibliografías }\end{array}$ & $\begin{array}{l}\text { 3 notas a pie de pá- } \\
\text { gina, 7 bibliografías } \\
\text { elaboradas bajo las } \\
\text { normas de la MLA. }\end{array}$ & $\begin{array}{l}12 \text { notas a pie de } \\
\text { página } \\
18 \text { bibliografúas } \\
\text { eleaboradas con } \\
\text { las normas MLA }\end{array}$ & $\begin{array}{l}111 \text { notas a pie de página, } \\
51 \text { citas en el cuerpo del } \\
\text { texto y 3 citas sin normas. } \\
17 \text { trabajos finales de los } \\
\text { cuales 8 utilizaron las nor- } \\
\text { mas MLA, 6 utilizaron las } \\
\text { normas de la APA y 3 traba- } \\
\text { jos no utilizaron ninguna } \\
\text { norma. }\end{array}$ \\
\hline \hline
\end{tabular}

La evaluación que se utilizó en el PFU del CELE tiene dos enfoques. Por una parte la evaluación cuantitativa de tipo sumativa, misma en que la metodología que se utilizó consistió en la revisión de trabajos finales de estudiantes del CFPL-C que asistieron al módulo en línea Herramientas de Investigación. Se analizaron los trabajos finales de tres generaciones 2005, 2006 y 2007 . Se trata de un ejercicio preliminar de evaluación que permite reunir evidencias de aprendizaje, a través del análisis de tres indicadores, para comprobar el desarrollo de habilidades informativas por parte de los estudiantes del CFPL-C. Este ejercicio de evaluación es un estudio analítico transversal. Los indicadores que se utilizaron en el ejercicio fueron los siguientes: uso de fuentes de información, estructura de los trabajos finales y el uso de normas para el asiento de citas, notas al pie de página o 
La formación de usuarios en el Centro de Enseñanza de ...

elaboración de bibliografía. Los resultados de este ejercicio de evaluación se muestran en las tablas 1, 2 y 3.

Mientras que el segundo enfoque consiste en la evaluación cualitativa. El enfoque metodológico proviene del método etnográfico y la técnica consistió en la observación directa en el salón de clases, en este caso en una clase de lengua extranjera. A través del uso de esta técnica no sólo se "retrata" lo que acontece en el aula, sino que se interpretan los sucesos, entonces se trata de una tarea que se complementa e integra, es decir por una parte el registro y por otra la interpretación de los hechos y de los actores participantes. De acuerdo con Corenstein (1989: 49) "en los estudios etnográficos cobran énfasis los actos cotidianos, ya que éstos otorgan una descripción profunda y detallada del fenómeno educativo". La tarea consistió en observar un acto cotidiano que sucede en una clase de lengua, en el salón de clases, en donde se da a conocer, a través de un video, al diccionario como obra de consulta, sus características, tipología, elementos que lo conforman, -macro, micro e icono estructurales- y en la que se promueve el uso del mismo y las ventajas que tiene en el proceso de aprendizaje de una lengua.

Los resultados en términos cualitativos acerca del uso de los programas de video a través de los cuales se promueve el uso adecuado de los diccionarios, bilingües y monolingües de la colección de consulta de la biblioteca del CELE, se presentan en la Tabla 4. 


\begin{tabular}{|c|c|c|c|c|c|c|c|c|c|c|c|c|c|c|c|}
\hline \multirow{4}{*}{ 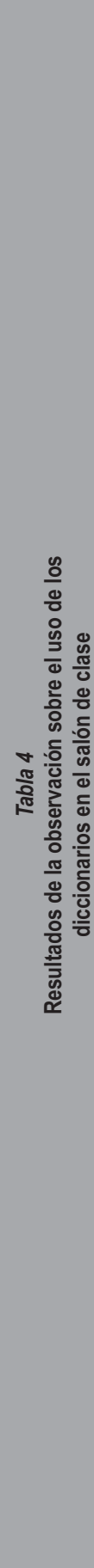 } & 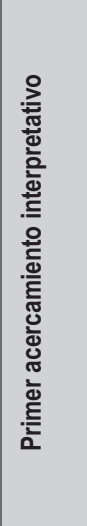 & 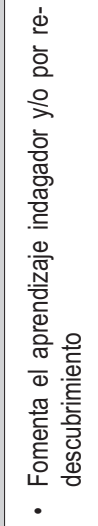 & 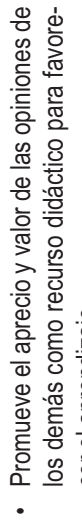 & 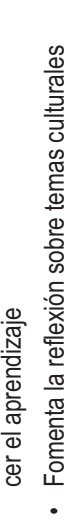 & 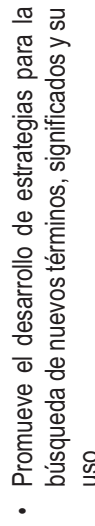 & 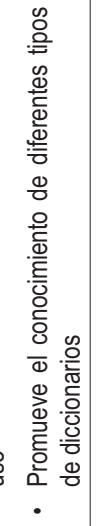 & 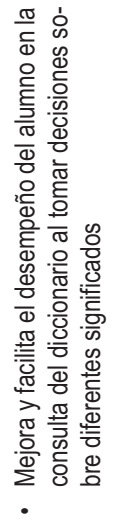 & 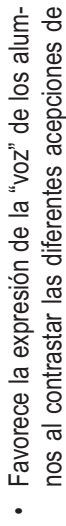 & 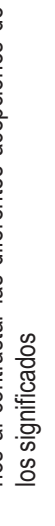 & 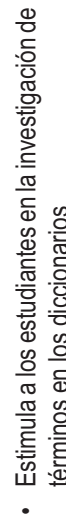 & 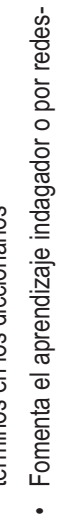 & 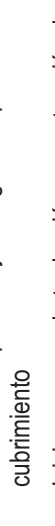 & 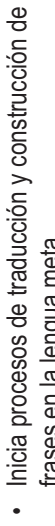 & & \\
\hline & 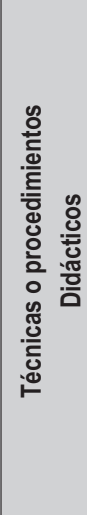 & 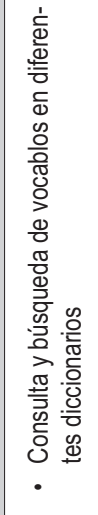 & 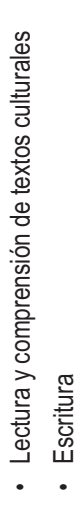 & 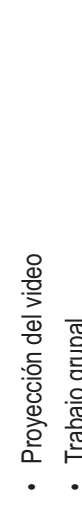 & 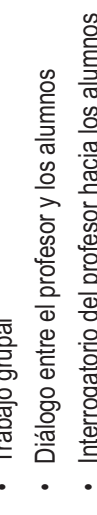 & 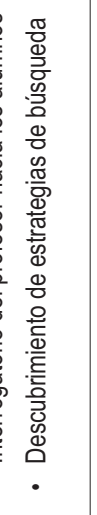 & 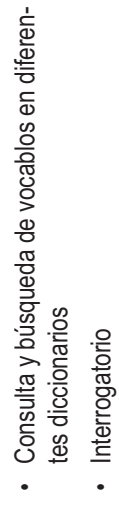 & 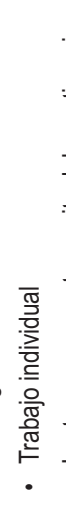 & 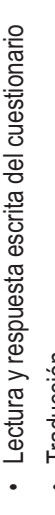 & 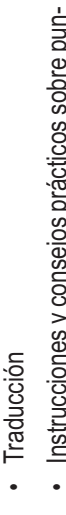 & 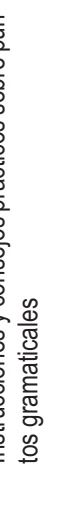 & 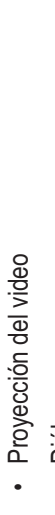 & 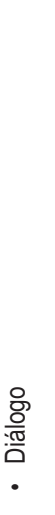 & & \\
\hline & 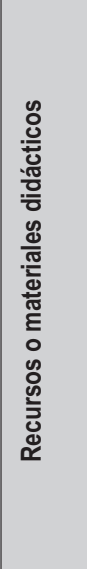 & 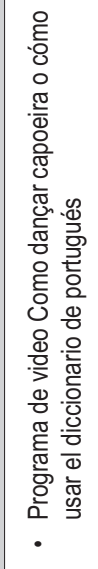 & 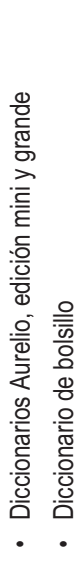 & 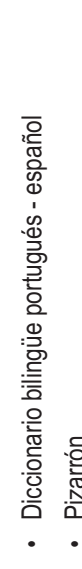 & 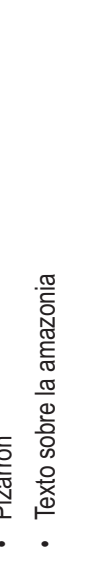 & & 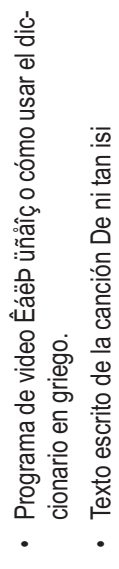 & 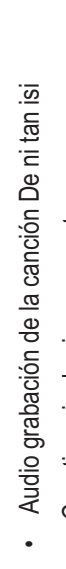 & 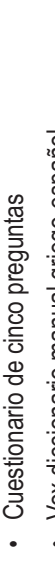 & 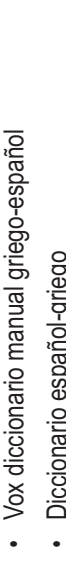 & 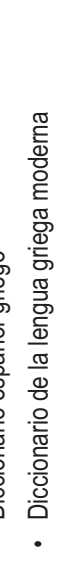 & 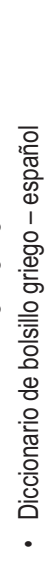 & 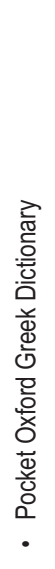 & 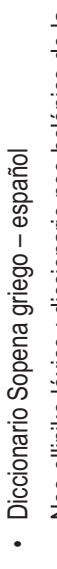 & 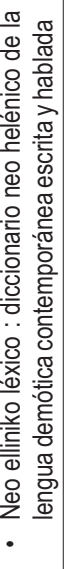 \\
\hline & $\begin{array}{l}\stackrel{\pi}{E} \\
\text { 응 }\end{array}$ & 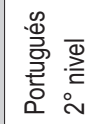 & & & & & 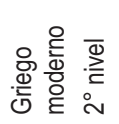 & & & & & & & & \\
\hline
\end{tabular}




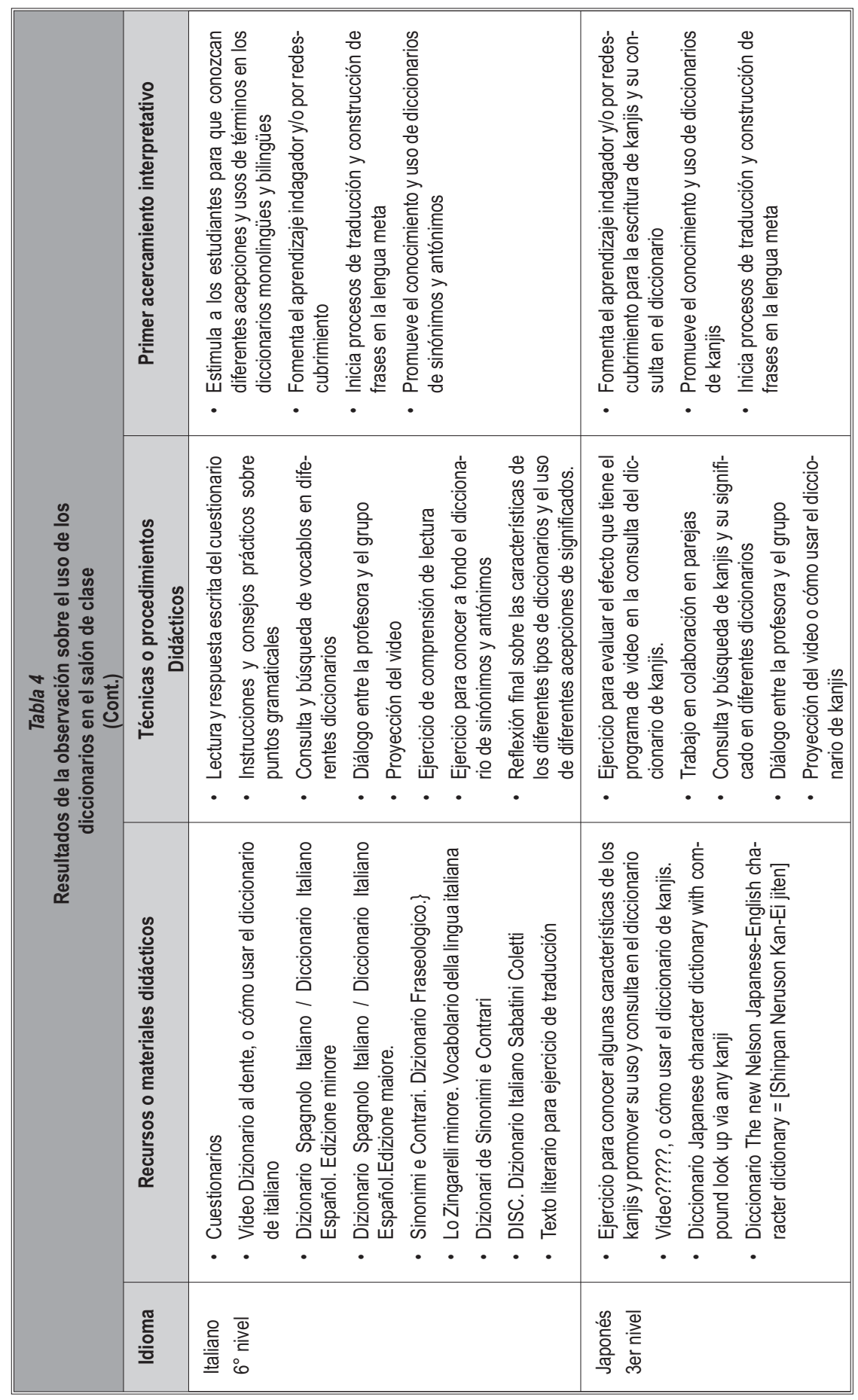


En la Tabla 4 se presentan los datos que se derivan del análisis de las observaciones realizadas en las aulas, la estructura es la siguiente: En la primera columna se encuentran datos sobre la lengua y el nivel del grupo que se observó. En la segunda columna los datos sobre los recursos y materiales didácticos que se utilizaron en la sesiones de clase observadas. En la tercera columna se pueden ver los datos sobre las técnicas o procedimientos didácticos que los profesores utilizaron. Y en la cuarta columna se presenta un primer acercamiento interpretativo de los datos que aparecen en las columnas anteriores.

Las interpretaciones que se presentan son reflexiones del autor sobre el desarrollo de algunas estrategias para el uso adecuado de los diferentes diccionarios y sobre los efectos de la aplicación de algunas técnicas o procedimientos didácticos utilizados en las sesiones de clase observadas.

\section{CONSIDERACIONES FINALES}

En una revisión como la que se ha hecho, se muestran la evolución y maduración del PFU, el camino que se ha recorrido ha sido enriquecedor para los integrantes del programa en la medida que permitió la colaboración y aporte de conocimientos para el diseño y desarrollo de las actividades del programa, es decir la colaboración multidisciplinaria. Asimismo se muestra que se ha promovido un cambio en el papel que tiene ahora el bibliotecario ante la presencia de recursos y herramientas electrónicas de información, dicho cambio se dirige hacia el reconocimiento del bibliotecario, por un lado como docente y promotor de aprendizajes por parte de los usuarios de una biblioteca universitaria. Y por otro, 
La formación de usuarios en el Centro de Enseñanza de ...

como diseñador de materiales didácticos en formatos impresos y en línea, entre otros papeles.

El análisis y la reflexión sistemática que se realizó a lo largo del documento permitió conocer lo complejo y variado que resulta la implantación de un programa institucional como el PFU del CELE. La complejidad y variedad se ve reflejada en los espacios institucionales, y las resistencias a los movimientos y cambios que supone el arranque PFU. En los compromisos profesionales que se contraen en el momento de plantear nuevas las formas de abordaje en las tareas de diseño didáctico y de la creación de materiales que apoyan el desarrollo del PFU. Y en los efectos que tiene en los estudiantes que participan en el PFU.

El PFU logró su objetivo, es decir, promovió en los estudiantes el desarrollo de las habilidades informativas necesarias para reconocer el momento en que tienen un problema en materia de información y cómo son capaces de resolverlo utilizando diferentes recursos electrónicos que se encuentran en la página web de la biblioteca. Se lograron avances evidentes en el aprendizaje de los estudiantes para el manejo de recursos de información de formatos impresos y electrónicos y en la elaboración de sus trabajos finales.

\section{REFERENCIAS}

Corenstein, Martha (1989) "Investigación etnográfica en educación”. En: Rueda Beltrán, M. y Miguel Escobar Guerrero (eds). La investigación educativa en el salón de clases universitario (pp. 44-54). México: Universidad Nacional Autónoma de México. Centro de Investigaciones y Servicios Educativos. 
Hernández Salazar Patricia, et al. (2000) Los materiales didácticos en la enseñanza y el aprendizaje de lenguas extranjeras: el uso del video y la multimedia. En: Estudios de Lingüistica Aplicada. (Edición Especial). 30/31. Dic 1999-jul 2000. (pp. 185-202). México: UNAM/CELE.

Cortés, Jesús et al. (2004). Normas sobre alfabetización informativa en educación superior: declaratoria. México: Universidad Autónoma de Ciudad Juárez, Dirección General de Información y Acreditación.

Valdez Ramos, Jesús (2008). El uso del diccionario a través del video: diseño, uso y evaluación. Ponencia Trabajo presentado y publicado en: Actas del II Congreso Internacional de Lexicografía Hispánica "El diccionario como puente entre las lenguas y culturas del mundo" (en línea). Madrid: Universidad de Alicante. Biblioteca Virtual Miguel de Cervantes. Disponible en: http://descargas.cervantesvirtual.com/ servlet/SirveObras/02585179777984117832268/031357. pdf?incr =1 España 2008.

Valdez Ramos, Jesús y Blanca Estela Solís Valdespino (2005, junio). "La formación de usuarios: un elemento de apoyo para el Curso de Formación de Profesores del Centro de Enseñanza de Lenguas Extranjeras (CELE) de la Universidad Nacional Autónoma de México (UNAM)". Trabajo presentado y publicado en: Encuentro Internacional de Educación Superior UNAM-Virtual Educa 2005: UNAM, DGSCA, CUAD y Virtual Educa (en línea). México. Disponible en: http://www.virtualeduca.org/documentos/ve/ extensos/paralelas/C-2/2005-03-18164educadis-nv.pdf 


\section{El desarrollo de competencias informativas en estudiantes universitarios. Una visión sobre avances y perspectivas desde la Universidad Autónoma de Ciudad Juárez \\ JESÚS CORTÉS \\ Universidad Autónoma de Ciudad Juárez}

\section{INTRODUCCIÓN}

A través de este documento el autor busca hacer 1 una descripción general de los esfuerzos que en materia de educación de los usuarios de la información han sido desarrollados en y desde la Universidad Autónoma de Ciudad Juárez (UACJ) en los últimos 15 años; es decir, a partir de 1995. El trabajo refleja la visión personal del autor, quien participó en la implementación de estos programas desde sus inicios. Lo expuesto se relaciona principalmente con lo realizado por las bibliotecas, pero también se hace referencia a otras actividades que con el mismo propósito fueron implementadas en otras instancias de la Universidad.

Los términos utilizados para referirse a estos programas (formación y educación de usuarios, alfabetización 
informativa, desarrollo de habilidades informativas y desarrollo de competencias informativas) se usan con bastante libertad, reflejando en ocasiones diferentes momentos o contextos de los programas, pero sin pretender adjudicarle a alguno de ellos un uso más correcto que el de los demás.

La elaboración de este documento ha sido una tentación para caer en detalles de remembranzas, sin embargo, se ha tratado de proporcionar solamente los datos que brinden un contexto a los ojos de un lector externo. Ojalá se haya podido evadir la tentación adecuadamente.

\section{CONTEXTO EN EL QUE SURGIERON LOS PROGRAMAS DE DHI}

Se proporcionan enseguida algunos datos generales que pueden hablar de los antecedentes, así como del contexto en el que empezaron a surgir los programas de formación de usuarios de la información en la Universidad Autónoma de Ciudad Juárez.

\section{Algunos datos de la UACJ}

La Universidad Autónoma de Ciudad Juárez fue fundada en octubre de 1973, época en la que se fundaron otras universidades públicas en México, como la Universidad Autónoma de Aguascalientes y la Universidad Autónoma Metropolitana. Es la segunda universidad pública en el estado: la otra es la Universidad Autónoma de Chihuahua, fundada casi 20 años antes, en 1954.

La UACJ es una universidad que ha crecido rápidamente en todos los aspectos. En 1995 tenía una matrícu- 
El desarrollo de competencias informativas en estudiantes ...

la oficial de aproximadamente 8,000 estudiantes y el 60 por ciento de sus profesores contaban únicamente con licenciatura (Lau, 2001). Para este año de 2010, la matrícula oficial fue de 21,221 estudiantes en el semestre enero-junio y el número de Profesores de Tiempo Completo es de 672, de los cuales 101 pertenecen al Sistema Nacional de Investigadores. Cuenta con 40 programas de licenciatura y prácticamente el 100 por ciento de sus programas de licenciatura evaluables se encuentra en los niveles máximos de calidad, lo que le permite a la UACJ incluirse entre las principales universidades del país y pertenecer al Consorcio Mexicano de Universidades, CUMEX, (Quintana, 2010).

La Universidad es poseedora de algunos activos que le han permitido estabilidad y crecimiento sostenido: uno de ellos es su gobernabilidad; esto significa que a través de su historia la institución no ha pasado por conflictos graves que hayan puesto en riesgo su buena marcha; otro activo, muy relacionado con el anterior es que en las grandes decisiones que deben tomarse se busca siempre privilegiar los criterios académicos sobre intereses de otro tipo.

\section{El fortalecimiento de los servicios bibliotecarios}

El rector de la Universidad que tomó posesión en octubre de 1994, jugó un papel fundamental en los programas que posteriormente desarrollarían las bibliotecas; un apasionado bibliógrafo y conocedor de la importancia de las bibliotecas para fortalecer los programas de docencia e investigación, había invitado al doctor Jesús 
Lau a coordinar un nuevo sistema de bibliotecas, quien a su vez invitó al autor de este documento.

En febrero de 1995, el Consejo Universitario aprobó la creación de la Dirección de Recursos Informativos, nombre oficial de la instancia que coordinaría los esfuerzos en materia bibliotecaria; esta dirección estaría a cargo de Lau y en un caso bastante raro en las universidades mexicanas, el director tendría comunicación directa con el rector.

Los primeros meses de trabajo, además de implicar el hecho de establecer y documentar una nueva estructura administrativa, estuvieron muy relacionados con los detalles de la terminación y el amueblado de una nueva Biblioteca Central de la Universidad, cuya construcción había sido iniciada en la administración rectoral anterior.

Se destaca la inauguración de esta biblioteca, en mayo de 1995, porque significó la culminación de un proyecto largamente acariciado por la comunidad universitaria, pero también el inicio de una nueva época. El día de la inauguración, que estuvo a cargo del gobernador del estado, se dio cita en el lugar un gran número de profesores, autoridades y estudiantes de la Universidad, así como de miembros de la comunidad en general de Ciudad Juárez, de El Paso, Texas e incluso de Las Cruces, Nuevo México.

Esta nueva biblioteca ofrecía condiciones muy cómodas y atractivas para los usuarios, mayores acervos y nuevos servicios, atendidos por personal mejor capacitado. Efectivamente, poco después de la inauguración se presentó una mayor afluencia de usuarios, motivados en gran parte por la novedad; sin embargo, desde el 
El desarrollo de competencias informativas en estudiantes ...

principio fue notable el desconocimiento de muchos de los visitantes sobre cómo utilizar y aprovechar los servicios de una biblioteca moderna, lo cual tiene varias explicaciones que narro a contiuación:

el estado de Chihuahua, y en particular Ciudad Juárez, han tenido una tradicional pobreza de servicios bibliotecarios. Para dar un ejemplo, según datos del Atlas de Infraestructura cultural de México, publicado en el 2003 por el Consejo Nacional de la Cultura y las Artes, con datos de la Red Nacional de Biblioteca y referidos a cifras de población del año 2000, el estado de Chihuahua tenía en ese año una biblioteca pública por cada 20,353 habitantes; muy lejos de la media nacional que era de 14,748; muy debajo también de estados considerados pobres, como Chiapas, que tenía para la misma época una relación de 11, 600 habitantes por biblioteca. Pero el problema más grave se daba en el municipio de Juárez, donde se encuentra la ciudad más grande del estado y donde la relación era de 93,755 habitantes por biblioteca.

Un gran porcentaje de los estudiantes que llegaban en ese tiempo a la Universidad conocían por primera vez una biblioteca con una colección clasificada y de estantería abierta, pues provenían de escuelas de nivel bachillerato en las que predominaban bibliotecas -cuando las había- que no tenían catálogos y requerían que los libros fueran olicitados a un encargado, sin tener acceso directo a los estantes.

Por otra parte, en aquel entonces, ya se mencionó que cerca de un 60 por ciento de los profesores solamente había alcanzado en su formación el nivel de licenciatura y -como sucedió en esa época en muchas universi- 
dades del país- un alto porcentaje de estos profesores eran estudiantes o egresados de la misma universidad, que habían recibido una mínima habilitación para convertirse en docentes (Lau, 2001).

Se detectó entonces lo que Lau (2001) refirió con el símil de que "el menú de las bibliotecas estaba ofreciendo muchos y deliciosos platillos, mientras que los comensales parecían tener anorexia”. Aunque también se presentaban muchos casos en los que los usuarios parecían tener buen apetito y deseos de probar la cocina bibliotecaria, pero desconocían cómo hacerlo. Era notorio que muchos de los comensales desconocían que la biblioteca ofrecía platillos tipo bufete y no sabían por tanto cómo servírselos ellos mismos.

Para quien esto escribe esta situación no significó ninguna novedad, había trabajado por ocho años en el Instituto Nacional de Estadística, Geografía e Informática, en el área de atención a los usuarios de la información, en un periodo en el que el Instituto producía enormes cantidades de publicaciones impresas, con información que muy poco se aprovechaba, debido a la falta de sensibilidad, conocimientos y habilidades de los usuarios potenciales.

Fue entonces cuando se decidió emprender un fuerte programa de formación de los usuarios de la información, en el que desde el principio se consideró importante involucrar prácticamente a todo el personal del sistema de bibliotecas, con excepción de algunos miembros del área administrativa y el personal de aseo y mantenimiento. 
El desarrollo de competencias informativas en estudiantes ...

Tal vez sea pertinente mencionar que antes de esto se tenían planes muy concretos para crear dentro de la nueva estructura de las bibliotecas un centro de información de apoyo para negocios, con el que se esperaba captar algunos ingresos e iniciar los cimientos de un Centro de Estudios Estratégicos, aprovechando la experiencia que Lau y Cortés habían tenido en trabajar en dos centros diferentes de este tipo. La necesidad de invertir tiempo y esfuerzo en el programa de Desarrollo de Habilidades Informativas, como se le llamó, fue haciendo necesario postergar estos planes indefinidamente.

\section{De dónde surgió el nombre para estos programas}

Como parte de la estrategia de lanzamiento de la campaña para promover las diferentes actividades de formación de usuarios, se pensó en encontrar un nombre que resultara atractivo para la comunidad académica de la universidad y los invitara a participar.

Se descartó el nombre de formación de usuarios o educación de usuarios, considerando que son nombres más bien técnicos y que les dicen algo a los bibliotecarios, mas no necesariamente son significativos para los usuarios.

También se descartó utilizar el nombre de alfabetización informativa, como traducción de Information Literacy, de un creciente uso en la literatura norteamericana; esto por el ya muchas veces explicado motivo de que el concepto de alfabetización es visto en México en un sentido que algunos interpretan como indeseable. Pensamos que a pocos estudiantes y a muchos menos profesores les habría gustado decir algo así como: "voy a asis- 
tir a una sesión en la que me van a ayudar a alfabetizarme", aunque se refiriera solamente a una alfabetización en el uso de la información.

En su lugar, se pensó en un término semejante al revisado en algunos documentos generados principalmente en la Gran Bretaña: Information skills, que fue traducido como habilidades informativas, pero se le agregó el término "desarrollo" para dar una idea de acción y del beneficio que tendrían quienes participaran en estas sesiones; así que el nombre quedó como "Desarrollo de Habilidades Informativas”. Para facilitar la identificación de estos programas se buscó popularizar desde el principio las siglas DHI (pronunciadas "de"-"hache""i”); con el tiempo, estas siglas serían adoptadas por otras instituciones del país, e incluso de más allá de las fronteras, para referirse en términos generales a este tipo de programas.

Podría decirse entonces que el término "Desarrollo de habilidades informativas" fue acuñado para los usuarios de los servicios de información, no para la comunidad bibliotecaria.

\section{El entorno}

Cuando surgieron los programas de DHI en la UACJ, hacía tiempo que se estaban dando ya en el contexto internacional y nacional diversos indicios sobre la importancia de fortalecer este tipo de programas.

Autores como Farber (1999) han señalado los principios de los años stenta como la época que marcó un incremento sustancial del interés en estos temas, el cual pudo observarse en un incremento en la producción de litera- 
El desarrollo de competencias informativas en estudiantes ...

tura. En alguna medida el creciente interés por este tema se fortalecía por la necesidad identificada por personas e instancias relacionadas con la educación, como la UNESCO, de que los sistemas educativos tenían que pensar en adelante en desarrollar habilidades que les permitieran aprender a lo largo de toda la vida; el concepto lifelong learning se fue haciendo cada vez más conocido.

Un documento que este autor reconoce entre los que más han influido en su visión sobre la importancia que el manejo adecuado de la información puede tener sobre la vida de las personas, fue el reporte publicado por la American Library Association en 1989, producto del trabajo de una comisión especial que fue integrada para analizar la situación y la importancia de los programas de alfabetización informativa en los Estados Unidos. Este reporte además proporcionaba una de las definiciones más claras, que se ha utilizado a lo largo de todo el mundo, sobre lo que podría entenderse por una persona que ha desarrollado las competencias necesarias para manejar la información: "(...) una persona alfabetizada en el uso de información posee un conjunto de aptitudes para reconocer una necesidad informativa y para localizar, evaluar y utilizar la información que necesita".

En México, en 1993, Verdugo publicó los resultados de una investigación realizada sobre los programas de formación de usuarios en México. Los resultados mostraban que en la mayor parte de las instituciones las actividades se limitaban a recorridos guiados por la biblioteca y en pocos casos a publicación de folletería. De 155 universidades estudiadas, solamente cuatro contaban con un programa que podía considerarse como de ins- 
trucción bibliográfica para sus estudiantes y que tenían valor en créditos.

Un año después, en 1994, la Escuela Nacional de Biblioteconomía y Archivonomía, con la participación del Consejo para Asuntos Bibliotecarios de las Universidades Públicas, CONPAB, publicó algunos textos básicos con el objetivo de que los bibliotecarios académicos, muchos de ellos sin formación profesional en bibliotecología, conocieran los aspectos fundamentales de la administración y operación de una biblioteca académica. Dentro de estos textos básicos se consideró importante incluir una guía para la realización de programas de formación de usuarios, elaborada por Arellano (1994).

Seis meses después de la inauguración de la Biblioteca Central, en noviembre de 1995, Lau y Cortés presentaron una ponencia en el VII Coloquio de Automatización de Bibliotecas en Colima, con el título de "La Agenda Rezagada: la formación de usuarios de los sistemas de información”, en la que se anunciaba el propósito de las bibliotecas de la UACJ de concentrar esfuerzos en el desarrollo de las habilidades informativas de sus usuarios, además de que se invitaba a la comunidad bibliotecaria del país a trabajar en proyectos conjuntos sobre este tema. Esta ponencia puede considerarse como la declaratoria formal del inicio de trabajos ante el resto de las bibliotecas de México y de otros países. Las repercusiones llegaron pronto, al año siguiente, la UACJ, recibió la encomienda por parte de la Red Nacional de Bibliotecas de Instituciones de Educación Superior, y posteriormente del Consejo Nacional para Asuntos Bibliotecarios de las Universidades Públicas Estatales, 
El desarrollo de competencias informativas en estudiantes ...

ahora CONPAB-IES, de promover este tipo de programas y el intercambio de experiencias entre las universidades afiliadas.

Un libro escrito por Delors y publicado en 1996, La educación encierra un tesoro: informe a la UNESCO de la Comisión Internacional sobre la educación para el siglo 21 , nos mostraba que íbamos por el camino correcto y nos daba más indicios de por dónde debían darse los cambios en los sistemas educativos tradicionales.

En 1998 surgieron tres documentos que resultaron de gran utilidad para inspirar y orientar los programa de DHI en la UACJ: Breivik publicó el libro Student Learning in the Information Age, en el que se mostraban situaciones y escenarios reales sobre la forma en que los programas de alfabetización informativa podrían dar una aportación importante a las nuevas maneras en que los estudiantes tendrían que aprender en una universidad.

Otro libro fue el publicado por Evers, Rush y Berdrow, con el título de: The Bases of Competence: Lifelong Learning and Employability. Este libro contenía los resultados de un amplio estudio realizado entre egresados de universidades norteamericanas y canadienses, en el que se demostraba la importancia de las competencias generales, como la del manejo eficiente de información, para el éxito profesional. Quizá esta obra nos causó un mayor impacto porque presentaba una visión más allá de la bibliotecología.

El tercer documento fue publicado a finales de 1998, por la misma UNESCO y consideramos que ha sido uno de los documentos que más han influido en la transformación de la educación en los últimos años, se trata de la 
"Declaración mundial sobre la educación superior en el Siglo XXI: Visión y acción". En forma muy breve y directa, este documento describía, como su nombre lo sugiere, las grandes transformaciones que deberían darse en la educación para enfrentar los retos del siglo XXI.

\section{ESTRATEGIAS IMPLEMENTADAS}

En este apartado se describen muy brevemente las principales actividades diseñadas en la UACJ para poner en operación el programa de Desarrollo de Habilidades Informativas, se sigue un orden básicamente cronológico.

\section{Talleres solicitados por los docentes}

Una de las primeras acciones realizadas por la Dirección de Recursos Informativos fue la de buscar una comunicación con los profesores, especialmente con los que tenían a su cargo materias relacionadas con investigación, como lo era y sigue siendo la materia de Técnicas de Investigación Documental. Se les ofreció a estos profesores apoyarlos en la explicación de los servicios de la biblioteca, en el abordaje de algún tema o en la demostración de algún producto informativo en particular. Las sesiones aprovechaban el horario de clases del grupo y eran básicamente demostrativas, pues se impartían en la Sala Audiovisual de la Biblioteca Central.

Una limitante de esta estrategia era que muchos profesores, sobre todo los de honorarios, eran difíciles de contactar y por tanto muchos grupos no llegaban a ser atendidos. 
El desarrollo de competencias informativas en estudiantes ...

\section{Talleres libres}

Una vez que se contó con el primer salón electrónico, se creó un sistema de talleres de dos horas para enseñar a los estudiantes cinco temas:

1) Cómo utilizar el catálogo automatizado;

2) Cómo utilizar bases de datos en línea;

3) Cómo utilizar recursos del CD-ROM;

4) Cómo navegar por Internet;

5) Cómo utilizar sitios de la Web, seleccionados de acuerdo con el perfil de los participantes.

Cada día de la semana se impartía un curso-taller de dos horas con la misma temática; de manera que un estudiante podía ir completando poco a poco el curso completo, después de los cuales obtendría una constancia. Estos talleres también estaban abiertos al público en general que pudiera estar interesado. Esta estrategia era muy flexible, pero tenía la desventaja de que los contenidos revisados en los talleres en ocasiones no eran relevantes para todos los participantes, además, dejaba al interés y criterio muy personal del estudiante el tomar o no los talleres, así que se pensó en una estrategia diferente.

\section{Los Cursos de Acceso a la Información}

En 1998, a solicitud de la Dirección de Recursos Informativos, el Consejo Académico universitario declaró obligatorios los cursos-talleres de acceso a la información, identificados con las siglas CAI. Estos talleres no tendrían valor en créditos, pero los estudiantes de primer ingreso deberían tomarlos y aprobarlos para poder inscribirse en el segundo semestre. 
Poco después se negoció con la Academia de Técnicas de Investigación Documental para que la calificación que los estudiantes recibieran en estos talleres formara parte de la calificación total del curso de TID, lo que en la práctica resultó muy complicado de operar y se fue abandonando poco a poco.

La responsabilidad de impartir estos talleres a los cientos de estudiantes de nuevo ingreso implicó el establecimiento de una estructura administrativa y un proceso de planeación detallado, bajo el cuidado de un coordinador. Para garantizar la calidad, solamente personal profesional podía participar como instructor y alguien que quisiera incorporarse en este papel tenía que pasar por un proceso de capacitación. Se tuvo que trabajar bastante para generar manuales, políticas, guías y materiales de apoyo.

Estos cursos se siguen impartiendo hasta el momento y más de 30,000 estudiantes han sido atendidos con ellos. Se han modificado varias veces los contenidos y se ha buscado también que haya un cambio en la manera de facilitarlos; de sesiones básicamente demostrativas, se fue buscando la manera en que los estudiantes interactuaran más directamente con los contenidos. Actualmente, el curso es semipresencial, apoyado con la plataforma de educación a distancia Moodle.

\section{Cursos para profesores}

Desde el principio de estos programas se consideró que los cambios en las formas en que los estudiantes interactúan con la información se daría principalmente a través de la labor de los docentes, de ahí que se trabajó en el 
El desarrollo de competencias informativas en estudiantes ...

diseño de un curso al que se le asignó el nombre nemotécnico de MADRID, acrónimo de Manejo de Recursos Informativos para Docentes.

La facilitación de este curso también pudo apoyarse con los salones electrónicos, para hacerlos más prácticos e interactivos. Los temas a cubrir retomaban los mismos que se enseñaba a los estudiantes, pero revisándolos a mayor profundidad y agregando otros, quedando así: - Módulo 1. Información, requerimiento básico para el aprendizaje.

- Módulo 2. Selección de material bibliográfico para su clase

- Módulo 3. Servicios de información para los docentes de la UACJ.

- Módulo 4. Navegación por Internet y en los mejores sitios

- Módulo 5. Medios digitales: bases de datos y otros recursos electrónicos

- Módulo 6. Revistas científicas y otras publicaciones periódicas.

Estos cursos ponían extremadamente nerviosos a la mayor parte de los bibliotecarios, al verse frente a un grupo de académicos; por cierto, los primeros en tomar este curso fueron los académicos con cargos administrativos de alto nivel, para poner el ejemplo al resto del profesorado, lo que incrementaba el nerviosismo de los instructores.

En un principio se determinó que cada módulo tendría una duración de seis horas, pero al poco tiempo se vio que esto era demasiado optimista, pues implicaba que los profesores dedicaran 36 horas a este curso. Poco 
a poco la duración se fue ajustando a la misma que tienen la mayor parte de los cursos que reciben los profesores, es decir $20 \mathrm{hr}$.

También se observó como conveniente que los cursos MADRID formaran parte del menú de opciones que tenían los profesores en sus programas de actualización y desarrollo; esto se facilitó cuando al doctor Lau se le asignó la Dirección General de Apoyo Académico, bajo cuya estructura siguió trabajando el sistema de bibliotecas. De esta manera, el profesor que tomaba el curso MADRID recibía reconocimientos válidos para su currículum y para los diferentes programas de estímulos al desempeño docente. Este esquema persiste hasta el momento. Regularmente los cursos se programan al final de cada semestre, aunque ha habido casos de jefes de departamentos académicos que han solicitado cursos especiales para sus profesores recién incorporados.

\section{Cursos especiales para estudiantes de posgrado}

Una situación que se fue presentando con el tiempo fue que los coordinadores de algunos programas de posgrado identificaron que los candidatos tenían limitadas competencias para investigar y manejar información, así que establecieron dentro de sus pre requisitos que estos aspirantes tomaran un curso-taller diseñado por las bibliotecas; los contenidos y la duración del taller se acuerdan con el coordinador del posgrado, pero ha sido común el que sean de 10 a 12 hrs., divididas en dos sesiones. 
El desarrollo de competencias informativas en estudiantes ...

Participación en la materia de Técnicas de Investigación Documental

Desde los primeros días de la creación de la Dirección de Recursos Informativos, fue considerado como prioritario el que al menos el director y el subdirector participaron en docencia, para estar más en contacto con la realidad de los profesores y de los estudiantes; se determinó que la materia más pertinente era la de Técnicas de Investigación Documental (TID).

Al participar en la academia de esta materia se pugnó para que se la declarara como una materia sello, es decir que fuera impartida a todos los estudiantes de la Universidad, sin importar la carrera que pretenderon estudiar. Esto se logró, a pesar de que con el tiempo algunos programas se fueron desligando de este acuerdo.

En la actualidad, esta materia es fundamental para la enseñanza de las habilidades informativas a estudiantes; en la última revisión de la carta descriptiva se logró apegar mejor los contenidos a los estándares de alfabetización informativa generados en México. Actualmente también se ha diseñado una versión para la enseñanza en línea y el autor de este documento la facilita en esta modalidad.

\section{Participación en la materia de desarrollo de compe-} tencias informativas

Por un buen tiempo las bibliotecas estuvieron insistiendo ante diferentes instancias académicas de que era necesario insertar en la currícula una nueva materia que le diera continuidad a la de Técnicas de Investigación Documental. Uno de los argumentos era que la materia de 
TID se enseña en los primeros semestres y que pasa mucho tiempo antes de que los estudiantes empiecen a desarrollar proyectos de investigación para sus tesis o para otros proyectos; otro de los argumentos era que la materia de TID no abordaba todas las competencias necesarias para manejar información con eficiencia, pues se enfocaba mayormente en el correcto registro de las fuentes consultadas.

En consecuencia, personal de las bibliotecas preparó y diseñó una materia denominada Desarrollo de Competencias Informativas, dirigida principalmente a estudiantes de niveles intermedios. Este proyecto se ha suspendido debido a que al tener un carácter de optativo, pocos estudiantes decidían registrarse en esta materia; y solamente se podía forzar que la tomaran estudiantes de nuevo ingreso, pero esto provocaba algunas duplicaciones con la materia de TID. Con la reestructuración en la última versión de esta última materia, la redundancia se hizo mayor.

\section{Actividades complementarias}

El programa de DHI se apoyó con otras tareas, como la generación de una importante cantidad de guías y folletería, dirigidas tanto a los estudiantes como a los docentes y con información encaminada a que pudieran aprovecharse mejor los diferentes recursos y servicios de las bibliotecas. En su momento, las bibliotecas de la UACJ fueron los mejores clientes de la imprenta universitaria y podría decirse que poco a poco propiciaron una cultura semejante en otras dependencias. 
El desarrollo de competencias informativas en estudiantes ...

También se contaba con un programa de visitas guiadas, tanto para estudiantes como para profesores. Cada semestre, todos los estudiantes recién incorporados realizaban un tour por las principales instalaciones de la Universidad, lo que incluía un recorrido por la Biblioteca Central. Ante el crecimiento de la matrícula, esta práctica debió abandonarse hace algunos años, cambiándose por pláticas en auditorio, cursos introductorios para estudiantes de nuevo ingreso e incluso la inserción de una materia que se llama Introducción a la Universidad, el tema de los servicios bibliotecarios y su importancia en la formación de los recién llegados sigue estando presente.

\section{LA PROYECCIÓN Y EXPANSIÓN DE LOS PROGRAMAS DHI}

En este apartado se mencionan, también muy brevemente, algunos de los proyectos en los que la UACJ ha participado, para promover programas de DHI fuera de la institución.

\section{Formación de formadores}

Personal de las bibliotecas UACJ ha impartido un número de talleres que sería difícil cuantificar, tanto en el contexto nacional como internacional, y ha colaborado a que más bibliotecarios se animen a implementar en sus instituciones programas de alfabetización informativa. Regularmente estos talleres buscan adecuarse a las necesidades particulares de las instituciones sede. 
Estos talleres se empezaron a impartir al poco tiempo de que se tuvieron las primeras experiencias en este tema. Por un acuerdo de la Red de Teleinformática y Bibliotecas del Noroeste, RETBIN, bibliotecarios de la UACJ facilitaron varios talleres para colegas de instituciones de esta red, integrada por instituciones de educación superior y de investigación de Baja California, Baja California Sur, Sonora, Sinaloa y Chihuahua. Fue un esfuerzo muy importante, que permitió conseguir más adeptos para esta causa.

\section{Proyecto para capacitar bibliotecarios en todo el país}

A principios de 1999, a petición de la Presidencia del Consejo Nacional para Asuntos Bibliotecarios, la UACJ preparó una propuesta para intentar extender los programas de alfabetización informativa en todas las universidades públicas del país. La estrategia planteada proponía impartir en una primera etapa un curso-taller de 20 horas, que se impartiría a 20 bibliotecarios de cada una de las seis regiones en las que la Asociación Nacional de Universidades e Instituciones de Educación Superior tiene dividido al país. De esta manera, al final del proyecto se contaría con 120 bibliotecarios motivados y con una capacitación básica para iniciar o fortalecer programas de este tipo en sus instituciones.

El proyecto consideraba también la publicación y distribución de una guía básica para la implementación de este tipo de programas, elaborada también en la UACJ, la cual se basaba en gran parte en una de las versiones de la guía para programas de instrucción en bibliotecas académicas, elaborado y publicado por la 
El desarrollo de competencias informativas en estudiantes ...

Association of College and Research Libraries, ACRL. El proyecto no se llevó a cabo porque no se obtuvo el financiamiento necesario.

\section{Los Encuentros de DHI}

Como una estrategia para promover el intercambio de experiencias y un avance mayor en el desarrollo del tema, la UACJ decidió organizar un evento que reuniera a interesados en este tipo de programas. Cabe señalar que originalmente se buscaba con esto principalmente cumplir con el compromiso asignado por la Red Nacional de Bibliotecas de Instituciones de Educación Superior y por el CONPAB-IES; es decir, al principio se esperaba solamente la asistencia y participación de bibliotecarios pertenecientes a instituciones de estas redes; sin embargo, pronto surgieron otras instituciones interesadas en participar.

A partir de 1997, la UACJ ha llevado a cabo seis encuentros internacionales sobre el Desarrollo de Habilidades Informativas, cada uno de ellos tratando de abordar un aspecto del tema que se consideró requería mayor atención y enlazarlo con el evento precedente. Así entonces, el Primer Encuentro (1997) estuvo dedicado al "Desarrollo de Habilidades Informativas en Instituciones de Educación Superior”. Como un producto de este Encuentro, se publicó una declaratoria elaborada con la participación de los asistentes, en la que se hacía un llamado a todas la Instituciones de educación superior a promover este tipo de programas (Aguilar, et al, 1997).

En el segundo Encuentro (1999) se analizó "La instrucción de usuarios ante los nuevos modelos educativos”. El tema fue en gran parte inspirado por la declara- 
toria que la Unesco había publicado el año anterior y que, como ya dijimos, había causado un fuerte impacto. Como producto de este evento, se generó otra declaratoria, en la que se resaltaba el rol de las bibliotecas en los nuevos entornos educativos (Cortés, et al, 2000).

El tercer encuentro, celebrado en 2002, tuvo como tema central las "Normas para la alfabetización informativa". El tema provino de que ante el trabajo realizado hasta ese momento era necesario tener una mayor claridad sobre los estándares que podrían guiar el trabajo de las bibliotecas, además porque dos años antes se habían publicado los estándares sobre competencias informativas de la Association of College and Research Libraries y era un documento ampliamente analizado y discutido internacionalmente. Este Encuentro permitió generar un conjunto de estándares identificados por los bibliotecarios asistentes como los que debían guiar el trabajo en los programas de DHI en México (Normas, 2004). Estos estándares han sido utilizados como referencia para el diseño de programas de DHI, aunque no existen estudios formales sobre el particular.

En el cuarto encuentro (2004) los participantes tuvieron la oportunidad de profundizar sobre "Competencias informativas: Hacia la implementación de programas”. Este título surgió de que numerosas instituciones que reconocían la importancia de trabajar en programas de desarrollo de competencias informativas mencionaban que necesitaban mayores referentes empíricos que les ayudaran a implementarlos.

En la quinta edición de este encuentro internacional, se analizó el tema: "Diagnóstico y evaluación: Elemen- 
El desarrollo de competencias informativas en estudiantes ...

tos fundamentales para los programas de alfabetización informativa". El tema de la evaluación estaba surgiendo con gran fuerza en el contexto de la educación en general, así como de las bibliotecas. Las normas y estándares sobre competencias informativas en los estudiantes habían establecido un parámetro de hacia dónde debían encaminarse los esfuerzos de formación de usuarios, pero se requerían de instrumentos más precisos para establecer diagnósticos, evaluar avances y calificar los resultados finales obtenidos en los diferentes programas.

La sexta edición del Encuentro se desarrolló en octubre de 2008 con el tema de "La innovación educativa en programas de Desarrollo de Habilidades Informativas". Como su nombre lo indica, fue una oportunidad para revisar cómo los esfuerzos que se están implementando recientemente para fortalecer la educación en general podrían también aprovecharse para los programas de alfabetización informacional.

El Séptimo Encuentro está programado para abril del 2011 y tendrá como tema: "Redes de Colaboración en Programas DHI”.

\section{Intercambios}

Las experiencias recabadas por las bibliotecas UACJ en materia de programas de ALFIN ha sido un motivo de intercambio de visitas y estancias de instituciones del país y del extranjero, entre estas últimas al menos tres universidades chilenas enviaron a sus bibliotecarios para tener estancias de entre tres y cuatro semanas en Ciudad Juárez. 


\section{Otras acciones}

Hay una diversidad de acciones que pueden mencionarse como complementarias a los esfuerzos por desarrollar los programas de DHI en el país. Como ya se mencionó, se han publicado y divulgado los resultados de los encuentros, con lo cual se ha buscado colaborar para cubrir la ausencia de información sobre el tema publicada en español.

Esta divulgación se apoyó con la creación de un sitio web, el primero de su tipo en América Latina, en el que se pusieron a disposición de los interesados algunos recursos generados por la UACJ y algunos otros de alcance internacional, de los cuales en ciertos casos se consideró necesario realizar primero una traducción.

De igual manera, se creó una lista de discusión que aún existe y que integra a bibliotecarios de diversos países de habla hispana, reunidos por un interés común en esta temática.

Por último se menciona que personal de la UACJ ha buscado mantener vivo el interés por este tema, a través de participaciones con talleres y ponencias en los principales eventos bibliotecarios del país.

\section{PROPUESTA DE UN FORO MEXICANO DE DHI}

En el III Encuentro de DHI, Moya y Cortés (2002) proponían la creación de un organismo nacional que integrara esfuerzos de una diversidad de personas e instituciones de los distintos sectores, para expandir los programas de alfabetización informacional en todo el país, en todos los niveles educativos e incluso entre la 
El desarrollo de competencias informativas en estudiantes ...

población en general. La idea era replicar algunos aspectos o acciones realizadas por el National Forum on Information Literacy (NFIL) de los Estados Unidos, a sabiendas de que sería necesario hacer muchas adecuaciones, dadas las diferencias culturales y de otro tipo.

La NFIL fue fundada en 1989 con el apoyo de la American Library Association y actualmente es una organización no lucrativa que integra a 93 instituciones u organizaciones que de alguna manera colaboran a que el Foro cumpla con su misión de promover la alfabetización informacional en todos los segmentos de la sociedad norteamericana (NFIL, 2010).

Entre los organismos que los autores sugerían que participaran inicialmente en la integración de este Foro se encontraban:

- La Asociación Mexicana de Bibliotecarios

- La Asociación Nacional de Instituciones de Educación Superior

- El Centro Universitario de Investigaciones Bibliotecológicas

- El Colegio Nacional de Bibliotecarios

- El Consejo Nacional de Ciencia y Tecnología

- El Consejo Nacional de la Cultura y las Artes

- El Instituto Nacional de Educación para los Adultos

- El Consejo Nacional de Evaluación Educativa

- Las diferentes escuelas de bibliotecología

Esta propuesta fue retomada en el Cuarto Encuentro e incluso se creó una comisión para seguir abundando sobre esta idea, pero gradualmente se fue perdiendo la comunicación y otras urgencias ocuparon la atención. 


\section{FACTORES QUE FAVORECIERON O SIGNIFICARON UN RETO}

A continuación se describen en forma muy esquemática cuáles fueron los factores que a juicio del autor han favorecido el desarrollo de los programas de DHI en la UACJ, agregando igualmente más adelante los factores que significaron o siguen significando un reto a superar.

\section{Factores que favorecieron los programas}

- Apoyo incondicional del rector en los inicios

- Posibilidad del director de servicios bibliotecarios de tener acuerdos directamente con el rector

- Aceptación de parte del personal bibliotecario de que las tareas de DHI eran responsabilidad de todos

- Alianza establecida con profesores

- Apoyo de programas de fondos federales

- Instalaciones atractivas, especialmente los salones electrónicos

- Cuidado con los detalles de la planeación, ejecución y evaluación de los cursos

- Materiales

> Puntualidad

- Evaluación

- Atractivos servicios de café en los recesos

- Participación relevante de las bibliotecas en la definición de un nuevo modelo educativo para la Universidad

- La certificación de los instructores de estos programas

- Entorno internacional y nacional propicio 
El desarrollo de competencias informativas en estudiantes ...

- La implementación de una diversidad de estrategias

- La aceptación de todo el personal de que había que trabajar un poco más de lo que regularmente se esperaría de él.

Retos que ba sido necesario superar y en los que babrá que seguir trabajando

En una síntesis muy apretada, éstos son los principales eventos relacionados con los programas de alfabetización informativa en la Universidad Autónoma de Ciudad Juárez desde que se decidió trabajar para fortalecerlos en 1995. La visión expuesta tiene seguramente el sesgo de una perspectiva personal y no hay duda de que la realidad de cada institución puede ser muy diferente; de cualquier manera, esta experiencia se comparte esperando que pueda ser de utilidad para quienes han reconocido la importancia de estos programas y aportan su mejor esfuerzo para desarrollarlos.

\section{REFERENCIAS BIBLIOGRÁFICAS}

Aguilar, V.; Almanza, J.; Cortés. J.; Endean, R.; García, J; Lau, J. and Rios, H. (1997), Declaratoria: desarrollo de habilidades informativas en instituciones de educación superior de México, UACJ, México.

American Library Association (1989), American Library Association Presidential Committee on Information Literacy: Final Report, trad. al español por Jesús Cortés, Chicago: ALA, $20 \mathrm{p}$. 
Arellano Rodríguez, J. A. (1994), Guía para la formación de usuarios de la información, México: SEP, 102 p. (Guías para bibliotecas universitarias).

Atlas de Infraestructura cultural de México (2003), México: Consejo Nacional de la Cultura y las Artes.

Breivik, P. S. (1998), Student Learning in the Information Age, Phoenix: American Council on Education: Oryx Press, 1998, 173 p., (Series on Higher Education).

Cortés, J.; García, J.; González, D.; Lau, J.; Moya, A.; Rodríguez, A. and Verdugo, J. (2000), Declaratoria: función de la biblioteca en modelos educativos orientados al aprendizaje (2000), UACJ, México.

Cortés, J. (2002), “Diseño y equipamiento de salones electrónicos para programas de DHI", en Información: Producción, Comunicación y Servicios. Año 12, Núm. 52, Invierno, pp. 20-23.

Evers, T., Rush, J. C and Berdrow I. (1998), The Bases of Competence: Lifelong Learning and Employability, San Francisco: Josey-Bass Publishers, xxviii, 273 p.

Farber, E. (1999), "College Libraries and the Teaching/Learning Process: a 25 Year Reflection", The Journal of Academic Librarianship, Vol. 25 Núm. 3, May, pp. 171-177.

Lau, J. (2001), "Faculty - Librarian Collaboration: A Mexican Experience", en Reference Services Review, vol. 29, Núm. 2.

Lau, J. y J. Cortés. (1995), La agenda rezagada: la formación de usuarios de sistemas de información, ponencia presentada en el VII Coloquio de Automatización de Bibliotecas, Colima, Col., noviembre 22-24, 1995. 
El desarrollo de competencias informativas en estudiantes ...

Moya, A. L. y J. Cortés (2002), Propiciando entornos de aprendizaje en las instituciones de educación superior de México con apoyo de normas e indicadores, 3 er. Encuentro DHI, Ciudad Juárez, Chih.

National Forum on Information Literacy, Welcome, recuperado el 17 de octubre de 2010 de: http://infolit.org/

Quintana, J. M. (2010), Cuarto Informe UACJ. Resumen ejecutivo, Ciudad Juárez: UACJ, recuperado el 17 de octubre de 2010 de http://www.uacj.mx/cuartoinforme/

Documents/resumen_ejecutivo_IV.pdf

Verdugo Sánchez, J. A. (1993), "Hacia un concepto de formación de usuarios y propuesta de un programa", Investigación bibliotecológica, Vol. 7, Núm. 15, Julio-diciembre, pp. 4-15 


\title{
Programa de Desarrollo de Habilidades Informativas de la Dirección General de Bibliotecas de la UNAM
}

\author{
MARÍA DE LOURDES ROVALO SANDOVAL
}

Dirección General de Bibliotecas de la UNAM

\section{INTRODUCCIÓN}

A nte la transformación del ejercicio de las profesio1 nes, la dinámica de los procesos educativos involucrados en la formación de profesionales ha cambiado, ya no basta con dominar los conocimientos y habilidades típicos de la propia disciplina, ahora se agregan a ellos las habilidades generales o metadisciplinares que juegan un papel sustantivo.

En el año 2000 la Universidad Nacional Autónoma de México (UNAM) establece el programa Desarrollo de Habilidades para la Formación Permanente (nombrado al principio Estudiante experto) con el fin de impulsar el desarrollo de habilidades indispensables para todas las disciplinas, que le garantizan al estudiante una trayectoria académica y profesional exitosa. 
La Dirección General de Evaluación Educativa (DGEE) coordinó el programa conformado por nueve actividades básicas: buscar y seleccionar información; manejar paquetes de cómputo aplicados al área de estudio; comunicación oral, escrita en español e inglés; capacidad de aprender de manera autónoma; trabajar en grupos cooperativos; autorregulación y buscar empleo eficientemente.

Las habilidades son generales y se requieren en todas las disciplinas por su naturaleza práctica u operativa, y son diferentes a las que están contenidas en cada una de ellas y que caracterizan al saber y a la actuación calificados. Este corpus de conocimiento acumulado, organizado y sistematizado de cada área de estudio, está integrado por un conjunto de conceptos, hechos, principios, reglas, leyes y procedimientos que le son propios, los cuales deben ser aprendidos para desarrollar las habilidades específicas de ese campo.

La investigación sobre "expertos y novatos" resalta que los primeros poseen, además de un núcleo firme de ese corpus de conocimientos particulares de la disciplina que ejercen, y de sus habilidades específicas, otro conjunto de habilidades que les permiten actualizarse, resolver problemas, comunicarse, adecuarse a las condiciones cambiantes y de incertidumbre actuales.

Las habilidades generales que subyacen a la adaptación y formación permanentes, se insertan en todas las disciplinas, mientras que las habilidades intelectuales de cada profesión, son específicas de cada una de ellas. Pero esas habilidades generales no sólo apoyan la práctica profesional, la investigación y el ejercicio tecnico, sino también el propio proceso de for- 
Programa de Desarrollo de Habilidades Informativas de la ...

mación de profesionales, investigadores, profesores y técnicos, por lo cual su desarrollo propicia que los estudiantes aprendan mejor, mientras estudian y que los egresados puedan tener condiciones más favorables en su desempeño (Rovalo y Quesadas, 2003. p. 123).

El aprendizaje se enriquece cuando se comprende lo que se lee, se sabe la estrategia de estudio adecuada de un tema en particular, se conoce cómo obtener información válida sobre un tema en particular, se tiene la capacidad para comunicarse en forma oral y escrita, se puede trabajar en forma productiva en grupos, y se planean y supervisan todas las actividades. Es innegable el manejo de la computadora, al menos la comprensión y de preferencia el dominio del inglés para acceder a mas fuentes de aprendizaje.

El programa se ofreció durante 2001 a 2007 a alumnos de primer ingreso que voluntariamente lo quisieron cursar, en horarios que no interfirieran con las clases de sus programas de estudios. Se cursarían en el transcurso de la carrera y los alumnos se comprometieron formalmente a llevarlos todos. Los cursos se impartieron en los planteles 2 y 8 de la Escuela Nacional Preparatoria y en el Plantel Vallejo del CCH, y a nivel licenciatura en las escuelas nacionales de Enfermería y Trabajo Social y las facultades de Arquitectura, Ingeniería, Química Odontología, Ciencias y la FES Aragón para las carreras de Ingeniería y Pedagogía.

Las actividades coincidieron en la mayoría de las entidades. Para la licenciatura se desarrolló la habilidad para 
buscar empleo y para el bachillerato la correspondiente a plantearse un proyecto de vida.

El Programa se dividió en ocho cursos para desarrollar las siguientes habilidades:

1.- Buscar, seleccionar y sistematizar información. Para encontrar información válida y confiable sobre cualquier tema de interés en fuentes de distinta naturale$\mathrm{za}$, desde las que se consultan en la biblioteca, las disponibles a través del Sitio Web de la DGB, hasta las de acceso libre en Internet. Responsable: Dirección General de Bibliotecas. Duración al principio seis y después 10 horas.

2.- Comunicarse correctamente por escrito y en forma oral (hablar en público). Con el objeto de comprender la información que se recibe, expresar lo que se piensa y se siente en forma lógica, secuenciada y con las palabras correctas, para que los demás comprendan lo que se desea, sin importar si es de forma escrita o al hablar en público. Responsable: Facultad de Filosofía y Letras. Duración 42 horas.

3.- Aprender de manera autónoma. El desempeño escolar cuando se es estudiante, y en la actualización permanente en la profesión, se facilitan si se sabe cómo aprender. Un buen repertorio de estrategias mejora el estudio y mejora la comprensión y el aprendizaje de disciplinas de distinta naturaleza. Responsable: Dirección General de Evaluación Educativa. Duración 16 horas.

4.- Trabajar en forma cooperativa. El aprendizaje en grupos cooperativos permite intercambiar y argumentar ideas, así como aprender con el apoyo de los 
Programa de Desarrollo de Habilidades Informativas de la ...

demás miembros, en donde cada quien desempeña una función y tiene una responsabilidad específica, para el logro de un objetivo común. Responsable: Dirección General de Evaluación Educativa. Duración 10 horas.

5.- Autorregularse. Es la capacidad para planear, realizar, supervisar y evaluar uno mismo sus actividades. Ello facilita el logro de objetivos y metas personales. Responsable: Dirección General de Evaluación Educativa. Duración 10 horas.

6.- Definir un proyecto de vida. Establecer lo que se quiere hacer en la vida, a partir del conocimiento en uno mismo, simplifica, entre otras cosas, la decisión sobre cuál carrera estudiar, dirigida a alumnos de Bachillerato. Responsable: Dirección General de Orientación Educativa. Duración 16 horas.

7.- Comprender textos en inglés y además lograr el dominio de ese idioma. Responsable: Centro de Lenguas Extranjeras. Duración 148 horas.

8.- Manejar con pericia los paquetes de cómputo. Los más requeridos en su especialidad. Responsable: Dirección General de Cómputo Académico. Duración 20 horas.

Como se mencionó el Programa fue coordinado por la DGEE y cada curso fue diseñado por las entidades y dependencias enumeradas las cuales aportaron a los profesores. Las escuelas y facultades contaban con un coordinador local capacitado. Cada semestre la DGEE evaluó los cursos con la participación de alumnos, profesores, especialistas, coordinadores locales, apoyos didácticos y organizadores. Con los resultados y la participación co- 
legiada de los coordinadores de cada curso, los coordinadores locales, expertos y autoridades se hicieron las modificaciones correspondientes y como había iniciado con el carácter de "piloto" con el nombre de "Estudiante experto" se hicieron las adecuaciones y cambios para garantizar su mejora continua, así se estableció el "Programa de Desarrollo para la Formación Permanente".

Es importante resaltar que las habilidades se apoyan entre sí, por ejemplo para realizar una buena búsqueda de información en la red, se necesita comprender el inglés y saber manejar la computadora.

\section{DESARROLLO DE HABILIDADES INFORMATIVAS}

A finales del 2000 la Dirección General de Evaluación Educativa, invitó a la Dirección General de Bibliotecas a participar en el "Programa Estudiante Experto" por lo que la Subdirección de Planeación y Desarrollo propuso el curso "Cómo buscar, seleccionar y sistematizar información”, una versión básica para alumnos de primer ingreso al bachillerato y otra más avanzada para alumnos de licenciatura. La DGB hizo extensiva la invitación a una bibliotecóloga profesional especializada en la enseñanza sobre el uso y manejo de obras de consulta y en el desarrollo de bases de datos para hacerse cargo de la impartición de los cursos a nivel bachillerato.

La propuesta incluyó: el objetivo general, los objetivos específicos, la temática, los materiales de apoyo y las actividades a desarrollar, abarcaba: la inducción del uso de la biblioteca de su escuela, la Biblioteca Central, co- 
Programa de Desarrollo de Habilidades Informativas de la ...

lecciones, servicios, uso y manejo materiales de consulta impresos, los catálogos electrónicos, la localización de material en bases de datos mexicanas, latinoamericanas, internacionales, revistas electrónicas, elaboración de bibliografías, fichas de contenido, la recopilación y sistematización de información para el desarrollo de actividades escolares, de tesis, elementos para valorar, localizar elementos, etc. Un programa muy ambicioso para impartirlo en forma ascendente en varios semestres. Lo anterior se expuso ante las autoridades de la DGEE, los coordinadores de los otros cursos, los coordinadores locales, los asesores, y en conjunto decidieron que algunos temas se podrían traslapar con los contenidos de otros cursos, que mejor se diera en cada semestre en dos sesiones de dos horas.

Como el curso fue evaluado al igual que los demás, el programa se adecuó y renombró como "Desarrollo de Habilidades para la Formación Permanente", el curso "Buscar, seleccionar y sistematizar información" a cargo de la DGB también se rediseñó, se ofrecieron cinco sesiones de dos horas y se impartió en instalaciones con equipos suficientes para al menos dos estudiantes por cada computadora personal conectada a Internet y con acceso garantizado a la Red UNAM, sobre todo en aquellas escuelas ubicadas fuera de Ciudad Universitaria, y se estableció formalmente como "Programa de Desarrollo de Habilidades Informativas de la DGB” nombre que aún conserva.

Objetivo: Desarrollar habilidades informativas en los alumnos, que les permitan ser autosuficientes para buscar, seleccionar y sistematizar información relevan- 
te, como apoyo a sus actividades académicas durante el periodo escolar y en su vida profesional.

Contenido:

$1^{a}$. Sesión. Introducción. La biblioteca. Colecciones: general, consulta, hemerográfica, colecciones especiales. Catálogos en línea, locales y globales. Bases de datos nacionales e internacionales. Servicios: préstamo interno, a domicilio, interbibliotecario, fotocopiado, cubículos. La Biblioteca Central y visita guiada a la biblioteca de su escuela o facultad por el Coordinador de la biblioteca.

$2^{a}$. Sesión. Catálogos globales en línea. LIBRUNAM, SERIUNAM, TESIUNAM, MAPAMEX. Uso y manejo.

3a. Sesión. Bases de datos latinoamericanas. CLASE, PERIÓDICA, INFOLATINA. Uso y manejo.

$4^{\text {a }}$. Sesión. Bases de datos especializadas (sobre la temática de la carrera). Química por ejemplo. Demostración y ejercicios conjuntos. Chemical Abstracts, Advanced Polymers Abstracts, EMBASE, Chembank, etcétera.

$5^{a}$. Sesión. Revistas electrónicas. Elsevier y Ebsco. Demostración y ejercicios conjuntos.

Redacción de citas bibliográficas de recursos electrónicos, y los derechos de autor.

Durante el periodo 2000- 2007 se ofrecieron en forma presencial 64 cursos a nivel licenciatura, impartidos por técnicos académicos de la DGB, a nivel bachillerato 20 cursos para los alumnos de bachillerato, y debido al interés despertado también se organizaron tres cursos con duración de 10 horas a profesores, éstos fueron imparti- 
Programa de Desarrollo de Habilidades Informativas de la ...

dos por la académica del CESU. El programa fue a nivel básico e incluyó: el uso y manejo de fuentes de información impresa, redacción de referencias bibliográficas, organización de bibliografías, búsquedas en catálogos en línea, ubicación de libros en los estantes, redacción de fichas de trabajo, etc. Esta académica preparó un manual sobre el uso de la biblioteca conjuntamente con la coordinadora general del Programa de la DGEE próximo a publicarse.

Con la Reforma universitaria, en enero de 2004, se crea la Secretaría de Desarrollo Institucional (SDEI) en sustitución de la Secretaría de Planeación y Reforma Universitaria, y la Dirección General de Bibliotecas pasa a ser parte de ella y deja de depender de la Secretaria General

La SDEI crea entre otros, el Programa de Fortalecimiento al Bachillerato a través de diplomados para la actualización de competencias y habilidades multidisciplinarias, dirigida a profesores del bachillerato de la UNAM, con objeto de que transmitan a sus alumnos estas competencias, y seleccionen a aquellos docentes que puedan fungir como facilitadores de alguno o varios de los módulos de un diplomado para el programa Formación de Formadores. Ambos en coordinación con la Dirección General de Asuntos del Personal Académico (DGAPA)

Para ello se diseñaron tres diplomados que se ofrecieron en dos ocasiones cada uno: 
- Desarrollo de habilidades para la comprensión y producción de textos en español, coordinado por el Centro de Estudios para Extranjeros (CEPE), con duración de 180 hrs.

- Actualización en la enseñanza de las lenguas extranjeras, a cargo del Centro de Lenguas Extranjeras (CELE) con duración de 190 hrs.

- Habilidades para el aprendizaje independiente, dirigido por la Dirección de Evaluación Educativa (DGEE) con duración de $240 \mathrm{hrs}$. En todos ellos se impartió el módulo DHI de manera presencial con duración de 30 y 60 hrs.

Objetivo del Módulo DHI:

- Construir un marco referencial que le permita a los profesores del bachillerato de la UNAM desarrollar en sus alumnos habilidades de búsqueda, selección y sistematización de la información. El marco deberá estar fundamentado en desarrollar y reforzar las habilidades que les permitan un mayor y mejor uso de los recursos informativos y de las tecnologías de la información y de la comunicación disponibles a través del Sistema Bibliotecario de la UNAM, con el fin de lograr en ellos una mayor autosatisfacción y eficacia en la búsqueda, selección y sistematización de información relevante, como apoyo a los procesos de enseñanza-aprendizaje, así como de proveerles conceptos y criterios para la evaluación y selección de fuentes y herramientas, de acuerdo a sus necesidades y demandas de información. 
Programa de Desarrollo de Habilidades Informativas de la ...

Contenidos:

1. Introducción

2. El ciclo de la información

3. Panorama mundial de la información

4. Sistema Bibliotecario de la UNAM

5. Investigación documental

6. Recuperación de Información

7. Catálogos de la UNAM

8. Bases de datos latinoamericanas. CLASE, PERIÓDICA, LATINDEX

9. IRESIE

10.Bases de datos especializadas (Ciencia y Tecnología) 11. Bases de datos especializadas (Ciencias sociales y humanidades)

12. Revistas electrónicas de texto completo

13.Libros electrónicos

14.Evaluación

Las unidades fueron desarrolladas e impartidas en forma presencial por diez técnicos académicos de la DGB y uno del Instituto de Investigaciones sobre la Universidad y la Educación (IISUE), seleccionados por su especialización y experiencia, algunos de ellos también participaban en los cursos dirigidos a los alumnos desde 2001. Los diplomados tenían un coordinador general de la entidad responsable y un coordinador del módulo de la DGB.

Se evaluaba el desempeño de cada instructor por parte de los participantes y se aplicaba un examen final, se elaboraban ejercicios según las materias que impartían los profesores ya fuera en la Escuela Nacional Preparatoria o en el Colegio de Ciencias y Humanidades. Con 
base en el resultado de las evaluaciones, se seleccionaron y capacitaron a otros técnicos académicos para contar con más instructores y sustituir a algunos que aunque dominaban su campo de trabajo, su desempeño como profesores no era el mejor.

A fines de 2004 coordinados por la Coordinación de Universidad Abierta y a Distancia (CUAED), se diseñó y ofreció por primera vez el "Curso propedéutico en línea”, dirigido a los alumnos de primer ingreso a las licenciaturas que oferta la UNAM en esa modalidad. La DGB participó anualmente durante tres años con el Módulo DHI, con duración de 30 hrs., como parte de dicho curso. La CUAED ofreció asesoría técnica para diseñar el programa en línea, lo cual resultó difícil, pues como es bien sabido, no es lo mismo la educación presencial que en línea, además hubo la necesidad de capacitar a más de 20 tutores en línea que tenían que atender a un promedio de 30 alumnos, que generalmente tenían equipo propio pero muchos no contaban con conexión a Internet, en sus lugares de origen carecían de bibliotecas y se les dificultaba el acceso y la comprensión a las fuentes de información en línea que poseía la UNAM, las evaluaciones no resultaban tan buenas, salvo algunas y como el curso no era obligatorio, muchos alumnos desertaban conforme se hacían más complejas las tareas. Después se realizó otra propuesta más sencilla donde se incluyeron también recursos libres disponibles a través de la red.

La DGB seleccionó a ocho académicos para que tomaran el curso "Formación de Núcleos PUEL" en el Centro de Alta Tecnología de Educación a Distancia de 
Programa de Desarrollo de Habilidades Informativas de la ...

la UNAM en Tlaxcala, Tlax., para tener listo el módulo a fin de año.

En 2005 fueron becados cuatro académicos para cursar el Máster a distancia en Nuevas Tecnologías Aplicadas a la Educación impartido por las universidades de Alicante, Autónoma de Barcelona, Carlos III de Madrid y el Grupo Santillana de Formación a través del Instituto Universitario de Posgrado de España.

A partir de 2006 los cursos de DHI para profesores cambiaron a la modalidad en línea y se creó el "Programa de cursos de actualización en habilidades genéricas con opción a diploma" coordinado por la SDEI y la DGAPA.

\section{EDUCACIÓN EN LÍNEA}

La Internet y el desarrollo de las Tecnologías de la Información y de la Comunicación (TIC) han propiciado que el proceso enseñanza-aprendizaje y aprendizaje-enseñanza hayan cambiado, lo que ha generado nuevos modelos educativos como el de educación en línea que favorece un mayor acceso a la educación.

El rol del profesor y el del alumno han cambiado, el alumno es responsable de su aprendizaje, por tanto debe estar motivado para tener una participación activa, administrar su tiempo y dosificar su estudio. Se han roto los paradigmas del tiempo y el espacio, alumno y tutor no se encuentran físicamente en el mismo lugar ni al mismo tiempo.

El trabajo a distancia es arduo, la construcción del conocimiento se basa en el estudio de contenidos y en la realización de actividades, la interacción se efectúa a tra- 
vés del chat, el foro, el correo electrónico, la video conferencia, entre otros; se propicia el aprendizaje independiente o autónomo y el trabajo colaborativo; se accede al curso sin restricción de horario; los objetos de aprendizaje pueden ser reusables y se distribuyen a través de Internet; estos objetos incorporan textos, imágenes fijas, animaciones, vídeos y sonido -son conocidos también como multimedia- y se requiere actualizar estos contenidos y actividades permanentemente

\section{GRUPO DE TRABAJO DE LA DGB}

El equipo de trabajo que intervino en la planeación, diseño, desarrollo e implantación de los cursos en línea está conformado por un grupo inter y multidisciplinario de seis académicos especializados en diferentes áreas del conocimiento, complementado por otros 18 técnicos académicos y una académica del IISUE. De acuerdo al modelo de la CUAED se constituye por:

1. Coordinador del proyecto, modera y coordina las actividades del grupo, da seguimiento al proyecto de acuerdo al plan y cronograma de trabajo. Cuenta con conocimientos de administración de proyectos y con autoridad para la toma de decisiones.

2. Expertos en contenidos de las áreas de Bibliotecología y Ciencias de la Información, que elaboran los contenidos del programa y/o fungen como instructores.

3. Diseñador instruccional, desarrolla objetos de aprendizaje, diseña la adaptación de los contenidos a un ambiente web, la interacción y reforzamiento del aprendizaje mediante herramientas de comunicación como foro y chat. Posee conocimientos en dise- 
Programa de Desarrollo de Habilidades Informativas de la ...

ño curricular de actividades educativas, diseño instruccional, recuperación de información y aplicación de las TIC.

4. Diseñador gráfico, desarrolla la interfaz, forma y programa el sitio web. Especialista en diseño gráfico web y multimedia.

5. Administrador y programador de sistemas, responsable de montar los contenidos en la web. Administra y supervisa la plataforma tecnológica, ofrece asesoría técnica en conectividad y es especialista en administración y programación de sistemas y bases de datos.

Ningún rol del equipo es más importante que otro, ya que la sumatoria del trabajo de todos da como resultado un curso de calidad. A veces una misma persona juega más de un rol.

\section{ESTRUCTURA DEL CURSO}

Ofrece información relativa a la presentación, objetivos generales, temario, créditos y requisitos del curso. Además guía al alumno mediante la forma de trabajo, el calendario, la carpeta de los alumnos, la lista de tutores, la bibliografía y el glosario.

El curso consta de 10 unidades de aprendizaje conformadas por: introducción, objetivos particulares, contenido formativo, tutoriales, actividades de aprendizaje y de autoevaluación, materiales adicionales, glosario y bibliografía.

\section{Unidades de aprendizaje:}

Introducción 
Tendencias de la Alfabetización Informativa en Iberoamérica

1.-Información. Concepto, características y atributos, ciclo de la información, información primaria y secundaria.

2.-Investigación documental y elaboración de referencias bibliográficas. Información documental, normalización y redacción de referencias y citas bibliográficas, elaboración de la bibliografía consultada. Ética de la información.

3.-Recuperación de información. Sistemas de recuperación de información. Lenguajes de recuperación y vocabulario de indización, estrategias de búsqueda.

4.- El Sistema Bibliotecario de la UNAM: Estructura, recursos informativos de la UNAM, Colecciones, Servicios, Biblioteca Central.

5.-El sitio de la DGB y la Biblioteca Digital, El sitio de la DGB, Catálogos en línea: LIBRUNAM, SERIUNAM, TESIUNAM. Biblioteca digital.

6.- Bases de datos producidas por la UNAM (CLASE, PERIÓDICA, IRESIE, EL SITIO DE LA UNAM, FILOS), Biblioteca jurídica virtual.

7.- Bases de datos adquiridas por la UNAM. Bases de datos regionales INF4RMEX, INFOLATINA, HAPI ON LINE. Bases de datos internacionales: Academic Search Premier, Business Source Premier, Newspaper Source, PsychINFO, ABI/INFORM Global, Proquest Social SCIENCE Journals.

8.- REVISTAS ELECTRÓNICAS. Definición, características, ventajas, Control bibliográfico internacional, Revistas electrónicas adquiridas por la UNAM, editadas por la UNAM, e Iberoamericanas. 
Programa de Desarrollo de Habilidades Informativas de la ...

9.- Libro electrónico. Definición, características y ventajas, Control bibliográfico universal

10.- Tesis electrónicas de la UNAM

Existen varios modelos de diseño instruccional basados en diferentes teorías del aprendizaje: conductista, cognoscitivista y constructivista. El diseño instruccional ha pasado de un aprendizaje conductual a una visión constructivista.

La teoría constructivista considera que el alumno aprende primordialmente a través de dos procesos: la resolución de conflictos y la reflexión teórica, esto implica que genere el conocimiento o lo descubra, pero no que lo espere pasivamente del profesor.

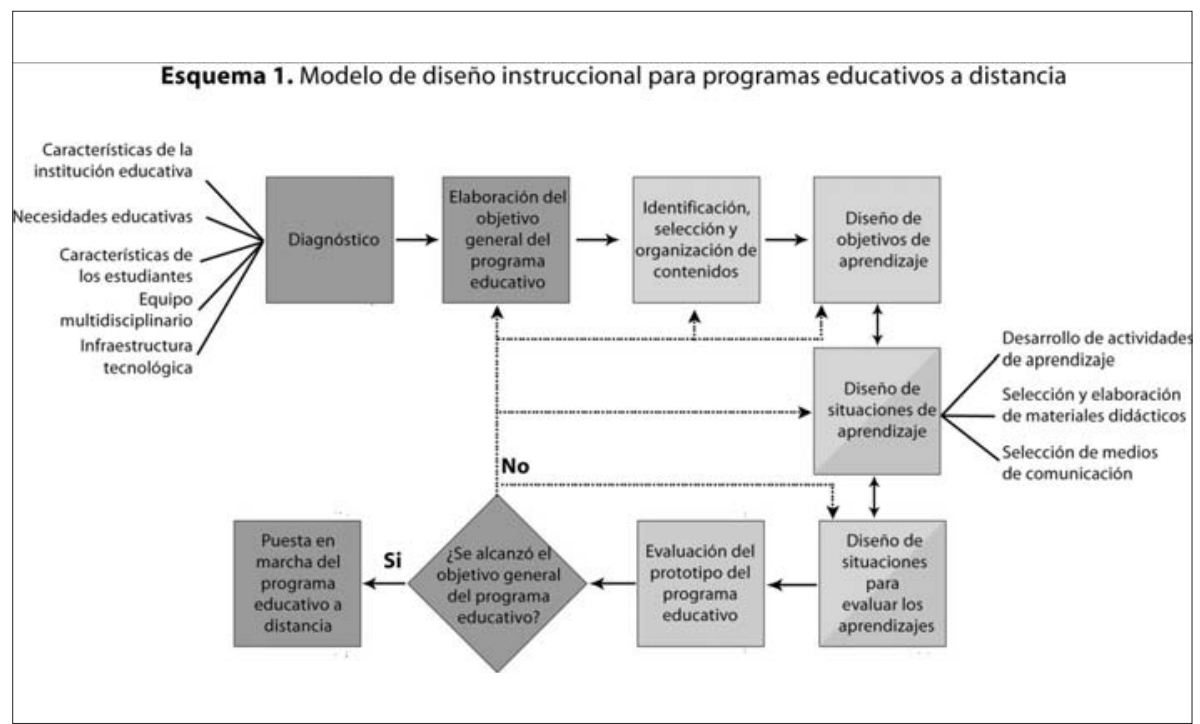


El modelo de diseño instruccional que la DGB adoptó es el propuesto por la Coordinación de Universidad Abierta y Educación a Distancia (CUAED).

\section{PlatAFORMA TECNOLÓGICA}

Plataforma o Sistema de Gestión del Aprendizaje, en inglés Learning Management System (LMS) es un conjunto de programas que se utilizan para la creación, gestión y distribución de actividades formativas a través de la Web. Son aplicaciones que facilitan la creación de entornos de enseñanza-aprendizaje, integrando contenidos, materiales didácticos, y herramientas de comunicación y gestión educativa

En la DGB se ha trabajado con dos plataformas de software sugeridas por la CUAED, ambas libres; la primera fue la Plataforma Universitaria de Educación en Línea (PUEL), desarrollada por la CUAED y en 2006 se inició la migración a Moodle (Modular Object Oriented Dynamic Learning Enviroment), debido a que presenta más y mejores características y herramientas.

Los requisitos de las dos plataformas utilizan software libre, por lo que son muy accesibles y no representan una inversión adicional.

Hasta 2007 el curso constaba de 202 archivos en HTLM, 16 tutoriales en Flash, 39 actividades de aprendizaje y 272 archivos de imágenes.

\section{RESULTADOS}

El Programa de Desarrollo de Habilidades Informativas de la Dirección General de Bibliotecas instituido for- 
Programa de Desarrollo de Habilidades Informativas de la ...

malmente a finales de 2000 forma parte de otros Programas universitarios integrales de desarrollo de habilidades dirigidos a alumnos de primer ingreso al bachillerato y la licenciatura presencial de la UNAM, así como a alumnos de primer ingreso a las licenciaturas en línea que durante el último quinquenio a puesto en marcha la Universidad, y además con el objeto de llegar a más población estudiantil desde el bachillerato a través de los profesores de ese nivel, tanto en la modalidad presencial como en línea, esto permite estar más cerca con la mayoría de usuarios de las unidades de información del Sistema Bibliotecario de la UNAM; es decir alumnos y maestros, fomentar el uso de los recursos informativos en lo que se invierte una parte sustancial del presupuesto universitario, y evaluar las colecciones y servicios que se ofrecen, entre otras acciones.

También permitió trabajar de manera colegiada con otras entidades y dependencias. Y capacitar, fortalecer y diversificar las actividades del personal académico DGB al diseñar, impartir, evaluar y actualizar los cursos de alfabetización informativa indispensables en la actualidad de manera presencial e incursionar en la educación en línea, conformar grupos de trabajo en equipo interdisciplinarios para llegar a un fin, cabe mencionar que de los cursos dirigidos a profesores, el impartido por la a DGB les abrió un mundo de información en muchas ocasiones poco conocido por los maestros quienes lo recomendaban a otros maestros y siempre los grupos eran numerosos, con mucha participación y con buenos resultados.

Los resultados en general fueron muy buenos, a excepción del curso propedéutico en línea para alumnos 
de primer ingreso a la licenciatura en esa modalidad, pues su preparación, ubicación, acceso a bibliotecas, etc. generalmente es heterogénea y diferente a la de alumnos que de forma presencial cursan sus estudios en la Universidad asunto que no se previó del todo.

Los cursos en línea deben ser permanentemente actualizados, pues los editores incluyen los nuevos avances de la tecnología en sus publicaciones o bien modifican sus interfaces para hacerlas más amigables, y es necesario equipo reciente para consultarlas mejor o bien cuando se ofrece el curso y los tutoriales no incluyen las últimas pantallas; entonces los tutores tienen que modificar algunas actividades pues los alumnos quieren que las imágenes de los cursos sean iguales a las que se despliegan en pantalla cuando toman el curso, y los tutores que están dedicados a otras actividades invierten mucho más tiempo en el curso, además los alumnos que ingresan cuando pueden quieren que el profesor esté disponible a toda hora, hasta 2007 no había personal contratado o dedicado ex profeso para el programa.

Se depende mucho de la conectividad a los recursos disponibles en el sitio de la DGB y durante el curso se les activan claves temporales a los participantes para acceder a los materiales adquiridos por suscripción, pese a todo es un gran logro contar con el Programa de carácter institucional, dónde además participan académicos de casi todas las subdirecciones de la Dependencia.

El Programa de cursos para actualización de habilidades genéricas con opción a diploma dirigido a profesores de bachillerato y coordinado por la Secretaría de Desarrollo Institucional y la Dirección de Asuntos del 
Programa de Desarrollo de Habilidades Informativas de la ...

Personal Académico, continúa hasta la fecha y la Dirección General de Bibliotecas sigue participando, con la actualización e impartición del Curso de Desarrollo de Habilidades Informativas realizando entre otras, las siguientes acciones, actualización y mejoramiento de los contenidos de los módulos, pero conservando estructura original y migró el programa de DHI de la plataforma PUEL a la de Moodle, al igual que los otros cursos dirigidos a los maestros de la ENP y el CCH desarrollados por otras entidades y dependencias que participan en el Programa de Cursos para la Actualización de Habilidades Genéricas con Opción a Diploma.

\section{CONCLUSIONES Y RECOMENDACIONES}

El Programa de Desarrollo de Habilidades Informativas de la DGB ha sido un reto para la Dirección General de Bibliotecas desde su diseño, desarrollo, aplicación, evaluación y mejora constante, que ha permitido al personal académico participar de manera colegiada en un programa conjunto en apoyo a la comunidad estudiantil y docente de la UNAM.

El Programa debe seguir formando parte integral de los programas intrainstitucionales de la UNAM.

El grupo de trabajo académico que participa en la coordinación, actualización de contenidos, desarrollo gráfico e informático y tutorial del Programa debe continuar siendo plural multi e interdisciplinario.

La capacitación, actualización y formación de recursos humanos que forman parte del Programa es indispensable. 
Los cursos de Desarrollo de Habilidades Informativas deben diversificarse por nivel (alumnos de primer ingreso, los que están cursando o concluyendo, por ejemplo los tesistas) y especializarse por escuela, facultad y/o carrera. Además de los ofrecidos a profesores de bachillerato y e incluir a los de licenciatura que lo requieran.

La mejora continua es básica y se sería deseable que el personal académicol que labora en las bibliotecas del Sistema Bibliotecario de la UNAM también participara en forma coordinada por la DGB y capacitada por la misma para lograr una mayor cobertura en el menor tiempo, y en consecuencia un mejor y mayor uso de los recursos documentales que produce y adquiere la UNAM y de aquellos disponibles a través de la red en apoyo a las funciones sustantivas de la UNAM.

\section{BIBLIOGRAFÍA}

Rovalo de Robles, Ma. de Lourdes y Quesada Castillo, Rocío, Habilidades generales del ejercicio profesional (2004), en Memorias del 3er. Encuentro de DHI (pp. 121-136), Ciudad Juárez, Chi: UACJ.

Rovalo de Robles, Ma. de Lourdes; Martínez Canchola, Ma. Teresa; Martínez Ortega, Martha Patricia; Carrillo Romero, Oralia; Zorrila Abascal, Miguel Antonio y García Martínez, Bardo Javier, Desarrollo de habilidades informativas en línea en la UNAM: Experiencia de la Dirección General de Bibliotecas (2007), en Memorias de las XXXVIII Jornadas Mexicanas de Biblioteconomía y Archivonomía, León, Gto. 14pp., México: AMBAC. 
Programa de Desarrollo de Habilidades Informativas de la ...

UNAM, Dirección General de Bibliotecas. Reunión anual de evaluación y planeación 2007, Subdirección de Planeación y Desarrollo. Actividades relevantes 2000-2007, Ciudad Universitaria: DGB-UNAM, Documento interno.

UNAM, Dirección General de Evaluación Educativa. Programa de desarrollo de habilidades genéricas, Informe 2000-2007 (2007), Ciudad Universitaria: DGEE-UNAM, Documento interno.

UNAM, Secretaría de Desarrollo Institucional. Programa de cursos de actualización en habilidades genéricas con opción a diploma, Evaluación 2006-2007, Cursos DHI, (2007) Documento interno. 


\section{Comunidad de Práctica de Destrezas de Información de la Universidad de Puerto Rico (UPR): colaborar y compartir conocimiento hacia una misma meta}

NORAIDA DOMÍNGUEZ

YESENIA HERNÁNDEZ

MAGDA PÉREZ

Universidad de Puerto Rico

\section{INTRODUCCIÓN}

a Universidad de Puerto Rico (UPR) es el sistema de Seducación superior más antiguo y reconocido como el de mayor excelencia en Puerto Rico. Los diversos programas académicos que se ofrecen cuentan con un sinnúmero de acreditaciones por parte de las principales entidades profesionales norteamericanas. Es necesario destacar que según las clasificaciones asignadas por la Fundación Carnegie, la UPR está catalogada como una institución doctoral y de investigación. La UPR consiste de 11 unidades ubicadas a lo largo de toda la Isla, con cuatro unidades en el área metropolitana de San Juan, tres unidades en el área sur y cuatro unidades en el área central y oeste. Entre sus ofrecimientos académicos, la UPR ofrece grados asociados, bachilleratos, maestrías y doctorados. Actualmente cuenta con más de 5,000 empleados 
docentes e investigadores y una matrícula que sobrepasa los 60,000 estudiantes, (Sobre la UPR, 2010).

Para apoyar los procesos de educación e investigación, la UPR cuenta con las bibliotecas más completas y especializadas del país. En este sentido, es importante destacar que el Recinto de Río Piedras de la UPR, cuenta con diversas colecciones que son las más completas en Puerto Rico y el Caribe. La Colección Puertorriqueña, albergada en la Biblioteca General del Edificio José M. Lázaro, contiene un amplio acervo de recursos de información sobre Puerto Rico, y es la mayor colección de esta naturaleza en la Isla (Colección Puertorriqueña, 2010). Por otro lado, en el mismo edificio se encuentra la Biblioteca Regional del Caribe y Estudios Latinoamericanos, una biblioteca de investigación que incluye fuentes primarias y secundarias en todas las áreas del saber relacionado con América Latina y el Caribe (Biblioteca Regional del Caribe y Estudios Latinoamericanos, 2010). Además, la UPR cuenta con otras bibliotecas especializadas, como son: la Biblioteca de Derecho, la Biblioteca de Arquitectura y la Biblioteca del Recinto de Ciencias Médicas, la cual posee la colección más completa de libros, revistas, bases de datos y materiales no impresos acerca de temas de las Ciencias de la Salud en Puerto Rico y el Caribe (Conrado F. Asenjo Library, 2005).

Para garantizar la excelencia de todas las bibliotecas de la UPR, durante el año 2007 se inició un proceso de evaluación de todas las bibliotecas. Para este proceso se le solicitó a la Association of College and Research Libraries (ACRL) que evaluara todas las bibliotecas según las normas para bibliotecas de instituciones de educación supe- 
Comunidad de Práctica de Destrezas de Información de la ...

rior que ellos publican, (ACRL, 2004). Durante el primer año de evaluación, varios miembros de la ACRL visitaron cinco unidades del sistema universitario; como resultado se evidenció la necesidad de fortalecer cinco áreas medulares de la gestión bibliotecaria. Una de las áreas identificadas fue la necesidad de continuar integrando las nuevas tecnologías en los servicios bibliotecarios, otra área fue la necesidad de demostrar que las bibliotecas apoyan efectivamente los procesos de investigación y creación de la comunidad universitaria. Además, se identificó la necesidad de desarrollar las colecciones en las bibliotecas de forma colaborativa, así como la gestión organizacional y el desarrollo efectivo de los programas de destrezas de información de cada biblioteca.

Una vez identificadas las áreas a fortalecer, el doctor José Sánchez-Lugo, quien es catedrático en la Escuela Graduada de Ciencias y Tecnologías de la Información de la Universidad de Puerto Rico, propuso la creación de comunidades de práctica, para que cada una trabajara para el fortalecimiento de cada área (Sánchez-Lugo, 2008). Basado en la teoría de Wenger (1998), quien indica que una comunidad de práctica es un grupo de personas que comparte un interés por algo que hacen y aprenden a cómo hacerlo mejor a través de la interacción con otros, se invitó a diferentes bibliotecarios de la UPR a formar una comunidad de práctica cuya meta principal sería atender un área que era necesario fortalecer. Como resultado, se formaron cinco comunidades de práctica:

- Comunidad de Práctica de Destrezas de Información,

- Comunidad de Práctica de Tecnologías Emergentes,

- Comunidad de Práctica de Desarrollo de Colecciones, 
- Comunidad de Práctica de Apoyo a la Investigación y la

- Comunidad de Práctica de Liderazgo Organizacional.

Aunque durante este primer proceso de evaluación se formaron cinco comunidades de práctica, nuevas comunidades se han formado al identificar otras necesidades durante el proceso. Una comunidad más reciente es la comunidad de Referencia Virtual, la cual busca fomentar y apoyar gestiones para desarrollar y ofrecer un servicio de referencia virtual a nivel sistémico, esto debido a que actualmente en diversas bibliotecas existen esfuerzos para ofrecer este tipo de servicio, pero con limitaciones. Otra comunidad que está actualmente en proceso de formación es la Comunidad de Práctica de Avalúo, la cual busca reunir al personal bibliotecario comprometido con fomentar una cultura de avalúo a través de todas las bibliotecas de la institución.

\section{COMUNIdAd de PRÁCTICA de Destrezas de INFORMACIÓN}

Para la formación de la Comunidad de Práctica de Destrezas de Información primero se identificó la persona que sería invitada a ser líder de la misma, la cual fue seleccionada por la evaluación positiva que recibió como encargada de un programa de destrezas de información. Luego de recibir una breve orientación sobre el propósito y metas de las comunidades de práctica, se le asignó la tarea de identificar e invitar al personal bibliotecario que formaría parte de esta comunidad. Para esto se identificó al personal bibliotecario que está a cargo de los 
Comunidad de Práctica de Destrezas de Información de la ...

Programas de Destrezas de Información en cada unidad de la UPR. Todas las personas que fueron invitadas a pertenecer aceptaron y participaron de una reunión inicial cuyo propósito fue orientar en torno al propósito de la Comunidad y las metas establecidas para cada una.

Una vez orientados, todos los integrantes de la Comunidad comenzaron con un proceso de planificación de actividades. Como primera etapa se identificó la necesidad de recopilar información por parte del personal bibliotecario de todos los recintos de la UPR, con el propósito de tener un mayor conocimiento sobre lo que ocurre en cada una de las bibliotecas relacionado con las destrezas de información. Además, se esperaba examinar la percepción del personal bibliotecario en torno al rol de cada uno, responsabilidades y esfuerzos que llevan a cabo o están dispuestos a hacer para lograr el desarrollo efectivo de los programas de destrezas de información. Para esto, se visitaron los recintos y se invitó a todo el personal bibliotecario a que participara de unas conversaciones con la Comunidad. El tema principal de la conversación fue el desarrollo de sus programas de destrezas de información, sus fortalezas, necesidades y la percepción que se tiene en torno al rol de la Comunidad de Práctica. Por otra parte, también se pudo examinar la situación actual de los diversos programas de destrezas de información, las prácticas que han sido desarrolladas y el tipo de apoyo que reciben por parte de la administración institucional. La información recopilada fue utilizada para desarrollar un plan de trabajo con las metas específicas, los objetivos y las actividades que se estarían planificando. 
Como primera meta se determinó que se trabajaría con la capacitación del personal bibliotecario en torno a la integración de las competencias de información del currículo académico. En este sentido se identificó la necesidad de compartir conocimiento en torno a los modelos a seguir, los estándares establecidos y las estrategias que se utilizarían para desarrollar nuevos proyectos de integración. Otro aspecto identificado fue la necesidad de adiestramiento relacionado con las técnicas de enseñanza, ya que en general el personal bibliotecario expresó confianza en torno al conocimiento sobre las destrezas de información, pero expresaron tener limitaciones en cuanto a las técnicas de enseñanza que deben utilizar para desarrollar y ofrecer las diversas actividades.

También se identificó la necesidad de publicar materiales de enseñanza, así como de describir las prácticas que se llevan a cabo en las bibliotecas. Fue así como el personal bibliotecario expresó el hecho de que la preparación de material de enseñanza requiere de mucho tiempo y dedicación, por lo que poder contar con recursos previamente diseñados sería un gran apoyo para el desarrollo de nuevos proyectos. Además tener un mayor conocimiento sobre lo que hacen en otras bibliotecas, cómo lo hacen y qué ha sido efectivo, les ayudaría a identificar ideas que pueden desarrollar en sus unidades. En general el personal bibliotecario mostró gran interés y apertura para compartir sus conocimientos y los productos que han desarrollado como parte de los esfuerzos para enseñar las destrezas de información. 
Comunidad de Práctica de Destrezas de Información de la ...

Otra meta establecida por la Comunidad es apoyar los esfuerzos en diversos recintos para lograr un reconocimiento institucional sobre la necesidad de integrar la enseñanza de las destrezas de información al currículo académico. Específicamente se espera identificar toda documentación que se desarrolla a diversos niveles y que evidencie este reconocimiento. Se espera que la divulgación de esta información apoye las gestiones que se llevan a cabo de forma individual y que, eventualmente, se lleven a cabo de forma colectiva. Además, la Comunidad espera continuar participando activamente en los foros que están disponibles para fomentar la integración de las destrezas de información en los diversos niveles.

Por último, la Comunidad de Práctica pretende fomentar la idea de desarrollar un Centro Institucional para el Desarrollo de las Competencias de Información (CIDCI) cuyo propósito principal sería asesorar a la comunidad universitaria en general sobre las destrezas de información. Por otro lado, este centro serviría para apoyar proyectos de integración en los diferentes recintos, y ofrecería el adiestramiento necesario y los recursos que pueden ser utilizados por el personal bibliotecario de todas las unidades de la institución. En general, el valor principal del CIDCI es que permitiría el desarrollo sistémico de diversos proyectos y la colaboración entre el personal de diversos recintos.

Además de las metas identificadas, actualmente la Comunidad está trabajando con el diseño de una guía sobre honestidad académica y plagio, la cual pretende servir como recurso para los profesores. Específicamente se busca que esta guía sirva de apoyo a aquellos profe- 
sores que reconocen la importancia de educar a los estudiantes sobre el uso correcto de la información, evitando el plagio. Además esta guía les mostrará a los profesores las técnicas que pueden utilizar para identificar si los estudiantes han cometido plagio o han hecho un uso incorrecto de la información. Por otra parte, también se estará diseñando un módulo dirigido a estudiantes para que aprendan estrategias de cómo hacer un uso correcto de la información y evitar el plagio.

Por último la Comunidad continuará con la publicación de informes pertinentes al tema de las destrezas de información a través del blog (http://redesupr.blogspot.com). También se espera que este espacio sirva para divulgar materiales que puedan ser utilizados por el personal bibliotecario u otro personal docente que enseñe las destrezas de información. Por último, se pretende mantener este blog activo y que sea considerado como un recurso valioso por el personal bibliotecario que trabaja con las destrezas de información o que se inicia en estas gestiones.

\section{PROGRAMAS DE DESTREZAS DE INFORMA- CIÓN DE LA UPR: SITUACIÓN ACTUAL Y PRÁCTICAS IDENTIFICADAS}

En reuniones y conversaciones entre los miembros de la Comunidad de Destrezas de Información, se identificaron tres tipos de prácticas que se llevan a cabo en los diferentes recintos de la UPR, las cuales se pueden clasificar de la siguiente forma: los proyectos de integración; las actividades aisladas (one-shot library session); y los 
Comunidad de Práctica de Destrezas de Información de la ...

cursos formales sobre destrezas de información. A continuación se presenta una breve descripción de cada uno.

\section{Proyectos de integración}

Los proyectos de integración requieren que los profesores y los bibliotecarios trabajen colaborativamente las actividades de destrezas de información de manera que se logre una integración efectiva en el currículo. El primer paso en este proceso es la planificación de las actividades que van a ofrecerse. En general, este proceso consiste en:

- Analizar el prontuario (o silabario) e identificar qué elementos pueden vincularse a las destrezas de información de acuerdo con los estándares establecidos por la Association of College and Resesarch Libraries (ACRL, 2000). Por ejemplo, si como parte de un curso los estudiantes necesitan realizar un informe oral sobre un tema en particular, puede integrarse en el currículo un taller sobre cómo desarrollar efectivamente presentaciones orales.

- Desarrollar un proyecto en el que se evidencie la integración de las destrezas de información en el currículo, además del avalúo del aprendizaje estudiantil.

Según expresaron en las diferentes conversaciones realizadas con el personal bibliotecario de los recintos de la UPR, como parte de estos proyectos de integración, el personal bibliotecario diseña y ofrece diversas actividades instruccionales, tales como talleres, conferencias y módulos instruccionales, entre otras, para que 
los estudiantes adquieran los conocimientos que necesitan. Estas actividades están destinadas a que los estudiantes:

1. identifiquen y seleccionen un tema para su trabajo,

2. aprendan diversas estrategias de búsquedas de información,

3. analicen la información recuperada y seleccionen aquélla que les sea útil para sus trabajos,

4. documenten la información apropiadamente y eviten el plagio, $y$

5. autoevalúen el proceso que llevaron a cabo para realizar su trabajo.

Estas actividades instruccionales siguen un orden lógico que guía a los estudiantes en todo el proceso, de manera que alcancen la meta instruccional y cumplan exitosamente con los requisitos de evaluación. Aunque existen diversos modelos para desarrollar las destrezas de información en los estudiantes, la mayoría de los programas de destrezas de información emplean el modelo Big6 desarrollado por Mike Eisenberg y Bob Berkowitz. Este modelo consiste de un proceso sistemático que les permite a los estudiantes solucionar problemas de información (Eisenberg, 2007). Las etapas de este modelo son:

1. Definir la tarea. Los estudiantes definirán qué es lo que tienen que hacer como parte de su trabajo investigativo.

2. Identificar estrategias de búsquedas de información. Identificarán qué estrategias de búsqueda son las más apropiadas para localizar los recursos de información relevantes a su tema. 
Comunidad de Práctica de Destrezas de Información de la ...

3. Localizar y acceder a la información; al enseñarles cómo funciona el catálogo en línea, las bases de datos, el Internet, etc., podrán acceder a información valiosa y relevante para su investigación, tanto en formatos impresos como electrónicos.

4. Utilizar la información; los estudiantes interactuarán con los recursos de información para extraer lo que necesitan.

5. Sintetizar; extraerán de diferentes recursos de información lo más importante y pertinente para su trabajo y así desarrollarán un producto original.

6. Evaluar; evaluarán tanto el producto como el proceso llevado a cabo.

Un ejemplo de proyecto de integración se lleva a cabo en el Recinto de Cayey, donde se integran las destrezas de información en tres cursos medulares en forma escalonada y utilizando la investigación. Estos cursos son:

1. QUIM 3124 Laboratorio de Química Orgánica 2. Este curso es de segundo año y ha sido diseñado de tal forma que los estudiantes se inicien en las destrezas de información a través del desarrollo de un proyecto de investigación de un tema asignado en síntesis orgánica.

2. QUIM 3006 Bibliografía, Literatura Química y Seminario. Para el desarrollo de las destrezas de información los estudiantes preparan un proyecto de investigación en literatura química. Se revisa la literatura y se produce un "Review Paper" sobre un tema de investigación en química. 
3. QUIM 4015 Análisis Instrumental. Los estudiantes aplican las destrezas de información a través de la realización de un proyecto de investigación.

Otro ejemplo de esta práctica se lleva a cabo en el Recinto de Carolina, donde se integran las destrezas de información en cuatro cursos básicos de inglés, también de forma escalonada y utilizando una tarea de investigación. Estos cursos son:

1. INGL 3101 Inglés Básico I. Este curso es de primer año, para el cual se ha diseñado un proyecto de integración para que los estudiantes desarrollen destrezas de información básicas a través del desarrollo de un proyecto que involucra directamente los diversos recursos y servicios de la biblioteca.

2. INGL 3102 Inglés Básico II. Este curso es la segunda parte que se toma también durante el primer año. El curso ha diseñado un proyecto de integración para que el estudiante desarrolle destrezas de información adicionales a las ya trabajadas durante la primera parte del curso, a través de un proyecto que requiere la búsqueda y el uso de diversos recursos de información para la preparación de un informe oral.

3. INGL 3201. Este curso es de segundo año. Para el mismo se ha diseñado un proyecto de integración para que el estudiante desarrolle destrezas de información un poco más avanzadas, se enfatiza la evaluación y selección apropiada de recursos de información y preparación de una bibliografía anotada.

4. INGL 3201. Este curso es la segunda parte que se toma durante el segundo año y ha diseñado un proyecto de integración para que el estudiante desarrolle 
Comunidad de Práctica de Destrezas de Información de la ...

destrezas de información avanzadas, enfocadas en aspectos de honestidad académica y uso correcto de la información, esto a través del desarrollo de un proyecto de investigación.

Es importante destacar que los proyectos de integración que se han desarrollado en Carolina han sido llevados a los recintos de Utuado y Aguadilla, donde el personal bibliotecario lo ha desarrollado de forma similar. Como resultado se ha evidenciado la efectividad de compartir conocimientos y recursos, en tanto que permiten que los mismos proyectos sean utilizados por otros colegas empleando los recursos previamente desarrollados en otras unidades.

Algunas de las prácticas que el personal bibliotecario de la UPR considera que han sido efectivas en los programas de destrezas de información para lograr que los estudiantes adquieran las destrezas que necesitan son:

1. Realizar planes de trabajo semestrales por medio de cursos coordinados entre el personal bibliotecario y los profesores,

2. Incluir en el prontuario o silabario las destrezas de información,

3. Lograr que las actividades instruccionales que ofrece el personal bibliotecario se lleven a cabo dentro del horario de los cursos y que haya una cátedra compartida con los profesores,

4. Publicar los materiales instruccionales en línea empleando blogs, wikis, BlackBoard, Moodle, etcétera, y

5. Avaluar el aprendizaje estudiantil. Algunas de las técnicas de avalúo son: pre y post pruebas, informes orales, ensayos, mapas conceptuales, portafolios, 
bosquejos, rúbricas, cuestionarios, diarios reflexivos, evaluaciones, entre otras.

\section{Actividades aisladas}

Las actividades aisladas se componen de sesiones de instrucción al usuario donde las actividades no son integradas al currículo. Durante muchos años este tipo de actividad fue la única alternativa disponible para que el personal bibliotecario tuviera contacto directo con los estudiantes para fomentar el uso correcto de diversos recursos de información, así como otras destrezas relacionadas con los procesos de búsqueda de infomación. Entre estas actividades se encuentran:

1. Recorridos por la biblioteca para conocer las diferentes áreas de servicios,

2. Búsquedas de recursos de información a través del Catálogo Público en Línea (OPAC) de la biblioteca,

3. Búsquedas de recursos de información en formatos electrónicos a través de las bases de datos,

4. Elaboración de monografías, ensayos y otros trabajos escritos,

5. Otros temas pertinentes a la búsqueda y uso de información a petición de los profesores.

Generalmente los profesores solicitan, con al menos dos semanas de anticipación, el taller que le interesa que sus estudiantes reciban. El personal bibliotecario encargado del programa de destrezas de información es responsable de preparar los materiales instruccionales que los estudiantes utilizarán durante el taller. Una vez finalizada la sesión, los estudiantes que lo consideren necesario pueden 
Comunidad de Práctica de Destrezas de Información de la ...

concertar una cita en la biblioteca para reunirse nuevamente y aclarar sus dudas o recibir más información. Por otro lado, si el personal bibliotecario cuenta con un espacio en la Web para alojar los materiales instruccionales (blogs, wikis, etc.) puede dirigir a los estudiantes hacia estos espacios para que revisen los materiales y la información contenidos en ellos. No obstante, una limitación de este tipo de enseñanza es que el personal bibliotecario no cuenta con la oportunidad de evaluar el aprendizaje del estudiante a lo largo de todo el proceso y así identificar si el ofrecimiento de la actividad fue efectivo.

Es importante destacar que, según fue expresado por el personal bibliotecario de las diversas unidades de la UPR, un aspecto que fomenta el ofrecimiento de las actividades aisladas es que ellos tienen asignadas diversas responsabilidades, además de la coordinación de las actividades instruccionales de destrezas de información, como por ejemplo:

1. Atender las salas de servicios (referencia, colecciones especiales, etc.),

2. Realizar labores técnicas características del área de administración de colecciones (selección, adquisición, catalogación, etc.) y

3. Realizar otras funciones afines con los servicios bibliotecarios.

\section{Cursos formales sobre destrezas de información}

En varios recintos de la UPR, además de planificar proyectos de integración de destrezas de información, el personal bibliotecario ofrece cursos formales con créditos que son parte de algunos currículos. Algunos de es- 
tos cursos deben ser aprobados por los estudiantes en tanto que son requisito para que logren graduarse; otros son cursos electivos.

En el Recinto Universitario de Mayagüez se ofrecen los siguientes cursos formales:

1. AGRO 4019 Seminario (un crédito). El contenido de este curso consiste de discusiones de informes y conferencias relacionadas con investigaciones recientes en las áreas del desarrollo de fincas y la producción de cultivos.

2. BIOL 3055. Investigación bibliográfica en las ciencias biológicas (un crédito). Introducción al uso de la biblioteca, el catálogo, los índices de revistas, los extractos, las enciclopedias, los diccionarios, las monografías y otros recursos de información en las ciencias biológicas.

3. CISO 3145 Investigación bibliográfica en las ciencias sociales (tres créditos). Introducción al uso de la biblioteca, el catálogo, los índices de revistas, los extractos, las enciclopedias, los diccionarios, las monografías y otras fuentes de información en las ciencias sociales.

4. INTD 3355 Métodos de investigación bibliográfica (electiva de tres créditos). Organización y servicios de la biblioteca del RUM. Selección y uso de los recursos de información tanto en formato impreso como electrónico. Se discuten las estrategias de búsqueda utilizando métodos tradicionales y tecnológicos, y las guías para el desarrollo de un tema de investigación. 
Comunidad de Práctica de Destrezas de Información de la ...

\section{RETOS A ENFRENTAR}

A pesar de las diversas actividades que se han llevado a cabo desde 2007, a la Comunidad de Práctica le queda mucho por hacer. Entre los retos identificados se encuentra la necesidad de superar la visión tradicional de que las destrezas de información se limitan exclusivamente al uso de los recursos de las bibliotecas y de las tecnologías. Es por ello necesario entender que se deben desarrollar estrategias para reeducar en las nuevas perspectivas e integrar las destrezas de información en otros programas académicos. Principalmente, la Comunidad busca promover la integración de las destrezas de información en otros ambientes tecnológicos y de aprendizaje, como pueden ser los "Learning Commons" (Sinclair, 2009). Además se propone identificar, atemperar y aplicar opciones tecnológicas como pueden ser: recursos de acceso abierto, manejo de recursos por acceso remoto a bases de datos y cualquiera otro que pueda identificarse. De esta manera, el personal bibliotecario puede colaborar en preparar a los estudiantes en destrezas para toda la vida, en todo momento.

Otro reto a superar es la visión de que los currículos recargados limitan el tiempo disponible para incluir las destrezas de información a los contenidos. La Comunidad de Práctica busca enfatizar la integración de las destrezas de información en contenidos pero no como algo adicional que limitará el tiempo para los contenidos. Se entiende, no obstante, que el cambio de esta visión necesitará del apoyo a nivel administrativo para que así el personal docente en general sea adiestrado en torno a qué son las destrezas de información y la responsabili- 
dad de cada uno para apoyar a los estudiantes en el desarrollo de estas destrezas.

Otro aspecto que la Comunidad de Práctica enfocará es el desarrollo de planes abarcadores para la integración sistemática y progresiva de las destrezas de información dentro de una secuencia curricular. Esto implica considerar al personal bibliotecario como un planificador sistémico que se debe enfocar hacia el desarrollo de las destrezas de información por niveles a través del currículo y participar en la revisión curricular. Es decir, el personal bibliotecario debe intervenir de manera integral y desde el principio.

Lograr la integración del personal bibliotecario en los procesos de: planificación, diseño, desarrollo y evaluación del currículo, es un reto que debe superarse. En este sentido, los comités institucionales como los de currículo, de Educación General y de planificación, son lugares idóneos para que el personal bibliotecario asuma un rol más activo y efectivo al promover la integración de las destrezas de información en el currículo. Además, esto ayudará también a cambiar las actitudes o percepciones que existen en relación con las capacidades del personal bibliotecario y las funciones que pueden desarrollar con una intervención adecuada. Para esto, el personal bibliotecario debe mantenerse actualizado y ser asertivo en su intervención, en especial, en los aspectos de las tecnologías de la información (TIC).

Un quinto reto es el de reconocer que el desarrollo de las destrezas de información es una responsabilidad que deben compartir: administradores, profesores, personal bibliotecario y estudiantes (toda la comunidad universi- 
Comunidad de Práctica de Destrezas de Información de la ...

taria). En esta dirección, el personal bibliotecario debe asumir un rol de educador sobre las destrezas de información para todos los involucrados. Es decir, el personal bibliotecario debe ser considerado como parte del andamiaje institucional en el proceso de involucrar en esto a toda la comunidad universitaria.

Otro reto que tiene que superar la Comunidad de Práctica es el de incorporar nuevas estrategias creativas para enfrentar el hecho de que el número de bibliotecarios y bibliotecarias es mucho menor que la cantidad de profesores y estudiantes. Por ello resulta necesario establecer estrategias para involucrar al profesorado en la enseñanza de las destrezas de información en sus estudiantes. Esto, en especial, en cuanto a los contenidos.

Esto significa que se debe mantener una comunicación efectiva entre el personal bibliotecario y el resto de los docentes. Además, el uso de tecnologías requiere de un adiestramiento y/o re adiestramiento en el uso y manejo de los recursos electrónicos, lo cual es una razón para mantener la comunicación entre los docentes.

Es importante incluir en estos retos el hecho de que las bibliotecas necesitan contar con espacios apropiados para la enseñanza y el aprendizaje activo. Esto aún cuando se reconocen las bibliotecas virtuales y el aula virtual. Los administradores deben admitir que la creación y el mantenimiento de las facilidades físicas y programadas deben ocupar un lugar similar al de otros aspectos en el currículo. Es un reto afrontar esta situación cuando la realidad económica es tan precaria.

Un reto de suma importancia y al cual se debe dedicar más tiempo y esfuerzo es el de promover que la ense- 
ñanza de las destrezas de información e investigación requieren avalúo del aprendizaje, así como evaluación formativa y sumativa. Lo cual implica tomar decisiones de acuerdo a resultados y permanecer receptivos a los cambios. También requiere cambios en estrategias de enseñanza- aprendizaje y en todo lo que se relaciona con las destrezas de información e investigación. Este proceso de avalúo requiere auto evaluación y reflexión continua sobre lo que se hace y cómo se hace.

Finalmente, la Comunidad de Práctica busca fomentar la importancia de documentar, investigar y publicar todo lo relacionado con las prácticas que se llevan a cabo en las bibliotecas y la enseñanza de las destrezas de información y, de esta manera, compartir lo aprendido desde las diferentes disciplinas y los modelos que se adopten. Para esto habrá que recabar el apoyo institucional y otorga el tiempo y los recursos necesarios a fin de que se convierta en una práctica común. Como parte de esta gestión, la Comunidad logró publicar diversos artículos en un número especial de Simbiosis, la revista electrónica de la Escuela Graduada de Ciencias y Tecnologías de la UPR, este número se dedicó a los diferentes proyectos de Destrezas de Información en los diferentes recintos tales como: Bayamón, Carolina, Humacao y Ciencias Médicas (Suárez Balseiro, et al., 2009).

\section{CONCLUSIÓN}

Como se ha evidenciado, la Comunidad de Práctica de Destrezas de Información de la Universidad de Puerto Rico reúne a un grupo de profesionales comprometidos con la enseñanza de las destrezas de información como 
Comunidad de Práctica de Destrezas de Información de la ...

parte del currículo académico. Las gestiones realizadas hasta el momento se han enfocado a conocer las prácticas actuales en las diferentes bibliotecas de la UPR, así como a identificar las fortalezas y necesidades expresadas por el personal bibliotecario. En cuanto a lo que queda por hacer, la Comunidad de Práctica continuará buscando nuevas oportunidades para publicar todas las gestiones relacionadas con la enseñanza de las destrezas de información. Además, se continuará fomentando una colaboración activa entre todas las unidades de la UPR hasta lograr un reconocimiento sistémico de la importancia de enseñar las destrezas de información a través de todo el currículo. Finalmente, la Comunidad de Práctica ha demostrado ser un apoyo efectivo para todo el personal bibliotecario que desea aprender sobre las destrezas de información o compartir su conocimiento.

\section{REFERENCIAS}

Association of College and Research Libraries (2000), Normas sobre aptitudes para el acceso y uso de la información en la enseñanza superior. Recuperado de http://www.ala. org/ala/mgrps/divs/acrl/standards/informationliteracy competencystandards.cfm

Association of College and Research Libraries (2004), Normas para bibliotecas de instituciones de educación superior: aprobadas por la Junta de Gobierno de la ACRL - ALA, recuperado de http://www.ala.org/ala/mgrps/divs/acrl/ standards/highered_sp.pdf

Biblioteca Regional del Caribe y Estudios Latinoamericanos (2010), recuperado de http://biblioteca.uprrp.edu/ BIB-COL/CARIBE.html 
Tendencias de la Alfabetización Informativa en Iberoamérica

Colección Puertorriqueña (2010), recuperado de http://biblioteca.uprrp.edu/BIB-COL/CPR.html

Conrado F. Asenjo Library (2005), Library description, recuperado de http://rcm-library.rcm.upr.edu/3e-geninf.html

Eisenberg, M. (2007), What is the Big6?, recuperado de http://www.big6.com/what-is-the-big6/

Sánchez-Lugo, J. (2008), Comunidades de práctica BIBLIO-UPR, recuperado de http://redbibliotecariaupr.wordpress.com /comunidades-de-practica-biblio-upr/

Sinclair, B. (2009, octubre), The blended librarian in the learning commons: Nerw skills for the blended library, recuperado de http://www.ala.org/ala/mgrps/divs/acrl/publications/crlnews/2009/oct/blended_librarian.cfm

Suárez Balseiro, C. (2009), Simbiosis, 6(2), recuperado de http://egcti.upr.edu/index.php?option $=$ com_content $\&$ task $=$ category\&sectionid $=21 \& \mathrm{id}=98 \&$ Itemid $=346$

Universidad de Puerto Rico (2010), Sobre la UPR, recuperado de http://www.upr.edu/?type $=$ items\&id $=0 \&$ string $=\mathrm{La}$ + UPR

Wenger, E. (1998), Communities of practice: learning, meaning, and identity, New York: Cambridge University Press. 


\section{Experiencias en formación para la información en el Instituto Politécnico Nacional}

NOEL ANGUlO MARCIAL

Instituto Politécnico Nacional

\section{INTRODUCCIÓN}

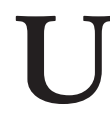

na razón para justificar el movimiento hacia la competencia en información es la idea de que la las habilidades básicas de alfabetización, entendidas como saber leer, escribir y tener un manejo de los rudimentos de la aritmética, no son ya suficientes para desenvolverse en la sociedad actual, sino que es necesario desarrollar nuevas habilidades para insertarse con éxito en los distintos ambientes familiares y de trabajo, así como para enfrentarse al volumen creciente de datos, estructurados en documentos o almacenados en dispositivos electrónicos. Se parte de aceptar que en alguna parte se encuentran disponibles datos pertinentes a los propósitos o intereses de las personas, pero que es necesario aprender a interactuar con las fuentes de información para lograr obtener los datos que responden a las necesidades o propósitos específicos de cada usuario. 
Bajo esta premisa se crea la llamada alfabetización en información que tiene como propósito habilitar a las personas para hacer uso adecuado de la información en todas sus actividades y en nuestro caso particular, en el aprendizaje para toda la vida. Hemos pasado así de algunas ideas desarticuladas y bien intencionadas, pero dispersas, a una situación en la que se llega a definir las normas de competencia que logran homogeneizar criterios que sustentan la competencia en información, pero que dentro de los principios de la llamada inteligencia colectiva propician que las aportaciones a la construcción colectiva tiendan a la baja al cerrarse los espacios a la diversidad de ideas.

Sin la pretensión de retomar la discusión acerca de si ha sido o no una buena medida adoptar la designación de Alfabetización en información, como traducción del término information literacy, sí considero necesario abonar con algunas ideas al propósito de darle sustento a dicha decisión. Para ello acudo a algunas definiciones del término literacy, que para propósitos convencionales se traducen como alfabetización.

La alfabetización, entendida en su forma más tradicional adquiere importancia a partir del momento en que se considera una necesidad el hecho de que las personas que no han aprendido la lectoescritura, accedan al mundo de cultura letrada. La acepción más antigua del término "analfabeto" se aplica en forma restringida a las personas que no saben leer ni escribir, por lo que al implementarse acciones sistemáticas contra el analfabetismo, el término se asoció sólo con los procesos de enseñanza-aprendizaje de la lectura y de la escritura, aunque 
después se incorporó el cálculo como otro elemento importante de la cultura letrada. Un factor que contribuye al establecimiento de programas de alfabetización fue la exigencia motivada por los avances científicos y tecnológicos en el sentido de proveerles a los iletrados un mínimo de conocimientos teóricos y habilidades técnicas para realizar tareas concretas en campos específicos, en relación directa con la producción de bienes y servicios. Si bien esta idea surge y es apoyada por quienes controlaban y usufructuaban esa producción, es desde cualquier punto de vista o interés, innegable su validez, (Medina).

Esta presión de los avances tecnológicos y las condiciones cambiantes de la sociedad es siempre un factor de transformación en las relaciones humanas y se vuelve más apremiante cuando la orientación de la economía se desplaza de los bienes tangibles hacia el conocimiento como eje de la creación de valor, lo que explica las discusiones y los ajustes cada vez más frecuentes del término "alfabetización”, sin dejar de lado su sentido original.

La alfabetización según Danny Vaughn (2010), es un medio que nos ayuda a desarrollar nuestros pensamientos, ideas, creencias, y otras abstracciones y a manejar, analizar, y finalmente comunicar a través del lenguaje oral y escrito. Las personas educadas leen para entender y escriben para ser entendidas. Escribir puede pensarse como una forma de expresión que busca documentar de manera clara lo que uno no puede articular adecuadamente. Al momento de escribir vamos descubriendo las conexiones, van surgiendo preguntas, se describen procesos, se expresan comprensiones, se encuentran res- 
puestas, y finalmente se desarrollan conclusiones. La claridad del escribir involucra una relación íntima entre lo que un escritor piensa y lo que el lector interpreta.

En términos generales, afirma Linda Dubin (2002), la literacy es la habilidad para generar y comunicar significados mediante una variedad de símbolos socialmente contextuales. Dentro de los varios niveles de habilidad de desarrollo, una persona letrada puede derivar y conducir significados, y usar su conocimiento para lograr un propósito deseado o alcanzar una meta que requiere el uso de habilidades del lenguaje, ya sea hablado o escrito. Una persona letrada puede mediar su mundo orquestando el significado de manera deliberada y flexible de una base lingüística de conocimiento y puede aplicar o conectar ésta a otra base de conocimiento. Por ejemplo, sabiendo que las letras simbolizan los sonidos, y que esos sonidos forman palabras a las que el lector puede atar el significado. La definición de alfabetización, continúa la autora, es dinámica, en tanto que evoluciona y refleja los cambios incesantes en nuestra sociedad. La alfabetización, advierte, ha extendido su significado para incluir la alfabetización en la información, las tecnologías de comunicación y la alfabetización crítica, entre otras.

Para Janaina Minelli de Oliveira (2009) La Alfabetización Multimodal [Multimodal Literacy] comparte con los Estudios de Nuevas Alfabetizaciones (New Literacies Studies) y el de las Alfabetizaciones Múltiples (Multiliteracies) la preocupación de atender las necesidades educativas de la sociedad actual, caracterizada por cambios, sin precedentes, impulsados por un incremento en los 
Experiencias en formación para la información en el ...

flujos de información, con sus ideologías y discursos asociados; y una progresiva centralidad de los medios digitales sobre la imprenta, donde la imagen desplaza a la escritura a un papel secundario. Para la Alfabetización Multimodal el significado se produce, distribuye, interpreta y reaprovecha, a través de diversos recursos de representación y comunicación, y el lenguaje verbal es sólo uno de ellos. Se asume que las escuelas no responden ya a la multiplicidad de textos con los que interactúan sus estudiantes. La escuela, sigue anclada en la comunicación escrita, pese a que la realidad ofrece una multiplicidad de modos de comunicación, como el visual, el auditivo y el gestual.

Esta expansión del significado tiene cabida dentro de los usos aceptados del término literacy, que también se refiere a la competencia o el conocimiento acerca de algo, no obstante, en español el término alfabetización en información, puede parecer ajeno si se olvida que, parte de su operatividad descansa en el uso de un lenguaje de búsqueda, que está dado por las palabras claves y los descriptores, más las reglas de sintaxis y su combinación mediante operadores lógicos. Esta idea tiene su antecedente en los lenguajes documentales que cumplen un doble propósito: describir los contenidos de los documentos y plantear las búsquedas de información en catálogos o en dispositivos de exploración en Internet.

Saber representar una necesidad de información y convertirla en una proposición de búsqueda comprensible para la computadora, supone el conocimiento y manejo eficaz del lenguaje de interrogación, ahora asociado al empleo de metadatos, que no son más que una 
versión adaptada de los elementos descriptivos utilizados en los procesos de catalogación y clasificación.

Encontrar correspondencia entre la proposición de búsqueda y la existencia real de contenidos hace posible la generación de información, en tanto que se logra darles significación a los datos al hacer coincidir el propósito del usuario, el contexto de aplicación y los modelos mentales del usuario; no obstante, la significación de los datos y su transferencia a situaciones distintas está necesariamente ligada a la lectura y la escritura, y por otra parte la sola información no es suficiente para cumplir los propósitos del usuario, se requiere de su proceso e interiorización para su aplicación y conversión en conocimiento, aspecto que está referido o implícito en las distintas competencias en información.

\section{LA ECONOMÍA DE LA ATENCIÓN}

Una justificación interesante para promover la competencia en información entre las comunidades académicas es sin duda la referente a la economía de la atención.

El economista Jack Hirshleifer (1971) nos advirtió desde hace más de 40 años que un exceso de información podría tener un efecto contraproducente al disminuir el bienestar. Ante esa sobreabundancia, la clave reside en identificar y dedicarle tiempo a aquella información que se muestre relevante y necesaria para la toma de decisiones correctas.

Este problema lo aborda en forma paralela el Premio Nobel de Economía Herbet A. Simon (1971), quien abre la discusión sobre lo que se ha dqado en llamar economía de la atención; la idea es muy sencilla, aunque no 
ha tenido impacto en nuestro medio. Señala que en un mundo rico en información, esta riqueza provoca una carestía de algo más importante, el tiempo de atención. Lo que la información consume es bastante obvio, consume la atención de sus destinatarios. De manera que una riqueza de información crea una pobreza de atención y lo que parece un juego de palabras se vuelve realidad, a mayor información, menor posibilidad de acceso, lo que hace evidente una correlación negativa que crea la necesidad de asignarle una atención eficaz, pero selectiva, a las fuentes de información.

Estamos expuestos a la explosión de mensajes, provocada por los avances en la tecnología de la información y la comunicación, lo que significa que se incrementa y diversifica el flujo de información, de tal manera que intercambiamos datos e información de muy distintas maneras y de forma cada vez más rápida, ese incremento y diversificación de la información determina una relación desproporcionada y desventajosa, en tanto que no existe en correspondencia, un incremento en nuestra capacidad de atención, la cual permanece constante. Por tanto, atendiendo a la propuesta de Jack Hirshleifer y Herbert Simon, debemos centrar la atención de la manera más eficientemente posible en aquello que merece la pena entre los datos dispersos y redundantes disponibles en la red y en las bases de datos.

Los conceptos anteriores emergieron durante la década de los setenta, cuando estábamos muy lejos de contar con la red Internet y mucho menos teníamos la posibilidad de acceder, en cualquier momento, de manera selectiva y gratuita a los contenidos disponibles en servido- 
dores distribuidos en distintas ubicaciones geográficas, lo cual representa un avance sin precedentes, no obstante, lejos de pensar que las ideas de Hirshleifer y Simon pierden vigencia hoy se hace más apremiante voltear hacia la economía de la atención. Se ha dicho que hoy lo importante no es proporcionar información sino saber dónde encontrarla y recuperarla de manera eficaz en el momento en que se necesita, pero también es de todos conocido, la carencia de control en la calidad y confiabilidad de los contenidos disponibles en la red.

Los usuarios de Internet se enfrentan a información muy desorganizada y aunque solamente un tercio de ella esté disponible en acceso libre, todavía es un volumen muy considerable. El caos del ciberespacio es solamente un aspecto del problema. La competencia entre los diferentes sitios hace que se establezca una guerra para captar el impacto de sus contenidos y atraer la atención de los usuarios, lo cual hace aún más difícil encontrar información relevante y confiable. Cuando un usuario plantea una proposición de búsqueda en la red, el resultado inmediato es una cantidad enorme de direcciones que le llevaría mucho tiempo desmenuzar. Para encontrar información relevante hay que ser prácticamente un especialista en la búsqueda de información, (Morán 1999).

Es cierto que el acceso a la información digital exige nuevos saberes o generalizar algunos que antes sólo estaban confinados a profesiones muy especializadas (los documentalistas, los bibliotecarios). La capacidad de manejar bases de datos, la utilización de palabras clave en las búsquedas, el uso de operadores booleanos en la 
Experiencias en formación para la información en el ...

indización de la documentación propia son saberes necesarios hasta para el estudiante que prepara sus tareas escolares. Pero además de estas competencias, vitalmente necesarias para la conversión de las informaciones halladas en el conocimiento, está la habilidad tradicional de lectura. La lucha por comprender y utilizar las nuevas tecnologías digitales nos exige nuevas competencias pero no excluye las antiguas. Y la más importante de ellas es la lectura, (Millan 2004).

\section{COMPETENCIA EN INFORMACIÓN Y CREA- CIÓN DE CONOCIMIENTO}

K. Alix Hayden (1993), bibliotecario de la universidad de Calgary, Canadá, señala que, como bibliotecarios, necesitamos volvernos facilitadores del aprendizaje y enseñarles a los discentes las habilidades de información que involucran su plan de estudios, y las estrategias de información para ayudarlos a formular las preguntas correctas. Necesitamos enseñarles cómo usar las fuentes de información para contestar sus preguntas; ayudarles a entender cómo amoldar y convertir la información en conocimiento, y ayudarles a aprender a comunicar ese conocimiento.

Holly Barton (1993), de la Universidad de Rodhe Island, citando a Christine Bruce, señala que el estudiante que posee las habilidades de alfabetización en información es dueño de su propio aprendizaje. Él pasa de simplemente encontrar y aprender los hechos, al proceso de crear la nueva información y a la creación de conocimiento, lo que implica: 
- Explorar para descubrir la información relevante. Las habilidades requeridas son la selección y la navegación, el estudiante competente en información organiza, mientras filtra y selecciona los datos pertinentes y exactos.

- Interpretar y traducir los datos en información, y la información en conocimiento.

- Generar nuevas ideas mostrando un visión y comprensión profunda de cómo se desarrollan los nuevos conocimientos, no haciendo sólo una refundición de la vieja información

Continuando la búsqueda de información sobre la propuesta de convertir información en conocimiento, el portal de la Biblioteca de St Joseph's Nudgee College (2010) ofrece una página llamada: 6 Steps To Turn Information Into Knowledge, no obstante su contenido sólo se limita a presentar algunas ideas generales acerca de la organización y presentación de los trabajos académicos.

La American Library Association (ALA 1989), sugiere que ser competente en información requiere saber cómo definir un asunto o área de investigación de manera clara y precisa, y seleccionar la terminología apropiada para expresar el concepto o tema, mientras formula una estrategia de búsqueda analizando los datos recolectados para evaluar su pertinencia, calidad y relevancia, $y$, consecuentemente, tornar la información en conocimiento, (ALA, 1989).

En los casos mencionados se hace referencia a la idea de convertir información en conocimiento pero sólo se logra un acercamiento al tema; en la red encontramos también una interesante propuesta de Elisabeth Tallak- 
Experiencias en formación para la información en el ...

sen Rafste, de la Agder University College de Noruega para conducir el proceso de conversión de la información al conocimiento en los espacios educativos, que involucra a maestros, bibliotecarios, bibliotecas escolares y aulas. El proceso se sustenta en una pregunta que lleva a los estudiantes a apropiarse de las estrategias destinadas a aprender más sobre un tema o asunto. Éste es un proceso de aprendizaje en el que los estudiantes participan de manera activa en la adquisición de nuevos conocimientos.

\section{ARTICULANDO COMPETENCIAS: UNA PRO- PUESTA EN CONSTRUCCIÓN}

Reconocer que las formas de representación son múltiples lleva implícita la idea de incorporar la lectura de la imágenes, lo que se considera dentro de la llamada alfabetización visual (visual literacy) y que bien podría ser un motivo de reflexión para incorporarla a la competencia en información y pertinente por su consideración dentro de las modalidades del lenguaje. Para Janette Hughes (2007), nosotros leemos el mundo a través de las imágenes, los símbolos, los colores, las señales, el idioma del cuerpo y en los huecos y márgenes así como a través del texto impreso. Advierte que el texto impreso ha sido privilegiado en las aulas, pero que no obstante eso, el concepto de "texto" se ha ampliado para incluir las imágenes, los sonidos, e incluso el cuerpo. En el caso de las imágenes señala que quizá su comprensión requiera de habilidades más complejas que la lectura de los textos impresos tradicionales. 
Retomando la asociación que refiero entre la competencia en información, la lectura y la escritura, podemos reconocer algunos elementos que hacen visible esta relación de complementariedad, y al mismo tiempo explorar entre la información disponible cómo esta idea ha venido tomando forma, para darle lugar a la idea de alfabetizaciones múltiples; en esta tarea me encuentro ocupado y aunque está en proceso de construcción, me ha tocado en suerte ser parte de un grupo interdisciplinario para crear un programa destinado a promover el desarrollo de competencias comunicativas de la comunidad politécnica en cuatro variantes; esto es, docentes, investigadores, personal de apoyo a la educación y estudiantes.

Este programa descansa precisamente en la articulación de la lectura, la escritura y la competencia en información, la modalidad es totalmente en ambiente virtual y de carácter autogestivo, lo cual se debe a que la población a la que se destina hace imposible abordar este programa en forma presencial. Cabe mencionar que el programa de referencia prevé la formulación de contenidos con diferentes niveles de complejidad y orientación, de tal manera que el lenguaje utilizado será más sencillo para la versión destinada a los estudiantes y personal de apoyo, en tanto que para docentes e investigadores se dará mayor profundidad a los contenidos y al tipo de estrategias de aprendizaje.

Ésta es una propuesta que descansa en la fortaleza del Centro de Formación e Innovación Educativa del Instituto Politécnico Nacional, que tiene ya la experiencia de impartir programas educativos en línea y, por supuesto, al apoyo que representa la Unidad Politécnica 
de Educación Virtual y la infraestructura de comunicaciones del propio Instituto. Entre las previsiones de la agenda de trabajo se espera tener una primera versión para estudiantes a fines del mes de noviembre del 2010.

Un componente interesante es la incorporación de un eje temático de interés general para la comunidad, es el caso de la educación ambiental, de tal manera que las estrategias de aprendizaje, las lecturas y los materiales de trabajo estarán referidos invariablemente al cuidado y preservación del medio ambiente, lo que propicia además el aprendizaje significativo.

En su producción se prevé incluir documentos de distinta naturaleza, como historietas, imágenes, videos, textos escritos, archivos de audio, y complementarlos con estrategias de autoevaluación que refuerzan los aprendizajes y le permiten al participante tener una retroalimentación de sus avances.

\begin{tabular}{|c|c|}
\hline Cursos & Competencias comunicativas \\
\hline Lectura crítica & $\begin{array}{l}\text { Examina las lecturas para lograr su comprensión, interpretación y valoración } \\
\text { crítica en función del contenido y géneros }\end{array}$ \\
\hline $\begin{array}{l}\text { Identificación de } \\
\text { problemas }\end{array}$ & $\begin{array}{l}\text { Identifica, describe y documenta problemas y establece la información re- } \\
\text { querida para su resolución }\end{array}$ \\
\hline $\begin{array}{l}\text { Búsqueda y se- } \\
\text { lección de infor- } \\
\text { mación }\end{array}$ & $\begin{array}{l}\text { Obtiene y relaciona la información de diversas fuentes con sus conocimien- } \\
\text { tos previos y expectativas para alcanzar sus propósitos, valorando su perti- } \\
\text { nencia y confiabilidad }\end{array}$ \\
\hline $\begin{array}{l}\text { Relaciones } \\
\text { conceptuales }\end{array}$ & $\begin{array}{l}\text { Organiza y reelabora la información que obtiene por diferentes medios para } \\
\text { ampliar su estructura conceptual y dejar constancia de las fuentes utilizadas }\end{array}$ \\
\hline $\begin{array}{l}\text { Resolución de } \\
\text { problemas }\end{array}$ & Elabora, documenta, planifica y sustenta las propuestas de solución \\
\hline $\begin{array}{l}\text { Producción } \\
\text { escrita }\end{array}$ & $\begin{array}{l}\text { Realiza diferentes tipos de textos de naturaleza académica o administrativa } \\
\text { con unidad, coherencia y claridad considerando el público a quien se dirige } \\
\text { y las características del medio }\end{array}$ \\
\hline $\begin{array}{l}\text { Producción } \\
\text { creativa }\end{array}$ & $\begin{array}{l}\text { Crea textos que trascienden la función informativa o académica e incorpora } \\
\text { creativamente recursos y técnicas literarias en la expresión de sus ideas }\end{array}$ \\
\hline
\end{tabular}




\begin{tabular}{|c|c|c|c|c|c|}
\hline \multirow{5}{*}{ 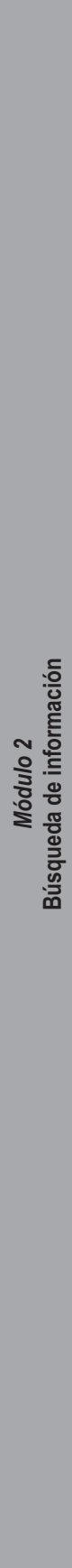 } & 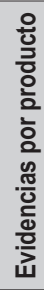 & 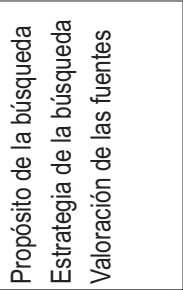 & & & \\
\hline & 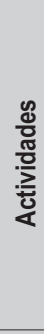 & 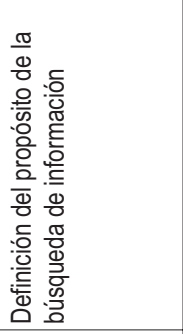 & 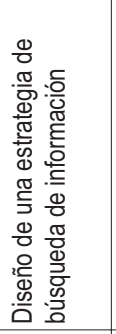 & 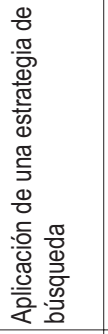 & 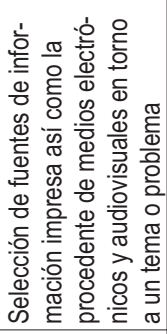 \\
\hline & $\begin{array}{l}\text { d্ㄴ } \\
\text { 흥 } \\
\text { 응 } \\
\text { ㅇ }\end{array}$ & 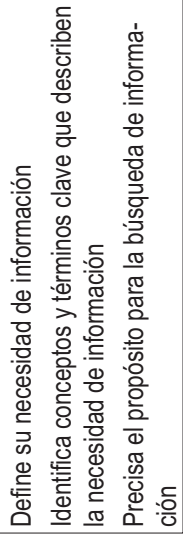 & 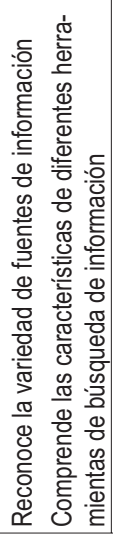 & 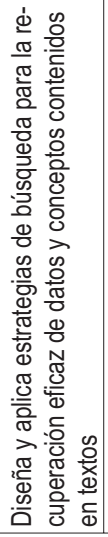 & 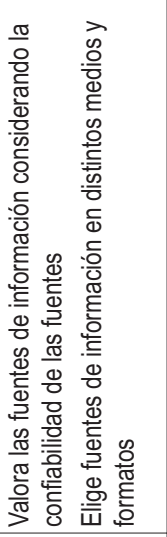 \\
\hline & 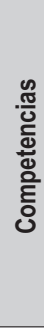 & 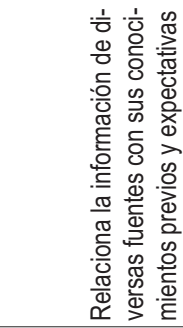 & 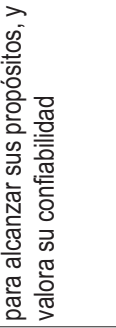 & & \\
\hline & 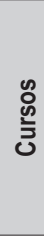 & 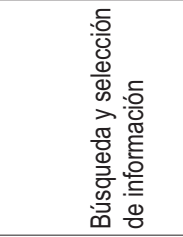 & & & \\
\hline
\end{tabular}




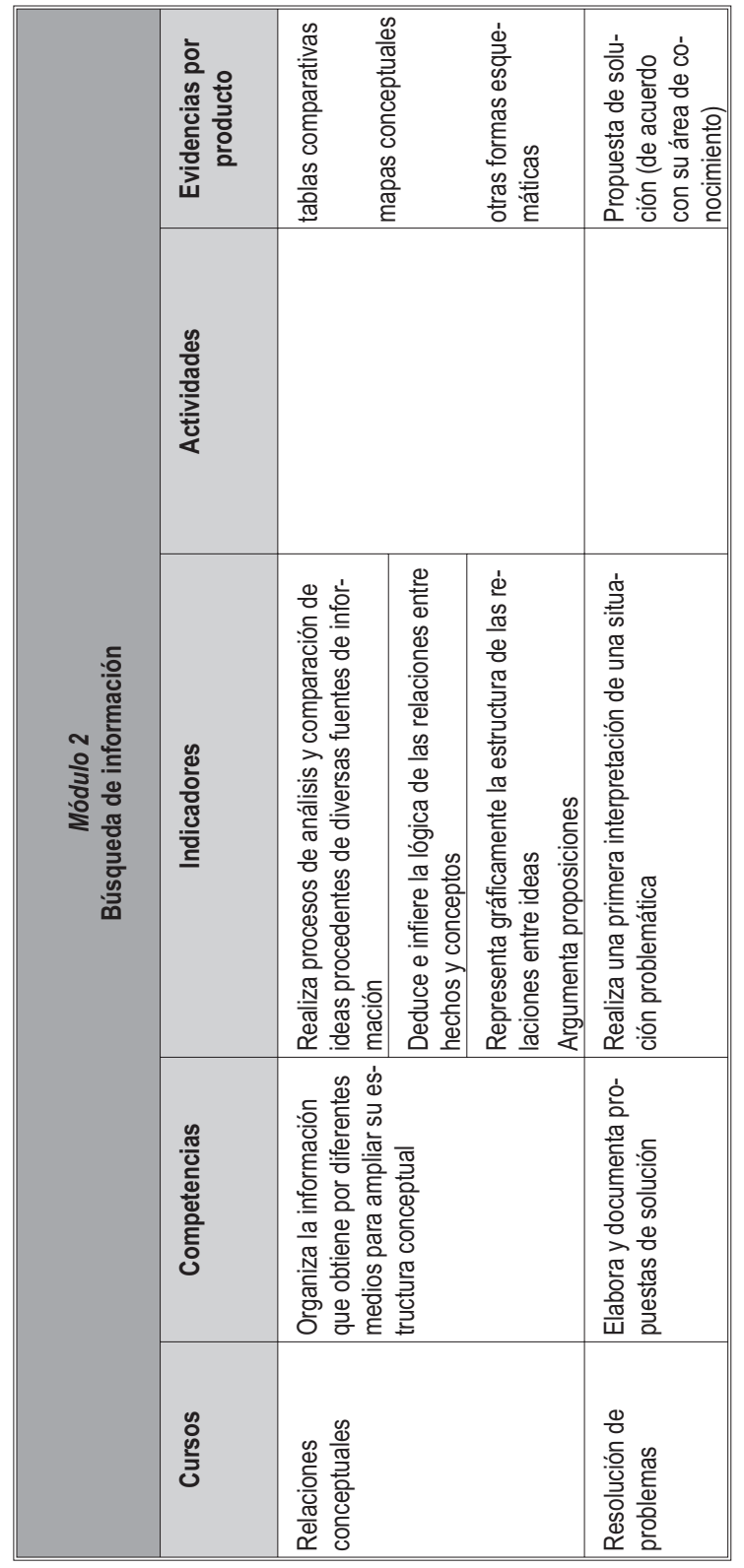




\section{CONCLUSIÓN}

La discusión sobre la importancia y la orientación de las normas de competencia en información aporta siempre ideas que contribuyen a la obtención de sinergias, la posibilidad de aprender de otros es muy evidente en la construcción de las experiencias conocidas en el campo de la competencia en información. La propuesta del Instituto Politécnico Nacional, al ser planeada como un programa totalmente virtual y autogestivo destinado a todos los miembros de la comunidad politécnica, ofrece una característica particular que espera contar con el apoyo de todos los colegas.

\section{REFERENCIAS}

Dubin, Linda (2002) Exemplary Practices: The Role of Discussions in the Acquisition of Literacy: Theory, Research and Practice, en http://www.bridgew.edu/Library/ CAGS_Projects/LDUBIN

Hayden, K. Alix (1993), Information Literacy, en http://people.ucalgary.ca/ ahayden/literacy.html

Hirshleifer, Jack (1971), "The Private and Social Value of Information and the Reward to Inventive Activity", en The American Economic Review, Vol. 61, Núm. 4, (Sep 1971), pp. 561-574.

Hughes, Janette (2007), Multiple Literacies, en Teaching Language and Literacy, en http://faculty.uoit.ca/hughes/ Contexts/MultipleLiteracies.html 
Medina, Guillermo, Segunda parte: alfabetización, post-alfabetización, educación de adultos y educación permanente, en: http://www.crefal.edu.mx/biblioteca digital/coleccion _crefal/retablos\%20de\%20papel/RP08/segunda.pdf

Millán, José Antonio (2004), La lectura y la sociedad del conocimiento. Federación de Gremios de Editores de España, en http://www.federacioneditores.org.

Minelli de Oliveira, Janaina (2009), Resultados de la práctica docente según la percepción de los estudiantes: La formación de maestros en la era digital, en: http://www.quadernsdigitals.net $/$ index.php?accionMenu $=$ hemeroteca. VisualizaArticuloIU.visualiza\&articulo_id $=10847$

Morán Nogales, Ramón (1999), Búsqueda en Internet, una aguja en un pajar. en: http://www.coit.es/publicac/ publbit/bit106/especi2.htm

Rafste, Elisabeth Tallaksen (2002), From bud to blossom - How to become an information - literate person and learn a subject/topic. (68th IFLA Council and General Conference, Glasgow, August 18-24, 2002), en: http://archive.ifla.org/ IV/ifla68/papers/027-097e.pdf

Simon, H. A. (1971), "Designing Organizations for an Information-Rich World", in Martin Greenberger, Computers, Communication, and the Public Interest, Baltimore, MD: The Johns Hopkins Press, pp. 40-41.

St Joseph's Nudgee College (2010), 6 Steps To Turn Information Into Knowledge, en: http://library.nudgee.com/ library/guides/6-steps-turn-information-knowledge

Vaughn, Danny (2010), A resolution to revisit the meaning of literacy, en: http://www.examiner.com/college-bound-in -national/a-resolution-to-revisit-the-meaning-of-literacy 
Tendencias de la Alfabetización Informativa en Iberoamérica

\section{Anexo 1}

Ejemplo de historieta a utilizar en el Programa

La importancia de citar
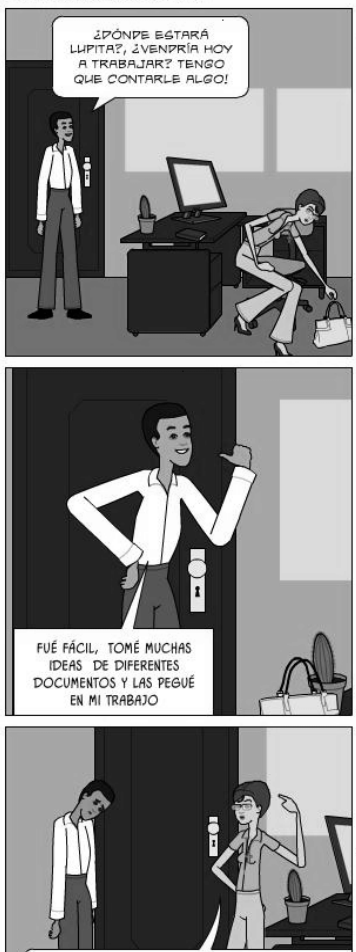

MARTIN, ES IMPORTANTE CITAR LAS FLENTES VE DONDE TOMAS INFORMACIÓN TRABA,IO DEL OTRO, NO ES MALO TOMPR IDEAS DE OTROS PERO ES DESLERL NO DARLES SU CRÉDITO Y HACERLAS PASAR
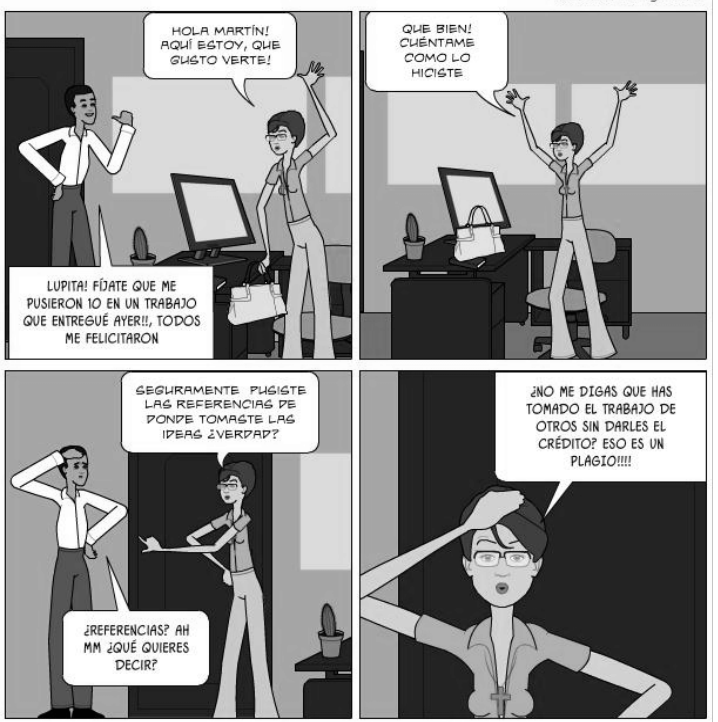

SI CITAS, TU TRABAJO TENDRÁ MAYOR SUSTENTO PERO DEBES SER CUIDADOSO, SOLAMENTE CITAR
TE LIBERA DE PLAGIO, ES TE LIBERA DE PLAGIO, ES
MPORTANTE INCORPORAR TUS APORTACIONES Y TH POSTLRA A

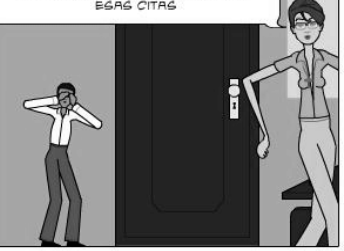

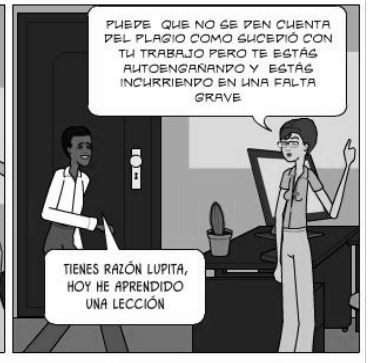

Internet|Modo protegido: activado 


\title{
Desarrollo de la formación de usuarios en el Sistema de Bibliotecas de la UASLP, ¿hacia la alfabetización informativa?
}

\author{
CELIA Mireles CÁRdenas \\ LAURA FIGUEROA BARRAGÁN \\ Universidad Autónoma de San Luis Potosí
}

\section{INTRODUCCIÓN}

$\mathbf{P}$ ara satisfacer necesidades de información no sólo es necesario acercarse a las bibliotecas, archivos, o centros de documentación que la almacenan, la organizan y la difunden. Se requiere también por parte de la persona que la busca, el que adquiera ésta, desarrolle y aplique competencias que le permitan determinar cuándo tiene una necesidad informativa, así como plantear estrategias para localizar, recuperar y, en su momento, transformar la información que necesita. A pesar de ello, una de las características de las sociedades actuales, sobre todo en países latinoamericanos, es la transición y 
convivencia de grupos con diferentes niveles en cuanto al conocimiento, acceso y uso de la información y las tecnologías en una misma comunidad.

Esta desigualdad en materia informativa (aunada a otros rubros, como por ejemplo, las diferencias generacionales en el uso de las tecnologías de la información), justifica la realización de programas de Formación de Usuarios que brinden la oportunidad de transitar de una etapa de conocimiento básico sobre la existencia de la información y la actualización constante, hasta los ideales planteados por la Alfabetización Informativa, que establece como meta final lograr un ciudadano informado, crítico y comprometido socialmente.

De esta forma el conjunto de actividades realizadas con la intención de que el usuario haga uso de los servicios bibliotecarios y de la información se han establecido conforme el desarrollo histórico, cultural, informativo y tecnológico de las sociedades. Resultado de ello son los distintos nombres empleados para denominar estas acciones, siendo mayormente aludidos los conceptos de Formación y Educación de Usuarios, Desarrollo de Habilidades y Competencias Informativas, y en la actualidad, el de Alfabetización Informativa.

Cada uno de estos conceptos refiere a una serie de características que deben tener las actividades que se realicen con la finalidad de lograr un usuario formado en el uso de la biblioteca y de la información. Tales conceptos han evolucionado y se han complementado al incluir aspectos acordes cn cada contexto como son la concepción teórica, el alcance, la metodología de enseñanza, la naturaleza y los recursos empleados, y en el 
Desarrollo de la formación de usuarios en el Sistema de ...

caso de los programas de Desarrollo de Habilidades y Competencias Informativas, se enfatiza el uso de las herramientas tecnológicas.

En la actualidad bajo el concepto de Alfabetización Informativa se busca lograr la autosuficiencia en las personas mediante el desarrollo de competencias que le permitan, además de formular y satisfacer necesidades de información, usarla, aplicarla, transformarla y comunicarla bajo un sistema de valores éticos y con el apoyo tecnológico, en todas sus actividades cotidianas, pero el logro de estas competencias depende de diversos factores inherentes a su campo de aplicación como son la infraestructura educativa, informativa y tecnológica del lugar en que el individuo se desenvuelva, como se analiza en el presente escrito.

\section{FORMACIÓN DE USUARIOS (FU)}

Conforme al análisis de diferentes definiciones sobre la Formación de Usuarios (FU) utilizadas en América Latina, por autoras como Hernández (1998) y Naranjo (2005), entre otros, se puede establecer que es un proceso que consiste en un conjunto de actividades pedagógicas para que el usuario desarrolle competencias (conocimientos, habilidades y actitudes), en el uso de la información, en cualquier formato y soporte en que ésta se encuentre, mediante el intercambio de experiencias significativas en su uso y aplicación, de tal forma que pueda emplearla en todos los ámbitos de su vida de forma ética y autosuficiente. 
La FU también es considerada como un servicio que se oferta en las Unidades de Información (UI), ${ }^{1}$ principalmente de tipo educativo, el cual se encuentra ligado con otros servicios bibliotecarios como el de referencia, la señalética y las actividades de difusión empleadas en la institución. Su establecimiento requiere de la categorización individual o colectiva de sus usuarios de tal forma que permita, en su momento, ubicarlos en el nivel adecuado de formación, ya sea (1) sensibilización, (2) orientación o inducción a la biblioteca, (3) instrucción y uso; y algunos autores agregan también la (4) producción, lo que llevará al usuario a pasar de un estadio a otro en el uso de la información, de acuerdo con las metas establecidas por la institución, (Naranjo, 2005).

Puesto que los objetivos principales de la FU son informar y formar, las actividades hacen énfasis en la orientación e instrucción sobre el uso de servicios y recursos informativos de la biblioteca, así como en el uso de las tecnologías de la información y la comunicación, pero las bibliotecas escolares y universitarias pueden transitar de la formación de usuarios a programas deDesarrollo

1 En el presente trabajo, se utiliza el término de Unidades de Información como referencia de instituciones como bibliotecas, archivos, centros de documentación o similares. 
Desarrollo de la formación de usuarios en el Sistema de ...

de Habilidades Informativas (DHI) y/o Competencias en el Manejo de la Información (CMI).

De forma general se puede sintetizar que los programas de DHI exaltan en los usuarios el desarrollo de habilidades en la búsqueda, recuperación, evaluación y uso de la información con el uso de las tecnologías en cualquier lugar en que ésta se encuentre. Para su implementación es deseable realizar un trabajo interdisciplinario que fomente el apoyo de la academia para que las actividades puedan ser elaboradas bajo un modelo pedagógico que les permita insertarse en los programas educativos, así como identificar cuál es el mejor momento dentro de la trayectoria académica del estudiante para generar estas habilidades y la secuencia en que debe de hacerlo.

Por otra parte un programa para el desarrollo de CMI, además de lo que se expresa en el DHI, busca integrar las habilidades, conocimientos y actitudes éticas en el uso de la información. Se pretende que las competencias pueden ser generalizables en más de una actividad e incluyan aspectos de evaluación, es decir, que sean demostrables cuando se ejecuta una tarea o se realiza una actividad escolar, laboral o de cualquier índole.

Con relación al término de competencia informativa es pertinente mencionar que de acuerdo con las diferen-

2 El Ministerio de Educación y Capacitación de Ontario (1995) define la Competencia en el Manejo de la Información (CMI), como la capacidad de adquirir, evaluar críticamente, seleccionar, usar, generar y comunicar información de tal modo que conduzca al conocimiento y a la sabiduría del individuo. 
tes normas sobre el tema, elaboradas por asociaciones como la Association of College and Research Libraries (ACRL,2000) y el Australian and New Zealand Institute for Information Literacy (ANZIIL, 2004), las principales habilidades y destrezas que le permiten a un individuo el manejo y uso eficiente de la información, se agrupan conforme con las etapas para realizar una investigación, (campo de aplicación en donde tienen su origen) y éstas que son: definir la necesidad de información, recuperar, evaluar, organizar, sintetizar y comunicar la información.

Respecto a las actitudes en el uso de la información, se pretende que el individuo tenga un comportamiento de respeto, responsabilidad, reflexión, exploración, solidaridad, colaboración, tolerancia al fracaso, cuestionamiento, análisis crítico y automotivación, (ACRL, 2000).

Por tanto una persona competente es aquella que ha desarrollado habilidades y conocimientos para: 1 . Determinar el alcance de la información requerida; 2. Acceder a ella con eficacia y eficiencia; 3 . Evaluar de forma crítica la información y sus fuentes; 4 . Incorporar la información seleccionada a su propia base de conocimientos; 5 . Utilizar la información de manera eficaz para acometer tareas específicas; 6 . Comprender la problemática económica, legal y social que rodea al uso de la información; 7. Acceder a ella y utilizarla de forma ética (ACRL, 2000), además de saber usar las herramientas prácticas y conceptuales de las tecnologías de la información (OLA, s/f) y reconocer la alfabetización en información como pre-requisito para el aprendizaje a lo largo de la vida, (CAUL 2002). 
Desarrollo de la formación de usuarios en el Sistema de ...

Visto de esta forma, se puede considerar que el término de FU sigue vigente para las instituciones bibliotecarias insertas en contextos que incluyen grandes desigualdades sociales, económicas y educativas, como el mexicano, en donde será preciso transitar de una sensibilización y orientación en el uso de los recursos bibliotecarios e informativos, hasta la consecución paulatina del desarrollo de habilidades y competencias en el uso de la información con el apoyo de herramientas tecnológicas, las cuales deberán formar parte de un programa que, a su vez, contribuya a lograr, en la medida de lo posible, los fines señalados en la Alfabetización Informativa, que se presentan a continuación.

\section{AlFABETIZACIÓN INFORMATIVA (AI)}

La Alfabetización Informativa (AI) es un proceso global, social, y educativo en el que se pretende que el individuo aprenda a aprender y a utilizar la información en todos los ámbitos de su vida y para toda la vida, mediante el dominio de una serie de competencias en el uso de la información y las tecnologías, con base en una actitud crítica, analítica y reflexiva.

De acuerdo con los principios sobre la AI elaborados por la Australian and New Zealand Institute for Information Literacy, una persona alfabetizada:

1. Se implica en el aprendizaje independiente mediante la construcción de nuevo significado, comprensión y conocimiento.

2. Obtiene satisfacción y realización personal gracias al uso eficaz de la información. 
3. Individual y colectivamente, busca la información en la toma de decisiones y la solución de problemas para afrontar tanto los personales, como los profesionales y sociales.

4. Demuestra responsabilidad social por medio de su compromiso con el aprendizaje continuo y la participación comunitaria, (ANZIIL, 2004).

$\mathrm{Al}$ analizar los puntos anteriores, se observa que la $\mathrm{AI}$ traspasa los límites de la educación formal y se inserta en la vida cotidiana de los individuos, en donde el término de usuario se traslada al de ciudadano, y no se separa el conocimiento y la recuperación de la información, de su aplicación.

Así la implementación de un programa con estas características, implica considerar, además de los requisitos ya vistos para la FU, DHI y CMI, la elección de un modelo pedagógico basado en actividades orientadas a fomentar la participación e innovación constante del usuario en la construcción de su aprendizaje de forma independiente, mediante la integración de distintas alfabetizaciones como son la lectura, escritura y edición, de forma tradicional o digital, individual o cooperativa, lo que implica también considerar la capacitación del personal docente y bibliotecario en el desarrollo de competencias informativas.

Un programa de AI implica salir del contexto institucional y colaborar y utilizar los recursos informativos de otras instituciones como archivos, centros de documentación y museos, así como los del sector gubernamental, educativo e industrial, entre otros, puesto que se busca fomentar el uso de competencias informativas 
Desarrollo de la formación de usuarios en el Sistema de ...

más allá de los ámbitos escolares, por lo que su implementación debe ser planeada desde el sector gubernamental para darle sustento a una infra e info estructura sólida que fomente la inclusión de los diversos sectores sociales y contribuya a reducir la brecha digital en el ámbito informativo. Pero en países con desigualdades educativas y tecnologías la AI es todavía un ideal, al no existir las condiciones necesarias como políticas educativas e informativas que sustenten el establecimiento de este tipo de programas. Por ejemplo, en México el nivel y alcance educativo es considerado todavía bajo, ${ }^{3}$ lo que, aunado a una carencia de infraestructura bibliotecaria y cultural en todos los niveles (Cuadros 1 y 2), indica que únicamente algunas bibliotecas estarían en condiciones de establecer programas de DHI y CMI, pero difícilmente de AI.

No obstante, un buen programa de FU puede formar parte de un proceso de AI, y sería altamente deseable que las instituciones públicas consideren, en la medida

3 "Según los resultados del Programa para la Evaluación Internacional de los Estudiantes (PISA, por sus siglas en inglés) 2009, México ocupó el lugar 48 de entre 65 naciones... Para la OCDE estar en esos niveles significa que al concluir la secundaria o cursar el primer año del bachillerato los estudiantes apenas reconocen en un texto ideas sencillas y su conocimiento científico es "tan limitado que sus explicaciones son muy obvias y son derivadas de las evidencias que se les muestran en la prueba [el examen PISA]". Persiste Deterioro educativo: OCDE, en El Universal, 7 de diciembre de 2010:

http://www.eluniversal.com.mx/noticias.html 
de sus posibilidades, incorporar aquellos aspectos en los que puedan contribuir a lograr avances en el tema.

El presente artículo analizó la situación del Sistema de Bibliotecas (SB) de una institución pública como la UASLP, con la intención de identificar su situación al respecto y la posibilidad de contribuir en la conformación de una sociedad informada. La metodología utilizada se basó en los elementos establecidos por Hernández (1998) para planear los programas de FU, así como para revisar la literatura sobre el tema.

\section{PROGRAMAS DE FORMACIÓN DE USUARIOS (PFU)}

Para lograr una transición por parte del usuario en el uso de la información, se requiere implementar un Programa de Formación de Usuarios (PFU), el cual debe ser visto como un proceso continuo y sistemático de actividades de enseñanza - aprendizaje, que se lleve a cabo como un servicio cuya finalidad es lograr una transformación del usuario en: a) el uso de los servicios bibliotecarios y b) el uso la información, de tal forma que le permita pasar de la situación actual detectada, hacia las metas planteadas por la UI (Unidades de Información).

Es decir, las actividades realizadas sin una organización y secuencia gradual, no constituyen un programa ya que no toman en cuenta el conocimiento en el uso de los recursos informativos que tienen los usuarios a quienes se dirige el servicio y por tanto tampoco sus necesidades reales, por lo que es frecuente que en el nivel de licenciatura se brinden actividades de orientación sobre 
Desarrollo de la formación de usuarios en el Sistema de ...

recursos informativos como el catálogo o las bases de datos de la misma forma a grupos que ya tienen experiencia en su uso y a quienes no han utilizado los servicios bibliotecarios, por lo que las actividades pueden no sólo resultar poco significativas, sino incluso aburridas o repetitivas, y que más adelante en el transcurso de su vida escolar, por ejemplo en una maestría, los usuarios soliciten orientación y/o talleres para poder utilizar las bases de datos.

Por ello, independientemente del contexto y del tamaño de la UI, es deseable llevar a cabo de forma secuencial los siguientes pasos para establecer un PFU adecuado y pertinente a la comunidad usuaria de los servicios bibliotecarios.

\section{Análisis interno, institucional y externo}

A partir de la identificación de las actividades que se realizan sobre formación, así como su relación con otros servicios, los recursos informativos, la infraestructura y características del personal bibliotecario, se inicia la labor de planeación. En el caso de la UASLP, la institución tiene una sólida infraestructura bibliotecaria conformada en la actualidad por una Dirección General, cuatro departamentos generales y siete grandes centros de información, de los cuales dependen administrativamente trece unidades informativas (Cuadro 3), además de la biblioteca virtual creativa que atiende a toda la comunidad universitaria, lo que permite contribuir en la formación integral del estudiante al brindarle espacios adecuados para el fomento del acceso y uso de la información. 
Con relación al acervo, el mismo se encuentra conformado por 425, 911 documentos impresos en diferentes formatos, 27,179 recursos electrónicos y tiene una plantilla laboral de aproximadamente 140 personas, 68 de ellas profesionales bibliotecólogos que le brindan servicios a una comunidad académica conformada por 22,468 alumnos de nivel bachillerato, licenciatura y posgrado $^{4}$ y 2,641 profesores con nombramientos de tiempo completo, medio tiempo, hora clase y técnico académico, (García, 2010).

Con respecto a los servicios de formación de usuarios, éstos se han desarrollado paulatinamente desde 1998, al igual que la elaboración de propuestas encaminadas al establecimiento de un programa que sirva de guía para ser implementado en todos los centros y unidades de información que conforman el sistema, algo que no se ha logrado aún concretar. Esta situación resulta imprescindible si se analiza que conforme los datos estadísticos brindados por la institución, en el 2009 se llevaron a cabo actividades de visitas guiadas y talleres de instrucción sobre el uso de los recursos bibliotecarios a una población de 18,324 estudiantes; 1,732 docentes; 170 investigadores; y 565 usuarios externos, ${ }^{5}$ es decir,

4 Bachillerato y carreras cortas 658; Licenciatura 20,277 y Posgrado 1,533 .

5 Además de su comunidad, los diferentes centros de información de la UASLP atienden a una población externa variable, conformada por ex -alumnos, alumnos de nivel bachillerato y público en general. 
Desarrollo de la formación de usuarios en el Sistema de ...

aproximadamente el $80 \%$ de la población universitaria, por lo que sería altamente recomendable fortalecer y dar continuidad a las acciones que se vienen realizando, (García, 2010).

En una biblioteca universitaria, además del análisis interno, se deben tomar en cuenta las políticas institucionales existentes que fundamentan la realización de estas actividades. En el caso de la UASLP, se identifican claramente aspectos que pueden ser tomados en cuenta para orientar el rumbo de un PFU, como se muestra a continuación:

La UASLP tiene establecida como misión la formación de profesionales, científicos, humanistas y académicos, competentes, críticos, creativos, reflexivos y éticos, comprometidos con el desarrollo del estado y del país y con una visión clara del mundo actual, en un marco de: responsabilidad, pertinencia, calidad, equidad, eficiencia y transparencia en el uso de los recursos, (Misión, Visión y Valores de la UASLP, 2010.).

Para el análisis externo es deseable ubicar tanto las instituciones con las que se puedan establecer convenios de cooperación, como los recursos informativos que pudieran utilizarse en el logro de los objetivos establecidos como por ejemplo, videos o tutoriales libres en Internet. Retomando el caso de la UASLP, en la década de los noventa el entonces Rector Alfonso Lastras (1992) afirmaba que el SB (Sistema de Bibliotecas) de la Universidad era el acervo de conocimiento más grande del Estado, y que de acuerdo con el gran desarrollo de infraestructura, tecnología y recursos informativos que 
ha tenido en las últimas décadas, no es aventurado considerar que la situación no ha cambiado. ${ }^{6}$

Lo anterior se confirma al observar que en la actualidad, la UASLP atiende aproximadamente al 40\% de los estudiantes de nivel licenciatura y al $70 \%$ de nivel posgrado del Estado, lo que la convierte en la institución educativa más importante del mismo (Cuadro 1). Ante esta situación, la UASLP no puede sustraerse de la responsabilidad social que le impone su entorno, considerando que en el Estado se tiene un porcentaje de 9\% de analfabetismo y una eficiencia terminal en alumnos de bachillerato de $66.4 \%$, lo que implica que más de 30,000 alumnos no continúen con sus estudios de nivel superior, (SEP, 2010).

\section{Estudios de Usuarios}

$\mathrm{Si}$ se considera que los estudios de usuarios son "[...] un conjunto de métodos de investigación utilizados para tener un conocimiento relevante y detectar los hábitos, características, actitudes y comportamiento de los usuarios en la recuperación, uso de los recursos y servicios de información que ofrecen las bibliotecas, de tal manera que

6 Salvo algunos datos parciales que ofrece el INEGI, como se muestra en el cuadro 2, no se consiguieron mayores datos o estadísticas oficiales sobre el número total de bibliotecas en el Estado.

7 Según el glosario de la SEP un analfabeta es aquella persona, con 15 años o más, que no posee dominio de la lectura, la escritura y el cálculo básico, en: http://www.sep.gob.mx/work/ models/sep1/Resource/890/1/images/PrincipalesCIF20082009.pdf 
Desarrollo de la formación de usuarios en el Sistema de ...

se establezca una comunicación que permita planear diversos servicios y satisfacer sus necesidades de información, (Figueroa, 2009).” la realización de los mismos se convierte en una actividad básica que permitirá determinar perfiles de usuarios para la planeación y actualización de actividades, establecer niveles de formación y, en su momento, ser un punto de partida para la medición del progreso en los usuarios. ${ }^{8}$ En el caso de la UASLP, no se detectaron evidencias sobre este tipo de estudios o diagnósticos similares en ninguna de las UI.

\section{Objetivos del programa}

Una vez identificada la situación en la que se inserta una UI (Unidad de Información), se deberá responder a los cuestionamientos ¿Qué se quiere lograr?, ¿Para qué? y ¿Cómo se deberá realizar?, para clarificar el rumbo de la FU. Los objetivos serán la guía para las actividades de formación que se desarrollarán. En una propuesta realizada en el 2003 por parte de diferentes dependencias universitarias, además del SB, se propuso como objetivo general para la formación, el hecho de:

8 Patricia Hernández (2007), enfatiza la relación de los estudios de usuarios con la formación, ya que los programas deben ser elaborados con base en necesidades reales de las comunidades, grupos y personas, por lo que en la actualidad se constituyen en una acción que debe ser constante, dados los cambios existentes en materia tecnológica, que conllevan a la generación de nuevas necesidades para saber usar herramientas y programas informativos a los que se les tiene que dar una respuesta oportuna en tiempos y contenidos. 
[...] contar con un programa de formación flexible y pertinente que facilite la capacitación y el desarrollo de habilidades de los usuarios para el manejo de recursos y fuentes de información y coadyuve a la articulación de los servicios de información con las actividades académicas de la universidad (Secretaría de Asuntos Académicos. Dirección de Educación a Distancia, 2003).

Lamentablemente no se dio continuidad a la propuesta y en la actualidad las actividades, los objetivos y los términos utilizados varían en cada centro de información, tal como se observa en la página web del SB, en donde se denominan como talleres de formación, FU o DHI, e inclusive se utilizan indistintamente dos términos en un mismo centro (Cuadro 4).

\section{Modelo pedagógico}

La elección de un modelo pedagógico debe realizarse tomando como base el modelo educativo institucional, de no ser así, alguno que sea acorde con la tendencia identificada. En este punto es deseable buscar la cooperación interdisciplinaria con profesionales pedagogos, informáticos y docentes de las áreas de conocimiento de interés, lo que permitirá una planeación de actividades pertinente, $y$ el fomento de la colaboración en beneficio de todos los involucrados. Además, entre otros beneficios, permitirá aumentar la presencia de la UI en distintos grupos universitarios, establecer lazos de comunicación, difundir logros entre la comunidad académica y, en su momento, insertarse en los programas educativos. 
Desarrollo de la formación de usuarios en el Sistema de ...

En la actualidad la UASLP no cuenta con un modelo educativo declarado. Sin embargo, conforme a la dinámica existente, la Universidad se encuentra inmersa en un proceso de cambios orientados hacia la mejora constante bajo un esquema de desarrollo de competencias, tal como lo menciona el actual Rector, se busca un modelo:
[...]dinámico, con visión de futuro, flexibilidad, per- tinencia y capacidad innovador. Nos proponemos atender los desafíos de la educación superior en tér- minos de calidad y cobertura. Por ello, al tiempo que diversificamos e incrementamos la oferta educativa, buscamos el desarrollo de competencias profesiona- les, laborales y transversales de los futuros egresados, a través de planes y programas con nuevos enfoques pedagógicos, aplicación de los avances de la ciencia y la tecnología, prácticas profesionales, la tutoría, la movilidad, impulso al conocimiento del idioma in- glés, vínculos con los sectores social y productivo, $\mathrm{y}$ la alianza con otras universidades en programas in- ternacionales (García, 2010, p.4).

En este sentido se cuenta con el antecedente de la propuesta realizada en 2003, elaborada con la finalidad de fomentar la cultura de aprender a aprender para toda la vida y que tomó como base el Modelo BIG6, por lo que el contenido de las actividades se orientó hacia el fomento de competencias que apoyaran la resolución de situaciones personales o académicas mediante el desarrollo de 6 áreas de habilidad: 1. Definición de la tarea a realizar, 2. Estrategias para buscar la información; 3. Localización y acceso; 4. Uso de la información; 5 . Síntesis; 6. Evaluación. 


\section{Contenidos}

Una vez que se ha elegido el modelo pedagógico que guiará la elaboración de contenidos es recomendable tomar en cuenta los siguientes aspectos:

- Temas: uso de la biblioteca, de la información y de las herramientas tecnológicas.

- Relación con las materias de los programas educativos para complementarlos y ofrecer un mayor significado, así como con otros servicios que ofrece la biblioteca, buscando una mejor eficiencia y aprovechamiento de los recursos.

- Establecer niveles que transiten de la sensibilización en el uso de la información hasta las metas establecidas. Este aspecto puede ser un indicador de evaluación del desarrollo de formación del usuario.

- Diseñar actividades que contengan los elementos que se buscan desarrollar, como por ejemplo, identificar, localizar, evaluar y usar efectivamente los recursos y servicios informativos disponibles en forma presencial y virtual, además de incluir la evaluación de resultados observables mediante las evidencias de aprendizaje.

- Considerar los recursos que ofrece el Internet en el tema, como son tutoriales y objetos de aprendizaje.

Actualmente, en el Sistema de Bibliotecas los temas que se abordan en las actividades de formación se refieren al conocimiento de las instalaciones: colección, servicios, uso del catálogo, bases de datos y servicios en línea, reglamentos, estrategias de búsqueda, recuperación 
Desarrollo de la formación de usuarios en el Sistema de ...

y navegación en las colecciones digitales y redacción de referencias.

Aun cuando se ofertan cursos y talleres con temas específicos, tal como se observa en el Cuadro 4, la mayoría de las acciones realizadas se encuentran enfocadas hacia la orientación, es decir, informan sobre aspectos puntuales como es el funcionamiento de los servicios, por lo que es deseable llevarlos hacia el nivel avanzado de instrucción para que se puedan optimizar al máximo los recursos de información existentes.

\section{Implementación del programa}

La ejecución del programa permitirá una retroalimentación y actualización de los contenidos al considerar que las características y necesidades de los usuarios pueden variar en lapsos relativamente cortos de tiempo. ${ }^{10} \mathrm{El} \mathrm{SB}$ identifica que las modalidades en que se ofertan estas actividades son la presencial y a distancia, algunas de ellas obligatorias, dependiendo del programa académico en las que puedan formar parte de una materia o sean re-

9 Eventualmente, diferentes centros han realizado actividades para el desarrollo de habilidades y competencias informativas, pero no se encontraron evidencias de continuidad.

10 Por ejemplo, hace poco tiempo era necesario ofrecer cursos en las bibliotecas para el uso del Internet, que tuvieron mucho éxito en las comunidades, pero que en un breve periodo de tiempo se volvieron obsoletos. Ahora las necesidades se orientan hacia la oferta de cursos- talleres en el uso de programas especializados en determinadas áreas y tecnologías. 
quisitos de la misma. La duración varía de treinta minutos a cinco horas y se ofrecen al inicio y/o durante el ciclo escolar. Para llevar a cabo estas actividades se utilizan principalmente estrategias como la exposición de temas y la instrucción personalizada sobre fuentes de información.

\section{Difusión del programa}

Además de los medios tradicionales como folletos y trípticos, las actividades de FU se deben incluir en el programa de mercadotecnia y la señalética de la institución, así como difundir la oferta de actividades en toda la comunidad académica, principalmente hacia profesores, mediante la utilización de los canales de comunicación que ofrece la misma institución como son la radio, la prensa, la televisión, y, por supuesto, la página web.

En el caso de la universidad potosina, los medios más utilizados son los trípticos, separadores y la página web de cada centro, los cuales proporcionan información de contacto (Biblioteca Pública Universitaria), información sobre la FU y los objetivos que pretenden (Centros de Información en Ciencias Biomédicas, CICBI y Ciencias Sociales, CICSA), la descripción de las actividades que se realizan (Centro de Información en Ciencias, Tecnología y Diseño, CICTD), tutoriales y manuales en línea (Biblioteca Creativa), y a partir del mes de noviembre de 2010, CICSA está empleando los medios de comunicación social como Twitter y Facebook. 
Desarrollo de la formación de usuarios en el Sistema de ...

\section{Evaluación}

La evaluación como un proceso que permite dar cuenta de los resultados obtenidos y brindar elementos para la mejora constante, es un aspecto que debe ser planeado e incluir los contenidos, al formador, y el aprendizaje obtenido. Actualmente con el apoyo tecnológico se pueden elaborar bases de datos para registrar las actividades de FU realizadas por cada usuario, lo que permitirá, entre otras cuestiones, identificar cambios en los procesos educativos y proporcionar evidencias del impacto de la formación, como pueden ser la continuidad y el éxito escolar. En el SB sólo algunas actividades reportan evaluaciones, principalmente a través de un cuestionario en el que se evalúa al facilitador y el contenido, y en el caso del CICTD, los talleres incluyen la realización de trabajos por parte del alumno que son evaluados por el profesor.

\section{Documentar y difundir resultados}

Dar a conocer a las autoridades, a la comunidad académica y a la sociedad en general las experiencias y resultados obtenidos en los procesos de formación, permitirá darles visibilidad a las actividades realizadas y fomentar la colaboración institucional e interdisciplinaria, pero principalmente, cimentarán el papel de las bibliotecas para contribuir a una sociedad de información más equitativa mediante el desarrollo de competencias informativas. En el caso potosino, no existe un archivo que dé cuenta de las actividades realizadas a lo largo de la historia del SB y los 
pocos registros que existen se encuentran dispersos en los diferentes centros de información.

\section{CONSIDERACIONES SOBRE LOS RESULTADOS OBTENIDOS}

Si se compara la situación que presenta el Sistema de Bibliotecas de la UASLP con relación a la investigación realizada por Naranjo y colaboradores (2005) sobre la situación de la FU en América Latina, se observa que no es muy diferente a los resultados de este estudio, ya que se identifica que la realización de actividades de la FU en instituciones universitarias son planeadas desde la perspectiva del bibliotecario, lo cual se viene realizando desde hace décadas y en muchos casos, aun cuando se cuenta con una buena infraestructura para tal fin, se adolece de programas institucionalizados que den cuenta de un seguimiento y evalúen los resultados obtenidos, además de tener también una lamentable omisión en el registro y documentación que obstaculiza un desarrollo del tema.

En el caso del SB-UASLP se detecta que sus debilidades radican principalmente en la falta de un programa institucional que normalice las actividades que realizan los distintos centros y que faciliten darle continuidad y seguimiento a los resultados obtenidos, así como el apoyo de las autoridades para permitir la inserción de las actividades en la práctica escolar.

Asimismo, la resistencia del personal para realizar nuevas actividades y romper con las rutinas, ocasiona que las actividades se realicen bajo el esquema de un mo- 
Desarrollo de la formación de usuarios en el Sistema de ...

delo educativo tradicional, en donde además se observa muy poca participación de los docentes. Otro aspecto importante es la insuficiente difusión que se realiza de los recursos y los servicios, situación que influye en un bajo aprovechamiento de los recursos informativos por parte de la comunidad usuaria.

Aun con este panorama, se observan muchas oportunidades para llevar a cabo un Programa de Información de Usuarios de forma exitosa, entre las que se destacan:

- Personal profesional en bibliotecología, casi un 50\% de su plantilla laboral.

- Experiencia y capacitación en FU por parte de los bibliotecarios encargados de las actividades.

- Infraestructura física y de equipo adecuadas.

- Comunidad académica que utiliza las TIC.

- El SB forma parte del Sistema de Calidad de la Universidad, y cuenta con la certificación de sus procesos bajo la norma ISO 9001:2008.

- La cercanía con la Escuela de Ciencias de la Información que ofrece la Licenciatura en Bibliotecología.

La elaboración de un PFU que opere en todo el SB se puede realizar mediante un trabajo en equipo que lleve a cabo la planeación, ejecución y seguimiento del programa y que permita, entre otras cuestiones, establecer objetivos generales, fomentar la cooperación bibliotecaria e interdisciplinaria, y normalizar la realización de las actividades y de la terminología empleada, así como de la información brindada en las páginas web de cada centro.

Además de lo ya mencionado, sería deseable considerar la difusión del programa entre el personal del SB, sus conceptos y alcances, fomentar la capacitación y actuali- 
zación del personal involucrado, ya que, aun cuando se cuenta con profesionales bibliotecarios que tienen en mayor o menor medida, conocimientos y experiencia el desarrollo de actividades de formación, se requiere fortalecer sus conocimientos con cursos -talleres de temas como: Tendencias en FU- DHI o ALFIN; Diseño de programas y contenidos; Formación de instructores o formadores; Didáctica y pedagogía (Estrategias, Habilidades docentes, estilos de aprendizaje y modelos de enseñanza); Comunicación (Herramientas para la difusión; comunicación efectiva y manejo de grupos), entre otros.

Por último, recordemos que los casos exitosos de PFU son aquellos que se incorporan en la práctica escolar, por lo que sería altamente benéfico retomar esta incitativa para que se incorpore en las clases de escuelas y facultades, así como fomentar la cooperación con los docentes de tal forma que le otorguen tiempo a estas actividades en sus materias.

\section{CONCLUSIONES}

La Alfabetización Informativa en sociedades con grandes brechas en materia educativa, económica y social, es sólo posible en ciertos sectores o grupos, pero puede ser considerada como un trabajo en construcción, en el cual toda institución o unidad informativa puede contribuir en la medida de sus posibilidades, ya que es una actividad compartida que requiere del compromiso de todos los sectores involucrados. 
Desarrollo de la formación de usuarios en el Sistema de ...

La UASLP como institución pública debe ser sensible a su entorno y colaborar en el fomento de una cultura informativa que permita la inclusión social de sectores desprotegidos, y una forma de hacerlo es mediante la difusión de actividades de FU en ámbitos formales e informales como conferencias, pláticas para diferentes sectores tales como padres de familia y niños. Estas actividades pueden motivar además, la inserción de bibliotecarios en otros espacios.

En contextos con grandes desigualdades como el expuesto, utilizar el término de formación de usuarios es adecuado para referirse a un programa de actividades en las que el usuario transita por varios niveles de formación hasta lograr la meta establecida por la unidad de información, ya sea el desarrollo de habilidades o de competencias informativas.

El SB-UASLP cuenta con los recursos necesarios para implementar un PFU, pero deberá enfatizar en los siguientes requisitos: 1 . Análisis del entorno interno y externo de la UI; 2. Realización continua de estudios de usuarios; 3. Establecimiento de objetivos alcanzables y medibles; 4. Cooperación con la Escuela de Ciencias de la Información, 5. Actitud propositiva y compromiso de los actores involucrados (autoridades, personal y usuarios, entre otros) para llevarlo a cabo.

Con referencia a este último punto, recordar que el principal factor para lograr un programa exitoso de FU, no se centra en los recursos y la infraestructura material disponibles, sino en el personal que lo lleva a cabo. La actitud y compromiso de los participantes y el personal directivo y operativo es determinante, por lo que debe 
considerarse como factor prioritario, así como la comunicación efectiva de lo que se quiere lograr hacia quienes tomarán el programa, de lo contario se puede caer en una dispersión y un eterno retorno a lo ya realizado, sin llegar a los objetivos establecidos.

Por último, citamos a Cencerrado Malmierca (1997), cuando menciona que:

[...] la FU debe ser vista como una actitud permanente, con la que la biblioteca busca crear situaciones de comunicación con el usuario, con el objeto de informar y educar en el uso óptimo de los recursos que ofrece y conseguir así un mayor aprovechamiento de sus servicios y unos usuarios informados y críticos.

\section{REFERENCIAS BIBLIOGRÁFICAS}

Adelaide, Australian and New Zealand Institute for Information Literacy (2004). El marco para la alfabetización informacional en Australia y Nueva Zelanda. Principios normas y práctica, en: http://www.aab.es/pdfs/gtbunormas08. pdf (consultado el 25 de noviembre de 2010)

Association of College \& Research Libraries, (2000), Normas sobre aptitudes para el acceso y uso de la información en la educación superior, en: http://www.ala.org/ala/mgrps/ divs/acrl/standards/informationliteracycompetencystandards.cfm, (consultado el 30 de septiembre de 2010). 
Desarrollo de la formación de usuarios en el Sistema de ...

Asociación de Bibliotecarios de Ontario (OLA), (sf), Estudios de la Información de kindergarten a grado 12, currículo para colegios y centros de información de bibliotecas escolares, en http://www.eduteka.org/pdfdir/Curricul_3A.pdf (consultado el 15 de noviembre de 2010).

Campello, B. (2010), Del trabajo de referencia hacia la alfabetización informativa: La evolución del papel educativo del bibliotecario, en Investigación Bibliotecológica, Vol 24, núm. 50, pp. 83-108.

Cencerrado Malmierca, L.M. (1997), La formación de Usuarios como difusora de los servicios e la biblioteca, en $A a b a-$ dom: Boletín de la Asociación Asturiana de Bibliotecarios, Archiveros, Documentalistas y Museólogos, Vol. 8, Núm. 2, pp. 31-35.

Dirección Institucional de Gestión de Calidad, SICAL, UASLP, en http://www.uaslp.mx/Spanish/Administracion/DGC/SICAL/Paginas/default.aspx (consultado el 15 de enero de 2011).

Figueroa Barragan, L. (2009), Estudios de usuarios: su conceptuación. Tesis para la obtención del grado de maestra en Bibliotecología y Estudios de la información, México: UNAM.

García Gòmez, F.J.; Diaz Grau, A. (2007), Formación de usuarios y Alfabetización Informacional: dinámicas de trabajo en bibliotecas públicas, en: http://biblioteca.sanjavier.es/RecursosBP/FU_ALFIN_BPxabide.pdf, (consultado el 5 de diciembre de 2010). 
Gomez Hernández, J.A.; Benito Morales, F., De la formación de usuarios a la alfabetización informacional. Propuestas para enseñar habilidades de información, en: http://www. um.es/gtiweb/jgomez/publicaciones/alfabinforzaragoza2.PDF, (consultado el 15 de octubre de 2010).

Gómez Sustaita, M.R. E. (2009), Educación de usuarios de la Información. Elaboración de Programas para el Desarrollo de Habilidades informativas. México: Infoconsultores, pp.7-51.

García Valdéz, M., Informe 2009-2010, en: http://www.

uaslp.mx/Spanish/Rectoria/rector/InfoAnual/Documents/ Informe\%202009-2010/Indicadores.pdf, (consultado 25 de septiembre de 2010).

Hernández Salazar, P. (2001), "La producción del conocimiento científico como base para determinar perfiles de usuarios”, en Investigación Bibliotecológica, v. 15 núm. 30, pp 29-64.

- - -. (2007), "La relación entre los estudios y formación de usuarios de la información", en Revista General de la Información y Documentación, v. 17, núm. 2, pp. 103-121.

Instituto Nacional de Estadística y Geografía. Estadísticas Sociedad. Cultura y recreación, en: http://www.inegi. org. $\mathrm{mx} /$ Sistemas/temasV2/Default.aspx?s $=$ est\&c $=21702$ (consultado el 8 de diciembre de 2010).

Lastras Ramírez, A. (1992), Informe de Rectoría, San Luis Potosí: UASLP, 
Desarrollo de la formación de usuarios en el Sistema de ...

Evolución y tendencias de la Formación de Usuarios en un contexto latinoamericano, (2005), Naranjo Vélez [et.al.], en: http://bibliotecologia.udea.edu.co/formausuarios/ parte1/14.htm y http://bibliotecologia.udea.edu.co/ formausuarios/parte1/referenciada.htm (consultados el 30 de septiembre de 2010).

Ontario Ministry of Education and Training (1995), Information Literacy and Equitable Access: A framework for change, en: http://www.accessola.com/data/6/rec_docs/112 ilea. pdf, (consultado el 29 de noviembre de 2010).

Programa de formación de usuarios, Curso "Desarrollo de competencias para el manejo de información" (2003), Secretaria de Asuntos Académicos. Dirección de Educación a Distancia, San Luis Potosí: UASLP.

Secretaría de Educación Pública, Sistema educativo de los Estados Unidos Mexicanos, Principales cifras ciclo escolar 2008-2009, en: http://www.sep.gob.mx/work/models/ sep1/Resource/890/1/images/PrincipalesCIF2008-2009. pdf ,(consultado el 8 de diciembre de 2010).

-- -- Glosario, en: http://www.sep.gob.mx/work/models/ sep1/Resource/890/1/images/PrincipalesCIF2008-2009 .pdf, (consultado el 8 de diciembre de 2010).

Sistema de bibliotecas de la UASLP, en: http://www.uaslp. $\mathrm{mx} /$ Spanish/sisbib/Paginas/default.aspx, (consultado el 20 de enero de 2011). 
Tendencias de la Alfabetización Informativa en Iberoamérica

\section{ANEXOS}

\begin{tabular}{|l|c|c||}
\hline \multicolumn{3}{|c||}{$\begin{array}{c}\text { Cuadro1 } \\
\text { Matrícula escolar y analfabetismo en México y el Estado } \\
\text { de San Luis Potosí }\end{array}$} \\
\hline \multicolumn{1}{|c||}{ Matricula Escolar } & México & $\begin{array}{c}\text { San Luis Poto- } \\
\text { sí }\end{array}$ \\
\hline Pr-escolar & $4,634,412$ & 130,953 \\
\hline Primaria & $14,815,735$ & 365,380 \\
\hline Eficiencia terminal & 93.8 & 95.3 \\
\hline Secundaria & $6,153,459$ & 155,207 \\
\hline Eficiencia terminal & 80.9 & 81.6 \\
\hline Profesional Técnico & 366,954 & 5,314 \\
\hline Eficiencia terminal & 46 & 49.3 \\
\hline Bachillerato & $3,556,858$ & 81,040 \\
\hline Eficiencia terminal & 61.7 & 66.4 \\
\hline Normal licenciatura & 131,763 & 3,359 \\
\hline $\begin{array}{l}\text { Licenciatura universita- } \\
\text { ria y tecnológica }\end{array}$ & $2,296,381$ & 47,523 \\
\hline Posgrado & 185,516 & 2,162 \\
\hline Índice de analfabetismo & $8761175(7.8 \%)^{*}$ & $232734(9.0 \%)^{*}$ \\
\hline $\begin{array}{l}\text { Fuente: INEGI, estadísticas } 2010,{ }^{*} \text { Cifras aproximadas considerando los } \\
\text { porcentajes brindados por la SEP. } \\
\text { Elaborado por las autoras. }\end{array}$ & & \\
\hline \hline
\end{tabular}


Desarrollo de la formación de usuarios en el Sistema de ...

\begin{tabular}{|c|c|c|}
\hline \multicolumn{3}{|c|}{$\begin{array}{c}\text { Cuadro } 2 \\
\text { Población e instituciones culturales en México y el estado de } \\
\text { San Luis Potosí }\end{array}$} \\
\hline Población & $\begin{array}{l}\text { México: } \\
112322757 \\
\text { habitantes }\end{array}$ & $\begin{array}{c}\text { San Luis Potosí: } \\
2585942 \\
\text { habitantes }\end{array}$ \\
\hline \multirow{4}{*}{ Bibliotecas } & Públicas 7319 & Públicas 116 \\
\hline & Escolares 5618 & Escolares $\mathrm{n} / \mathrm{d}^{*}$ \\
\hline & Especializadas 226 & Especializadas $\mathrm{n} / \mathrm{d}$ \\
\hline & Total 13163 & Total n/d \\
\hline Librerías & 3892 & 39 \\
\hline Museos & 1123 & 21 \\
\hline Teatros & 573 & 11 \\
\hline Pantallas de cine & 3892 & 47 \\
\hline Casas y centros de cultura & 1828 & 60 \\
\hline
\end{tabular}




\begin{tabular}{|c|c|}
\hline \multicolumn{2}{|c|}{$\begin{array}{l}\text { Cuadro } 3 \\
\text { Sistema de Bibliotecas de la UASLP al } \\
\text { mes de enero de } 2011\end{array}$} \\
\hline Centros de Información & $\begin{array}{c}\text { Unidades de Información que dependenn } \mathrm{n} \text { admi- } \\
\text { nistrativamente de los Centros: }\end{array}$ \\
\hline $\begin{array}{l}\text { 1. Centro de Información en Ciencia, } \\
\text { Tecnología y Diseño (CICTD) }\end{array}$ & $\begin{array}{l}\text { 1. Agronomía; 2. Posgrado del Hábitat; } 3 \text {. Instituto de Física; } \\
\text { 4. Instituto de Geología, } 5 \text {. Instituto de Zonas Desérticas; } 6 . \\
\text { Posgrado en Ciencias Químicas; 7. Instituto de Investigacio- } \\
\text { nes de Ciencias Ópticas. }\end{array}$ \\
\hline $\begin{array}{l}\text { 2. Centro de Información en Ciencias } \\
\text { Sociales y Administrativas (CICSA) }\end{array}$ & $\begin{array}{l}\text { 8. Comunicación, } \\
\text { 9. Economía } \\
\text { 10. Centro de Información en Investigación y Posgrado. }\end{array}$ \\
\hline $\begin{array}{l}\text { 3. Centro de Información en Humani- } \\
\text { dades, Bibliotecología y Psicología } \\
\text { (CIHBYP) }\end{array}$ & 11. Instituto de Ciencias Educativas \\
\hline \multicolumn{2}{|l|}{$\begin{array}{l}\text { 4. Centro de Información en Ciencias } \\
\text { Biomédicas (CICB) }\end{array}$} \\
\hline \multicolumn{2}{|l|}{$\begin{array}{l}\text { 5. Biblioteca Pública Universitaria } \\
\text { (BPU) }\end{array}$} \\
\hline \multicolumn{2}{|l|}{$\begin{array}{l}\text { 6. Centro Integral de Aprendizaje } \\
\text { (CIA-Zona Huasteca) }\end{array}$} \\
\hline \multicolumn{2}{|l|}{$\begin{array}{l}\text { 7. Centro Integral de Aprendizaje } \\
\text { (CIA-Zona Media) }\end{array}$} \\
\hline & $\begin{array}{l}\text { 12. Escuela Preparatoria de Matehuala } \\
\text { Comunidad de bachillerato. } \\
\text { 13. CIA - Matehuala } \\
\text { (Administrativamente depende del Departamento de Pla- } \\
\text { neación) }\end{array}$ \\
\hline \multicolumn{2}{|c|}{$\begin{array}{l}\text { Fuentes: Informes de Rectoría, página web del SB, y página web de la Dirección Institucional de Gestión de Calidad, } \\
\text { de la UASLP. } \\
\text { Elaborado por las autoras. }\end{array}$} \\
\hline
\end{tabular}




\section{Desarrollo de la formación de usuarios en el Sistema de ...}

\begin{tabular}{|c|c|c|}
\hline \multicolumn{3}{|c|}{$\begin{array}{c}\text { Cuadro } 4 \\
\text { Información sobre la FU en los Centros de Información } \\
\text { del SB-UASLP }\end{array}$} \\
\hline $\begin{array}{l}\text { Denominación } \\
\text { utilizada }\end{array}$ & Objetivos & Actividades \\
\hline $\begin{array}{l}\text { CICTD. } \\
\text { 1. Formación de } \\
\text { usuarios. } \\
\text { 2. Actividades de } \\
\text { instrucción. }\end{array}$ & $\begin{array}{l}\text { - Dar a conocer a los usuarios } \\
\text { los recursos y servicios que } \\
\text { ofrece el CICTD. } \\
\text { - Desarrollar en los usuarios ha- } \\
\text { bilidades y competencias que } \\
\text { les permitan ser autosuficien- } \\
\text { tes en la búsqueda y gestión } \\
\text { de la información. }\end{array}$ & $\begin{array}{l}\text { Actividades en dos niveles: } \\
\text { 1. Formación de nuevos usuarios, (visitas } \\
\text { guiadas y actividades de introducción } \\
\text { a los servicios de la biblioteca y al ca- } \\
\text { tálogo. } \\
\text { 2. Sesiones de Información especializa- } \\
\text { da. (Recursos de información para la } \\
\text { investigación; Libros electrónicos; Re- } \\
\text { vistas electrónicas; Bases de datos.) }\end{array}$ \\
\hline $\begin{array}{l}\text { CICBI. } \\
\text { 1.Formación de } \\
\quad \text { usuarios }\end{array}$ & $\begin{array}{l}\text { Programar actividades que le per- } \\
\text { mitan al usuario el óptimo uso de } \\
\text { los servicios y recursos de infor- } \\
\text { mación del CICBI. }\end{array}$ & $\begin{array}{l}\text { Actividades generales, a solicitud y para } \\
\text { alumnos de nuevo ingreso: Visitas guia- } \\
\text { das, pláticas, uso del catálogo en línea, } \\
\text { cursos (Redacción de referencias biblio- } \\
\text { gráficas y Bases de datos). }\end{array}$ \\
\hline $\begin{array}{l}\text { CICSA. } \\
\text { 1. Formación de } \\
\text { usuarios. } \\
\begin{array}{l}\text { 2. Desarrollo de habili- } \\
\text { dades informativas. }\end{array}\end{array}$ & $\begin{array}{l}\text { Promover el aprendizaje y la in- } \\
\text { vestigación de los usuarios inter- } \\
\text { nos y externos, mediante el uso } \\
\text { autónomo y eficiente en la bús- } \\
\text { queda y acceso de la información, } \\
\text { en el modo tradicional y con la } \\
\text { aplicación de las tecnologías de la } \\
\text { información. }\end{array}$ & $\begin{array}{l}\text { - Formación de usuarios. Salas de usos } \\
\text { múltiples, Área de exposiciones y Pro- } \\
\text { moción de servicios. } \\
\text { - Visitas guiadas, asesorías en búsque- } \\
\text { da de información y cursos de induc- } \\
\text { ción relacionados con el uso de los } \\
\text { recursos de información. }\end{array}$ \\
\hline $\begin{array}{l}\text { CIHBYP. } \\
\text { Formación de Usuarios }\end{array}$ & $\begin{array}{l}\text { No ofrece mayor información al } \\
\text { respecto. }\end{array}$ & \\
\hline \multicolumn{3}{|c|}{$\begin{array}{l}\text { Fuente: Página Web del SB y de cada centro de Información. } \\
\text { Elaborado por las autoras. }\end{array}$} \\
\hline
\end{tabular}


Tendencias de la Alfabetización Informativa en Iberoamérica

\begin{tabular}{|c|c|c|}
\hline \multicolumn{3}{|c|}{$\begin{array}{l}\text { Cuadro } 4 \\
\text { Información sobre la FU en los Centros de Información } \\
\text { del SB-UASLP } \\
\text { (Cont.) }\end{array}$} \\
\hline $\begin{array}{l}\text { Denominación } \\
\text { utilizada }\end{array}$ & Objetivos & Actividades \\
\hline $\begin{array}{l}\text { BPU. } \\
\text { Talleres para usuarios }\end{array}$ & $\begin{array}{l}\text { No ofrece mayor información al } \\
\text { respecto. }\end{array}$ & \\
\hline $\begin{array}{l}\text { CREATIVA. } \\
\text { Formación de usuarios }\end{array}$ & $\begin{array}{l}\text { No presenta objetivos, sino que } \\
\text { describe lo que son: son cursos, ta- } \\
\text { lleres o pláticas dirigidas al perso- } \\
\text { nal universitario acerca de las } \\
\text { diferentes herramientas y servicios } \\
\text { del portal tanto a nivel general } \\
\text { como específico, diseñadas de } \\
\text { acuerdo con las necesidades. }\end{array}$ & $\begin{array}{l}\text { Talleres, presentaciones, pláticas infor- } \\
\text { mativas, cursos de inducción. }\end{array}$ \\
\hline \multicolumn{3}{|c|}{$\begin{array}{l}\text { Fuente: Página Web del SB y de cada centro de Información. } \\
\text { Elaborado por las autoras. }\end{array}$} \\
\hline
\end{tabular}




\title{
Estudiantes universitarios ¿nativos digitales? Una reflexión sobre sus competencias tecnológicas y su formación en competencias
}

\author{
ENEDINA ORTEGA GUTIÉRREZ
}

Instituto Tecnológico de Estudios Superiores Monterrey

\section{INTRODUCCIÓN}

$\mathrm{E}$

n la sociedad de la información y del conocimienfio y las transformaciones de su relación con las tecnologías de la comunicación y de la información, en esta relación consideramos a la educación y a las bibliotecas como un "entorno tecnológico". Lo que estamos diciendo al denominarlo "entorno tecnológico" es que el panorama al que actualmente se asiste en el cruce cultu$\mathrm{ra} /$ tecnología, es un lugar de intersección en el que muchos jóvenes sitúan tanto sus saberes como sus prácticas cotidianas, su sociabilidad grupal y sus inversiones personales. En este entorno se reconocen una diversidad de actores, una considerable porosidad de límites y una penetración dispar de lo tecnológico, lo cultural y lo per- 
sonal. Así cuando hablamos de formar usuarios en el "entorno tecnológico" debemos considerar esta nueva naturaleza de los fenómenos de la cultura digital o cibercultura, que impacta en la forma en que bibliotecarios, maestros y jóvenes estudiantes se relacionan con el conocimiento.

Nuestros jóvenes estudiantes establecen estrategias complejas de relaciones con los otros, con el mundo -físico y su extensión a lo virtual el denominado "ciberespacio"- y con el saber.

Derrick de Kerchove (1999), identifica tres características esenciales de esta cultura digital:

a). Interactividad que es la relación entre las personas y el entorno digital definido por el hardware y software que los conecta a los dos;

b). Hipertextualidad que es el acceso interactivo a cualquier cosa desde cualquier parte, con una nueva condición de almacenamiento y entrega de contenidos;

c). Conectividad es la tendencia a juntar entidades separadas mediante un vínculo o una relación, supone la ampliación del espectro de acción de la comunicación, en tanto abre nuevas y mejores posibilidades, más allá de la bidireccionalidad del tiempo real.

Estas características actualmente son potenciadas por el desarrollo de la tecnologías de la WEB.02 y la WEB.3.

En este contexto se enfoca esta reflexión. Intento ir tejiendo y construyendo puentes entre dos ejes: por un lado, el análisis del perfil, las competencias y las necesidades actuales de nuestros jóvenes usuarios y, por otro, la necesaria reflexión en torno al modelo actual que predomina en los programas de formación de usuarios en 
Estudiantes universitarios ¿nativos digitales? Una reflexión...

las bibliotecas, basados sólo en el desarrollo de las habilidades informativas.

Trataré de responder a un conjunto de preguntas emplazándome entre estos dos ejes analíticos: ¿quiénes son los usuarios digitales competentes?, ¿cuál es su perfil?, ¿cuáles son sus necesidades?, ¿cuáles y cómo adquieren estas competencias digitales?, ¿qué papel juegan la formalidad y la informalidad en el aprendizaje de estas competencias?, ¿para qué las utilizan? y ¿cuáles serían los retos y tareas desde este entorno tecnológico que tendrían que asumir la bibliotecas y los bibliotecarios de formadores de una usuarios competentes digitales (heterogéneos/homogeneidad) que se desempeñan en la sociedad del conocimiento y de la información?

\section{LA GENERACIÓN INTERACTIVA}

En la sociedad red, los sujetos son entendidos como actores sociales que participan e interactúan en redes virtuales. Los jóvenes suelen asumirse como el grupo social que con mayor intensidad se construye a partir de un contexto de innovación tecnológica en permanente re-creación y dinamismo. La carencia de datos empíricos que aporten mayor claridad acerca de los mitos existentes en torno a la relación de los jóvenes con la tecnología y sobre los rasgos que caracterizan a la llamada generación digital en el entorno mexicano, impide la comprensión profunda de su complejidad.

El acceso, la adopción y la apropiación de las nuevas tecnologías les generan preguntas y retos a las instituciones socializadoras (principalmente la familia, la escuela y el Estado) que están obligadas a responder con acciones dili- 
gentes a las necesidades, peculiaridades y prácticas de los jóvenes. La población joven es representada en el imaginario social como aquella que incorpora naturalmente la tecnología en su vida y es asumida como la que más se despla$\mathrm{za}$, vive, interactúa, produce, consume, aprende y se divierte en el ciberespacio en este entorno que ha empezado a gestarse. ${ }^{1}$ En este contexto, es necesario plantearse algunas preguntas que tienen que ver con las formas en que los jóvenes se constituyen como actores sociales en la red: ¿Poseen las competencias tecnológicas que la nueva sociedad red demanda? ¿De qué manera y en qué contextos las adquieren? ¿Qué papel juegan la formalidad y la informalidad en el aprendizaje de estas competencias? ¿Para qué las utilizan? ¿Cómo se manifiestan las brechas digital y generacional en este universo? ¿Cómo habrían que diseñarse los cursos de formación de usuarios para contribuir a los nuevos perfiles y necesidades de los jóvenes en estos entornos tecnológicos?

\section{EL CIBERESPACIO UN LUGAR HABITADO POR LOS JÓVENES}

El ciberespacio es un "nuevo espacio social" (Echeverría, 1999) que simultáneamente reproduce, cuestiona y amplia las posibilidades de la realidad física. En este sentido, la red no es un medio de comunicación más, sino

1 Si consideramos que a mediados de los noventa se comienza a popularizar Internet y que a partir del nuevo siglo se abre la web social, entonces en términos reales estamos hablando de apenas quince años de la llamada revolución tecnológica. 
Estudiantes universitarios ¿nativos digitales? Una reflexión...

un universo que se construye en un entorno de socialización en el que el joven crea su propia autoconciencia se relaciona y siente. Las comunidades virtuales se construyen como una continuidad de sus espacios sociales tradicionales, sirven para reforzar o renovar esos vínculos preexistentes o construir nuevos, son una proyección del universo emocional de los jóvenes.

Es así como el ciberespacio es uno de los lugares de habitación de los jóvenes tomado y poblado por ellos que les permite agregarse socialmente como comunidades virtuales, (Rheingold, 2003). Por lo tanto los bibliotecarios al momento de diseñar los nuevos cursos de formación y servicios de la biblioteca deberemos tener en mente estos nuevos "entornos tecnológicos".

\section{LAS GENERACIONES ENFRENTADAS: NATIVOS VS. MIGRANTES DIGITALES}

Para comprender las implicaciones del desarrollo tecnológico en "el entorno tecnológico" de la educación y las bibliotecas es fundamental analizar los cambios generacionales que están influyendo en la construcción de nuevas formas de relacionarse, de aprender y enseñar en los distintos actores en juego: estudiantes, maestros, bibliotecarios y padres de familia.

Si bien es cierto que las definiciones de generación y de joven son parte de una polémica teórica que no está cerrada, partimos de la postura de retomarlas desde su construcción sociocultural. A esta discusión se le suma la distinción fundamental entre aquellos grupos generacionales que han tenido que incorporarse al uso de las nue- 
vas tecnologías y los que han nacido teniendo a las tecnologías como una parte constitutiva de sus vidas, Prensky (2001) propone la diferenciación entre migrantes y nativos digitales para caracterizar a estos dos grupos.

Para Ortega y Ricaute (2009), esta conceptualización significó un momento de inflexión en la discusión acerca de la naturaleza y las implicaciones de desarrollo tecnológico en los procesos cognitivos como una variable que ahonda la brecha entre generaciones. La discusión teórica se ha centrado en explicitar los rasgos distintivos y habilidades tecnológicas que definen a esta nueva generación y que de acuerdo a la literatura se han denominado también competencias digitales Cobo, (2009), alfabetización digital (digital literacy), Mizuko Ito et. al. (2008) o alfabetización tecnológica. Sin embargo, propongo con Ricaute (Ortega y Ricaute, 2009) y Bennet, Matons y Kervin (2008), que este debate categorial aún no está cerrado y debe continuar, partiendo de una discusión racional y crítica basada en evidencia empírica, la cual descarte la noción hiperbólica de nativos digitales.

\section{¿Quiénes son los nativos digitales?}

La discusión acerca de quiénes pertenecen o son los nativos o los nacidos digitales es variable según los autores. De acuerdo con una visión amplia, son los jóvenes nacidos a fines del siglo XX e inicios del XXI y que han sido denominados de diferentes maneras: generación net (Tapscott, 1998), generación@, generación I (Internet), generación Google, generación digital, nativos digitales (Prensky, 2001) o nacidos digitales (Palfrey, 2008). En este punto, podríamos tomar como referencia la distin- 
Estudiantes universitarios ¿nativos digitales? Una reflexión...

ción conceptual que realizan Strauss y Howe (1991) entre generaciones (Baby Boomers, generación X, Y y Z). "A pesar de que son categorías construidas para contextos distintos al latinoamericano y que responden a marcas culturales e históricas específicas del contexto de origen (Estados Unidos, países desarrollados, principalmente occidentales) pensamos que pueden ser útiles para el análisis, haciendo las adecuaciones a los respectivos contextos”, (Ortega y Ricaute, 2009). Si lo consideramos de manera estricta, estaríamos siendo testigos del nacimiento de la primera generación de nativos digitales. ${ }^{2}$ Sin embargo Ortega y Ricaute hacen el señalamiento de que las fechas que enmarcan el nacimiento y fin de una generación deben asumirse únicamente como marcos referenciales y no en sentido estricto, debiéndose tomar en cuenta que una generación está marcada por los hechos históricos, políticos, mediáticos, culturales, tecnológicos, que perfilan la memoria, los gustos, las prácticas de los que son jóvenes en ese periodo, y que les permiten construir una identidad generacional a partir del reconocimiento e identificación de estas vivencias compartidas. Por otra parte, es necesario considerar que en América Latina la desigualdad social determina que estas categorías sean aplicables solamente a los sectores minoritarios de la población que poseen acceso a la educación y la tecnología, quienes constituyen los sujetos de nuestro estudio.

2 Que corresponderían a la generación Z de acuerdo con la clasificación de Strauss y Howe (1991). 
Coincidimos con autores como Tapscott (1998) y Feixa (2005) en que si en el siglo XIX los Baby Boomers de posguerra protagonizaron la revolución cultural de los sesenta, basada en la emergencia de los medios masivos, las culturas del rock, el pacifismo, la libertad de expresión y la libertad sexual; los jóvenes de hoy son protagonistas de la revolución tecnológica y los niños del siglo XXI conforman la primera generación que habrá nacido y vivido toda su vida en la era digital. Podemos hablar de las generaciones B.C. (Before Computer) y las generaciones A.C. (After Computer), como la distinción fundamental que va a separar a las generaciones de migrantes de las generaciones de nativos digitales. Feixa (2005) sostiene que antes de la revolución tecnológica la brecha generacional se marcaba por los grandes hechos históricos (guerras, guerrillas, mayo del 68, movimiento estudiantil) o por las rupturas musicales (Beatles, Sex Pistols, la trova); sin embargo, en la actualidad, la brecha generacional se distingue particularmente por el acceso, participación, uso y apropiación de las nuevas tecnologías. En la concepción de las nuevas generaciones es necesario considerar, además de los aspectos culturales, históricos y tecnológicos, los componentes ideológico-discursivos que configuran la visión que los jóvenes tienen del mundo. Consideramos que las condiciones materiales e ideológicas determinan la relación e interacción de los jóvenes con su entorno y los otros, principalmente a través de un empoderamiento generacional fundado en sus competencias tecnológicas, (Ortega y Ricaurte). Las nuevas tecnologías y el ciberespacio han generado nuevas prácticas sociales como el cibersexo, la ciberpolítica (campañas políticas a través de la red) el ciberactivismo (formas de protesta y de participación ciudadana); 
Estudiantes universitarios ¿nativos digitales? Una reflexión...

comunicativas (produsers), económicas (e-commerce, e-bussiness, prosumers) y éticas (open source knowledge, copyleft, creative commons), que instauran nuevas formas de socialización, inclusión y exclusión.

Algunas de las preguntas que se plantean los autores sobre la distinción entre estos jóvenes y las anteriores generaciones giran en torno a las diferencias cognitivas, afectivas, sociales y políticas de los sujetos que están creciendo, desarrollándose y socializándose en el nuevo entorno tecnológico, sustancialmente distinto al que tuvieron sus padres y sus maestros. Estos jóvenes son multifuncionales, piensan diferente, hacen las cosas de manera distinta, tienen otras capacidades, otras prioridades, aprenden de otra manera, son otro tipo de ciudadanos. Para Prensky (2001) estos factores son los que van a caracterizar a los jóvenes estudiantes e incluso sugiere a través de sus observaciones que se producen cambios neuronales como resultado de los diferentes estímulos y múltiples sistemas de información a los que están expuestos. Aún no existe evidencia empírica suficiente para demostrar estas hipótesis, por lo que éste es uno de sus planteamientos más cuestionados.

La distinción entre migrantes y nativos digitales se empieza a cuestionar por autores como Alejandro Piscitelli (2006), John Palfrey (2008), Neil Selwin (2009) y otros. Sin embargo, como acertadamente lo menciona el mismo Piscitelli, esta diferenciación "es de una fabulosa actualidad que, antes que temer, deberíamos desconstruir y eventualmente rediseñar", (p.181). Este investigador se plantea algunas preguntas fundamentales que debemos empezar a responder: ¿Existe una brecha 
cognitiva sumada a la brecha generacional? ¿Las visiones encontradas entre padres (migrantes) e hijos, estudiantes y maestros (migrantes) pueden pasar de la confrontación-separación a una colaboración? Francis Pisani (2009), señala algunos ejemplos que constatan estos cambios relacionados con esta brecha: los maestros detentaban el monopolio del saber, un conocimiento válido y para siempre, actualmente el ejercicio de su magisterio a partir de su posición jerárquica choca con el hecho de que la gente tiende a cada vez tener más confianza en sus pares. Los estudiantes pueden ahora discutir la validez de la información, tienen acceso a mayores fuentes y a la actualización permanente. Esta coyuntura desvirtúa la posición jerárquica del maestro y su verdad.

Solamente una aproximación empírica profunda y rigurosa a este fenómeno nos permitirá generar acciones consecuentes para que la sociedad alcance una comprensión atinada de las transformaciones que se están gestando de manera tan vertiginosa.

\section{Los nativos digitales en el contexto mexicano}

Cuando hablamos de una generación digital en América Latina, hay que considerar las distintas brechas a las que nos enfrentamos. La brecha digital es un fenómeno complejo que comprende a su vez varias brechas interdependientes: la económica, la tecnológica, la de conocimiento, la cultural y la política, (Crovi, Toussaint, Tovar, 2006, pp. 30-32). La económica se refiere a la carencia de recursos materiales para acceder a las nuevas tecnologías; la tecnológica está relacionada con la disponibilidad de equipamiento tecnológico y la capacidad de renovación de la 
Estudiantes universitarios ¿nativos digitales? Una reflexión...

infraestructura tecnológica; la de conocimiento tecnológico, que nosotros preferimos denominar competencia tecnológica, comprende las habilidades, capacidades y destrezas motoras necesarias para adoptar y apropiarse efectivamente de las nuevas tecnologías; la cultural, que preferimos denominar como competencias cognitivas, tiene que ver con el nivel educativo, las competencias en el procesamiento de la información, el dominio de categorías conceptuales que les permitan encontrar, relacionar, jerarquizar, incorporar y re-crear con mayor eficiencia los contenidos requeridos/desplegados por las nuevas tecnologías; y por último la brecha política, que involucra las políticas públicas en relación con el acceso a las nuevas tecnologías, el contexto democrático, el marco jurídico y social que pueden obstaculizar o fomentar la igualdad de oportunidades para acortar la brecha digital. La brecha digital se sostiene sobre abismos profundos y difíciles de revertir en las actuales condiciones políticas, económicas, educativas y sociales de nuestros países.

3 La penetración de Internet en México es del 24.9\% con 27,4 millones de usuarios, frente al 74.9\% de penetración y 227 millones de usuarios en Estados Unidos (Internet World Stats, 2009). En México existen solamente 11.1 millones de computadoras con acceso a Internet (AMIPCI, 2008). El 54\% de mexicanos tiene celular, 29\% de ellos con acceso a Internet, pero sólo el 7\% lo usa (AMIPCI, 2008). El 33\% tiene entre 12 y 18 años, el $22 \%$ entre 19 y 24 y el $23 \%$ entre 25 y 34 (AMIPCI, 2008). En México sólo el 14.5\% de la población posee algún grado aprobado en estudios superiores (INEGI, 2005). Más de la mitad de los internautas se ubican en un nivel socioeconómico ABC+C, (AMIPCI, 2008). El 91\% de los internautas reside en zonas urbanas. 
Además de la brecha digital hay que tomar en consideración el papel que juega la brecha generacional en la construcción del perfil de los nativos digitales. Ambas brechas enmarcan las relaciones que establecen los jóvenes con la tecnología, por lo tanto, no podemos soslayar su importancia en un estudio que quiera dar cuenta de nuestra realidad social. La brecha generacional se refiere a la distancia significativa en naturaleza e intereses que existe entre una generación y otra. Para el caso de la generación digital esta brecha se encuentra definida principalmente por su relación con las nuevas tecnologías. Las competencias tecnológicas acentúan la capacidad que tienen los sujetos para adaptarse a los cambios tecnológicos y culturales; capacidad que en las nuevas generaciones suele ser superior con respecto a las anteriores. Para algunos autores (Castells, Feixa) la brecha digital es sinónimo de brecha generacional. En este sentido, los migrantes y los nativos digitales ${ }^{4}$ estarían separados no por el hecho de pertenecer a generaciones distintas, sino por el hecho de poseer una mayor o menor competencia tecnológica.

4 ¿Quiénes son los migrantes digitales? En nuestro estudio, los padres de nuestros jóvenes nativos poseen alrededor de 50 años y tienen una infraestructura básica de computadora y celular y todos usan correo electrónico. Poseen en su mayoría un nivel de educación superior ( $81.4 \%$ con licenciatura o posgrado), lo que los sitúa en la élite intelectual del país (en México sólo el $14.5 \%$ de la población tiene estudios a nivel superior). 
Estudiantes universitarios ¿nativos digitales? Una reflexión...

Desde una postura menos rígida y más correspondiente con la realidad empírica, sostenemos que la brecha digital contribuye a reforzar la brecha generacional, pero que esa distancia se vuelve reversible cuando la brecha digital se reduce. Es frecuente la percepción de que los jóvenes son naturalmente cercanos a la tecnología y la brecha en consecuencia se asume como algo previsto entre las generaciones. Sin embargo, a partir de nuestros datos, consideramos que es necesario matizar que en nuestro país las generaciones poseen apropiaciones dispares de la tecnología, lo cual significa que no todos los jóvenes de la generación digital poseen las competencias que los marcan como generación, ni tampoco que las generaciones anteriores son incompetentes tecnológicamente. Las competencias tecnológicas, como mencionamos anteriormente, varían de acuerdo con las condiciones determinadas por la brecha digital (infraestructura tecnológica, nivel socioeconómico, etc.), la ocupación de los sujetos y otra serie de factores que hay que considerar. En este escenario, hemos encontrado que los más hiperconectados y equipados de nuestra sociedad, poseen competencias que los sitúan en un uso intermedio de la tecnología, a pesar de poseer todas las ventajas que su nivel educativo y socioeconómico les ofrece.

La brecha digital refuerza la brecha generacional a través del empoderamiento de los jóvenes a través de la tecnología. El empoderamiento se materializa sobre la base de las competencias tecnológicas de los jóvenes y de su habitación del ciberespacio. Por una parte se encuentra la apropiación de espacios virtuales, como lugares poblados predominantemente por jóvenes (Face- 
book, YouTube, MySpace, Twitter, blogs, messenger, sms) y a los cuales las generaciones de migrantes no quieren o no pueden acceder por desconocimiento, desinterés o falta de competencia tecnológica. Por otra parte, un espacio más de empoderamiento se erige sobre la percepción de que el mundo es abarcable, próximo y contenido en la Red. Internet se convierte en la fuente de todo el conocimiento universal, de la sabiduría y la experiencia ancestral del mundo. Esto permite que la autoridad que antes se les concedía a las anteriores generaciones se traslade a Internet: el mundo se define según Google y Wikipedia.

Proponemos desglosar algunas de las principales características señaladas como distintivas de esta generación de jóvenes nativos digitales entre 16 y 24 años, estudiantes de nivel medio y superior, de estrato medio, medio alto y alto de la ciudad de México. Son rasgos que no se plantean como excluyentes de las generaciones precedentes de migrantes digitales y que por supuesto consideran como punto de partida fundamental los factores del contexto social y la brecha digital que tienen que ver con el acceso, la adopción y apropiación de la tecnología más allá de su fecha de nacimiento. Algunos investigadores observan que ciertos jóvenes latinoamericanos comparten algunas de estas características (Balardini 2009), igualmente con los estadunidenses (Selwin 2009) y con jóvenes españoles, (Feixa 2005). 
Estudiantes universitarios ¿nativos digitales? Una reflexión...

\begin{tabular}{|c|c|}
\hline \multicolumn{2}{|c|}{$\begin{array}{l}\text { Cuadro } 1 \\
\text { Características de los jóvenes } \\
\text { estudiantes mexicanos }\end{array}$} \\
\hline Variables & Características \\
\hline 1. Edad & $\begin{array}{l}\text { Los principales usuarios de las TIC son los más jóvenes en- } \\
\text { tre los rangos de edad } 15 \text { y } 19 \text { años. A partir de esa edad tan } \\
\text { sólo las utilizan los que poseen estudios superiores. }\end{array}$ \\
\hline $\begin{array}{l}\text { 2. Nivel educativo y tipo de } \\
\text { escuela }\end{array}$ & $\begin{array}{l}\text { Los jóvenes poseen un nivel educativo superior a la media } \\
\text { mexicana y estudian principalmente en escuelas privadas. }\end{array}$ \\
\hline 3. Ocupación & $\begin{array}{l}\text { Ser estudiante es una condición importante para que utilicen } \\
\text { más las nuevas tecnologías, puesto que se encuentran incor- } \\
\text { poradas al sistema educativo, no necesariamente en el currí- } \\
\text { culum, pero sí como parte de sus herramientas de estudio. }\end{array}$ \\
\hline 4. Nivel socioeconómico & $\begin{array}{l}\text { Los jóvenes de clase media y alta son los que poseen mayor } \\
\text { acceso a la infraestructura tecnológica y mejores competen- } \\
\text { cias tecnológicas. }\end{array}$ \\
\hline 5. Género & $\begin{array}{l}\text { Siguen existiendo diferencias de género, los hombres tienen } \\
\text { mayor acceso y se apropian más de las nuevas tecnologías, } \\
\text { aunque cada vez se diluyen más estas diferencias entre } \\
\text { hombres y mujeres. }\end{array}$ \\
\hline $\begin{array}{l}\text { 6. Infraestructura y renovación } \\
\text { de equipo }\end{array}$ & $\begin{array}{l}\text { El equipamiento básico es la computadora de escritorio o } \\
\text { portátil, celular sin Internet, Ipod y videojuegos; que renuevan } \\
\text { entre uno a cuatro años. Los jóvenes con mayores posibilida- } \\
\text { des económicas se distinguen por tener netbook, teléfono in- } \\
\text { teligente (iPhone, Blackberry) consolas de juego (XBox, } \\
\text { PlayStation, Nintendo, Guitar Hero Wii), videojuegos portáti- } \\
\text { les (PSP, Game Boy, etc.). }\end{array}$ \\
\hline $\begin{array}{l}\text { 7. Permeabilidad entre las es- } \\
\text { feras de la educación, el tra- } \\
\text { bajo y el ocio }\end{array}$ & $\begin{array}{l}\text { Los jóvenes estudiantes pueden comprender las ventajas } \\
\text { personales y sociales de permitir la permeabilidad entre las } \\
\text { esferas de la educación, lo laboral y el entretenimiento para } \\
\text { posibilitarles más oportunidades en la vida }\end{array}$ \\
\hline
\end{tabular}




\begin{tabular}{|c|c|}
\hline \multicolumn{2}{|c|}{$\begin{array}{l}\text { Cuadro } 1 \\
\text { Características de los jóvenes } \\
\text { estudiantes mexicanos } \\
\text { (Cont.) }\end{array}$} \\
\hline Variables & Características \\
\hline $\begin{array}{l}\text { 8. Aprendizaje en redes y } \\
\text { durante todo el ciclo de } \\
\text { vida }\end{array}$ & $\begin{array}{l}\text { Existe una relación entre el aprendizaje formal, e informal } \\
\text { (entre pares y autodidactismo) donde el conocimiento se va } \\
\text { construyendo y descontruyendo a lo largo del ciclo de vida, lo } \\
\text { cual va generando actitudes estratégicas hacia el aprendizaje } \\
\text { combinando el capital cultural formal con las experiencias in- } \\
\text { formales }\end{array}$ \\
\hline 9. Lugares de acceso & $\begin{array}{l}\text { Son principalmente la casa y la escuela; luego los cibercafés } \\
\text { y otros lugares donde exista la red inalámbrica a la que pue- } \\
\text { den conectarse por dispositivos móviles. }\end{array}$ \\
\hline 10. Usos & $\begin{array}{l}\text { Se concentran en la comunicación, entretenimiento y sociali- } \\
\text { zación: búsqueda de información, correo electrónico, chat, } \\
\text { mensajes cortos de texto, redes sociales. }\end{array}$ \\
\hline 11. Orientación a las multitareas & $\begin{array}{l}\text { Los nativos digitales se caracterizan por la realización de } \\
\text { múltiples tareas simultáneamente, que se deriva en la pérdi- } \\
\text { da de atención centrada en un solo estímulo. }\end{array}$ \\
\hline $\begin{array}{l}\text { 12. Convergencia tecnológica } \\
\text { y apropiación }\end{array}$ & $\begin{array}{l}\text { La importancia de la tecnología en sus vidas y el uso cons- } \\
\text { tante de la convergencia de distintas tecnologías tanto en el } \\
\text { espacio físico como en el virtual. }\end{array}$ \\
\hline \multicolumn{2}{|c|}{$\begin{array}{l}\text { Los datos mostrados en el cuadro y en el texto provienen de un estudio exploratorio realizado por las investiga- } \\
\text { doras durante el mes de julio, cuyo propósito era realizar una primera exploración al universo de los jóvenes nati- } \\
\text { vos digitales residentes en la ciudad de México. El grupo de estudio pertenece a un estrato social medio, medio } \\
\text { alto y alto, son estudiantes de nivel medio superior y superior de instituciones educativas privadas, de ambos se- } \\
\text { xos y edades entre } 16 \text { y } 25 \text { años. Esta aproximación se realizó a través de una mirada metodológica mixta: cuali- } \\
\text { tativa y cuantitativa, virtual y física. Los datos empíricos fueron obtenidos a partir de } 106 \text { encuestas en línea } \\
\text { realizadas utilizando sus propios espacios virtuales académicos dentro del contexto de una institución privada de } \\
\text { educación superior en la Ciudad de México. Se aplicaron además siete entrevistas en profundidad y la técnica } \\
\text { de mapas cognitivos por medio de dibujos con el fin de identificar las rutas que siguen en los procesos de acce- } \\
\text { so, uso y apropiación tecnológica en relación con sus prácticas de socialización, aprendizaje y entretenimiento. }\end{array}$} \\
\hline
\end{tabular}


Estudiantes universitarios ¿nativos digitales? Una reflexión...

"La tecnología no es tan relevante como el conocimiento que pueda ser accesado, comprendido, creado y comunicado" (Cobo, C. 2009).

Dado el panorama mostrado anteriormente en relación con las características heterogéneas y competencias digitales adquiridas desde su aprendizaje informal por los jóvenes en su entorno digital, ¿los actuales modelos, programas y políticas públicas de Formación de Usuarios incluyen en sus propuestas estas características, competencias, y necesidades?, ó los cursos actuales de Formación de Usuarios en Habilidades Informativas y Digitales, implementados a través de las instituciones socializadoras y formativas, como son las escuelas y las bibliotecas, sólo contemplan desde las miradas y expectativas de la generación de adultos, qué competencias y funcionalidades esperan de sus jóvenes. Y de ahí que estos cursos no tengan la efectividad e impacto deseado en esta generación interactiva de estudiantes.

The one thing that does not change is that at any and every time it appears that there have been 'great changes. Marcel Proust, Within a Budding Grove.

\section{CONCLUSIONES}

A partir de las consideraciones y reflexiones anteriores proponemos que los cursos de formación de usuarios en habilidades informativas se transformen en cursos de Educación y Cultura Digital incorporadas al curriculum desde los primeros años de educación básica en correspondencia con el hecho de que el acceso, adopción y 
apropiación de las tecnologías de la información y el uso de la web.02 se da en edades tempranas.

Este modelo iría mucho más allá de la sola formación en habilidades digitales e informativas. Pasa por la adquisición y desarrollo de un conjunto de competencias de manera simultánea: lectora, de socialidad, respeto a la diversidad, ciudadanía digital, trabajo colaborativo, convergencia de nuevos medios, lectura crítica y significativa y transferibilidad del conocimiento. Aunado a este fomento y desarrollo de competencias, es necesario trabajar con los obstáculos que presenta la educación digital, como son el determinismo tecnológico y el empoderamiento generacional.

Estas competencias van mucho más allá del dominio instrumental de las TIC y difícilmente se pueden adquirir al margen de vincular los conocimientos de las diversas áreas que integran el currículum, con la propia experiencia y aprendizaje informal que hacen los jóvenes estudiantes en las diversas esferas de su participación social.

En ese sentido, se propone que los Cursos de Formación en Educación y Cultura Digital, tanto en su diseño e implementación por las bibliotecas, tomen en cuenta que forman parte del "entorno tecnológico" de los jóvenes estudiantes, $\mathrm{y}$ les den así un uso significativo entre su entorno tecnoloógico. También proponemos como uno de los objetivos principales de estos cursos, que contribuyan a formar ciudadanos críticos que participen activamente en la sociedad de la información y del conocimiento. 
Estudiantes universitarios ¿nativos digitales? Una reflexión...

Sin embargo estas reflexiones y la propuesta exigen tres consideraciones a tomar en cuenta en el diseño de estos cursos:

a). No fundamentar el marco conceptual del diseño en las teorías que generalizan que "todos los jóvenes son nativos digitales", ya que las investigaciones están comprobando que existe una proporción significativa de gente joven que no posee los niveles de acceso o las competencias tecnológicas predichas por estas generalizaciones.

b). La investigación realizada, por ejemplo, Bennet, Maton y Kervin (2008), en su artículo The digital natives debate: a critical review of the evidence empieza a mostrar evidencias que indican que una proporción considerable de gente joven es altamente adicta a las tecnologías y confía en ellas para la recolección de información y otras actividades de comunicación, hecho que se empieza a documentar como sobrecarga digital.

c). En el contexto mexicano, esta propuesta de cursos deberá representar desde su diseño la heterogenidad que existe en las lógicas de usos y niveles de acercamiento juvenil a las tecnologías, las cuales se encuentran determinadas por las brechas tecnológica, cultural, política y económica, las cuales excluyen a grandes sectores de la población joven.

Finalmente proponemos la necesidad de seguir realizando una más amplia y a la vez profunda investigación-acción sobre los jóvenes como generación interactiva y sobre sus competencias, para seguir reflexionan- 
Tendencias de la Alfabetización Informativa en Iberoamérica

do sobre las implicaciones que estas situaciones tienen para la educación de los usuarios en las bibliotecas.

\section{REFERENCIAS}

AMIPCI (Asociación Mexicana de Internet), (2008), Nuevas Tecnologías de Internet en México, recuperado el 6 de junio de 2009 de http://www.amipci.org.mx

Bennet, S., karl, M., kervin, L. (2008), "The digital natives debate: a critical review of evidence?", en Brithish Journal of educational technology, Vol.39, pp 775-786.

Cobo Romani, C. (2009), Strategies to promote the development of E-competencies in the Next Generation of Professionals; European and International Trends, Monograph 13, Oxford: SKOPE.

Crovi, D., Toussaint, F. y Tovar, A. (2006), Periodismo digital en México, México: UNAM.

Castells, M. (2006), Sociedad Red, Madrid: Alianza.

Castells, M. (2001), Internet y la sociedad red, recuperado el 6 de junio de http://www.uoc.es/web/cat/articles/castells /castellsmain2.html

Echeverría, J. (1999), Los señores del aire: Telépolis y el tercer entorno, España: Destino. 
Estudiantes universitarios ¿nativos digitales? Una reflexión...

Feixa, C. (2005), Los hijos en casa: ¿hackers o hikikomoris?, en Revista de comunicación y Pedadogía, 208, recuperado el 31 de mayo de 2009 de http://www.xtec.cat/ abernat/ articles/feixa.pdf

INEGI. (2008), Encuesta Nacional sobre Disponibilidady Uso de las Tecnologías de la Información en los hogares, ENDUTIH, recuperado el 6 de junio de 2009 de http://www.inegi.org.mx

Jenkins, H. (2009), Confronting the challenges of participatory culture. Media education for the 21st century, USA: MIT press.

Kerckhove, De, D. (1999), La piel de la cultura. Investigando la nueva realidad, Barcelona: Gedisa.

Ortega Gutiérrez, E. y Ricaurte Quijano, P. (2010), “Jóvenes nativos digitales: mitos sobre la competencia tecnológica" en Urteaga Castro Pozo Maritza Alida (coordinadora), En Juventudes culturas, identidad y tribus juveniles en el México contemporáneo, Diario de Campo Núm. 106, Octubre- diciembre, CCNA-Instituto Nacional de Antropología e Historia, pp. 43-49.

Mizuko,I; Horst, H; Matteo B; boyd, d; et.al. (2008), Living and Learning with New media. USA, MacArthur Foundation.

Palfrey, J. \& Gasser, U. (2008), Born digital.Understanding the first generation of digital natives, New York: Basic Books.

Pisticelli, A. (2006), "Nativos e inmigrantes digitales: ¿brecha generacional, brecha cognitiva o las dos juntas y más aún?” en Revista Mexicana de Investigación Educativa, 11 (28), pp. 179-185. 
Tendencias de la Alfabetización Informativa en Iberoamérica

Prensky, M. (octubre, 2001), Digital Natives, Digital Immigrants, en On the Horizons, 9 (5), Pisani, F. (2009, Noviembre 16), ELEC-Crónicas, A aprender en la era de las redes sociales, Sección Interfase, El Norte.

Rheingold, H. (1996), La comunidad virtual: una sociedad sin fronteras, Barcelona: Gedisa.

Tapscott, D. (2009), Grown Up Digital: How the Net Generation is Changing Your World, New York: McGraw-Hill.

Strauss, W. \& Howe, N. (1991), Generations: The History of America's Future, 1584 to 2069, New York: William Morrow \& Co. 
La Alfabetización Informativa $y$ el sector cultural 


\section{Alfabetización Informativa, asignatura pendiente en la Red Nacional de Bibliotecas Públicas}

DANIEL BAÑUELOS BEAUJEAN

Universidad Nacional Autónoma de México

\section{Red NaCional De Bibliotecas Públicas}

$\mathbf{E}$ 1 Programa Nacional de Bibliotecas Públicas inició formalmente el 02 de agosto de 1983 con el objetivo de permitirle el acceso gratuito a la lectura formativa, informativa y recreativa al mayor número posible de mexicanos, para cumplir tal propósito se repartieron responsabilidades a los tres niveles de gobierno.

En un país donde el total de las gubernaturas y senadurías, así como las tres cuartas partes de los diputados y la absoluta mayoría de los presidentes municipales pertenecen a un mismo partido político, no resultaba difícil cumplir con el mandato presidencial. Los números así lo constatan, al término de la administración de Miguel de la Madrid la cobertura municipal de bibliotecas públicas pasó de $10 \%$ en 1983 al 85\% en 1988, y en términos absolutos la Red Nacional de Bibliotecas Públicas (RNBP) aumentó de 351 a 3,047 recintos bibliotecarios. 
No obstante al apoyo presidencial que posibilitó la instalación de 2,696 nuevas bibliotecas públicas en menos de sesenta meses, la instrumentación jurídica que permitía la coordinación de la Red Nacional era muy endeble, pues sólo existían los convenios de colaboración que la Secretaría de Educación Pública (SEP) había firmado con los gobiernos de los estados para la puesta en marcha del Programa Nacional de Bibliotecas, los cuales tenían un programa de trabajo y acuerdos entre ambas partes hasta el año de 1988, pero no existía una norma superior que obligara a los gobiernos federales, estatales y municipales a continuar con el programa una vez que finalizara el sexenio de Miguel de la Madrid Hurtado. Es por ello que se piensa en la necesidad de contar con una ley que articule los esfuerzos de todos los actores involucrados en el diseño, instrumentación y operación de las bibliotecas públicas, así como que establezca los compromisos y obligaciones de cada uno de ellos.

En los siguientes años se tendría que continuar el esfuerzo para dotar de servicios bibliotecarios al mayor número de municipios de México; actualmente la Red Nacional está conformada por 7,298 bibliotecas públicas instaladas en 2,493 municipios, cifra que representa el $92 \%$ del total de los ayuntamientos del país. La siguiente gráfica expone el incremento en número de las bibliotecas públicas en la Red Nacional de 1983 a 2010.

La proliferación de bibliotecas públicas conformadas con material bibliográfico destinado principalmente al apoyo del sistema de educación formal básico y la dotación de material de lectura que atendía las necesidades lectoras de un arquetipo definido desde las oficinas cen- 
Alfabetización Informativa, asignatura pendiente en la Red ...

\section{Figura 3}

Manual básico para la búsqueda y recuperación de la información

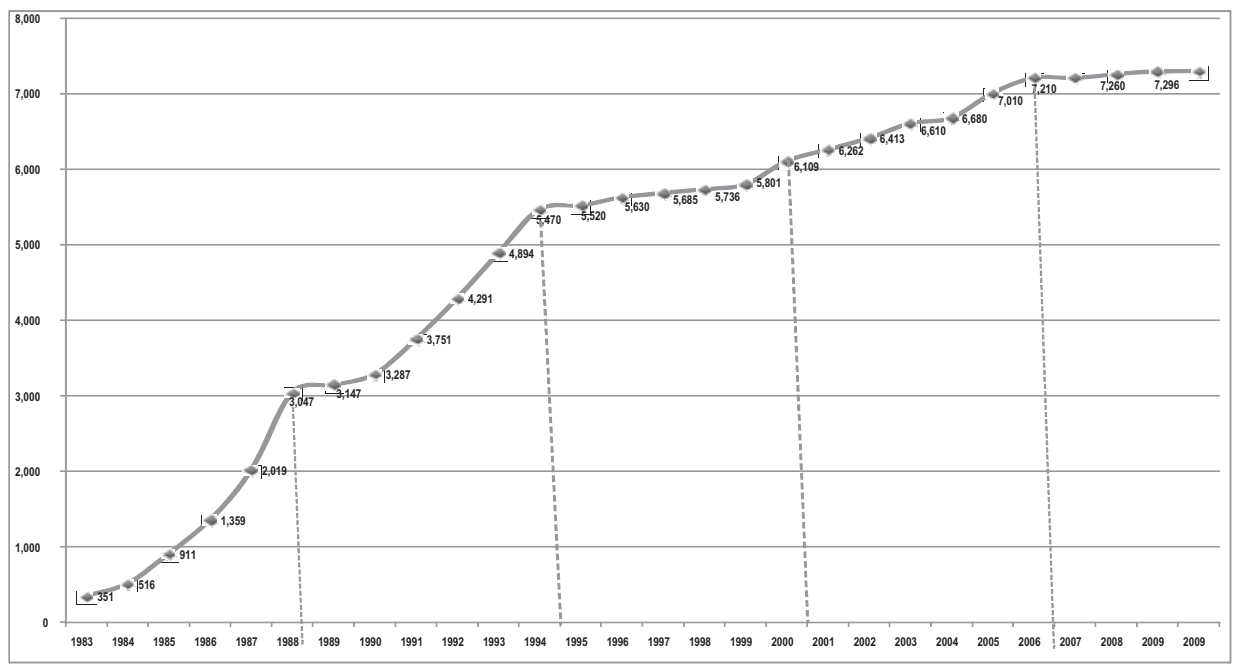

Fuente: Dirección de Operación de Biblioteca, DGB, CONACULTA

trales de la Dirección General de Bibliotecas (DGB), definió un modelo de biblioteca pública para México.

\section{DEFINICIÓN DE BIBLIOTECA PÚBLICA Y SERVI- CIOS BIBLIOTECARIOS}

El 21 de enero de 1988 se publicó en el Diario Oficial de la Federación el decreto presidencial por el cual se expide la Ley General de Bibliotecas, con la cual se establece la normatividad, identidad y visibilidad de las bibliotecas públicas. 
El Artículo $2^{\circ}$ de esta Ley, concibe a la biblioteca pública como "todo establecimiento que contenga un acervo de carácter general superior a quinientos títulos, catalogados y clasificados, que se encuentra destinado a atender en forma gratuita a toda persona que solicite la consulta o préstamo del acervo en los términos de las normas administrativas aplicables. La biblioteca pública tendrá como finalidad ofrecer en forma democrática los servicios de consulta de libros y otros servicios culturales complementarios que permitan a la población adquirir, transmitir, acrecentar y conservar en forma libre el conocimiento en todas las ramas del saber". ${ }^{1}$

Esta definición nos indica el destino y el objetivo de la biblioteca, pues queda asentado su carácter público tanto por el acceso ilimitado a toda la población a sus servicios como la atención gratuita a los usuarios de la biblioteca. Aunque para ello se condiciona que el usuario solicite en persona el servicio para el acceso al acervo y demás servicios complementarios que le permitan a la población adquirir, transmitir, acrecentar y conservar el conocimiento en todas las ramas del saber. Por otro lado, la expresión "en forma democrática" resulta ambigua, a menos que se quiera con ello decir de trato igualitario y equitativo a toda la población nacional.

1 Secretaría de Educación Pública. Ley General de Bibliotecas, México, página 64. 
Respecto a la definición de los servicios bibliotecarios debemos acudir a lo que registra el Reglamento de los servicios bibliotecarios, cuya primera versión se publica en 1985 y de la cual se desprende el Artículo $9^{\circ}$ que a la letra dice:

Los servicios básicos que la biblioteca pública otorgará a sus usuarios son: préstamo interno con estantería abierta, préstamo a domicilio, préstamo interbibliotecario, consulta, orientación a los usuarios y servicios de extensión intramuros, como el fomento al hábito de la lectura. ${ }^{2}$

Podemos advertir que los servicios bibliotecarios de la Red Nacional (RNBP) están basados en la asistencia del usuario a la biblioteca y de la solicitud que éste realice para el acceso al material bibliográfico ya sea para préstamo interno o a domicilio; sobre el préstamo interbibliotecario no existe normatividad alguna que permita la instrumentación de este servicio.

Para los dos otros servicios a los que hace referencia el reglamento se publica en 1991 el manual La orientación a los usuarios, cuyo propósito central es instruir al personal bibliotecario en la necesaria señalización de las áreas, colecciones y servicios que les permitan a los usuarios ubicarse dentro de la biblioteca. Para la DGB:

La vocación esencial de la biblioteca pública es orientar a quienes la visitan para adentrarse al mundo del conocimiento, la información y el entreteni-

2 Consejo Nacional para la Cultura y las Artes, Dirección General de Bibliotecas, Reglamento de los servicios bibliotecarios, p.11. 
miento, a través de los libros, y para lograrlo es necesario que se conozcan y aprovechen al máximo los servicios que ofrece; en la medida en que esto se logre, la presencia y el sentido de la biblioteca como espacio abierto se fortalece. ${ }^{3}$

Cabe señalar que bajo esta premisa es responsabilidad de los bibliotecarios orientar a los usuarios en los recursos y servicios de la biblioteca mas no formarlos en el uso de la información, en esta materia las bibliotecas públicas carecen de metodología alguna para la formación de los usuarios.

Como anteriormente se afirmó el objetivo del Programa Nacional de Bibliotecas Públicas era permitir el acceso gratuito a la lectura formativa, informativa y recreativa al mayor número de mexicanos, razón por la cual desde entonces las actividades de fomento al hábito de la lectura se asumieron como parte de los servicios básicos de la biblioteca pública. La DGB capacita anualmente a centenares de bibliotecarios en diversas metodologías para el encuentro del libro y la lectura con los usuarios de la biblioteca porque el hecho de "fomentar la lectura entre niños, jóvenes y adultos, es invitarlos a hacer uso de un beneficio gratuito, a intercambiar opiniones y a disfrutar de la práctica de la lectura como experiencia nueva, dinámica y divertida; una opción diferente fuera de la escuela. Al realizar actividades de

3 Consejo Nacional para la Cultura y las Artes, Dirección General de Bibliotecas, Hacia la formación de lectores en la biblioteca pública, ideas y estrategias para el bibliotecario, p. 15. 
Alfabetización Informativa, asignatura pendiente en la Red ...

fomento a la lectura en la biblioteca pública, se promueve el acervo bibliográfico". ${ }^{4}$

En los años de 2001 y 2003 se publicaron la segunda y tercera ediciones corregidas y aumentadas del Reglamento General de los servicios bibliotecarios, versiones en las que se detallan a mayor profundidad los servicios bibliotecarios, las funciones del personal bibliotecario, $\mathrm{y}$ las obligaciones y derechos de los usuarios.

La maestra Norma Aída Manzanera Silva señala que a diferencia de la primera versión del reglamento en donde se define a la biblioteca pública como institución de servicio destinada a atender en forma gratuita a toda persona que lo solicite; en la versión vigente del reglamento se las define:

[...] como establecimientos que contienen un acervo de carácter general [...] mismo que está destinado a atender en forma gratuita a toda persona que lo solicite para su consulta o préstamo, a través de distintos servicio cuyo fin es proporcionar el libre acceso a la información, al conocimiento y a la cultura en general. ${ }^{5}$

Este cambio en la definición original de biblioteca ya supone una ampliación en los servicios "tradicionales" que se ofrecían, incluso en la edición 2003 del Reglamento General de los servicios bibliotecarios aparece un apén-

\section{Ibídem.}

5 Consejo Nacional para la Cultura y las Artes, Dirección General de Bibliotecas, Reglamento general de los servicios bibliotecarios, p. 13. 
dice titulado Reglamento para el acceso y uso de los servicios digitales en bibliotecas públicas, cuyo propósito era instrumentar una serie de principios y derechos para los usuarios de la biblioteca pública en materia de acceso a las tecnologías de información y comunicación.

Seis años después de haberse publicado la normativa para el acceso y uso de los servicios digitales en bibliotecas públicas, el Poder legislativo reformó algunos artículos de la Ley General de Bibliotecas de 1988. Entre las modificaciones a esta norma se destacan las siguientes: el impulso al equipamiento, mantenimiento y actualización permanente del área de servicios de cómputo (Artículo $4^{\circ}$ ); la dotación en formato impreso y digital de publicaciones informativas, recreativas y culturales, así como la asesoría técnica en materia bibliotecaria e informática a las bibliotecas incluidas en la Red Nacional $\left(\right.$ Artículo $7^{\circ}$ ) y la actualización tecnológica de las bibliotecas que integran las redes estatales de bibliotecas $\left(\right.$ Artículo $\left.8^{\circ}\right) .^{6}$

Con estas reformas se establece como norma la incorporación de los recursos y servicios sustentados en las tecnologías de información y comunicación a los servicios bibliotecarios; con ello se buscaba tranformar profundamente el vigente modelo de biblioteca pública para que respondiera a los cambios que exigía la sociedad de información y el conocimiento.

6 Decreto. 


\section{INCORPORACIÓN DE LAS TECNOLOGÍAS DE INFORMACIÓN Y COMUNICACIÓN}

En el año 2002 operaban de manera regular 6,413 bibliotecas públicas, las cuales les permitían a sus usuarios el acceso a fuentes de información impresas a través de los servicios de préstamo en sala y a domicilio y en tan sólo 120 bibliotecas los usuarios tenían acceso al uso de una computadora para realizar principalmente trabajos escolares.

En este conjunto de bibliotecas el servicio de computadoras e Internet no se había normalizado, en algunos recintos los usuarios tenían que pagar para poder utilizar las computadoras, mientras que en otros el servicio era gratuito y en no pocas bibliotecas el servicio estaba acotado a un uso exclusivamente académico (realización de tareas e investigaciones escolares) o la impartición de un taller de cómputo, incluso en aquellas computadoras que contaban con el servicio de Internet, los usuarios tenían severas restricciones para el uso social de la tecnología pues existía la prohibición al uso del correo electrónico y el Chat.

El 28 de mayo del año 2002, el presidente de la República, Vicente Fox Quesada, presentó en la Biblioteca de México "José Vasconcelos" el Programa Nacional "Hacia un país de lectores", el cual incluía acciones puntuales enfocadas al fortalecimiento, modernización y creación de 
las Bibliotecas Públicas. ${ }^{7}$ En este evento se contó con la presencia de Bill Gates, quien a través de una videoconferencia anunció el donativo de cerca de 30 millones de dólares para dotar de computadoras, soporte técnico y capacitación a personal de bibliotecas públicas, así como la donación en especie de la empresa Microsoft México por otros diez millones de dólares en programas de software para los equipos de cómputo de las bibliotecas públicas. Además de estos recursos se contó con el apoyo del Sistema Nacional e-México de la Secretaría de Comunicaciones y Trasportes (SCT) para dotar de conectividad a las bibliotecas equipadas y el Instituto Latinoamericano de la Comunicación Educativa (ILCE) para la capacitación tecnológica del personal bibliotecario.

Para garantizar el aprovechamiento de estos recursos, la DGB instituyó el Programa de Acceso a Servicios Digitales en Bibliotecas Públicas (PASDBP) cuyo objetivo era: contribuir a mejorar la calidad de vida de las personas en comunidades de bajos ingresos brindándoles acceso a las tecnologías de la información y la comunicación a través de la Red Nacional de Bibliotecas Públicas.

7 Para Jorge Von Ziegler, Director General de Bibliotecas de 2001 a 2006, "el desarrollo y la modernización de los servicios de consulta fueron planteados en términos de la provisión de una infraestructura tecnológica que contribuyera a generar un nuevo concepto de la biblioteca pública mexicana y a transformar su organización y administración, sus acervos, contenidos y el tipo de sus servicios al público", La columna rota, p. 72. 
En palabras de la doctora María Josefa Santos, evaluadora del impacto social del programa de 2004 a 2006, "El PASDBP es la versión mexicana de PAC (Public Access Computers) que la Fundación Bill y Melinda Gates ha financiado en distintos países, como parte del Program Global Libraries que comenzó en 1997. El PASDBP es un paquete tecnológico integrado por tres componentes: el de equipamiento, consiste en dotar de computadoras e Internet a bibliotecas públicas; un proyecto de capacitación para quienes se encargarían de facilitar el uso de las computadoras y administrar el Módulo de Servicios Digitales, $y$ un proyecto de evaluación con el cual se pretendía ayudar la puesta en marcha del programa".

Para el proceso de equipamiento tecnológico se establecieron una serie de requisitos para aquellas bibliotecas beneficiadas por el programa, los que principalmente solicitaban la firma de una acta de cabildo donde se estableciera un compromiso de corresponsabilidad con las autoridades municipales para que éstas realizaran una serie de adecuaciones físicas al inmueble (espacio, impermeabilización, corriente eléctrica aterrizada, seguridad en puestas y ventanas) previo a la llegada de los equipos de cómputo.

A pesar del establecimiento de condiciones mínimas antes de la entrega de equipos informáticos en las bibliotecas públicas, el proceso de instalación de los mismos no fue tarea sencilla, pues en menos de treinta meses el

8 María Josefa Santos y Rebeca de Gortari Rabiela, Computadoras $e$ internet en la biblioteca pública mexicana, p. viii. 
número de computadoras personales en la Red Nacional creció de 1,800 equipos informáticos en 2002 a más 16 mil computadoras personales en $2006 .^{9}$

En el presente sexenio se mantiene el propósito de equipar con tecnologías de información y comunicación a las bibliotecas públicas, intención plasmada en el proyecto de cultura 2007-2012, del eje $6^{\circ}$ del Plan Nacional de Cultura, "Espaciamiento y fomento de la lectura", se desprende el apartado Desarrollo cultura infantil, cuyo objetivo número 5 señala: Ampliar el acceso a la información electrónica en las bibliotecas públicas, a través de "[...] reforzar en las bibliotecas públicas la infraestructura informática y de telecomunicaciones que mejore y fortalezca el servicio de consulta por Internet $\mathrm{y}$ otras fuentes electrónicas de información al mayor número posible de unidades de la Red Nacional, de manera que se amplíe el equipamiento que existe en la Red, derivado del apoyo de la Fundación Gates”. ${ }^{10}$

Con recursos adicionales que proporcionó el CONACULTA, en 2007 se iniciaron los trabajos para la implementación de la cuarta fase de equipamiento del programa. Actualmente 3,162 bibliotecas públicas han sido equipadas por el Programa de Acceso a Servicios Digitales en Bibliotecas Públicas, (PASDBP), esta cifra repre-

9 De enero de 2004 a julio de 2006 se distribuyeron e instalaron 15,262 computadoras personales, 2,717 impresoras láser, 6,346 fuentes ininterrumpibles de energía, 2,717 concentradores de datos y 144 proyectores en 2,728 bibliotecas públicas.

10 Consejo Nacional para la Cultura y las Artes, Programa Nacional de Cultura 2007-2012, página 141. 
Alfabetización Informativa, asignatura pendiente en la Red ...

senta el $43 \%$ del total de los recintos bibliotecarios de la Red Nacional. La tabla que se presenta a continuación muestra el número de bibliotecas beneficiadas en cada entidad federativa, así como el porcentaje cubierto en cada Red Estatal de Bibliotecas.

\begin{tabular}{||l|c|c|c||}
\hline \multicolumn{1}{|c|}{ Entidad } & $\begin{array}{c}\text { Número de } \\
\text { bibliotecas en } \\
\text { cada red estatal }\end{array}$ & $\begin{array}{c}\text { Número de } \\
\text { bibliotecas } \\
\text { equipadas por } \\
\text { PASDBP }\end{array}$ & $\begin{array}{c}\text { Porcentaje de } \\
\text { bibliotecas } \\
\text { con TIC }\end{array}$ \\
\hline Aguascalientes & 64 & 61 & $95 \%$ \\
\hline Baja California & 89 & 89 & $100 \%$ \\
\hline Baja California Sur & 57 & 43 & $95 \%$ \\
\hline Campeche & 61 & 42 & $69 \%$ \\
\hline Coahuila & 139 & 86 & $62 \%$ \\
\hline Colima & 59 & 45 & $76 \%$ \\
\hline Chiapas & 400 & 70 & $17 \%$ \\
\hline Chihuahua & 159 & 102 & $64 \%$ \\
\hline Distrito Federal & 410 & 37 & $9 \%$ \\
\hline Durango & 150 & 97 & $65 \%$ \\
\hline Guanajuato & 176 & 72 & $41 \%$ \\
\hline Guerrero & 210 & 63 & $30 \%$ \\
\hline Hidalgo & 282 & 124 & $44 \%$ \\
\hline Jalisco & 275 & 234 & $85 \%$ \\
\hline México & 662 & 170 & $25 \%$ \\
\hline Michoacán & 230 & 71 & $31 \%$ \\
\hline Morelos & 149 & 106 & $71 \%$ \\
\hline Nayarit & 82 & 60 & $73 \%$ \\
\hline Nuevo León & 142 & $45 \%$ \\
\hline & 317 & & \\
\hline
\end{tabular}


Tendencias de la Alfabetización Informativa en Iberoamérica

\begin{tabular}{||l|c|c|c||}
\hline \multicolumn{1}{|c|}{ Entidad } & $\begin{array}{c}\text { Número de } \\
\text { bibliotecas en } \\
\text { cada red estatal }\end{array}$ & $\begin{array}{c}\text { Número de } \\
\text { bibliotecas } \\
\text { equipadas por } \\
\text { PASDBP }\end{array}$ & $\begin{array}{c}\text { Porcentaje de } \\
\text { bibliotecas } \\
\text { con TIC }\end{array}$ \\
\hline Oaxaca & 466 & 215 & $46 \%$ \\
\hline Puebla & 607 & 132 & $22 \%$ \\
\hline Querétaro & 62 & 24 & $39 \%$ \\
\hline Quintana Roo & 116 & 33 & $66 \%$ \\
\hline San Luis Potosí & 178 & 66 & $57 \%$ \\
\hline Sinaloa & 141 & 122 & $76 \%$ \\
\hline Sonora & 564 & 73 & $13 \%$ \\
\hline Tabasco & 106 & 36 & $34 \%$ \\
\hline Tamaulipas & 137 & 85 & $62 \%$ \\
\hline Tlaxcala & 509 & 340 & $67 \%$ \\
\hline Veracruz & 160 & 83 & $52 \%$ \\
\hline Yucatán & 231 & 103 & $44 \%$ \\
\hline Zacatecas & 7,298 & 3,162 & $43 \%$ \\
\hline Total & & & \\
\hline
\end{tabular}

Dada la complejidad de incorporar las tecnologías de la información y la comunicación en el contexto de las bibliotecas públicas, el PASDBP implementó un intenso programa de capacitación tecnológica para los bibliotecarios, que se proponía lograr un mayor impacto en la capacitación, para lo cual contó con la participación del ILCE en el diseño de un modelo de formación presencial basado en el uso social de la 
tecnología, el cual es atravesado por dos ejes fundamentales: uno técnico y otro social. ${ }^{11}$

El primer eje destaca el uso del equipo de cómputo, sus recursos periféricos y la conectividad dispuesta en los módulos. A través de ejercicios simples los participantes adquieren seguridad y confianza en la administración y uso de la infraestructura informática y de telecomunicaciones de la biblioteca. El segundo eje profundiza en la orientación e impacto social de la tecnología y encamina a los bibliotecarios a conseguir la participación de la ciudadanía en favor de la biblioteca y la comunidad.

Las investigadoras María Josefa Santos y Rebeca de Gortari, del Instituto de Investigaciones Sociales de la UNAM, fueron las encargadas de realizar la evaluación del impacto social del PASDBP para lo que se realizaron una serie de entrevistas de campo en diversas bibliotecas, así como algunos cursos de capacitación y congresos nacionales de bibliotecas, y coordinaron también la

11 De febrero de 2004 a octubre de 2006 se capacitaron en el uso de las tecnologías de información y comunicación a 3,600 bibliotecarios. La eficiencia terminal de los bibliotecarios fue del 59 por ciento. Es decir, 6 de cada diez participantes asistieron a la totalidad de las sesiones de capacitación. El otro $41 \%$ no concluyó el proceso de capacitación principalmente por dos aspectos: ya no laboraban en la biblioteca o el municipio no le proporcionaba los recursos financieros para viajar a la sede de capacitación. 
aplicación de más de nueve mil encuestas a diversos actores relacionados con el programa. ${ }^{12}$

A continuación se presentan algunas conclusiones de las doctoras M. Josefa Santos y Rebeca de Gortari al finalizar la investigación:

- El PASDBP se distingue de otros proyectos gubernamentales y de la sociedad civil por dos aspectos fundamentales; la gratuidad en el uso del equipo de cómputo y los esfuerzos realizados para formar capacidades entre los usuarios.

- Con frecuencia se condicionaba el uso de las computadoras sólo a quienes antes consultaban el acervo (aparentemente, debido al prejuicio de que el uso de computadoras puede reducir el hábito a la lectura) en poco más del $10 \%$ de las bibliotecas encuestadas, se encontró a bibliotecarios que impedían por completo el acceso a las computadoras a los niños, bajo el pretexto de que no sabían usar el equipo y que podrían dañarlo.

- La falta de conectividad que actualmente afecta a poco menos de la mitad de las bibliotecas equipadas, es un grave problema que debe ser resuelto. Sin embargo, la posibilidad de consultar las enciclopedias electrónicas [Encarta e Enciclomedia] disponibles en

12 En la evaluación del impacto social del PASDBP un grupo de investigadores sociales acudió a 379 bibliotecas de las 32 entidades federales para aplicar encuestas a 379 bibliotecarios, 295 encargados de módulos de servicios digitales, 3,660 usuarios de las bibliotecas, 3,613 no usuarios de la biblioteca, 609 autoridades municipales y 473 autoridades escolares. 
todos los equipos, ayuda significativamente a subsanar las deficiencias observadas en muchos de los acervos en las bibliotecas. No obstante la falta de internet deja fuera una gran cantidad de recursos informativos, socioeconómicos y recreativos que contribuirían a trascender el papel tradicional de las bibliotecas públicas.

- El Programa de Acceso a Servicios Digitales en Bibliotecas Públicas (PASDBP) es uno de los pocos programas que atiende el problema de la brecha digital, no solamente desde la perspectiva del acceso, sino también en cuanto al aspecto cognoscitivo. El problema reside en que la capacitación que se imparte en la biblioteca no tiene un referente social adecuado a las necesidades de los usuarios y aún no ha trascendido a los usos tradicionales de la biblioteca.

- Los módulos de servicios digitales (MSD) están permitiendo que las bibliotecas sean más visibles en los lugares donde se localizan, lo que se refleja en un aumento en el flujo de usuarios y en el tiempo de uso de estos espacios. El MSD está contribuyendo al apalancamiento de las bibliotecas en dos sentidos: por un lado reforzando su papel tradicional, pues la búsque$\mathrm{da}$ de información sigue siendo muy importante; $y$ por el otro, cada vez más usuarios llevan a cabo actividades siociocomunicativas y de entretenimiento, principalmente en los módulos donde las restricciones son menores.

- La biblioteca pública debe adquirir nuevas responsabilidades al reforzar dos de sus actividades más legítimas: la formación de los usuarios y el impulso a even- 
tos significativos para la comunidad. Así, las bibliotecas públicas, más que limitarse al papel de guardianes de una herencia bibliográfica, deben convertirse en catalizadores de los activos culturales, educativos y sociales de cambio y contribuir a la revitalización de las comunidades. Para ello es indispensable lograr la colaboración de los sectores público y privado a fin de impulsar el nuevo papel que debe ocupar la biblioteca en una comunidad.

Precisamente de la formación de usuarios en la biblioteca pública se ocupará el siguiente apartado, presentamos un recuento de los proyectos en los cuales intervino la DGB ya sea en su creación o en apoyo a éstos.

\section{FORMACIÓN DE USUARIOS}

La formación de usuarios en las bibliotecas públicas se realiza prácticamente desde los orígenes de la Red Nacional porque las actividades de fomento a la lectura fueron parte de los servicios bibliotecarios básicos que se ofrecían a los usuarios. Dado que existió un legítimo interés para inculcar en los usuarios el gusto por la lectura recreativa y de esta forma ampliar el número de usuarios, difundir el acervo y generar nuevos servicios, la DGB puso en marcha el programa de capacitación de fomento al hábito de la lectura, el cual buscaba dotar a los

13 María Josefa Santos y Rebeca de Gortari, Acceso Tecnológico: una reinterpretación de la biblioteca pública mexicana, pp. 163-165. 
Alfabetización Informativa, asignatura pendiente en la Red ...

bibliotecarios de las metodologías, estrategias y actividades que permitieran la formación de lectores desde los recintos bibliotecarios.

Las actividades de fomento a la lectura se han realizado durante más de 25 años y quizá su cara más visible es el programa Mis Vacaciones en la biblioteca; durante los meses de julio y agosto miles de niños acuden a la biblioteca a realizar una serie de actividades lúdicas y recreativas vinculadas con la literatura.

Otra experiencia de formación de usuarios donde se registra una participación de la DGB fue el programa Computación Gratuita para los niños y jóvenes, proyecto impulsado por la Academia Mexicana de Ciencias desde 1986, que tiene por objetivo el apoyo a la enseñanza en computación a alumnos de educación básica. Esta iniciativa representa el primer esfuerzo de la Red Nacional para alfabetizar en habilidades informáticas a los usuarios de las bibliotecas públicas.

Actualmente los cursos de Computación Gratuita para los niños y jóvenes se implementa en ochenta y cinco bibliotecas públicas de los estados de Aguascalientes, Chiapas, Distrito Federal, Guanajuato, Hidalgo, Michoacán, Nuevo León y Sinaloa, en donde se imparten dos tipos de talleres; el primero, dirigido a niños de nivel primaria, a quienes se les capacita para a utilizar el lenguaje de programación "Logo"; el segundo taller está orientado a la enseñanza de las matemáticas en los alumnos de secundaria basado en "Geómetra", éste es un programa que permite el análisis y compresión de la geometría. Además desde el 2006 en algunas bibliotecas se puso en marcha el "Módulo de aplicaciones científicas", 
orientado al desarrollo de aplicaciones de robótica por parte de los niños y jóvenes participantes.

De reciente aparición en la Red Nacional, está el programa Intel Aprender, el cual es una iniciativa de la empresa Intel para la alfabetización tecnológica de niños y jóvenes que no han tenido acceso suficiente a la tecnología. El modelo pedagógico fue desarrollado por el Institute of Computer Technology de Estados Unidos para encarar la creciente brecha digital de los países en desarrollo, el programa se implementa en más de una docena de países que incluyen Argentina, Brasil, Chile, China, Egipto, India, Israel, Malasia, Palestina, Rusia, Turquía, Ucrania y México.

En México el programa Intel Aprender inicia en 2004 con el propósito de desarrollarse fuera del ámbito educativo formal y por ello se decide implementar el proyecto en programas de transferencia tecnológica con sentido social y comunitario como los Centros Comunitarios de Aprendizaje coordinados por la Secretaría de Desarrollo Social, los Centros Comunitarios Digitales instalados por el Sistema Nacional e-México y en las bibliotecas públicas de la Red Nacional. Cabe señalar que previo a la implementación del programa se tuvo la participación de la Universidad Pedagógica Nacional, institución encargada de la traducción y adaptación de los contenidos educativos, además es la responsable de la capacitación de los facilitadores de Intel Aprender.

La oferta educativa de Intel Aprender está destinada a la atención de niños y jóvenes entre 18 y 20 años, particularmente en comunidades donde existe un acceso limitado a las tecnologías en hogares y escuelas. Actual- 
mente el programa se compone de dos tipos de cursos. En el primer curso "Tecnología y Comunidad" se introduce a los participantes en habilidades tecnológicas tales como el procesador de textos, gráficos, la hoja de cálculo, el multimedia y la búsqueda por Internet. Durante el desarrollo del curso los participantes trabajan en equipo un proyecto de investigación, que atienda o resuelva uno de los problemas, carencias o retos de la comunidad donde habitan.

El segundo curso “Tecnología en el Trabajo” se muestra a los participantes cómo se emplean las computadoras en una gran variedad de trabajos y carreras, además de incrementar las habilidades al emplear mayores herramientas de software; en este curso los estudiantes también deben crear en equipo diversos proyectos que van desde el diseño de una encuesta hasta el desarrollo de un plan de gestión de recursos.

A seis años de su implementación en la Red Nacional, más de 450 bibliotecarios provenientes ${ }^{14}$ de 150 bibliotecas públicas se han capacitado como instructores del programa Intel Aprender; los resultados de esta capacitación se refleja en los más de 27 mil niños y jóvenes capacitados en veinte estados.

14 La alta rotación del personal que labora en la Red Nacional de Bibliotecas Públicas (RNBP) es un factor determinante que impide el desarrollo y evolución de los servicios. Se estima que después de cada proceso electoral para elegir a nuevos alcaldes, una tercera parte del personal bibliotecario cambia por decisión de las nuevas autoridades municipales. 
Un aspecto digno de resaltar es que al final de cada curso los alumnos participantes reciben un diploma por parte de Intel, este diploma carente de validez académica oficial es para los padres de familia un aspecto muy apreciado, pues usualmente le otorgan al diploma la categoría de "certificación" que realiza una empresa líder en desarrollo tecnológico a las competencias informáticas que tienen sus hijos.

Uno de los ejes del PASDBP fue atender el principio de necesidad, expresado como la atención a las necesidades de información de los usuarios de las bibliotecas públicas y la reducción de la brecha digital existente en nuestro país. Para atender las necesidades de información se instalaron en los discos duros de las computadoras adquiridas por el programa las bibliotecas digitales Encarta y Enciclomedia, además se gestionó con el Sistema Nacional e-México la instalación del servicio de Internet en las bibliotecas equipadas con recursos de la Fundación Bill y Melinda Gates. ${ }^{15}$

Respecto a la reducción de la brecha digital ${ }^{16}$ se trasladó a los bibliotecarios la responsabilidad de la formación

15 A pesar del compromiso del Sistema Nacional e-México para dotar de conectividad a las bibliotecas equipadas por el PASDBP; actualmente el servicio de internet no está presente en todas las 3,162 bibliotecas públicas.

16 Para el Arquitecto Pedro Cerisola, Secretario de Comunicaciones y Transportes de 2001 al 2006, brecha digital es "la división que existe entre los que tienen acceso y los que no. Esta brecha está creando un nuevo tipo de segregación social y económica basada en la información". 
de usuarios en el uso de la tecnología, particularmente en el aprendizaje de la paquetería instalada en las computadoras del programa (Office de Microsoft), para ello la DGB con el apoyo del Instituto Latinoamericano de la Comunicación Educativa (ILCE), capacitaron en materia tecnológica a más de 3,600 bibliotecarios, además se entregaron materiales impresos para la consulta rápida sobre las herramientas de Word, Excel, PowerPoint y Encarta, y se distribuyeron paquetes con 16 DVD de la serie Sep@Computo con los cursos "Introducción a la Computación", "Procesador de palabras", "Hoja electrónica de cálculo" y "Presentaciones Electrónicas". ${ }^{17}$

Derivado de la capacitación tecnológica al personal bibliotecario y la entrega de material de apoyo impreso y audiovisual, algunas bibliotecas públicas empezaron a ofrecer cursos de cómputo a sus usuarios. De acuerdo con la información generada por las doctoras Santos y de Gortari 179 de 379 bibliotecas encuestadas ofrecen diversos cursos de computación, entre los que sobresalen "Uso básico de la computadora" y "Paquetería de Office". De acuerdo con los datos proporcionados por las evaluadoras del programa, en el $47 \%$ de los bibliotecas visitadas se encontraron evidencias de formación de

17 Sep@computo fue desarrollado por la UNAM para ofrecer una alternativa de capacitación a distancia utilizando el video y la televisión. La adquisición de esta serie y su posterior entrega en 2,500 bibliotecas se realizó para que los bibliotecarios y los usuarios tuvieran acceso un tutorial que los capacitará en el uso de las computadoras y aplicaciones de paquetería. 
Tendencias de la Alfabetización Informativa en Iberoamérica

usuarios. La siguiente gráfica representa la variedad de cursos impartidos:.

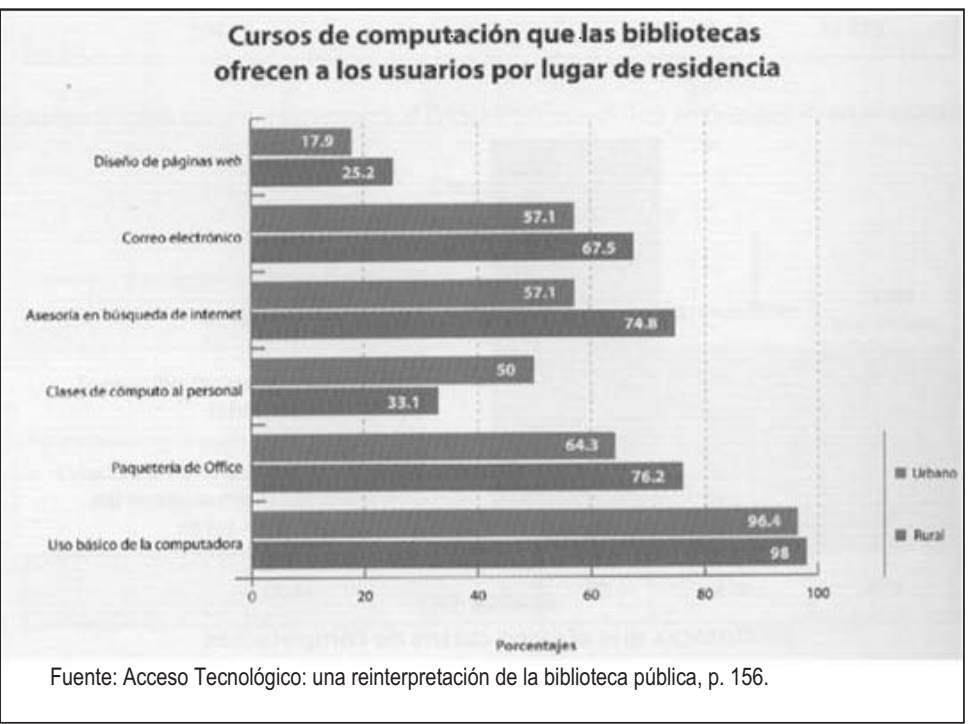

Cabe señalar que en las experiencias de formación de usuarios de las bibliotecas públicas la alfabetización informacional es aún incipiente, incluso en los proyectos más sólidos es tan reducido el número de bibliotecas donde ésta se aplica que no se podría hablar de un programa general para toda la Red Nacional, sino de un proyecto externo con objetivos y prioridades propios, pero que utiliza la infraestructura bibliotecaria pública para cumplir con sus objetivos. 
La brecha digital en México todavía es muy amplia; hoy, prácticamente siete de cada diez mexicanos carecen del acceso a Internet, realidad que pone al descubierto el incumplimiento de los objetivos del Sistema $\mathrm{Na}$ cional e-México. Esta situación se pretende cambiar con la creación en 2009 de la Coordinación de la Sociedad de la Información y el Conocimiento, la cual es responsable de promover el acceso universal a los servicios de la Sociedad de la Información y del Conocimiento a través de la promoción y difusión, de la capacitación y la adopción del uso de dichas tecnologías.

Para María Eloísa Talavera Hernández, Coordinadora General para la Sociedad de la Información y el Conocimiento, en México existen dos tipos de brecha digital una blanda y una dura; esta última se integra por la población mayor de 18 años de edad que no tiene acceso a tecnologías de información y comunicación: indígenas, migrantes, adultos mayores, personas con discapacidad, jornaleros, agrícolas, pequeños y medianos comerciantes y/o empresarios, y mujeres, niños y jóvenes en condiciones de marginación y vulnerabilidad.

Es por ello que abatir la brecha digital dura es en nuestro país una de las prioridades de la actual agenda digital y por ello se han diseñado tres proyectos articuladores orientados a masificar la apropiación de la tecnología (Campaña Nacional de Inclusión Digital Vasconcelos 2.0); facilitar el acceso (plataforma e-México 2.0) y hacer universal la conectividad (redes de cobertura social). 


\section{CONCLUSIONES}

Las bibliotecas públicas en el siglo XXI están llamadas a jugar un papel cada vez más activo en el proceso democratizador de acceso a la información de los ciudadanos, esta tarea es imposible realizarla sin la incorporación de los recursos informáticos y de telecomunicaciones. En este sentido es imprescindible que se mantenga la tarea de equipar con tecnologías de información y comunicación al cien por ciento de los recintos bibliotecarios que integran la Red Nacional de Bibliotecas Públicas, tal como lo establece la vigente Ley General de Bibliotecas.

La incorporación de los equipos informáticos a la biblioteca pública ha ocasionado la integración de otros agentes sociales, quienes tienen necesidades de información distintas al usuario tradicional (estudiante de educación básica y media superior). Esta situación deberá configurar nuevos servicios bibliotecarios orientados a las nuevas necesidades, gustos e intereses de los usuarios $\mathrm{y}$ los actuales soportes y medios donde se almacena y viaja la información.

Esta transformación debe trascender de la incorporación de las computadoras e Internet a la biblioteca pública, a la conformación de una serie de servicios orientados al ejercicio del derecho al acceso a la información, que a su vez le permita a la ciudadanía conocer su entorno, tomar mejores decisiones e incorporarse con mayores herramientas a la Sociedad de Información y del Conocimiento. En la evolución de los servicios bibliotecarios la alfabetización informacional deberá ocupar un papel primordial en las tareas habituales de las bibliotecas públicas de la Red Nacional. 


\section{BIBLIOGRAFÍA}

Consejo Nacional para la Cultura y las Artes, Dirección General de Bibliotecas, Hacia la formación de lectores en la biblioteca pública, ideas y estrategias para el bibliotecario, México, D. F.: CONACULTA, 2003, 187pp.

Consejo Nacional para la Cultura y las Artes, Dirección General de Bibliotecas, Reglamento Genera de los servicios bibliotecarios, Serie: leyes y reglamentos, México, D. F.: CONACULTA, 2005, 39pp.

Consejo Nacional para la Cultura y las Artes, Programa nacional de cultura 2007-2012, México, D. F.: CONACULTA, México, D. F.: CONACULTA, 2007, 232pp.

México, Secretaría de Educación Pública, Dirección General de Publicaciones y Bibliotecas, Ley general de bibliotecas: texto y debate parlamentario, México, D. F.: SEP, 1988, 69pp.

Santos, María Josefa y De Gortari, Rebeca, Acceso tecnológico: una reinterpretación de la biblioteca pública mexicana, México, D. F.: CONACULTA, 2006, 194 pp.

Santos, María Josefa y De Gortari, Rebeca, Computadoras e Internet en la biblioteca pública mexicana, México, D.F.: Universidad Nacional Autónoma de México y Pearson Education de México, 2009, 192pp.

Secretaría de Educación Pública, Dirección General de Publicaciones, Reglamento de los servicios bibliotecarios, México, D.F.: SEP, 1985, 19pp.

Ziegler, Jorge von, La columna rota: la biblioteca de México o la voluntad de construir, México, D. F: Océano, 2006, 128p. 


\section{Información y educación no formal en el Instituto Nacional de Antropología e Historia a través de su Programa de Trabajo}

Miguel NÁJERA PÉREZ

Instituto Nacional de Antropología e Historia

\section{INTRODUCCIÓN}

G 1939 se fundó el Instituto Nacional de AntropoUlogía e Historia (INAH) con la finalidad de garantizar la investigación, conservación, protección y difusión del patrimonio prehistórico, arqueológico, antropológico, histórico y paleontológico de México. La creación del INAH, al igual que otros organismos del gobierno federal, colabora en la preservación de nuestro patrimonio cultural.

El Instituto realiza sus labores sustantivas a través de diferentes áreas administrativas en la Ciudad de México, así como en los centros regionales, distribuidos en los 31 estados de la República.

Este organismo es responsable de más de 110 mil monumentos históricos construidos entre los siglos XVI y $\mathrm{XIX}, \mathrm{y}$ "29 mil zonas arqueológicas registradas en todo el país; de estas últimas, sólo 178 están abiertas al público”. 
Asimismo, tiene a su cargo 116 museos en el territorio nacional divididos en categorías obedeciendo a la amplitud y calidad de sus colecciones, su situación geográfica y el número de sus visitantes.

Una de las tareas fundamentales del INAH es la investigación, para lo cual colaboran más de 800 académicos en las áreas de historia, antropología social, arqueología, lingüística, etnohistoria, etnología, antropología física, arquitectura, conservación y restauración del patrimonio.

Las labores de investigación se complementan con la formación de profesionales en sus tres escuelas superiores: la Escuela Nacional de Conservación, Restauración y Museografía y la Escuela Nacional de Antropología e Historia, esta última, con sede en la ciudad de México y en la ciudad de Chihuahua.

El INAH, por otra parte, integra un importante conjunto de acervos documentales, como en la Biblioteca Nacional de Antropología e Historia, que reúne una de las mayores colecciones bibliográficas y documentales de carácter histórico y antropológico en México.

También contamos con otros acervos no menos importantes, la Fototeca Nacional del INAH (en la ciudad de Pachuca, Hidalgo), donde se custodia una verdadera riqueza iconográfica; se cuenta también con una Fonoteca dedicada al registro y la conservación de testimonios de tradición musical y oral.

Durante el año 2009 tuvimos la oportunidad de recibir a más de 16 millones y medio de visitantes distribuidos de la siguiente manera: 
Información y educación no formal en el Instituto Nacional ...

\begin{tabular}{|l|c||}
\hline \multicolumn{1}{|c|}{ INAH } & VISITANTES 2009 \\
\hline Zonas Arqueológicas & $9,186,160$ \\
\hline Monumentos Históricos & 274,921 \\
\hline Museos & $6,959,272$ \\
\hline Bibliotecas & 117,119 \\
\hline Total General: & $16,537,472$ \\
\hline
\end{tabular}

De acuerdo con las estadísticas de lo que va del año, se considera que se puede superar la meta en un $25 \%$, lo cual nos habla del interés del público por conocer e investigar sobre nuestro pasado.

Las actividades de difusión del patrimonio se realizan no sólo con un vasto programa de publicaciones periódicas, sino también a través de ferias de libro, y la producción de fonogramas y videogramas, además de comunicados para los medios informativos. También se cuenta con un portal de Paseos Virtuales con el que se pueden recorrer a distancia Zonas Arqueológicas, Sitios, Museos y Exposiciones.

De manera general, esto es el Instituto Nacional de Antropología e Historia, cuya presencia institucional está en todo el país y cuya participación en la sociedad es permanente para mantener salvaguardar y difundir el patrimonio cultural.

\section{LOS MUSEOS Y BIBLIOTECAS DEL INAH ANTE LA SOCIEDAD}

De acuerdo con las colecciones contenidas y las temáticas abordadas en cada uno de los museos, podemos co- 
nocer un pasaje de la historia nacional, estatal, o bien reforzar los conocimientos sobre una localidad, un sitio histórico o arqueológico. En otras palabras contamos con museos nacionales, regionales, locales, de sitio y comunitarios.

Una de las herramientas más utilizadas hasta ahora en los museos es el lenguaje visual, ya que a través de la presentación de objetos los visitantes pueden iniciar una relación de acercamiento, misma que varía según la necesidad de cada persona. Hoy en día la tecnología les permite una mayor interacción a los visitantes, y también se los motiva a desarrollar sus sentidos a través de sonidos, olores y superficies con lo cual el público se convierte en parte del museo.

Durante el 2009, el INAH contó con la visita de casi 7 millones de personas a sus 116 museos. Los visitantes tuvieron la oportunidad de recibir la propuesta educativa que ofrece el Instituto y a partir de ello, enriquecer su conocimiento.

\section{LOS SERVICIOS EDUCATIVOS}

Para el Instituto es muy importante considerar al museo como un espacio educativo donde se contribuye de manera significativa en la formación y promoción de la cultura, teniendo en claro que el aprendizaje dependerá de cada individuo.

Las exposiciones presentadas en los museos, ya son, por sí mismas, un cúmulo de información; sin embargo, existen otros elementos de apoyo, o detonadores de interés, para nuestros visitantes, como es el área de Servicios Educativos. Esta área se encarga de complementar 
Información y educación no formal en el Instituto Nacional ...

la visita al museo, para asegurar la comprensión de los temas vistos durante el recorrido.

Entre las actividades que podemos enunciar, encontramos, entre otras:

- Visitas guiadas,

- Conferencias,

- Talleres de Artes,

- Teatro y titeres,

- Cursos,

- Seminarios,

- Proyección de películas y videos,

- Edición de material didáctico,

- Impresión de monografías o publicaciones especiales,

- Audioguías y

- Atención a escuelas.

Con respecto a la atención a escuelas, nuestro público es principalmente el de educación básica, pero habrá que reconocer, que en algunas ocasiones, no es posible ofrecer atención a todos los usuarios por falta de recursos o infraestructura.

Es importante recordar lo que nos dice Luz Maceira, ${ }^{1}$ con respecto a los tres niveles de comunicación para divulgar el conocimiento que tratan de emplear los museos: el emotivo, el didáctico y el lúdico.

1 L. Maceira, (2008), Los museos, espacios para la educación de personas jóvenes y adultas, en:

http://tariacuri.crefal.edu.mx/decisio/d20/index.php 
- El emotivo consiste en producir emociones en el público a través de la evocación y de la experiencia estética que se genera mediante la museografía.

- El nivel didáctico implica brindar información organizada y sintetizada para la interpretación o lectura de los temas de la exposición.

- La comunicación lúdica supone la participación directa del público manipulando objetos o realizando actividades en la exposición o talleres.

En todos los museos del INAH se busca cubrir estos niveles de comunicación, pero es claro que existen factores que dificultan la actividad, sin embargo, estamos abiertos para compartir experiencias que ayuden a mejorar nuestro trabajo.

\section{DE LAS BIBLIOTECAS}

El INAH integra un importante conjunto de acervos documentales distribuidos a través de sus 68 bibliotecas en todo el territorio nacional, a través de museos, escuelas, centros de investigación y áreas administrativas.

Tan sólo en la Biblioteca Nacional de Antropología e Historia (BNAH), se reúne una de las mayores colecciones de publicaciones periódicas y bibliográficas de carácter histórico y antropológico en México, además de fondos documentales, fotográficos, sonoros, fondos conventuales y especialmente la colección de testimonios pictográficos mejor conocidos como códices. 
Información y educación no formal en el Instituto Nacional ...

$\mathrm{La} \mathrm{BNAH}$, realiza las funciones propias de cualquier biblioteca, se da a la tarea de fungir como biblioteca central de la Red de Bibliotecas del INAH y, con la finalidad de hacer más sencillo el trabajo técnico de las bibliotecas que no cuentan con personal especializado, se brinda asesoría y capacitación técnica en aspectos de organización bibliotecológica, así como soporte informático y conservación documental.

A través de ciclos de conferencias se difunden los acervos de la biblioteca, como por ejemplo, el Ciclo de Conferencias sobre Códices, para lo cual cuenta con la colaboración de investigadores nacionales y extranjeros. En estos eventos destaca la gran cantidad de público especializado, estudiantil y en general aquél que se interesa en conocer sobre nuestro pasado.

La BNAH colabora en el proceso de formación de estudiantes de bibliotecología ya sea para realizar su estancia profesional o para reforzar sus conocimientos de restauración y conservación, como es el caso de los alumnos de archivonomía. Para esto se cuenta con restauradores profesionales que acompañan a los estudiantes en el mejoramiento de su técnica brindándoles asesoría permanente según la requieran.

La Biblioteca ofrece sus servicios vía electrónica en el sitio web www.bnah.inah.gob.mx. También periódicamente se realizan exhibiciones de algunos de sus documentos; prestamos de obra para exposiciones nacionales; se elaboran trípticos informativos y se colabora con el Museo Nacional de Antropología para enriquecer con material bibliográfico las exposiciones temporales que se estén presentando. 
En lo referente a fondos bibliográficos y documentales, el Instituto Nacional de Antropología e Historia busca de manera permanente contribuir a la Sociedad de Información a través de la difusión y conservación de sus colecciones; por ejemplo, en 1997 se inscribió la colección de códices en resguardo del INAH al Programa de Memoria del Mundo de la UNESCO, lo cual permitió que toda la colección se pudiera digitalizar en alta resolución, con los beneficios que ello implica para los procesos de investigación, toda vez que también le permite al usuario poder manipular la copia digital para destacar detalles que a simple vista el ojo humano no puede distinguir.

También durante el 2010, el INAH contribuyó en el proyecto de la Biblioteca Digital Mundial con cinco de sus códices para su consulta en la web. Éstos son: el Códice Colombino, el Códice Chavero de Huexotzingo, El Mapa de Sigüenza, el Códice de Huamantla y la Matrícula de Tributos.

Estamos seguros que el INAH seguirá participando en la difusión de sus colecciones e investigaciones a través de las tecnologías existentes y "hasta en las que aun no se han inventado", realizando para ello estudios de público y enriqueciendo sus programas de formación de profesionales.

Todas estas acciones permiten difundir los acervos de la biblioteca y colaboran en la formación de un público lector al ofrecer servicios de calidad. 
Información y educación no formal en el Instituto Nacional ...

\section{Programa ANUAL de Trabajo INAH y SU EVALUACIÓN}

El INAH permanentemente se evalúa para determinar el impacto que tiene con la sociedad, por lo cual ha desarrollado el Sistema de Evaluación de la Gestión Institucional (SEGEI) como parte de las acciones para "[...]fomentar una administración eficiente, eficaz y de alta calidad, para cumplir con sus objetivos sustantivos de investigar, difundir y conservar el patrimonio cultural".

Los esquemas de trabajo que desarrolla el Instituto están enfocados a conseguir estos objetivos, entre los cuales destaca la implementación de una serie de Programas de Acción, que vinculan los Ejes del Programa de Trabajo INAH 2007-2012 y sus respectivos objetivos generales, con los Programas Presupuestarios de la Secretaría de Hacienda y Crédito Público (SHCP), bajo los cuales se le ministran recursos al INAH, y sobre los que se han desarrollado una serie de indicadores institucionales en conjunto con las áreas para el ejercicio fiscal 2011. Todo ello permitirá evaluar en forma global la labor del Instituto.

Se diseñó una metodología para desarrollar el Programa Anual de Trabajo (PAT) 2011 de todas las áreas del Instituto, conforme al esquema de 25 Programas de Acción, lo que permite conseguir un engranaje entre las distintas actividades que desarrolla el INAH.

2 Instituto Nacional de Antropología e Historia. (2010), Sistema de Evaluación de la Gestión Institucional, México: INAH, 
Finalmente todas estas actividades son puestas a consideración de un Gabinete de Evaluación Interna, que es el responsable de la interpretación de este cúmulo de información y de estar en posibilidad de mejorar el desempeño de nuestras funciones.

\section{Construcción de los Programas de ACCIÓN}

Se plantearon estos Programas de Acción conforme a las actividades reportadas por las áreas durante el 2010 y de acuerdo con los Objetivos Generales de los Ejes Temáticos del Programa de Trabajo del INAH.

Otro punto relevante en su concepción fue la integración de los Indicadores Institucionales, los cuales se crearon a partir de los Programas Presupuestarios del INAH.

Con ello se construyeron 25 Programas de Acción, 23 de ellos enfocados a las actividades sustantivas y 2 de ellos se relacionan con acciones de índole administrativa.

Cada Programa de Acción está relacionado con el Programa de Trabajo INAH 2007-2012 y con los Ejes Temáticos de acuerdo con los siguientes esquemas.

\section{Objetivos de los Programas de Acción}

Los objetivos de dichos programas son:

- Vincular los Ejes del Programa de Trabajo INAH 2007-2012, con los Programas Presupuestarios SHCP, los Indicadores Institucionales y las Actividades PAT. 
Información y educación no formal en el Instituto Nacional ...

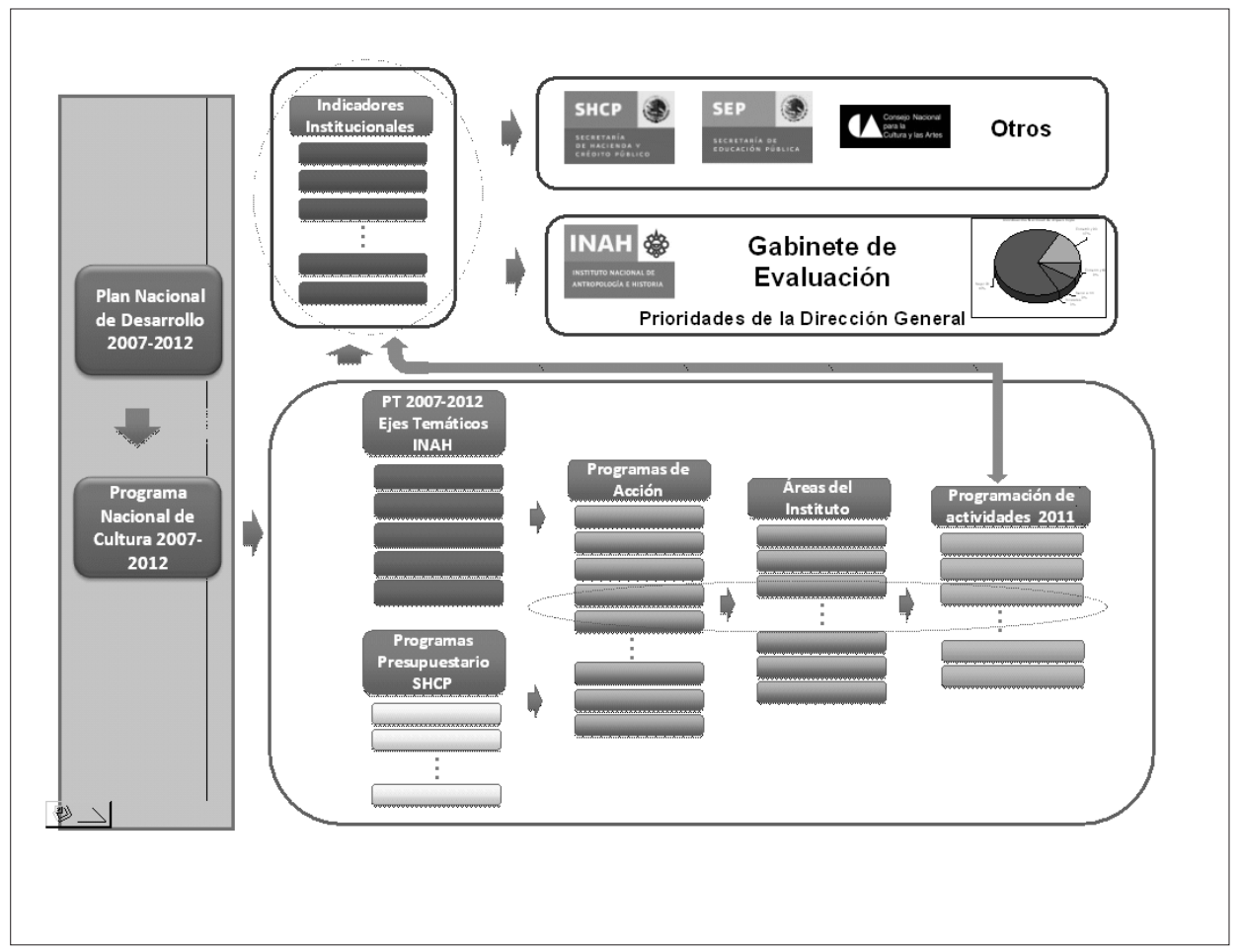

- Reflejar de manera integral y vinculatoria la totalidad de acciones que realizan tanto las áreas sustantivas como las de apoyo administrativo.

- Evaluar las Actividades, las Áreas, los Ejes del Programa de Trabajo y los Programas Presupuestarios, bajo un mismo modelo. 
Tendencias de la Alfabetización Informativa en Iberoamérica

\section{DESARROLLO DEL PROGRAMA DE TRABAJO}

\section{Eje 1. Patrimonio y diversidad cultural}

Objetivos Generales

- Inventario, catalogación y registro del patrimonio cultural tangible e intangible bajo custodia y normatividad del Instituto.

- Protección técnica y legal del patrimonio cultural mueble e inmueble.

- Evaluación y planificación de la infraestructura cultural.

- Aprovechamiento de sitios y zonas históricos patrimoniales y reglamentación de su uso.

- Diversidad cultural, culturas populares y pueblos indígenas.

- Coordinación interinstitucional y gubernamental en la preservación del patrimonio cultural.

- Participación social para la preservación del patrimonio cultural.

- Información y comunicación para la preservación del patrimonio cultural de propiedad federal.

\section{Eje 1. Patrimonio y diversidad cultural}

Programas de Acción

1. Registrar, catalogar e inventariar el patrimonio cultural

- Se refiere a: piezas registradas y catalogadas, monumento histórico inmueble catalogado, acervo inventariado y/o catalogado, actas con- 
Información y educación no formal en el Instituto Nacional ...

ciliadas de inventario, registro a sitios y monumentos históricos y arqueológicos, actualización de registros, catálogos e inventarios, digitalizar acervos.

2. Proteger técnica y legalmente el patrimonio cultural

- Se refiere a: otorgar asesorías técnicas y legales de las posibles afectaciones al patrimonio cultural, trámites de regulación, delimitación a zonas de monumentos arqueológicos y zonas de monumentos históricos, acciones de rescates y salvamentos arqueológicos, atención a denuncias, trámites INAH, visitas de inspección, planes de manejo.

3. Fortalecer acciones enfocadas a la diversidad cultural

> Se refiere a: compilar y difundir el patrimonio cultural intangible, culturas populares e indígena.

4. Realizar acuerdos y convenios interinstitucionales, gubernamentales y con la sociedad civil

> Se refiere a: realizar convenios y/o acuerdos con dependencias del Gobierno Federal, Estatal o Municipal, con organizaciones civiles y con instituciones de educación superior.

5. Conservar y restaurar el patrimonio cultural mueble e inmueble por destino

- Se refiere a: bien mueble intervenido en talleres o in situ, bien inmueble por destino intervenido en talleres o in situ, colección de bienes restaurados, mantenimiento a piezas de exposición. 
Tendencias de la Alfabetización Informativa en Iberoamérica

6. Brindar seguridad a la infraestructura del INAH

- Se refiere a: mantenimiento a equipo de seguridad de museos y zonas arqueológicas, instalación de equipo de seguridad, PREVINAH.

\section{Eje 2. Infraestructura cultural}

Objetivos Generales

> Infraestructura cultural nacional.

> Proyectos especiales.

Programas de Acción

7. Conservar y restaurar el patrimonio cultural inmueble

- Se refiere a: patrimonio cultural inmueble restaurado, actividades de conservación de inmuebles.

8. Realizar mantenimiento menor al patrimonio cultural y a la infraestructura bajo custodia del INAH

- Se refiere a: mantenimiento menor al patrimonio cultural e infraestructura, sala de exposición conservada y/o adecuada, programa de empleo temporal.

9. Mantener y realizar obra pública a la infraestructura y ampliar el patrimonio cultural bajo resguardo del INAH

- Se refiere a: espacio arquitectónico renovado, sala de exposición reestructurada y abierta al público, obras realizadas en el patrimonio cultural, programa de obras del INAH, zonas arqueológicas de nueva apertura y nuevos espacios museológicos abiertos al público. 
Información y educación no formal en el Instituto Nacional ...

Eje 3. Promoción cultural nacional e internacional

Objetivos Generales

- Programación de la difusión y divulgación del patrimonio cultural tangible e intangible.

> Difusión.

> Intercambio internacional.

- Cooperación y fortalecimiento institucionales.

> Estudios y creación de públicos.

Programas de Acción

10. Realizar exposiciones temporales y permanentes

> Se refiere a: exposiciones internacionales, nacionales e itinerantes.

11. Editar, publicar y difundir material editorial

- Se refiere a: edición, impresión, encuadernación, publicación y distribución de libros y revistas.

12. Prestar servicios culturales

> Se refiere a: usuario o visitante atendido en bibliotecas, fototeca, fonoteca, eventos académicos y/o actividad cultural, acervos consultados.

13. Ofrecer eventos académicos

- Se refiere a: ponencias, conferencias, jornadas, cursos y talleres para el público en general.

14. Difundir en medios masivos de comunicación la cultura

- Se refiere a: cápsulas de video, radio, boletines de prensa, conferencias de prensa, entrevistas, páginas de Internet para ser consultadas, inserciones en periódicos. 
Tendencias de la Alfabetización Informativa en Iberoamérica

15. Realizar material de difusión cultural

> Se refiere a: impresión de material de divulgación como trípticos, folletos, volantes, cuadernillos de eventos culturales y exposiciones a realizarse en inmuebles del Instituto.

16. Realizar actividades culturales

> Se refiere a: feria del libro, presentaciones de libros, conciertos, festivales, ciclos de cine, obras de teatro.

Eje 4. Formación e investigación antropológica, histórica y cultural

Objetivo General

> Formación e investigación en antropología, historia y conservación del patrimonio cultural.

Programas de Acción

17. Realizar investigaciones antropológicas, arqueológicas, históricas y culturales

- Se refiere a: proyectos de investigación, libros elaborados y/o dictaminados, artículos elaborados y/o publicados, apoyo a proyectos individuales o colectivos, realización de conferencias magistrales, seminarios, coloquios, diplomados, SNI, Premios INAH.

18. Formar profesionales

- Se refiere a: permanencia de alumnos en los programas educativos, eficiencia terminal: egresados y titulados de las escuelas del Instituto, aspirantes inscritos, prácticas de campo. 
Información y educación no formal en el Instituto Nacional ...

19. Actualizar y capacitar a la planta docente

- Se refiere a: pertinencia de la planta docente en licenciatura y posgrado, actualización de profesores, calidad de la planta docente.

20. Actualizar y adecuar los planes y programas de estudio

- Se refiere a: actualizar y/o adecuar los planes de estudio, evaluar y/o acreditar programas, reconocer los planes de estudio.

21. Otorgar becas

- Se refiere a: otorgamiento de becas a estudiantes de educación superior y posgrado, seguimiento general a los distintos programas de becas en los que participan las escuelas del INAH.

\section{Eje 5. Cultura y turismo}

Objetivos Generales

> Oferta turística cultural.

- Sensibilización y capacitación de las comunidades locales.

Programas de Acción

22. Ofrecer turismo cultural

- Se refiere a: proyectos de SECTUR con participación del INAH, paseos culturales.

23. Generar estadísticas de visitas a espacios culturales

- Se refiere a: visitas a museos, zonas arqueológicas y monumentos históricos, así como las visitas guiadas que se ofrecen. 
Tendencias de la Alfabetización Informativa en Iberoamérica

\section{Eje 6. Actividades de apoyo administrativo}

Programas de acción

24. Gestionar las actividades administrativas

> Se refiere a: actividades de apoyo administrativo en las áreas de recursos humanos, financiero y materiales, capacitación al personal del Instituto, atención de solicitud de apoyo, atención de solicitudes de información de instancias externas, captación de recursos financieros, acciones enfocadas al SPC.

25. Realizar actividades de planeación y mejora de la gestión

- Se refiere a: evaluaciones de las acciones y actividades realizadas por las áreas administrativas y sustantivas del instituto, desarrollo de sistemas informáticos, implementación del sistema de control y evaluación gubernamental, acciones realizadas en la mejora regulatoria interna, modernización y profesionalización del servicio público en el Instituto, realización de auditorías internas a las áreas administrativas y operativas del Instituto, creación y revisión de manuales internos, programas de ahorro.

Al final del día, toda la infraestructura, las actividades y los programas de trabajo que desarrolla el INAH tienen que verse reflejados en las miradas de nuestros visitantes, en su asombro o confirmación de lo que imaginaron o leyeron previamente porque, a fin de cuentas, el ser humano siempre es el mismo sólo cambia su circunstancia. 


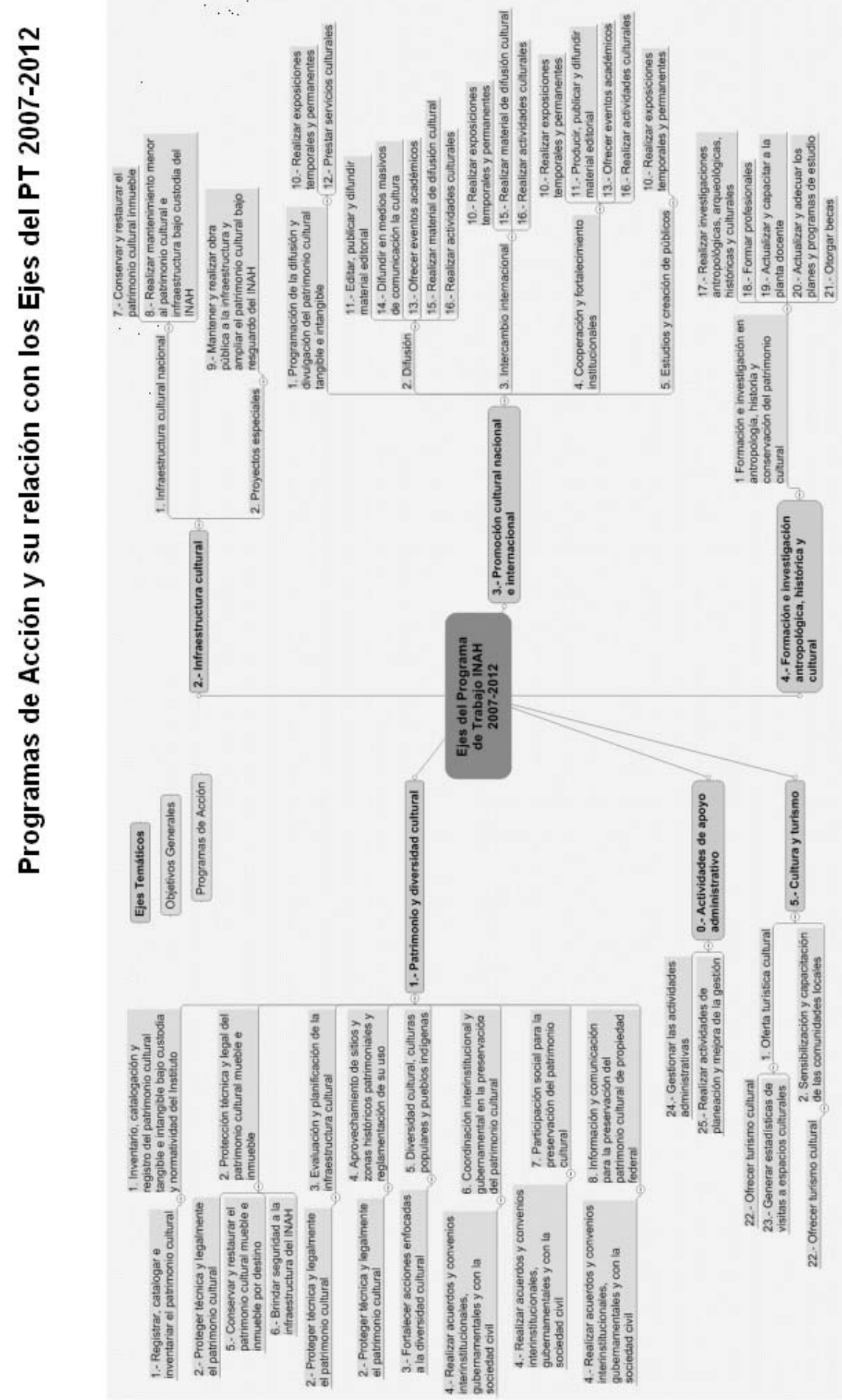


NUESTROS PENDIENTES FRENTE A LA FORMACIÓN Y EDUCACIÓN NO FORMAL EN LAS INSTITUCIONES GUBERNAMENTALES

Está claro que existen grandes esfuerzos por parte de los especialistas para hacer un trabajo de calidad frente al público visitante y colaborar en su proceso de aprendizaje. Sin embargo, no existe una manera efectiva para comprobar el impacto de la información en cada persona. Si a esto agregamos la falta de infraestructura y personal en muchos lugares, la falta de interés de los mismos visitantes y maestros, podemos darnos cuenta que el proceso de aprendizaje no siempre está garantizado.

Tampoco debemos olvidar que la elaboración de métodos y propuestas para evaluarnos ayuda a organizarnos en el cumplimiento de las funciones, pero necesariamente, tiene que existir el compromiso de los actores para llevar a buen término los proyectos o planes de trabajo.

Pero lo verdaderamente urgente, desde mi punto de vista, es la necesidad de unificar estrategias de desarrollo en las áreas gubernamentales, considerando que en algunos casos su relación es muy directa, como por ejemplo: el Conaculta es una institución que coordina al Canal 22, el Centro Cultural Tijuana, el Instituto Mexicano de Cinematografía, el Instituto Nacional de Bellas Artes y Literatura, la Dirección General de Bibliotecas Públicas y por supuesto el Instituto Nacional de Antropología e Historia, entre otros.

En estas importantes áreas se cuenta con bibliotecas o centros de información, que en principio se supone que son herramientas fundamentales para el desarrollo de la 
Información y educación no formal en el Instituto Nacional ...

investigación pero tristemente, si indagamos con cuidado, se llega a apreciar que existen graves carencias y desigualdad en cosas fundamentales, como la utilización de diferentes tipos de software para la atención a un mismo problema, tener un catálogo automatizado. El equipo de cómputo, en muchas ocasiones va desde sus formas más arcaicas hasta la tecnología de punta más sofisticada. El acceso a bases de datos es una necesidad, pero muchas bibliotecas, si bien les va, sólo llegan a un catálogo tarjetero.

La respuesta para encontrar posibles soluciones es la creación de Consejos Especializados conformados, no sólo de funcionarios de alto nivel, que mucho ayudan en la gestión, sino también de especialistas en materia de bibliotecología o manejo de información, donde todos ellos tengan un mismo peso para dar sus puntos de vista y puedan en conjunto presentar un frente común para solucionar problemas similares.

Se tienen que reconocer, por supuesto, los grandes esfuerzos de nuestras instituciones por formar parte de la Sociedad de la Información o del Conocimiento, pero también tenemos que reconocer que mientras las tecnologías no lleguen en igualdad de condiciones a estas instituciones, habrá un vacío de las investigaciones, en los alumnos y en futuros profesionales y funcionarios. 


\section{BIBLIOGRAFÍA CONSULTADA}

Hernández, H. (1988), El museo como espacio de comunicación, España: TREA,

Instituto Nacional de Antropología e Historia. (2010), Paseos culturales, México: INAH, en: http://www.paseos.culturales-inah.gob.mx

Instituto Nacional de Antropología e Historia (2007), Programa de Trabajo 2007-2012, México : INAH,

Instituto Nacional de Antropología e Historia, (2010), ¿Quiénes somos? México: INAH, en: http://www.inah.gob.mx/ index.php/iquienes-somos

Instituto Nacional de Antropología e Historia, (2010), Sistema de Evaluación de la Gestión Institucional, México: INAH,

Morales, E. (2006), Infodiversidad y cibercultura : globalización e información en América Latina, Buenos Aires : Alfagrama,

Maceira, L. (2008), Los museos, espacios para la educación de personas jóvenes y adultas, en: http://tariacuri.crefal.edu. $\mathrm{mx} / \mathrm{decisio} / \mathrm{d} 20 /$ index.php

Monfasani, R. (2008), Usuarios de la información: formación y desafíos, Buenos Aires : Alfagrama,

Payo, L. (2008), "Alfabetización informacional: una breve reflexión sobre el tema”, en $A C I M E D, 17(2), 18-32$. Obtenido de Fuente Académica database.

Placeres, G. (2008), “Aproximaciones teóricas a la evaluación de la alfabetización informacional en la educación superior", en $A C I M E D, 18(1), 1-12$, Obtenido de Fuente Académica database. 
Información y educación no formal en el Instituto Nacional ...

Salvador Oliván, J. A. (2008), Recuperación de la información, Buenos Aires: Alfagrama, 2008, 222 p. (Biblioteca Alfagra$\mathrm{ma})$.

Taller Unesco sobre Formación de Formadores en Alfabetización informacional, (2008), Boletín de la Asociación Andaluza de Bibliotecarios, 22(90/91), 245-249, obtenido de Fuente Académica database.

Valdés, M. (2008), "Metodología para el desarrollo y aplicación del Programa de alfabetización informacional en las bibliotecas y centros de información en ciencias de la salud", en $A C I M E D, 18(5), 1-8$, obtenido de Fuente Académica database. 
Formación profesional para alfabetizar informativamente 


\section{Entre noveles y hacedores \\ JUDITH LICEA DE ARENAS \\ $U N A M$ \\ JosÉ ANTONIO GÓMEZ-HERNÁNDEZ \\ Murcia, España}

\section{INTRODUCCIÓN}

Qué se necesita hoy en México para disminuir las deSigualdades y alcanzar la equidad en la distribución de la riqueza y de la cultura de una población de $111 \mathrm{mi}$ llones de habitantes, caracterizada por una pobreza casi generalizada y con escasas oportunidades para superar los rezagos sociales? La educación y, en particular, la alfabetización informacional, sin duda, podrían contribuir pero ¿cómo y con quiénes puede llevarse a la práctica esa convicción?

Los siguientes números pretenden ayudar a comprender las palabras antes mencionadas: 
Tendencias de la Alfabetización Informativa en Iberoamérica

\begin{tabular}{|c|c|}
\hline Población del país (millones) & $112,468,855$ \\
\hline 0-14 años & $32,255,701$ \\
\hline 15-24 años & $20,854,096$ \\
\hline 25-59 años & $49,040,144$ \\
\hline 60 o más años & $10,318,914$ \\
\hline Población analfabeta & $5,406,742$ \\
\hline $\begin{array}{l}\text { Población en zonas urbanas con acceso a la Internet } \\
\text { (millones) }\end{array}$ & 22.7 \\
\hline $\begin{array}{l}\text { Población en zonas no urbanas con acceso a la Internet } \\
\text { (millones) }\end{array}$ & 4.9 \\
\hline Población en la opulencia (millones) & 1 \\
\hline Excluidos por la pobreza (millones) & 50 \\
\hline $\begin{array}{l}\text { Ninis millones de jóvenes entre } 15 \text { y } 19 \text { años (ni es- } \\
\text { tudian ni trabajan) }\end{array}$ & 7.5 \\
\hline \multicolumn{2}{|c|}{$\begin{array}{l}\text { Fuentes: www.census.gov/ipc/www/ibd/groups.php; } \\
\text { https:stats.uis.unesco.org/unesco/Tableviewer/tableview.aspx?Report1d } \\
\text { =210-Worlddataoneducation; } \\
\text { www.amipci.org.mx/estudios/temp/Estudiofinalversion1110-0198993300001 } \\
\text { 274287495013.pdf }\end{array}$} \\
\hline
\end{tabular}

¿A qué grupo de edad o condición social debe dirigirse la Alfainfo, al más numeroso, al de los que comienzan a vivir, a quienes tienen que mantenerse activos, a los marginados, a los que constituyen la población cautiva o a los que forman parte de la población abierta de las bibliotecas?, ¿a aquellos que no son competentes en las alfabetiza- 
Entre noveles y hacedores

ciones básicas y por tanto desconocen, entre otros asuntos, la correcta escritura de palabras frecuentes? (Figura 1 y Figura 2) ¿A los que tienen que saber cómo desenvolverse en una sociedad cada vez más demandante de competencias?, (Area Moreira, Gros \& García Quismondo, 2008) ¿a los que difícilmente conocen recursos más allá de los que se obtienen comercialmente y que los maestros de instrucción primaria que, de una amplia oferta de "estampitas" o "monografías" orillan a sus alumnos a adquirir?, (Figura 3). Entendemos que los bibliotecólogos no van a subsanar las deficiencias ortográficas de la población, pero sí deben colaborar con los maestros en la educación de sus alumnos. Asimismo, el hábito de los niños al uso de las "estampitas" debe ser eliminado y, para ello, la alfabetización informacional debe tener presencia en las instituciones educativas del país.

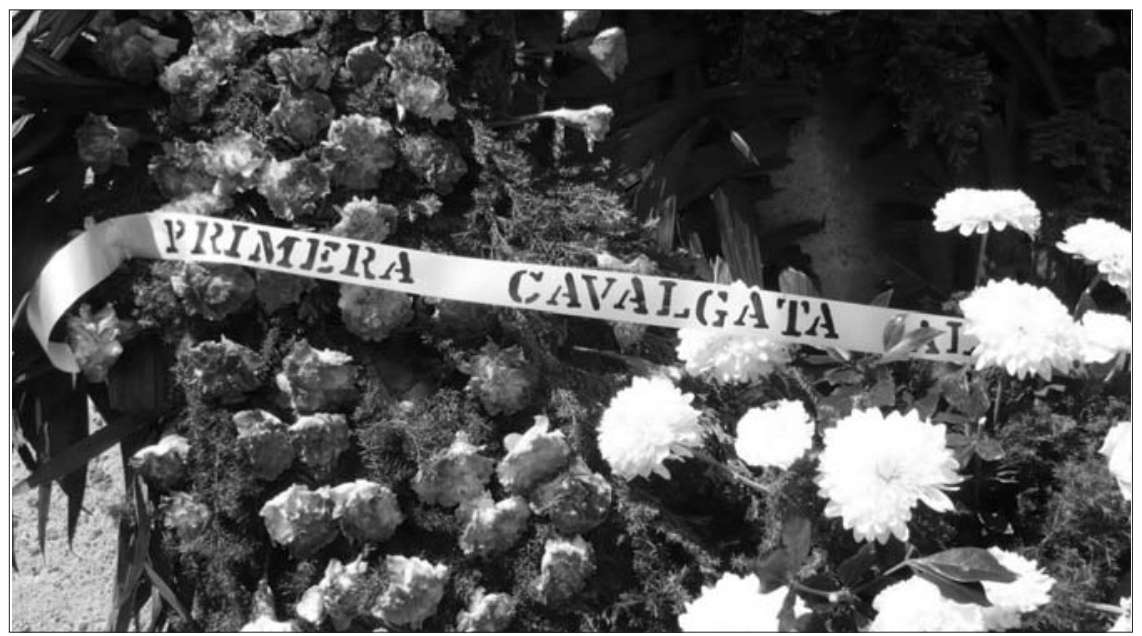

Figura 1

Arreglo floral en a Ignacio Allende en San Miguel Allende, Gto. Septiembre 15, 2010 
Tendencias de la Alfabetización Informativa en Iberoamérica

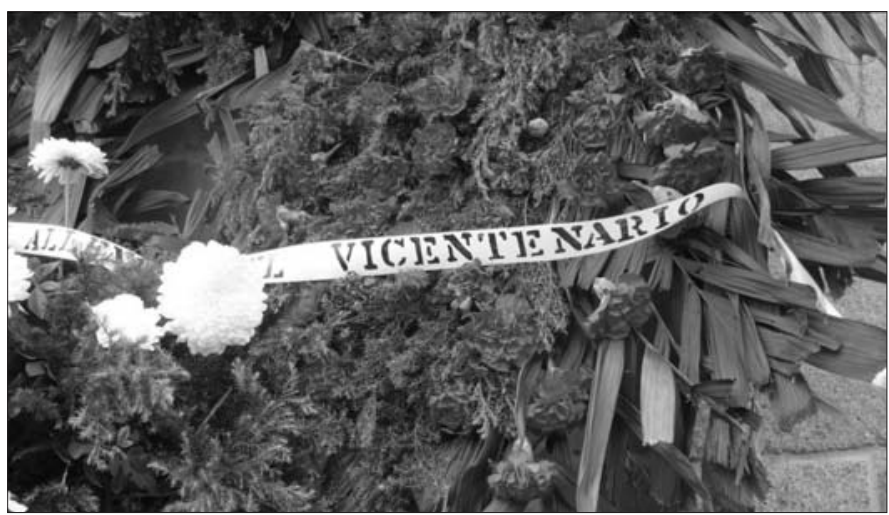

Figura 2

Arreglo floral en monumento a Ignacio Allende en San Miguel Allende, Gto. Septiembre 15, 2010

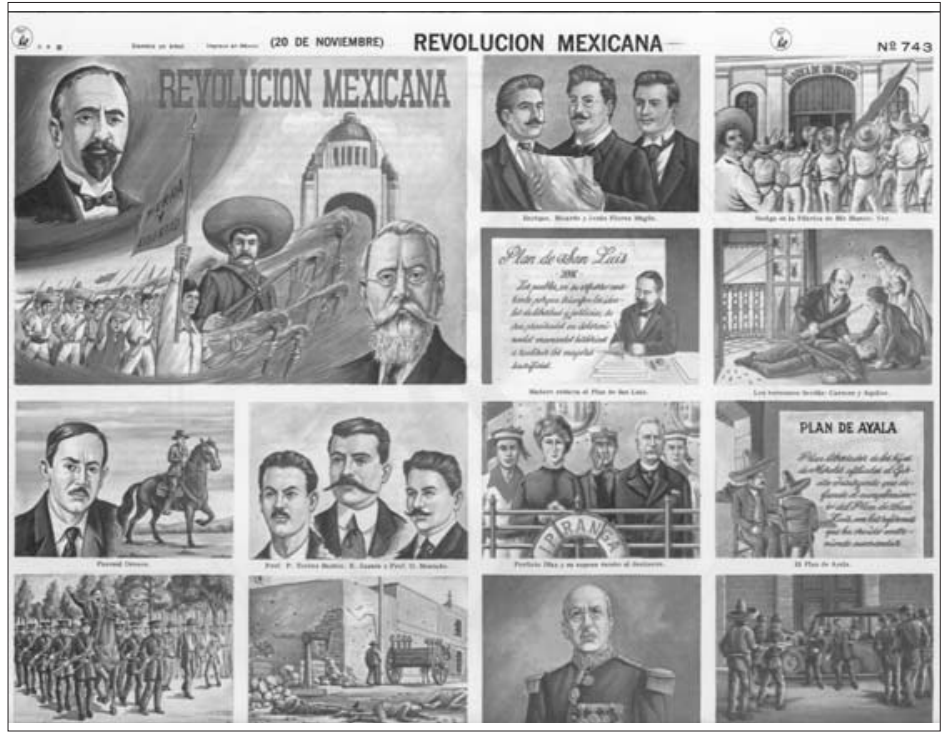

Figura 3

"Monografía" sobre la Revolución Mexicana disponible para su venta en papelerías 
A continuación se incluyen dos apartados: el de los noveles (Cuadros 1-9) y el de los hacedores. En el primero se presentan resultados seleccionados de algunos estudios dirigidos a niños de escuelas primarias (Licea de Arenas et al., 2007); a profesores de la UNAM (Recursos electrónicos de información en la UNAM, 2009; Crovi Druetta, 2010); estudiantes universitarios de la UNAM (Licea de Arenas et al, 2004; Licea de Arenas \& Arenas, 2007; Licea de Arenas J, et al., 2010) y, finalmente, adultos mayores de 60 años egresados de la UNAM, algunos de la carrera de veterinaria (Licea de Arenas, Arenas \& Valles, 2009) y otros de diversas licenciaturas (Licea de Arenas \& Arenas, 2009). Dichos diagnósticos llevan a enfatizar la necesidad de que la población mexicana esté alfabetizada informacionalmente. El segundo apartado además de mirar a las instituciones mexicanas que ofrecen estudios de bibliotecología, de cuestionar la práctica docente y de sugerir la integración de la Alfainfo a los planes de estudio de las instituciones universitarias, ilustra la vinculación de la Alfainfo con el desarrollo de una asignatura obligatoria: Introducción a la Investigación, que se imparte en la licenciatura en bibliotecología que se ofrece en la Facultad de Filosofía y Letras de la Universidad Nacional Autónoma de México.

\section{RECUENTO DE DATOS EMPÍRICOS ACERCA DE LOS NOVELES}

Los siguientes resultados de investigaciones realizadas con diferentes grupos de la población mexicana sirven para repensar el papel que le corresponde desempeñar a 
las instituciones bibliotecarias nacionales, entendiendo que los noveles son aquellos que son nuevos en una situación o actividad determinadas, por lo que carecen de experiencia.

\begin{tabular}{|c|}
\hline $\begin{array}{l}\text { Cuadro } 1 \\
\text { Encuesta realizada en bibliotecas públicas de la } \\
\text { ciudad de México a niños usuarios de } \\
\text { bibliotecas públicas (6-11 años) }\end{array}$ \\
\hline $\begin{array}{l}\text { Asisten a la biblioteca a: leer, hacer los deberes, a hacer traba- } \\
\text { jos... a esperar a su madre }\end{array}$ \\
\hline $\begin{array}{l}\text { Utilizan los siguientes materiales: libros, diccionarios, enciclope- } \\
\text { dias, periódicos, revistas, videos y "hojas". }\end{array}$ \\
\hline Encuentran lo que buscan porque saben cómo hacerlo. \\
\hline $\begin{array}{l}\text { Utilizan el siguiente equipo: computadora, TV . . . mesas y sillas, } 0 \\
\text { ninguno. }\end{array}$ \\
\hline $\begin{array}{l}\text { La computadora sirve para usar Internet, el correo electrónico, } \\
\text { consultar una enciclopedia. }\end{array}$ \\
\hline $\begin{array}{l}\text { Lo que menos les gusta de la biblioteca es: el silencio, que haya li- } \\
\text { bros maltratados, que no se presten los libros. }\end{array}$ \\
\hline $\begin{array}{l}\text { Lo que más les gusta de la biblioteca es que hay libros, muchos li- } \\
\text { bros, espacio para trabajar, leer e Internet. }\end{array}$ \\
\hline $\begin{array}{l}\text { El personal de la biblioteca los atiende no mal, no bien, sólo regu- } \\
\text { lar. }\end{array}$ \\
\hline $\begin{array}{l}\text { Fuente: Licea de Arenas J, Díaz E, Fuentes L, Palacio J, Trillo D, Radillo J, } \\
\text { Reyes F. Los niños mexicanos y su percepción de las bibliotecas públicas. } \\
\text { 2007. Documento no publicado }\end{array}$ \\
\hline
\end{tabular}




\begin{tabular}{|l|c|}
\hline \multicolumn{2}{|c|}{$\begin{array}{c}\text { Cuadro 2 } \\
\text { Porcentaje de profesores con habilidades para buscar y obtener } \\
\text { información a través de la Internet }\end{array}$} \\
\hline \multicolumn{1}{|c|}{ Habilidad } & $\%$ \\
\hline Avanzada & 26 \\
\hline Media & 48 \\
\hline Básica & 17 \\
\hline No utiliza & 8 \\
\hline $\begin{array}{l}\text { Fuente: Recursos electrónicos de información en la UNAM: diagnóstico de uso entre } \\
\text { estudiantes y profesores. México: UNAM; 2009 }\end{array}$ \\
\hline
\end{tabular}

\begin{tabular}{|c|c|}
\hline \multicolumn{2}{|c|}{$\begin{array}{c}\text { Cuadro } 3 \\
\text { Servicios de Internet que el personal académico de la UNAM utili } \\
\text { za para su docencia }\end{array}$} \\
\hline Servicio & Núms. \\
\hline Ninguno & 70 \\
\hline Mensajería instantánea & 213 \\
\hline Chat & 121 \\
\hline Sindicación RSS & 91 \\
\hline Listas de correo & 327 \\
\hline Weblogs & 118 \\
\hline Correo electrónico & 1004 \\
\hline Wikis & 51 \\
\hline Foros & 220 \\
\hline Bases de datos & 540 \\
\hline Revistas en línea & 790 \\
\hline Portales institucionales & 733 \\
\hline Páginas electrónicas & 824 \\
\hline
\end{tabular}


Tendencias de la Alfabetización Informativa en Iberoamérica

\begin{tabular}{||l|c||}
\hline \multicolumn{2}{|c|}{$\begin{array}{c}\text { Cuadro } 4 \\
\text { Problemas a los que se enfrentan los académicos } \\
\text { de la UNAM cuando realizan una búsqueda } \\
\text { en una base de datos }\end{array}$} \\
\hline \multicolumn{1}{|c|}{ Problema } & Números \\
\hline Bases que requieren registro previo & 456 \\
\hline $\begin{array}{l}\text { Bases que requieren un programa para des- } \\
\text { plegar la información }\end{array}$ & 257 \\
\hline \begin{tabular}{l} 
Ligas rotas \\
\hline Toma mucho tiempo cargar las bases de datos
\end{tabular} & 289 \\
\hline $\begin{array}{l}\text { No ser capaz de regresar a un artículo luego } \\
\text { de buscar en varias bases de datos }\end{array}$ & 246 \\
\hline $\begin{array}{l}\text { No ser capaz de encontrar un artículo que } \\
\text { sabe está en una base de datos }\end{array}$ & 35 \\
\hline $\begin{array}{l}\text { No ser capaz de organizar la información en- } \\
\text { contrada }\end{array}$ & 102 \\
\hline No encontrar la información deseada & 305 \\
\hline $\begin{array}{l}\text { Fuente: Crovi Druetta D. Acceso, uso y apropiación de las TIC en comunidades } \\
\text { académicas: diagnóstico en la UNAM, México: UNAM, Plaza y Valdés; } 2010 .\end{array}$ \\
\hline
\end{tabular}

\begin{tabular}{|l|c||}
\hline \multicolumn{1}{||c||}{$\begin{array}{c}\text { Cuadro 5 } \\
\text { Interés de los estudiantes de la UNAM } \\
\text { por asistir a actividades de Alfainfo }\end{array}$} \\
\hline Interesados & $53.55 \%$ \\
\hline No interesados & $45.63 \%$ \\
\hline Sin respuesta & $0.82 \%$ \\
\hline $\begin{array}{l}\text { Fuente: Licea de Arenas J, Rodriguez JV, Gómez JA, Arenas M. } \\
\text { Information literacy: implications for Mexican and Spanish univer- } \\
\text { sity students, Library Review 2004;53:451-60. }\end{array}$ \\
\hline
\end{tabular}


Entre noveles y hacedores

Cuadro 6

Opiniones de los estudiantes de dos universidades

mexicanas sobre a quién recurrir si tienen algún problema relacionado con

sus estudios

\begin{tabular}{||l|c|c|}
\hline & $\begin{array}{c}\text { UAMX } \\
\%\end{array}$ & $\begin{array}{c}\text { UNAM } \\
\%\end{array}$ \\
\hline A sus compañeros & 49.7 & 40.60 \\
\hline A su profesor & 75.9 & 64.23 \\
\hline A la biblioteca & 57.9 & 58.27 \\
\hline A la Internet & 71 & 57.04 \\
\hline A los bibliotecólogos/bibliotecarios & 8.92 & 5.86 \\
\hline Sólo a los apuntes & 16.361 & 6.78 \\
\hline A los libros propios & 11.1 & 4.21 \\
\hline Funnt:LicadeAras & & \\
\hline
\end{tabular}

Fuente: Licea de Arenas J, Rodríguez JV, Gómez JA, Arenas M. Information literacy: implications for Mexican and Spanish university students, Library Review

2004;53:451-60 y Licea de Arenas J, Arenas M., Los estudiantes de la UAM-X. 2007.

Documento no publicado. 
Tendencias de la Alfabetización Informativa en Iberoamérica

\begin{tabular}{|c|c|c|c|c|c|}
\hline \multicolumn{6}{|c|}{$\begin{array}{c}\text { Cuadro } 7 \\
\text { Familiaridad de estudiantes de la UNAM de humanidades } \\
\text { y ciencias sociales con recursos } \\
\text { de información }\end{array}$} \\
\hline & 1 & 2 & 3 & 4 & 5 \\
\hline & $\%$ & $\%$ & $\%$ & $\%$ & $\%$ \\
\hline Revista/periódico en línea & 21 & 63 & 10 & 5 & 5 \\
\hline Libros electrónicos & 5 & 53 & 21 & 0 & 5 \\
\hline Noticieros en línea & 10 & 42 & 32 & 10 & 5 \\
\hline El Rincón del Vago & 5 & 16 & 21 & 16 & 26 \\
\hline Wikipedia & 26 & 32 & 26 & 0 & 10 \\
\hline Monografías.com & 5 & 37 & 16 & 32 & 5 \\
\hline Encarta & 5 & 37 & 21 & 16 & 10 \\
\hline Educ.ar & 0 & 16 & 26 & 5 & 32 \\
\hline Escolares.net & 0 & 16 & 16 & 5 & 47 \\
\hline \multicolumn{6}{|c|}{$\begin{array}{l}\text { Claves: } \\
\text { 1=extremadamente familiar; } \\
\text { 2=muy familiarizado; } \\
\text { 3=algo familiarizado; } \\
\text { 4=no muy familiarizado; } \\
\text { 5=nunca había oído hablar de él. }\end{array}$} \\
\hline \multicolumn{6}{|c|}{$\begin{array}{l}\text { Fuente: Licea de Arenas J, Arenas R, Córdoba M, Rivera Y., Los estudiantes universita- } \\
\text { rios y la alfabetización digital, SIECI 2010, Orlando, FI. Junio 29-julio 2, } 2010 .\end{array}$} \\
\hline
\end{tabular}


Tendencias de la Alfabetización Informativa en Iberoamérica

\begin{tabular}{|c|c|}
\hline \multicolumn{2}{|c|}{$\begin{array}{l}\text { Cuadro } 9 \\
\text { Uso que dan a la computadora los } \\
\text { veterinarios de más de } 60 \text { años }\end{array}$} \\
\hline Computer usage & $\%$ \\
\hline E-mail & 100 \\
\hline Chat & 0 \\
\hline Search for profesional information & 100 \\
\hline Music/video & 0 \\
\hline Group discussions & 25 \\
\hline Calls (Skype) & 25 \\
\hline Word processor & 50 \\
\hline Social networks & 25 \\
\hline \multicolumn{2}{|c|}{$\begin{array}{l}\text { Fuente: Licea de Arenas J, Arenas M, Valles J. Before the NetGen. Positioning } \\
\text { the Profession: the Tenth International Congress on Medical Librarianship. Bris- } \\
\text { bane, Australia. August 31-September 4, 2009. http://espace.library.uq.edu.au/ } \\
\text { eserve/UQ:179759/n6_3_Fri_Arenas_104.pc. }\end{array}$} \\
\hline
\end{tabular}

\section{LOS HACEDORES}

En México los estudios universitarios de bibliotecología inician el año de 1956, cuando en el país comenzaba a prepararse la nueva élite que tendría a su cargo la industrialización y la modernización del país (Lomnitz et al, 1983). Los escasos estudiantes de bibliotecología de ese tiempo fueron formados en la corriente de la bibliotecología estadounidense y pronto aprendieron que la biblioteca, en particular la universitaria, tenía una función docente, en donde no tenía cabida una actitud pasiva en la formación de estudiantes. Asimismo las bibliotecas debían preparar cuidadosos programas de instrucción en el uso de la biblioteca con el fin de brindar el 
máximo de beneficio a estudiantes y profesores (Wilson $\&$ Tauber, 1956). También en uno de los primeros textos de bibliotecología publicados en México se decía que: "Las cualidades del maestro, deben añadírsele al bibliotecario de consulta de una universidad, porque su trabajo no se reduce a dar una respuesta o a redactar la información requerida, sino a enseñarle al estudiante o al maestro a utilizar ciertas obras de información que les son desconocidas. Este papel de maestro desempeñado por el bibliotecario de consulta es fundamental en una biblioteca universitaria. El enseñar a los lectores el cómo usar la biblioteca y el destacar sus partes más importantes es, también, un deber del servicio de consulta. Esta enseñanza puede darse por medio de pláticas a los estudiantes y de conferencias a los maestros", (Perales Ojeda, 1959).

No obstante, los textos anteriores, transcurren varias décadas antes de incorporar una asignatura acerca de los usuarios en el plan de estudios no sólo de la carrera de bibliotecología en la UNAM sino en las demás escuelas que han surgido con los años en el país, (Cuadros 10-13). Sin embargo, ¿qué se necesita para que se comprenda el papel docente de la biblioteca o de los bibliotecólogos? $¿$ ¿Cómo se aprende a interactuar con los usuarios, a acercarlos a la información, a que aprendan a utilizarla? ¿Es suficiente una asignatura, generalmente de un semestre de 14 a 16 semanas con un total de 64 horas? ¿Debe haber algún curso en el que se aprenda cómo se aprende o su significado, incluyendo la responsabilidad de ser maestro? ¿cuál de las dos expresiones siguientes en uso en España se adecua más a lo que acontece en México?: 
Cada maestrillo tiene su librillo.

- ¿La pescadilla que se muerde la cola?

La primera expresión significa que cada quien tiene su propio método para llevar a cabo su tarea; la segunda se utiliza para indicar que se le pueden dar una y otra vuelta a un problema del que nunca se sale por no tener solución.

\begin{tabular}{||c|c||}
\hline \multicolumn{2}{|c|}{$\begin{array}{c}\text { Cuadro } 10 \\
\text { Asignaturas sobre o relacionadas con la Alfainfo que se imparten } \\
\text { en instituciones mexicanas que ofrecen estudios } \\
\text { de bibliotecología }\end{array}$} \\
\hline El Colegio de México* & $\begin{array}{l}\text { - Formación de usuarios+ } \\
\text { - Estudios de usuarios+ }\end{array}$ \\
\hline $\begin{array}{l}\text { I. Tecnológico y de Estudios Supe- } \\
\text { riores de Monterrey }\end{array}$ & $\begin{array}{l}\text { - Servicio de referencia y formación } \\
\text { de usuarios+ }\end{array}$ \\
\hline U Autónoma de Chiapas & $\begin{array}{l}\text { Necesidades de información y } \\
\text { adquisiciones+ }\end{array}$ \\
\hline U Autónoma de Chihuahua* & $\begin{array}{l}\text { - Usuarios de la información } \\
\text { - Formación de usuarios }\end{array}$ \\
\hline U Autónoma del Estado de México & $\begin{array}{l}\text { Análisis y formación de usuarios } \\
\text { Desarrollo de habilidades } \\
\text { informativas+ }\end{array}$ \\
\hline * Institución con estudios de maestría. \\
+ Asignatura que se imparte en maestría. \\
\hline
\end{tabular}




\section{Cuadro 10}

Asignaturas sobre o relacionadas con la Alfainfo que se imparten en instituciones mexicanas que ofrecen estudios de bibliotecología

(Cont.)

\begin{tabular}{|c|c|}
\hline U Autónoma de Guadalajara & $\begin{array}{l}\text { - Introducción a las habilidades } \\
\text { informativas. } \\
\text { - Formación de usuarios. } \\
\text { - Desarrollo de habilidades informativas. } \\
\text { - Usuarios de la información }\end{array}$ \\
\hline U Autónoma Metropolitana* & - \\
\hline U Autónoma de Nuevo León & - Usuarios de la información \\
\hline U Autónoma de San Luis Potosí & - Usuarios de la información \\
\hline U Guadalajara & $\begin{array}{l}\text { - Diagnóstico de necesidades de } \\
\text { formación de usuarios }\end{array}$ \\
\hline UNAM* $^{*}$ & $\begin{array}{l}\text { - Usuarios de la información } \\
\text { - Estudios de usuarios+ } \\
\text { - Educación de usuarios+ }\end{array}$ \\
\hline Escuela Nal de Biblioteconomía & - Usuarios de la información \\
\hline \multicolumn{2}{|c|}{$\begin{array}{l}\text { * Institución con estudios de maestría. } \\
\text { + Asignatura que se imparte en maestría. }\end{array}$} \\
\hline
\end{tabular}


Tendencias de la Alfabetización Informativa en Iberoamérica

\begin{tabular}{||l|l||}
\hline \multicolumn{2}{|c|}{$\begin{array}{c}\text { Cuadro } 11 \\
\text { Asignaturas con orientación hacia la docencia que se imparten } \\
\text { en las instituciones mexicanas }\end{array}$} \\
\hline U Autónoma de Chiapas & $\begin{array}{l}\text { - Didáctica. } \\
\text { - Didáctica instrumental y crítica }\end{array}$ \\
\hline U Autónoma de Nuevo León & - Estrategias de enseñanza-aprendizaje \\
\hline UNAM* & $\begin{array}{l}\text { - Didáctica de la bibliotecología. } \\
\text { - Teoría de didáctica de la } \\
\text { bibliotecología+ }\end{array}$ \\
\hline Escuela Nal de Biblioteconomía & - Didáctica \\
\hline *Institución con estudios de maestría. \\
+ Asignatura que se imparte en maestría.
\end{tabular}

\begin{tabular}{||l|l|l||}
\hline \multicolumn{3}{|c||}{$\begin{array}{c}\text { Cuadro 12 } \\
\text { Objetivos de la asignatura "Usuarios" que se imparte en dos } \\
\text { instituciones educativas }\end{array}$} \\
\hline \multicolumn{1}{||c||}{ Institución } & \multicolumn{1}{|c||}{ Asignatura } & \multicolumn{1}{c||}{ Objetivo } \\
\hline $\begin{array}{l}\text { U Autónoma de } \\
\text { Guadalajara }\end{array}$ & $\begin{array}{l}\text { Diagnóstico de } \\
\text { necesidades de } \\
\text { formación de } \\
\text { usuarios }\end{array}$ & $\begin{array}{l}\text { [...] el alumno tendrá la capacidad de iden- } \\
\text { tificar y desarrollar estrategias de capacita- } \\
\text { ción y formación de usuarios de cualquier } \\
\text { centro de información, para promover, esti- } \\
\text { mular y propiciar el desarrollo de compe- } \\
\text { tencias informativas, búsqueda, } \\
\text { localización, análisis, evaluación, procesa- } \\
\text { miento, uso y difusión de la información. }\end{array}$ \\
\hline $\begin{array}{l}\text { U Autónoma de } \\
\text { Nuevo León }\end{array}$ & $\begin{array}{l}\text { Usuarios de la } \\
\text { información }\end{array}$ & $\begin{array}{l}\text { Identificar las características de los diferen- } \\
\text { tes tipos de usuarios, así como sus necesi- } \\
\text { dades de información y su comportamiento } \\
\text { de búsqueda. Aplicar diferentes métodos } \\
\text { y técnicas para la formación de usuarios. }\end{array}$ \\
\hline
\end{tabular}




\begin{tabular}{|c|c|c|}
\hline \multicolumn{3}{|c|}{$\begin{array}{c}\text { Cuadro } 13 \\
\text { ¿Qué se enseña o socializa en relación } \\
\text { con los usuarios? }\end{array}$} \\
\hline $\begin{array}{l}\text { U Autónoma } \\
\text { de Chiapas }\end{array}$ & $\begin{array}{l}\text { Usuarios de la Infor- } \\
\text { mación } \\
\text { Formación y educa- } \\
\text { ción de usuarios }\end{array}$ & $\begin{array}{l}\text { - El usuario } \\
\text { - Necesidades de información } \\
\text { - Comportamiento informativo } \\
\text { - Satisfacción de usuarios } \\
\text { - Estudio de usuarios } \\
\text { - Formación de usuarios }\end{array}$ \\
\hline $\begin{array}{l}\text { UAutónoma } \\
\text { Metropolitana* }\end{array}$ & $\begin{array}{l}\text { Temas de socializa- } \\
\text { ción }\end{array}$ & $\begin{array}{l}\text { - Los usuarios: estudio y com- } \\
\text { portamiento } \\
\text { - Usos de información }\end{array}$ \\
\hline \multicolumn{3}{|c|}{ *Institución con estudios de maestría } \\
\hline
\end{tabular}

Las asignaturas de Usuarios, salvo en una universidad se imparten en el modelo educativo predominante en las universidades mexicanas: el tradicional. Las características de ambos modelos son las que semuestran en el Cuadro 14.

En las universidades y fuera de ellas aún se dice que el docente le transmite sus conocimientos al alumnado, por tanto convendría revisar la visión de las universidades en relación con los profesionales que se comprometen a formar: egresados críticos y comprometidos socialmente o egresados dispuestos a continuar a pie juntillas con el statu quo. 
Tendencias de la Alfabetización Informativa en Iberoamérica

\begin{tabular}{||l|l||}
\hline \multicolumn{2}{|c||}{$\begin{array}{c}\text { Modelos educativos predominantes en las } \\
\text { universidades mexicanas }\end{array}$} \\
\hline \multicolumn{1}{|c||}{ Docencia tradicional } & \multicolumn{1}{c||}{ Docencia innovadora } \\
\hline Desconocimiento de técnicas educativas & $\begin{array}{l}\text { Conocimiento de técnicas educativas innovado- } \\
\text { ras }\end{array}$ \\
\hline Uso excesivo de la pizarra y la tiza & Discusión grupal \\
\hline Uso de las clases orales & Investigación \\
\hline $\begin{array}{l}\text { Utilización de libros de texto como mate- } \\
\text { rial de apoyo }\end{array}$ & Uso de información vigente y relevante \\
\hline Falta de relación con el entorno & Vinculación con la realidad \\
\hline Indiferencia a cómo aprende el alumno & Conocimiento de lo que el alumno debe conocer \\
\hline Fomento al individualismo & Fomento a la socialización \\
\hline $\begin{array}{l}\text { Desconocimiento de los recursos de in- } \\
\text { formación }\end{array}$ & Conocimiento de los recursos de información \\
\hline $\begin{array}{l}\text { Ausencia en los cursos del desarrollo de } \\
\text { competencias informacionales }\end{array}$ & Desarrollo de competencias informacionales \\
\hline $\begin{array}{l}\text { Incomunicación con los bibliotecólo- } \\
\text { gos/bibliotecarios de la universidad }\end{array}$ & $\begin{array}{l}\text { Colaboración con los bibliotecólogos de la uni- } \\
\text { versidad }\end{array}$ \\
\hline
\end{tabular}

El profesor tendrá que preguntarse cómo se da el aprendizaje y cómo se puede comprobar que hubo tal. Las técnicas de enseñanza participativa seguramente serán más eficientes que las conferencias donde sólo se estimula la pasividad de los aprendices. Por ejemplo, ¿se ha abandonado el conductismo donde todo se mueve al ritmo del educando, donde hay recompensas? ¿prevalece la corriente congnoscitiva, que señala que se aprende cuando el individuo está listo para aprender? o ¿se ha avanzado hacia el constructivismo que enfatiza el aprendizaje en contexto? 
Si bien las diferentes escuelas del aprendizaje tienen características propias que no necesariamente las hacen todas buenas o todas malas, el conocimiento de las que han mostrado mayor efectividad contribuiría a una alfabetización informacional más eficiente. Por tanto, ¿cómo debe formarse a los futuros bibliotecólogos docentes si los propios profesores tienen carencias? De esta manera, conviene repensar el papel que corresponde desempeñar a quienes pueden intervenir en la educación de la población abierta o cautiva del país. En el entorno universitario compete a los profesores y a los bibliotecólogos docentes participar en la formación de los estudiantes (Figura 4) y donde el compromiso debe estar por encima de la adopción de una actitud de laissez faire que lleve a escudarse en el curriculum oculto que, como su nombre lo dice, no está escrito ni tiene objetivo alguno. Lo anterior se ilustra en el Cuadro 15: de una serie de preguntas sobre Alfainfo realizadas a estudiantes del $7^{\circ}$ semestre de la licenciatura en bibliotecología de la Facultad de Filosofía y Letras, respondieron de la siguiente manera a una de ellas: ¿cuáles son los componentes del artículo científico?

\section{Figura 4}

Relación estudiantes-profesores-bibliotecólogos docentes en el proceso Alfainfo

\section{ESTUDIANTES}
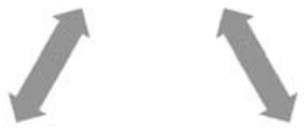


\begin{tabular}{|c|c|}
\hline \multicolumn{2}{|c|}{$\begin{array}{c}\text { Cuadro } 15 \\
\text { ¿De qué elementos se componen los } \\
\text { artículos científicos? }\end{array}$} \\
\hline Un resumen del contenido del artículo & $100 \%$ \\
\hline Una sección de agradecimientos & - \\
\hline Una lista de referencias & - \\
\hline Todos los mencionados & - \\
\hline
\end{tabular}

Si bien al bibliotecólogo le corresponde crear el medio propicio para el aprendizaje, el papel de las bibliotecas universitarias como copartícipes en la formación de universitarios tiene que revisarse: no se trata sólo de manifestar que se quiere ser una biblioteca escuela (Walter, 2006), o algo más que un repositorio sino de demostrar que se dispone de los elementos para convertirse en una institución educativa capaz de integrar una comunidad de aprendizaje, (Figura 5). (Torras \& Saetre, 2008). De esta manera, el entorno de aprendizaje debe construirse tomando en cuenta aquellas actividades que tiendan a modificar la conducta de los estudiantes, siempre y cuando tales atividades estén sustentadas en teorías del aprendizaje bien establecidas que vayan más allá del currículum oculto y del currículum formal, (Figura 6). Por tanto ¿Cómo se llega a ser docente? ¿Por error vocacional? ¿Es suficiente el título o grado universitario para emprender una tarea de tal envergadura? ¿El hábito hace al maestro? (Walter, 2008). 
Entre noveles y hacedores

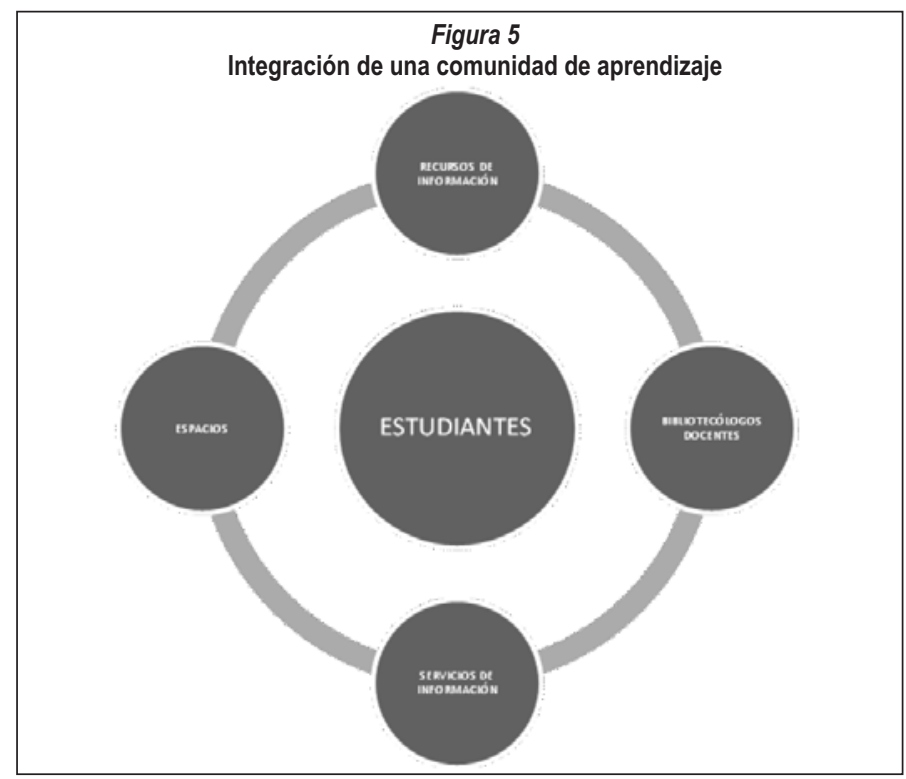

Figura 6

Prerrequisitos de la Alfainfo

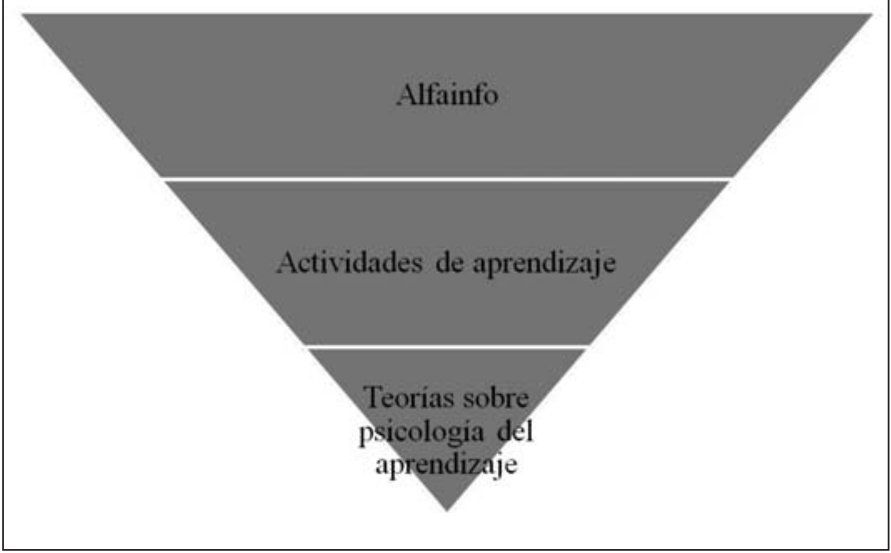


¿Cómo probar si los bibliotecólogos docentes están cumpliendo con su cometido? Las páginas web de las bibliotecas universitarias mexicanas nos aproximan una respuesta y a nuevas preguntas: ¿Qué tan relevantes son los contenidos instrumentales y los contenidos competenciales cuando se trata de desarrollar competencias informacionales? (Cuadro 16).

\begin{tabular}{|c|c|}
\hline \multicolumn{2}{|r|}{$\begin{array}{l}\text { Cuadro } 16 \\
\text { Contenidos de las páginas web de } \\
\text { las universidades mexicanas }\end{array}$} \\
\hline $\begin{array}{l}\text { Contenidos instrumen- } \\
\text { tales }\end{array}$ & Contenidos indefinidos y competenciales \\
\hline Los servicios & Atención a usuarios \\
\hline El reglamento & Programa Regional de Desarrollo de Actividades Informativas \\
\hline $\begin{array}{l}\text { El catálogo de la biblio- } \\
\text { teca }\end{array}$ & Soporte en línea (asesor): charla electrónica, correo electrónico \\
\hline $\begin{array}{l}\text { Los recursos de infor- } \\
\text { mación }\end{array}$ & Talleres de orientación de usuarios \\
\hline $\begin{array}{l}\text { Las bases de datos } \\
\text { disponibles }\end{array}$ & Tutoriales \\
\hline \multirow[t]{5}{*}{ La biblioteca digital } & Formación de usuarios \\
\hline & La importancia de la información \\
\hline & Fuentes de información \\
\hline & Búsqueda y recuperación de información \\
\hline & $\begin{array}{l}\text { Ejercicios (presentación en power point): criterios para la eva- } \\
\text { luación de páginas web, formato de evaluación de páginas web }\end{array}$ \\
\hline \multicolumn{2}{|c|}{$\begin{array}{l}\text { Fuente: Gómez Hernández JA, Licea de Arenas J., La alfabetización informacional: su reflejo en la for- } \\
\text { mación de los bibliotecólogos y en los servicios de las bibliotecas de universidades públicas de México y } \\
\text { España, VIII Encuentro EDIBCIC: Asociación de Educadores e Investigadores de Bibliotecología, Archi- } \\
\text { vología, Ciencias de la Información y Documentación de Iberoamérica y el Caribe, México, D.F., Noviem- } \\
\text { bre 12-14, 2008. }\end{array}$} \\
\hline
\end{tabular}


Ya se mencionó la necesidad de alfabetizar informacionalmente a quienes en su vida profesional serán, posiblemente, bibliotecólogos docentes ¿cómo lograrlo? La alfabetización informacional "natural" debe ser parte de los estudios universitarios. Una muestra de ello se da enseguida tomando en consideración que: si la alfabetización informacional es la competencia para acceder, evaluar y usar información, los alumnos de la asignatura Introducción a la Investigación que se imparte en el primer semestre de la licenciatura en bibliotecología en la Facultad de Filosofía y Letras de la UNAM serán alfabetos informacionales cotidianamente por lo que toca a su vida personal y práctica profesional futura cuando aprendan a distinguir un problema de información, a acopiar, evaluar y usar información para comunicarla, (The Alexandria proclamation, 2005). Lo anterior se apoya en las observaciones realizadas a lo largo de años de docencia que concuerdan con lo reportado por autores como (Kamler \& Thomson, 2006; Head \& Eisenberg, 2010) en relación con los retos a vencer por los estudiantes de licenciatura y de postgrado cuando tienen que enfrentarse al proceso de investigación:

- Delimitación del tema de investigación.

- Formulación de las preguntas de investigación.

- Azoro ante la exposición a la información.

- Evaluación de la información analítica y críticamente.

- Uso de la terminología correcta.

- Transformación de los datos para ser comunicados en un texto. 
- Estructuración del texto de manera lógica.

- Argumentación coherente.

- Elaboración de conclusiones.

- Uso ético de la información.

- Reconocimiento al trabajo de otros .

De acuerdo con lo anterior se trata de una muestra de cómo el profesor de la asignatura y los bibliotecólogos pueden interactuar, donde al docente le corresponde orientar y guiar al estudiante en el proceso de aprendizaje, y a los bibliotecólogos docentes participar en dicho proceso por medio de su experiencia en el manejo de recursos de información; con ello, los estudiantes relacionan el proceso de la investigación científica con la información, (Torras \& Saetre, 2008), a la vez que abandonan las malas prácticas previas relacionadas con la adquisición de "estampitas" en la papelería de la esquina de sus domicilios, en El Rincón del Vago o "googleando" sin valorar la explosión bibliográfica y la información inexacta, (Julien, 2005), (Figuras 7 a la 12).

¿Cómo se vinculan el proceso de alfabetizarse informacionalmente y la investigación científica si no se forma parte del conocimiento tácito de los estudiantes? ¿cómo se adquieren las destrezas necesarias para pasar del "escribiendo para pensar", o sea la "lluvia de ideas", al "escribiendo para presentar"; es decir a la comunicación? A continuación se presenta cómo se articula el "flotador" o "salvavidas" que va a convertir al estudiante en alfabeto informacional. 
Entre noveles y hacedores

Figura 7

Articulación de los procesos de Alfainfo y de investigación científica
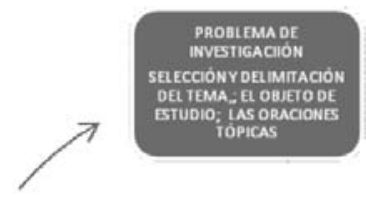

COMUNicación

PRESENTACIÓN FORMAL E

INFORMAL DELOS

RESULTADOS DE

INVETIGACIÓN
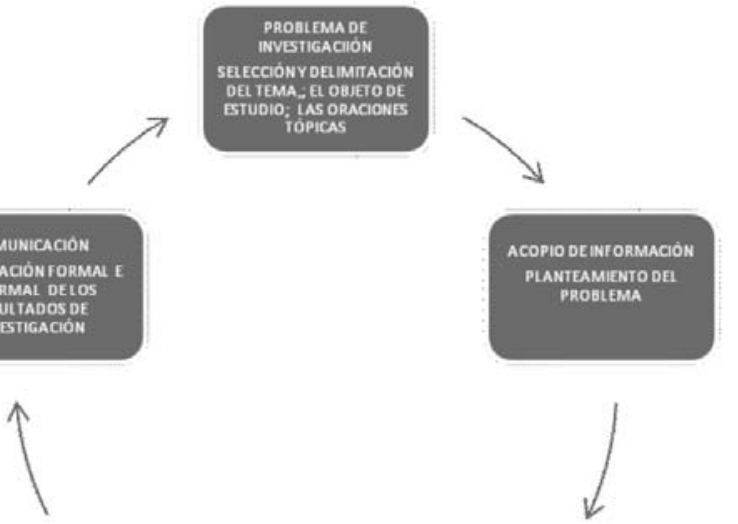

USO DELA INTORMACIÓN

RESULTADOSDELA

INVESTIGACIÓN, ANALLSE E

IMTERPRETACION DEL LS

DATOS, SUREPRESENTACIÓN

$\leftarrow$

Figura 8

El problema de investigación

SELECCIÓN Y

DELIMITACION DEL

TEMA; EL OBJETO DE

ESTUDIO

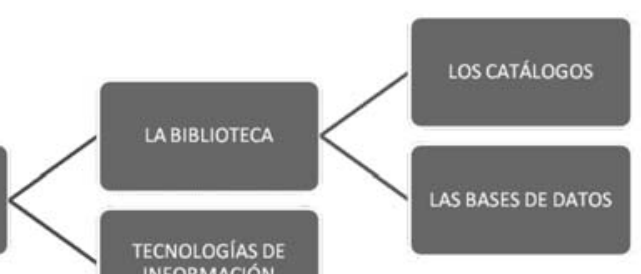


Tendencias de la Alfabetización Informativa en Iberoamérica

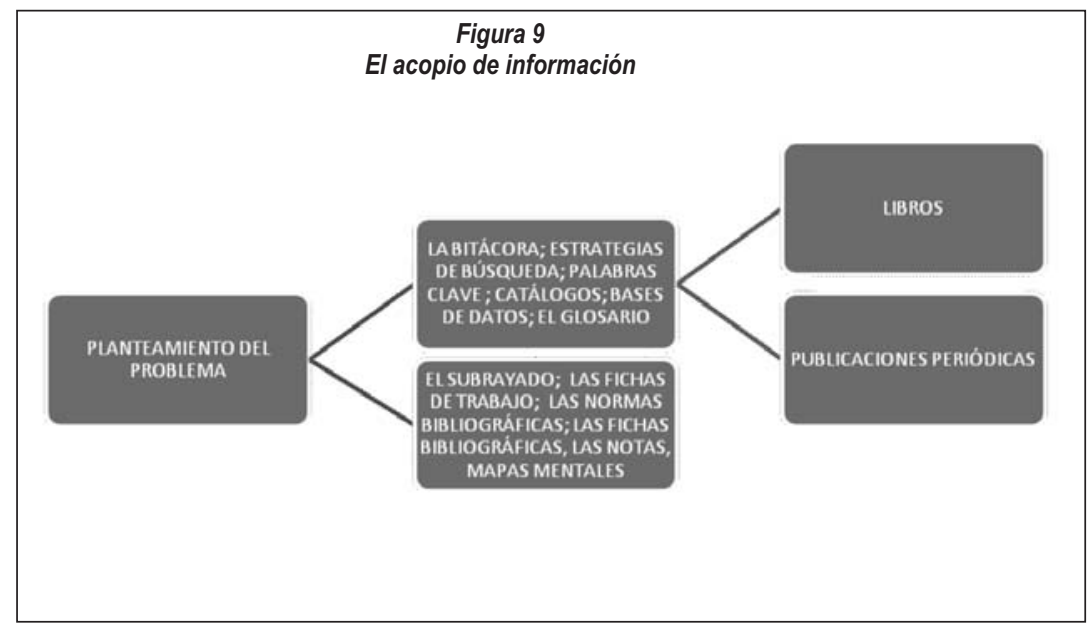

Figura 10

La evaluación de la información

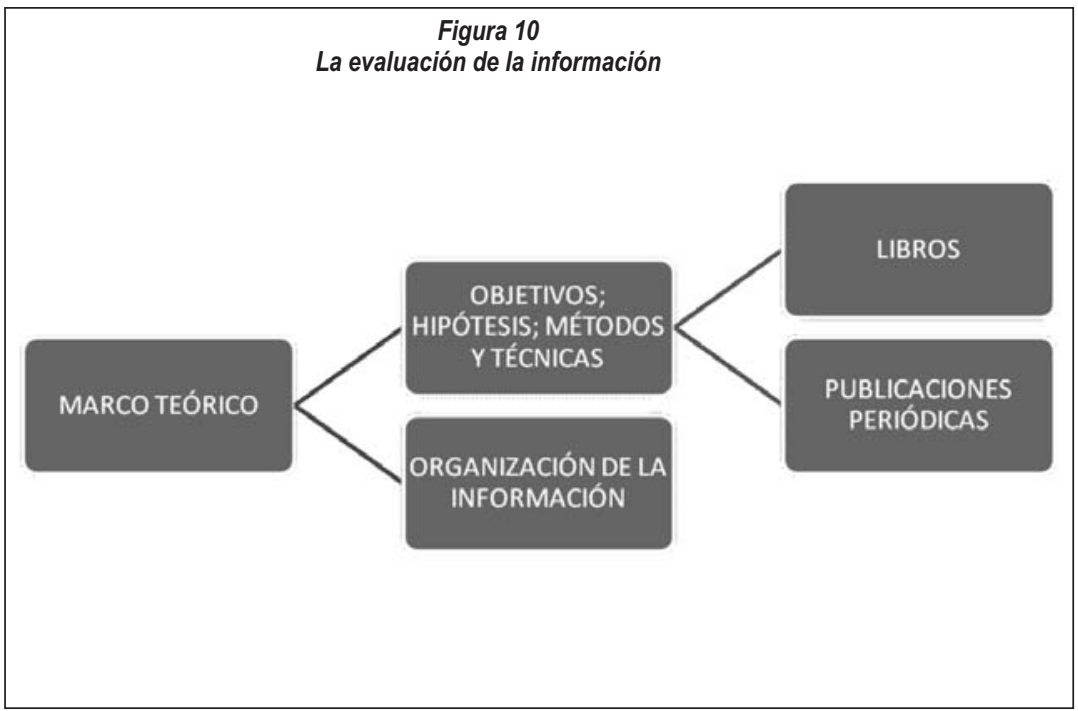


Entre noveles y hacedores
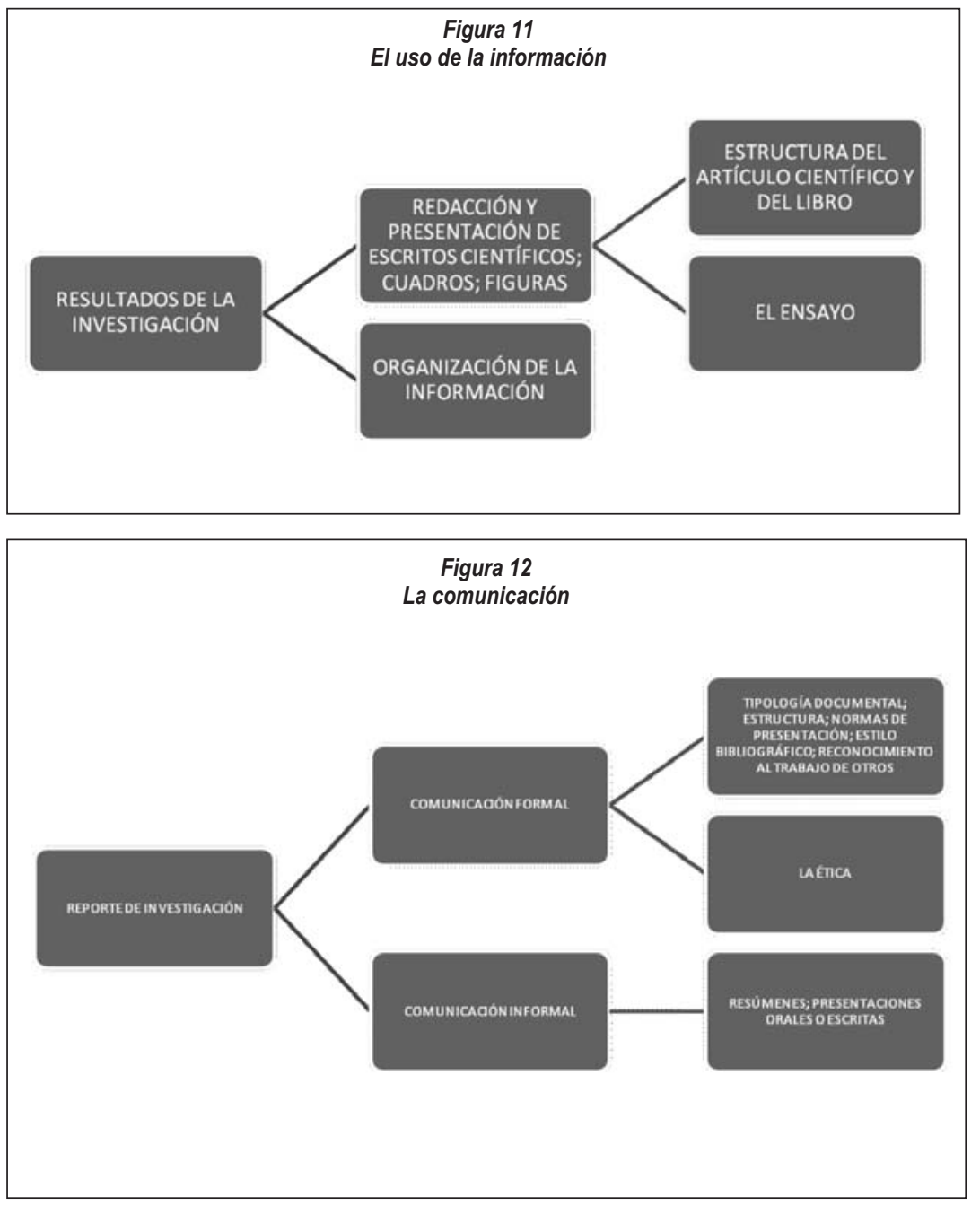
Tendencias de la Alfabetización Informativa en Iberoamérica

\section{CONCLUSIONES}

Con hechos podemos probar que es posible que el estudiante de bibliotecología se alfabetice informacionalmente a lo largo de sus estudios, sin embargo, queda pendiente ¿cómo puede convertirse en docente? es decir, ¿dónde debe adquirir las habilidades para hacerlo? Parece que en todas las instituciones formadoras de bibliotecólogos debe incluirse alguna asignatura que enseñe a ello, pero ¿cuál debe ser su enfoque? ¿el diseño de un programa de alfabetización informacional con orientación universal y local, que acerque a los estudiantes a su propio entorno? ¿los métodos y técnicas que permitan el aprendizaje? ¿la plataforma para enseñar? ¿la evaluación diagnóstica, formativa o sumaria de los alumnos y del programa? El país no requiere bibliotecólogos ninis, o sea los que ni tienen qué enseñar ni saben cómo enseñar. 


\section{REFERENCIAS}

Area Moreira, M, Gros Salvat, B. \& García-Quismondo, M. A. (2008), Alfabetizaciones y tecnologías de la información y la comunicación, Madrid: Síntesis.

Crovi Druetta, D. (2010), Acceso, uso y apropiación de las TIC en comunidades académicas: diagnóstico en la UNAM, México: UNAM, Plaza y Valdés.

Gómez Hernández, J. A. \& Licea de Arenas, J. (2008), La alfabetización informacional: su reflejo en la formación de los bibliotecólogos y en los servicios de las bibliotecas de universidades públicas de México y España, VIII Encuentro EDIBCIC: Asociación de Educadores e Investigadores de Bibliotecología, Archivología, Ciencias de la Información y Documentación de Iberoamérica y el Caribe, México, D.F., Noviembre 12-14.

Head, A. J. \& Eisenberg, M. B. (2010), How college students evaluate and use information in the digital age, Project Information Literacy Progress Report: "Truth be told".

Julien, H. (2005), "Education for information literacy instruction: a global perspective", en Journal of Education for Library and Information Science, 46, 210-216.

Kamler, B. \& Thomson, P. (2006), Helping doctoral students write. Pedagogies for supervision, London: Routledge.

"High Level Colloquium on Information Literacy and Lifelong Learning. Beacons of the information society (2005)", en The Alexandria proclamation on information literacy and lifelong learning. Disponible: www.bibalex. org/infolit2005/proclamation/alexproceng.doc, (consulta: Oct 2, 2010) 
Licea de Arenas, J. \& Arenas, M. (2007). Los estudiantes de la $U A M-X$, documento no publicado.

Licea de Arenas, J., Arenas, M. \& Valles, J. (2009), Before the NetGen, Positioning the Profession: the Tenth International Congress on Medical Librarianship, Brisbane, Australia, August 31-September 4, 2009, http://espace.library. uq.edu.au/eserve/UQ:179759/n6_3_Fri_Arenas_104.pc.

Licea de Arenas, J. \& Arenas, R. (2009), “Alfabetización tecnológica y digital de adultos mayores ¿problema cultural o generacional?" en Revista Iberoamericana de Sistemas, Cibernética e Informática, 6 , 72-77.

Licea de Arenas, J., Arenas, R. , Córdoba, M. \& Rivera, Y. (2010), Los estudiantes universitarios y la alfabetización digital. SIECI 2010, Orlando, Fl., Junio 29-julio 2.

Licea de Arenas, J. , Díaz, E., Fuentes, L., Palacio, J., Trillo, D., Radillo, J. \& Reyes, F. (2007), Los niños mexicanos y su percepción de las bibliotecas públicas, documento no publicado.

Licea de Arenas, J., Rodríguez, J. V., Gómez, J. A. \& Arenas, M. (2004), "Information literacy: implications for Mexican and Spanish university students", en Library Review, $53,451-60$.

Lomnitz, L., Mayer, L. \& Rees, M.W. (1983). "Recruiting technical elites: Mexico's veterinarians”, en Human Organization, 42, 23-29.

Perales Ojeda, A. (1959), Servicios bibliotecarios en universidades. México: UNAM. 
Recursos electrónicos de información en la UNAM: diagnóstico de uso entre estudiantes y profesores (2009), México: UNAM.

Torras, M. C. \& Saetre, T. P. (2008), Information literacy education: a process approach: professionalising the pedagogical role of academic libraries, Oxford: Chandos.

Walter, S. (2006), "Instructional improvement: building capacity for the professional development of librarians as teachers", en Reference E User Services Quarterly, 43.

Walter, S. (2008), "Librarians as teachers: a qualitative inquiry into professional identity", en College $\mathcal{E}$ Research $\mathrm{L} i$ braries, 69.

Wilson, L. R. \& Tauber, M. F. (1956), The university library: the organization, administration, and functions of academic libraries, 2 ed., New York: Columbia University. 


\section{Innovación y mentorización para la formación en ALFIN: nuevos retos para las bibliotecas universitarias}

MARÍA PINTO

Universidad de Granada, España

\section{INTRODUCCIÓN}

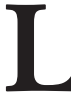

a innovación y la formación en la biblioteca ententecnológico como centrado en la persona son un pilar esencial para el desarrollo, la promoción y el impacto de los servicios en la comunidad universitaria y en el entorno. Por tanto estos conceptos han de calar profundamente entre los bibliotecarios, para que su formación sea por competencias, y haga especial hincapié en la adquisición de conocimientos y las habilidades informacionales y tecnológicas acordes con los nuevos modelos de gestión del cambio en el marco del proceso de convergencia europea de la educación superior (Comisión Europea, 2003). En España, los protocolos de evaluación de la calidad de las bibliotecas (Pinto, M. Balagué, N., Anglada, L1, 2007), han incorporado como criterio relevante de valoración la participación de la biblioteca 
en programas de innovación y mejora, tanto hayan sido éstos desarrollados por el servicio de biblioteca, o de forma conjunta con otras entidades y grupos de la misma universidad o de fuera, y hayan fomentado el uso y la dinamización de los recursos de información.

En este sentido, hoy más que nunca la biblioteca universitaria/CRAI ha de apoyar la innovación, la investigación, y la formación de los miembros de la institución, para convertirse así en un eje esencial para desarrollar los procesos de gestión y transferencia del conocimiento en la organización. Ya en el Informe Atkinson se afirmaba que la biblioteca "[...]es el corazón de la universidad, ocupando un lugar central y básico, como un recurso que es, ocupa y sirve a todas las funciones de una universidad: enseñanza e investigación, creación de nuevo conocimiento y la transmisión a la posteridad de la ciencia y la cultura del presente", (University Grants Commitee, 1976).

\section{EL PAPEL ACTUAL DE LA BIBLIOTECA/CRAI EN LOS NUEVOS ESCENARIOS DE APRENDIZAJE}

La biblioteca actual enclavada en un sistema universitario competitivo, caracterizado por la globalización, la internacionalización y la masificación, (Altbach, Ph., et. al., 2009) necesita ofrecer evidencias documentales sobre el impacto que su trabajo tiene en la comunidad universitaria, tanto desde el punto de vista del aprendizaje, destacando los logros educacionales de los estudiantes en el dominio de la competencia informacional, como desde su contribución como proveedora de infor- 
mación de calidad y de servicios de valor añadidos a la docencia, a la investigación y al desarrollo, con lo cual contribuye a la creación de infroestructuras documentales para la docencia y la investigación (plataformas digitales, repositorios, bibliotecas digitales...).

Los cambios que se producen en la biblioteca universitaria son directamente proporcionales a los que ocurren en la propia universidad. La biblioteca ha de ser considerada como una organización dinámica que aprende de manera continua y que tiene una estructura moderna para gestionar los recursos y servicios de información independientemente del soporte o la localización que éstos tengan, con el fin último de proporcionar el acceso a esos recursos a través de diferentes medios y en diferentes puntos, (Pinto, Sales y Osorio, 2008).

La biblioteca universitaria apoya la docencia, el aprendizaje y la investigación, y se convierte en el eje esencial para desarrollar los procesos de gestión de información y gestión del conocimiento que soportan estas actividades, sin las cuales la universidad dejaría de existir. Además, para cumplir con la política científica de la universidad, el uso y el acceso estratégicos de la información es un aspecto necesario e importante. La universidad debe dotar a la biblioteca de infraestructuras y equipamientos que le permitan la innovación metodológica, integrando las TIC en los nuevos modelos de enseñanza-aprendizaje e impulsando la colaboración de expertos en tecnologías, profesores y bibliotecarios, con la finalidad de producir y organizar contenidos y recursos docentes y de participar en proyectos transversa- 
les relacionados con la gestión y organización del conocimiento.

La biblioteca se convierte en el centro de acción para que los estudiantes desarrollen su aprendizaje y para que gestionen la información y el conocimiento en su formación como profesionales. El cambio es algo evidente, sobre todo si se hace referencia al paradigma de la alfabetización informacional (Pinto, 2008), como una forma más social, integradora y humana de que los estudiantes comprendan la importancia de utilizar la información de modo ético y consciente, en todas las acciones que se realizan tanto en el ámbito personal, académico o el profesional. Pero los profesores también se encuentran en un momento diferente de desarrollo y uso de la biblioteca. El profesor ha de prepararse y adquirir conocimientos actualizados que le permitan la conducción del proceso de enseñanza-aprendizaje y la orientación adecuada a sus estudiantes en un entorno donde todavía el aprendizaje e-learning es algo novedoso. Los docentes, además de utilizar la biblioteca como soporte de su docencia e investigación, habrán ahora de considerarla desde una perspectiva más amplia teniendo en cuenta la formación por competencias y los nuevos modelos de aprendizaje, de corte constructivista y basados en los recursos.

La Universidad y su biblioteca tienen que prepararse para dar respuesta a las necesidades que surgen en consonancia con los cambios acontecidos en la educación y formación de los individuos en la actual sociedad de la información y el conocimiento. El cambio realizado en la biblioteca universitaria en su conversión a CRAI (Centro de Recursos para el Aprendizaje y la Investiga- 
ción), contribuye a la educación informacional de la comunidad universitaria, especialmente de los estudiantes (Kazmer, 2002), ayudando a profesores y estudiantes en las actividades de aprendizaje, formación, gestión y resolución de problemas técnicos, metodológicos y de conocimiento en el acceso y uso de la información.

Por tanto en este contexto formativo-informativo, cobran fuerza en las actuales bibliotecas-CRAIS los procesos de formación integrada de los propios profesionales de la información, más allá del conocimiento técnico y del manejo de la información, que se centran en el dominio de conocimientos y habilidades pedagógicas, tecnológicas, investigadoras y comunicacionales. Su adecuada competencia en el dominio y aplicación de esas habilidades en el puesto de trabajo, les permitirá afrontar con éxito los retos derivados de los nuevos cambios.

\section{EL BIBLIOTECARIO EN EL CONTEXTO DE LA ALFABETIZACIÓN INFORMACIONAL}

En su renovación hacia el Centro de Recursos para el Aprendizaje y la Investigación (CRAI), la biblioteca se transforma en un importante nodo para el aprendizaje y la investigación, donde el usuario interactúa con nuevas ofertas informativas y con profesionales competentes que requieren de un entrenamiento continuo en las nuevas habilidades para gestionar, organizar y difundir la información. El profesional de la información ha de ser competente para:

- organizar el conocimiento y la información digita,. 
- difundir la información procedente de recursos digitales,

- proporcionar servicios digitales/ electrónicos de información y referencia,

- ser mediadores entre los recursos informacionales y el usuario, captando e interiorizando las necesidades y expectativas de éstos,

- garantizar el acceso y recuperación global del conocimiento digital y multimedia y

- formar a los usuarios en alfabetización informacional, convirtiéndose en facilitadores de su aprendizaje.

Por consiguiente necesitan actualizar sus perfiles laborales en consonancia con una formación integrada por competencias, que incluya tanto conocimientos teóricos y prácticos como habilidades y aptitudes relacionadas con el saber, con el hacer y con el ser, todo ello orientado hacia las siguientes áreas de trabajo:

\section{Búsqueda}

Los profesionales necesitan conocer bien las tipologías de fuentes de información, saber cómo interrogarlas y cómo recuperar de forma adecuada la información en función de la diversidad de recursos, los contextos de uso, la diversidad de usuarios y la complejidad de las necesidades informativas.

\section{Evaluación}

Deben ser también capaces de saber evaluar la calidad de las fuentes para seleccionar los mejores recursos, y fomentar en los usuarios el desarrollo del espiritu critico y 
Innovación y mentorización para la formación en ALFIN ...

la aplicación de criterios de calidad para garantizar la fiabilidad y utilidad de la información que hay en Internet.

\section{Procesamiento}

Deben saber manejar las herramientas de tratamiento de la información organizando, clasificando, analizando y resumiendo los recursos para su control y utilización futura; además de extraer contenidos y datos, y de sistematizarlos mediante bases de datos y hojas de cálculo, para su posterior uso y toma de decisiones.

\section{Comunicación y difusión}

Deben tener la capacidad de interactuar eficazmente con los usuarios, y gozar de conocimientos comunicacionales y pedagógicos de alto nivel para anticiparse y entender las necesidades y expectativas de los usuarios . Es aconsejable que sepan elaborar informes y divulgar la información utilizando las nuevas tecnologías de la información y la comunicación, así como trabajar en grupo dentro de proyectos y organizaciones. Además deberán conocer los aspectos éticos y legales relacionados con la propiedad intelectual.

En esta nueva coyuntura de cambio, en la que emerge con fuerza el paradigma de la ALFIN como faro de la sociedad de la información y del conocimiento, el profesional de la información con experiencia debería desempeñar la labor de tutor y guía en los procesos de formación de los recursos humanos de la institución, para generar así un proceso de aprendizaje y docencia en 
cascada que lo transforme en co-entrenador de otros profesionales.

La bibliografía sobre ALFIN es variada y en crecimiento (Pinto, Cordón y Gómez, 2009). La educación de usuarios, propia del ámbito educativo, ha sido campo fértil para la evolución de algunos aspectos de la ALFIN, especialmente desde el ámbito de las bibliotecas, donde investigadores y profesionales se hallan inmersos en esta área de trabajo y estudio, e intentan contribuir a su avance. La certeza de que cada persona debe ser capaz de desarrollar sus potencialidades en un aprendizaje continuo a lo largo de toda la vida, hace que el tema requiera de una reflexión intensa y actualizada en la educación formal y por tanto, de su integración en el marco reflexivo y docente de una universidad alfabetizada en información, (Webber, 2006; Webber y Johnston, 2006).

Es preciso señalar que para que haya una formación eficaz en ALFIN, los formadores, ya sean bibliotecarios o profesores o ambos, tienen que perfeccionar sus propias destrezas en el uso, manejo y evaluación de la información. Por tanto el conocimiento de las normas (ACRL/ALA, 2000, SCONUL, 1999, ANZIL, 2004...) y de los modelos pedagógicos de ALFIN (Kuhlthau, 1991, Bruce, 1997, Eisemberg, 2000, Markless, 2007 ...) se convierte en una gran e imperiosa necesidad para ser aplicada a los programas educativos, extendiendo el proceso formativo a bibliotecarios y educadores, con el fin de medir el nivel de competencia en el acceso y uso de la información, y de determinar las necesidades formativas para mejorar el nivel de aprendizaje y potenciar 
la eficacia de la institución. De esta forma, la ALFIN se relaciona con los procesos evaluadores de modo que cada institución debe considerar en qué medida la ALFIN contribuye a mejorar los resultados de aprendizaje de sus estudiantes y ayuda a producir graduados competentes y profesionales capacitados para el aprendizaje a lo largo de la vida, (Pinto, M., Uribe, A, 2010, (en prensa).

En España destacan algunas iniciativas formativas y estratégicas procedentes de redes y asociaciones profesionales, como REBIUN (2009), CBUC (2008), SEDIC (2006). Un estudio exploratorio analiza la percepción que tiene de ALFIN un grupo bibliotecarios españoles, destacando que algunos carecen de una visión estratégica de la importancia que tiene ALFIN como competencia nuclear en las curricula de los estudiantes, (Pinto, Sales, Osorio, 2009). Estas personas se consideran alfabetizadas porque responden a las necesidades y demandas de información de los usuarios; facilitan el apoyo a la docencia e investigación; enseñan los recursos de la biblioteca, y afrontan la formación de usuarios. Creen que por el hecho de ser bibliotecarios son infoalfabetos, sin saber qué les aporta el paradigma de ALFIN para su autoformación y la formación de los demás. Pero el bibliotecario tendrá que estar alfabetizado en información para resolver además de las cuestiones anteriores, problemas complejos relacionados con la gestión de la información y del conocimiento.

Como opina Wasik (2007), el bibliotecario infoalfabetizado ha de tener solvencia en estas competencias: dominio de las tecnologías, habilidades para procesar las 
referencias virtuales y el uso de recursos digitales, habilidades para evaluar el servicio, habilidades para crear procedimientos innovadores, habilidades como instructor, habilidades para colaborar y participar en la comunidad virtual, y habilidades para usar las bases de conocimiento.

Según Virkus hay dos posibles enfoques para ser una persona alfabetizada (2007):

- Convertirse en una persona infoalfabetizada, autoapropiándose de las habilidades informacionales que le permitan reconocer cuando necesita información, localizarla, acceder a ella, organizarla, evaluarla y presentarla de manera efectiva, considerando las cuestiones ético - legales que implica cada proceso.

- Aprender a ser facilitador para convertir a otros en personas infoalfabetizadas. Esta visión implica el conocimiento de teorías y estilos de aprendizaje, el diseño de programas de formación, el manejo de instrumentos de evaluación y mejora, etcétera.

Cualquiera de estas modalidades conlleva que el bibliotecario tenga interiorizada la cultura de la evaluación en la educación superior, y pueda demostrar el impacto que tiene la formación en alfabetización informacional en el aprendizaje de los estudiantes y cómo la biblioteca contribuye a la formación de graduados de calidad. Esto implica que los bibliotecarios evalúen el impacto de los programas de formación de usuarios que imparten, pero no saben cómo medir el impacto de las competencias informacionales pues reconocen que no se sienten preparados todavía para ello, (Oakleaf, 2008). En este sentido, además del conoci- 
Innovación y mentorización para la formación en ALFIN ...

miento básico sobre evaluación, necesitan manejar estos dos conceptos fundamentales: por un lado, que también hay que evaluar los resultados de cualquier diseño previo de formación en ALFIN, y por el otro, que hay que asumir el precepto de la evaluación como oportunidad para mejorar, (Oakleaf, 2009). Y precisamente esta misión autoformativa y formativa de los bibliotecarios para formar mejor es un valor que pone de manifiesto cómo la biblioteca contribuye a la misión docente de las universidades que las financian, (Oaklead, 2010).

\section{INNOVACIÓN Y MENTORIZACIÓN COMO ES- TRATEGIAS PARA LA FORMACIÓN EN ALFABE- TIZACIÓN INFORMACIONAL}

En este contexto se plantea el interrogante de cómo deberían los bibliotecarios caminar hacia un modelo de profesional más competente, y que implique un marcado posicionamiento en el contexto docente e investigador y una significativa presencia activa en los procesos de aprendizaje de los estudiantes. Son numerosas las incógnitas pero también abundantes los frentes de trabajo relacionados con la innovación.

En la literatura publicada sobre el tema se ha abordado con intensidad la necesidad de trazar políticas que marquen el camino para desarrollar la innovación en los servicios universitarios, la cual tiene particularidades que la diferencian de la innovación tecnológica, (Cunningham, 2006; Howells, 2000). Innovar no es sólo bacer cosas distintas sino hacer cosas mejores. Innovar no es estar cambiando constantemente sino introducir va- 
riaciones como resultado de procesos de evaluación y ajuste en lo que se estaba haciendo. La innovación supone una estrategia permanente de cambio y una exigencia que responde a la nueva concepción de biblioteca, más competitiva y flexible, más dinámica y participativa, inteligente, alfabetizada en información, que innova y aprende y está más centrada en las personas, en el estudiante y en los resultados y el impacto que provoca en la sociedad.

La innovación desde la biblioteca universitaria/CRAI debe estar enfocada esencialmente hacia el desarrollo de servicios y estrategias que permitan un cambio en la manera en que los profesores y los estudiantes se relacionan con la información y el conocimiento. Este pensar de forma distinta constituye la base para lograr los siguientes cambios:

- En la proyección de los servicios de información;

- En los procesos que soportan el desarrollo de la actividad de información en la universidad;

- En las relaciones que establece la biblioteca con el resto de los departamentos de la universidad y con sus usuarios, y

- En los procesos formativos que se desarrollan desde la biblioteca dirigidos a los distintos segmentos de la comunidad universitaria.

También la innovación ha de estar presente en la modalidades de formación de los profesionales y en el uso de nuevas estrategias para adquirir las competencias informacionales en el entorno de trabajo, (Badke, 2008). Destacamos algunas de ellas: 
Innovación y mentorización para la formación en ALFIN ...

- Coaching: entendido como proceso de mejora guiado por el facilitador (coach), estructurado y al que se le da un seguimiento continuo. Requiere de un compromiso de ambas partes: de la persona en formación y de la organización a la que pertenece.

- Autodesarrollo: entendido como proceso de mejora individual, aplicado a personas con un nivel de disciplina y de autoconfianza elevado.

- Counselling: estrategia encaminada a lograr un ajuste óptimo entre la persona y su entorno, y/a fomentar el desarrollo pleno de la persona y el despliegue de sus potencialidades. Su finalidad es facilitar un aprendizaje cognitivo-emocional que prevenga, el cambio y el desarrollo personal.

- Mentoring: es un proceso de mejora guiado por un mentor flexible y que tiene el apoyo continuo de la organización, para lograr el desarrollo formativo-profesional a largo plazo de la persona mentorizada.

No hay un método exclusivamente válido, cualquiera de ellos tiene ventajas e inconvenientes dependiendo de los agentes implicados, de los escenarios donde se utilicen, de los objetivos y de los resultados que se proponga lograr. No obstante, como afirma Hepworth (2007), para formar en competencias informacionales a otros profesionales el bibliotecario necesita conocer bien las características del entorno de trabajo y comprender las experiencias, percepciones y necesidades de las personas que trabajan en él. Pero además es conveniente que conozca los aspectos clave de la teoría educativa y del proceso de enseñanza-aprendizaje, (Russell, 2008). De ahí que necesite familiarizarse con los diferentes modelos y 
estilos de aprendizaje para ser capaz de aplicar eficazmente estos conceptos a la práctica de la alfabetización informacional.

Desde mi experiencia profesional como mentora de profesores noveles, apostamos por emular esta filosofía y sus estrategias para adaptarlas a las bibliotecas. Si convertirse en profesor es un largo proceso, también hacerse bibliotecario-docente es una tarea compleja que requiere conocimientos y habilidades metodológicas y didácticas. Requiere imbuirse bien de la nueva cultura docente y de aprendizaje (conocimientos, modelos y valores de la actividad docente) y cooperar con los académicos en los procesos formativos de los estudiantes, mejorando los resultados de su aprendizaje. Además debe adquirir competencias pedagógicas, y también tener una buena base de conocimiento teórico, saber organizar éste de forma que sea fácil su transmisión y aprender de la práctica profesional, indagando lo que los estudiantes hacen y piensan, y cómo comprenden e integran lo aprendido en sus esquemas de conocimiento.

El término mentorización es utilizado para definir el proceso de desarrollo y transferencia de buenas prácticas y hábitos hacia otros, tanto en el ámbito académico como en el profesional y en otros entornos de la vida, (Mullen, 1999).

Los conceptos de mentor y mentorización han sido definidos en la literatura de múltiples formas. Algunas de ellas sugieren que el mentor es una persona cuyos actos como guía y facilitador sirven de consejo, referencia y soporte para la consecución de metas. 
La mentorización es un proceso y una función compleja que requiere de una estructura adecuada y de sensibilidad para acomodarse a las diferentes situaciones. Implica apoyo, ayuda y orientación pero no una evaluación de la persona mentorizada y además, requiere de tiempo para que los agentes implicados entren en contacto y se comuniquen, (Bey y Colmes, 1992). Es un recurso de cambio y de mejora de la organización que lo aplica. Pero el proceso de mentorización debe ser protagonizado por profesionales expertos y experimentados, preocupados por mejorar su actividad profesional y por ser capaces de reorientar las necesidades del profesional principiante en distintos frentes (sociocognitivo, emocional, comunicacional...). La mentorización conlleva un componente afectivo que permite el logro, o no, de lo esperado tanto por el mentor como por el tutelado, con lo cual se debe tener muy presente tanto lo aprendido en términos de conocimientos y habilidades, como lo vivido, en términos de sentimientos, experiencias, aptitudes y actitudes. Para ello se necesita recibir formación, orientación y apoyo de la comunidad universitaria (Moir, 2003). En algunas universidades extranjeras como la de Colorado en Boulder, los mentores reciben formación sobre coaching cognitivo, centrado en técnicas para promover la reflexión y el espíritu crítico. Además, es imprescindible que el mentor posea una serie de cualidades, (Flores, 2006):

- Personales: empatía, flexibilidad, facilidad para la comunicación, diplomacia,

- Profesionales: capacidad para transmitir la cultura de la organización a la que pertenece, habilidades en ges- 
tionar las clases, habilidades para procesar la transferencia de conocimientos, la capacidad de cambio y la capacidad para planificar y organizar,

- Sociales: habilidad para trabajar con otros, capacidad para actuar de guía, y para generar confianza, respeto y responsabilidad.

El diseño de un programa de mentorización tendrá que atender estos dos frentes fundamentales: por un lado, formar a los bibliotecarios noveles para conseguir los siguientes objetivos:

- Identificar sus necesidades docentes, sus carencias y dificultades iniciales;

- Adquirir los hábitos y las competencias metodológicas necesarias para conseguir transferir con éxito sus conocimientos;

- Capacitar a los participantes para adaptar los programas de formación a los requisitos de los nuevos títulos de grado;

- Facilitar la adquisición de habilidades, conocimientos y actitudes para el desempeño de la actividad docente, resaltando el entrenamiento en habilidades comunicativas, de relación y éticas que la docencia requiere;

- Crear equipos de trabajo de calidad que generen, potencien y transfieran buenas prácticas para el desempeño de la labor docente;

- Tomar conciencia de la necesidad de promover un desarrollo profesional continuo, y

- Elaborar medios de control y evaluación que permitan reflexionar sobre la propia actuación y autoevaluarse. 
Innovación y mentorización para la formación en ALFIN ...

Por otro lado, debe contribuir a consolidar la labor de los bibliotecarios mentores afrontando los siguientes objetivos:

- Adquirir procedimientos e instrumentos útiles para realizar estas labores de asesoramiento;

- Desarrollar conciencia crítica y reflexiva sobre su propia actividad docente y la de sus asesorados;

- Obtener pautas de evaluación de los bibliotecarios noveles que puedan ser aplicadas a su propia actuación docente;

- Continuar el proceso de investigación en el diseño de programas de asesoramiento y autorización, y

- Programar acciones de intercambio de experiencias entre los bibliotecarios mentores de la misma universidad

En suma, con un programa de mentorización se pretende lograr estas competencias generales:

- Reflexión y análisis crítico del proceso enseñanzaaprendizaje;

- Adquisición de la capacidad para orientar al alumno en el uso y aprovechamiento de los recursos de información;

- Promoción de la capacidad de trabajo en equipo

- Capacitación para la elaboración de técnicas de evaluación de los resultados del aprendizaje y el rendimiento de los alumnos, $\mathrm{y}$

- Adquisición de un compromiso con el progreso y rendimiento del alumno.

Para implantar procesos de mentorización en bibliotecas es necesario promover formas de comunicación 
proactiva y desarrollar estrategias diversas de formación basadas en necesidades y expectativas de aprendizaje, que además incorporen estrategias que incidan en los resultados del aprendizaje, como:

- El uso de los ciclos de mejora como estrategia para el proceso reflexivo de aprendizaje, tanto de mentores como de mentorizados;

- Talleres de análisis, que incluyan procesos de reflexión compartida;

- Grupos de discusión, que tengan como epicentro el tema de aprender a aprender;

- Instrumentos pedagógicos basados en las TIC que promuevan la construcción y el uso del portafolio, el empleo del chat y el correo electrónico para el intercambio de experiencias, $y$

- enseñar, fomentando la adquisición de habilidades cognitivas complejas, utilizando recursos varios como, mapas, juegos, videos, etcétera.

Odell (2006) ha definido una serie de dimensiones importantes que debe tener un programa de mentorización:

- Definición del propósito y justificación del programa, señalando las metas, los objetivos y los componentes básicos. Es necesario identificar tanto la necesidad que tiene una organización o individuo de integrarse en un proceso de ALFIN, como conocer el diagnóstico de la institución donde se desarrollará el proceso de alfabetización, (Horton, 2008);

- Selección de los mentores y emparejamiento con los bibliotecarios noveles en el marco del Programa de alfabetización como parte de un proceso educativo-formativo integral. El mentor ha de ser una perso- 
Innovación y mentorización para la formación en ALFIN ...

na que conozca y supere los estándares de calidad en su actividad profesional y que sea sensible a los puntos de vista de otros;

- Formación de los mentores: los bibliotecarios que van a actuar como mentores deben recibir formación para el desarrollo de su práctica, especialmente en aspectos relacionados con la comunicación, con la pedagogía emocional, con el trabajo colaborativo y con las técnicas de evaluación de la actividad docente;

- Roles y prácticas de los mentores, que deben percibirse a sí mismos como formadores de profesionales noveles y como modelos a seguir, y

- Administración, desarrollo y evaluación de los resultados del programa, realizando una retroalimentación constante con los participantes. Es un punto importante que la biblioteca tenga bien interiorizados los diferentes modelos para implementar el Programa de alfabetización informacional y haya definido un plan de divulgación y promoción de las distintas actividades realizadas.

\section{CONCLUSIONES}

Ante la actual revolución académica de la enseñanza superior de nuestro siglo, caracterizada por la masificación, la competitividad, la movilidad social, las nuevas pautas de financiación, la diversificación de los sistemas de enseñanza y la disminución global de los niveles académicos, consideramos que apostar por la innovación, la creatividad y la formación por competencias, en y desde la biblioteca, es una manera segura de contribuir a la mejora de la calidad de la enseñanza superior. Por otro lado hemos de tener 
presente que el protagonismo de la información y del conocimiento, y de las TIC han revolucionado la formación, la comunicación científica y la generación de conocimiento, más allá de los contextos locales, (Altbach, P, et. al., 2009). De ahí que la alfabetización informacional y el desarrollo de competencias informacionales estén entre las principales prioridades de los profesionales de la información dados los beneficios que supone para aquéllos que logran aprender a utilizar la información desde una perspectiva holística e integradora.

Por tanto es necesario que las universidades y sobre todo las bibliotecas tengan un plan de alfabetización informacional para la comunidad universitaria como parte de una macroestrategia organizacional de gestión del conocimiento, donde la formación continua e integral del personal en su conjunto sea un pilar importante de progreso para la institución universitaria. Además, lograr que los bibliotecarios que tienen pocas competencias en ALFIN para ser formadores de otros, las mejoren, es un reto fundamental para caminar hacia una universidad alfabetizada en información, donde profesores, investigadores y estudiantes sean competentes informacionalmente.

Finalmente, pensamos que la mentorización puede ser una buena estrategia formativa y un compromiso proactivo de aprendizaje y de enseñanza para las bibliotecas-CRAI a nivel mundial, ya que incorpora posibilidades únicas para el desarrollo profesional de los bibliotecarios del siglo XXI en pos de construir una sociedad con mayor acceso a la información, que aprende de manera sostenible y de forma crítica. 
Innovación y mentorización para la formación en ALFIN ...

\section{REFERENCIAS BIBLIOGRÁFICAS}

ACRL/ALA. (2000), "Normas sobre aptitudes para el acceso y uso de la información en la Educación Superior", en Boletín de la Asociación Andaluza de Bibliotecarios, 15 (60), Disponible en: http://www.aab.es/51n60a6.pdf, [consulta: 10 de sepdiembre 2010].

Altbach, Ph., Reisberg, L., Rumbley, L., Tras la pista de una revolución académica: informe sobre las tendencias actuales, Bruselas: UNESCO, 2009

Anzil/Caul, (2004), Normas de Alfabetización Informacional, disponible en http://www.aab.es/pdfs/gtbunormas08. pdf , [consulta: 10 de septiembre 2010].

Badke, W. (2008), "A rationale for information literacy as a credit-bearing discipline", en Journal of information literacy 2(1), en línea] 2008, [http://jil.lboro.ac.uk/ojs/index. $\mathrm{php} / \mathrm{JIL} / \mathrm{article} / \mathrm{view} / \mathrm{RA}-\mathrm{V} 2-\mathrm{I} 1-2008-1$.

Bey, T. M., Holmes, C. T. (1992), Mentoring: Contemporary Principles and Issues, Boston, Association of Teachers Educators.

Bruce, C. (1997), The Seven Faces of Information Literacy, Adelaide: Auslib Press.

Consorcio de bibliotecas universitarias de Cataluña (CBUC), (2008), Seminario para bibliotecarios sobre la Alfabetización informacional y sus retos en la Universidad, Barcelona.

Comisión Europea (2003), El papel de las universidades en la Europa del conocimiento, Bruselas.

Cunningham, P.N. (2006), European Trend Chart on Innovation, Policy Review Workshop 10: "Innovation in Services", Workohop Input Report. 
Tendencias de la Alfabetización Informativa en Iberoamérica

Eisenberg, M. et al. (2000), Teaching information E technology skills : the Big6 in secondary schools, Worthington, $\mathrm{OH}$ : Linworth Pub.

Flores, M.A. (2006), "Induction and mentoring. Policy and Practice", en J. R. Dangel (ed.), Research on Teacher Induction. Teacher Education Yearbook, XIV, v. 37-66, Rowan and Littlefield Publishers, Toronto.

Hepworth, M. (2007), Information Literacy in the workplace: implications for trainers, [en línea] 2007, [consultado el 6 de agosto de 2010]. www.cilip.org.uk/NR/rdonlyres/ BA723EF5-1D8C-4DE4-809C-6E112BD51FF5/0/hepworth07. ppt.

Horton, F W. (2008), Understanding Information Literacy: a Primer, [en línea] 2008, [consultado el 15 de septiembre de 2010]. http://unesdoc.unesco.org/images/0015/001570/ 157020E.pdf.

Howells, J. (2000), "Services and systems of innovation", en B. Andersen, J. Howells, R. Hull, I. Miles and J. Roberts (eds), Knowledge and Innovation in the New Service Economy, Cheltenham: Edward Elgar, 215- 228.

Kazmer, M. (2002), Distance Education students speak to the library: here's how you can help even more, The Electronic Library, 20 (5), 395-400.

Kuhlthau, C.C. (1991), "Inside the Search Process: Information Seeking from the User's Perspective," en Journal of the American Society for Information Science, 42(5), 361-371.

Markless, S., Streatfield, D.R. (2007), "Three decades of information literacy: redefining the parameters", en Andretta, S. Change and challenge: information literacy for the 21st century, (pp.15-36), Adelaide: Auslib Press. 
Innovación y mentorización para la formación en ALFIN ...

Moir, E. (2003), Launching the next generation of theachers though quality induction, ERIC, 2003.

Mullen, C.A., Lick, D.W (1999), Nerw directions in Mentoring, Creating an Culture of Synergy, London: Routledge Falmer.

Oakleaf, M. (2008), Dangers and opportunities, portal: Libraries and the Academy, 2008, 8, 3, págs. 233-253.

Oakleaf, M. (2009), Guiding Questions for Assessing Information Literacy in Higher Education, portal: Libraries and the Academy, 2009, 9, 2, págs. 273-286.

Oakleaf, M. (2010), The Value of Academic Libraries. Association of College \& Research Libraries, 2010, disponible: www.ala.org/ala7mgrps/divs/acrl/issues/value/val_ report.pdf

Odell, S. (2006), Overview and framework. In: J.R. Dangel (ed.). Research and Teacher Induction", en Teacher Education Yearbook, XIV, vol 201-211, Ronan and Littlefield Publisher, Toronto.

Pinto, M. (2008), Alfabetización informacional y e-learning. Diseño de tutoriales y cursos on line, en J. A. Gómez y A. Calderon, (Eds), Brecha digital y nuevas alfabetizaciones, El papel de las bibliotecas, Madrid: Universidad Complutense, disponible en: http://www.ucm.es/BUCM/biblioteca/ OLibro.pdf, [consulta: 12 de abril 2010].

Pinto, M., Balagué N., Anglada, L. (2007), "Evaluación y calidad en las bibliotecas universitarias: experiencias españolas entre 1994-2006", en Revista Española de documentación cientifica, 30(3), 364-383. 
Pinto, M., Cordón, J.A., Gómez, R:, “Thirty years of Information Literacy (1977-2007): a terminological, conceptual and statistical analysis", en JOLIS, 2010, 42, No. 1, 3-19.

Pinto, M., Sales, D., Osorio, P. (2008), Biblioteca Universitaria, CRAI y alfabetización informacional, Gijón, Trea.

Pinto, M., Sales, D., Martínez, P. (2009), "El personal de la biblioteca universitaria y la alfabetización informacional: de la auto percepción a las realidades y retos formativos", en Revista Española de Documentación Científica, 32(1), 60-80.

Pinto, M., Uribe, A. (2010), "Formarnos y autoformarnos en alfabetización informacional: un programa de mentorización en bibliotecas universitarias", en Revista Investigación Bibliotecológica, núm 52, (en prensa).

REBIUN (2009), Competencias informáticas en informacionales en los estudios de grado, 2009, disponible en: http://www.rebiun.org/opencms/opencms/handle404? exporturi $=/$ export $/$ docReb/documento_competencias _informaticas.pdf\&\%5d, (consultado: 12-08-2009).

Russell, P. (2008), "Information literacy support for off-campus students by academic libraries in the Republic of Ireland", en Journal of Information Literacy 2(2), [en línea] 2008, [citado el: 25 de noviembre de 2009]. http://jil.lboro.ac.uk/ojs/index.php/JIL/article/view/RA-V2-I2-2008-4.

SCONUL. (1999), Aptitudes para el acceso y uso de la información en la enseñanza superior: la postura de Sconul, Informe preparado por el grupo de trabajo Sconul sobre Aptitudes para el Acceso y Uso de la Información, disponible en: http://www.aab.es/pdfs/baab62/62a4.pdf, [consulta: 4 de septiembre 2010]. 
Innovación y mentorización para la formación en ALFIN ...

SEDIC (2006-), Cursos e-learning de formación permanente sobre Alfabetización informacional desde la biblioteca universitaria.

University Grants Commitee (1976), Capital provision for university Libraries (Informe Atkinson), Londres: HMSO.

Virkus, S. (2007), Information Literacy within LIS Currículo, Milan, [Consultado el: 11 junio de 2009], disponible en: http://dspace-unipr.cilea.it/handle/1889/530

Wasik J. A. (2007), Comprehensive VR Training Program, en Lankes D, et. al. Virtual Reference Service: From Competencies to Assessment, New Jersey: Neal Schuman; pp.115 - 92, 2007.

Webber, S. (2006), Information Literacy in Higher Education, en Stopar, K. and Rabzeljl, (Eds), Informacijska Pismenost med teorijo in prakso: vloga visokošolskih in specialnih knjižnic: Zbornik prispevkov, [Information Literacy between theory and practice: The role of academic and special libraries: Proceedings] Ljubljana: ZBDS, pp. 9-20.

Webber, S.; Johnston, B. (2006), "Working towards the Information Literate University", en G. Walton y A. Pope (Eds.), Information Literacy: Recognising the need, Oxford: Chandos, pp. 42-53. 
Tendencias de la Alfabetización Informativa en Iberoamérica. Coordinación editorial, Zindy E. Rodríguez Tamayo. Formación editorial, Carlos Ceballos Sosa. Revisión especializada, Francisco Xavier González y Ortiz. Centro Universitario de Investigaciones Bibliotecológicas/ UNAM. Fue impreso en papel cultural ahuesado de 90 gr. en Producciones Editoriales Nueva Visión, ubicados en Juan A. Mateos número 20, Col. Obrera, México D. F. Se terminó de imprimir en el mes de junio de 2012. 